Portland State University

PDXScholar

Winter 1-9-2019

\title{
Recognizing and Addressing Risk Ambiguity in Sea \\ Level Rise Adaptation Planning: a Case Study of Miami-Dade County, Florida
}

Mary Ann Rozance

Portland State University

Follow this and additional works at: https://pdxscholar.library.pdx.edu/open_access_etds

Part of the Environmental Policy Commons, and the Urban Studies Commons Let us know how access to this document benefits you.

\section{Recommended Citation}

Rozance, Mary Ann, "Recognizing and Addressing Risk Ambiguity in Sea Level Rise Adaptation Planning: a Case Study of Miami-Dade County, Florida" (2019). Dissertations and Theses. Paper 4673.

https://doi.org/10.15760/etd.6557

This Dissertation is brought to you for free and open access. It has been accepted for inclusion in Dissertations and Theses by an authorized administrator of PDXScholar. Please contact us if we can make this document more accessible: pdxscholar@pdx.edu. 
Recognizing and Addressing Risk Ambiguity in Sea level Rise Adaptation Planning:

A Case Study of Miami-Dade County, Florida

by

Mary Ann Rozance

A dissertation submitted in partial fulfillment of the degree requirements for the degree of

\author{
Doctor of Philosophy \\ in \\ Urban Studies
}

\author{
Dissertation Committee: \\ Vivek Shandas, Chair \\ Connie Ozawa \\ Thaddeus Miller \\ Amy Lubitow
}

Portland State University

2019 
(C) 2018 Mary Ann Rozance 


\begin{abstract}
As coastal cities around the world identify and implement adaptations to sea level rise, they are faced with competing interests around what should be done and how to prioritize actions. Often, environmental problems - like confronting the challenge of sea level rise — are posed as requiring expert driven, technical solutions to identify and mitigate risks across the landscape. This framing, however, ignores the way in which diverse knowledge can help inform long-term planning horizons that address complex ways that sea level rise affects communities. The failure to integrate diverse knowledge into sea level rise adaptation can result in barriers to implementation and outcomes that can reproduce inequities.

In environmental planning, knowledge integration challenges can stem from ambiguity around the construction of environmental risk knowledge, as well as institutional arrangements that inhibit diverse involvement. Ambiguity refers to a context in which there are different and sometimes conflicting views on how to understand the problem or system to be managed, for example, conflicts around what risks to measure and how to measure them. This manifests in the ways that different groups construct and use knowledge about risks. Often ignored in planning contexts and research on sea level rise adaptation, ambiguity—particularly around social risks—are critical to address, since they can determine whether diverse knowledge about risks are integrated or ignored in planning.
\end{abstract}

This dissertation uses a case study of Miami-Dade County, Florida and is guided by the question: how do different groups understand risk within sea level rise, and what planning and governance factors influence the way diverse dimensions of risk are 
integrated into adaptation strategies? Findings from this case study suggest that baselines, projections, and the focus of risk rooted in an economic discourse based on short-term planning horizons and technical constructions of risk have more authority as compared with counter arguments around ecological and social risks. Recommendations include the need for transparent adaptation decisions and the inclusion of diverse stakeholders in the production of regional climate science, sea level rise assessments, and adaptation planning. A more integrated approach can better address diverse risks and facilitate long-term planning. 


\section{Acknowledgements}

I am thankful to the hard-working and committed people in Miami-Dade County, Florida and across the country who took time out of their busy lives to share their stories with me. Thank you for your work preparing communities for climate challenges and striving for a better climate future and thank you for your generosity towards this dissertation and my life.

I am thankful to my committee who have been supportive guides during this entire process. I am grateful to my dissertation chair, Vivek Shandas, for his guidance as I encountered challenges, questions, and difficulties. The encouragement, enlightened conversations, and pathways he provided helped me overcome these obstacles and will stay with me throughout my career. To Connie Ozawa for her support and pointing me towards methods and approaches for bringing people together and building more collaborative planning environments. To Thad Miller for his support and encouragement to push boundaries and explore different approaches to research and thinking about infrastructure. To Amy Lubitow for her valuable insight and enthusiasm for this work. The collective input and encouragement from my committee brought me through challenging times of this process.

Over the past five years I was a part of incredible teams at Portland State University that influenced my work and supported me throughout the process. Thank you to the Ecosystem Services Supporting Urbanizing Regions IGERT program. The generous funding from the National Science Foundation and the Institute for Sustainable Solutions gave me the opportunity to pursue research topics meaningful to me, which will shape my future work and career. Thank you to the Urban Studies and IGERT faculty 
who opened my mind to different ways of thinking about urban and environmental problems and encouraged me to find my own path forward. Thank you to all the Urban Studies and IGERT students, the discussions we have had over the years have shaped my perspectives and research. Thank you to Diana Denham and Melanie Malone who have been great collaborators and beacons of inspiration. Thank you to the Restoration/Infrastructure crew_-Ashlie Denton, Marissa Matsler, Sarah Kidd, and Zbigniew Grabowski-for the exciting conversations and collaborations and constantly raising the bar on research, I look forward to seeing what we do next!

A warm thank you to my family for your love and support. To my parents who have been with me since the beginning and watched me go through over 25 years of schooling-I promise, this is the end! Thank you for always reminding me that I can do whatever I set out to do. Thank you to my siblings and friends for helping me stay grounded and providing often needed comic relief. Finally, my deepest thank you to my husband David, who I met two months prior to starting this journey. He has been with me through all the ups and downs, the self-doubt and excitement, I could not have done this without your endless enthusiasm and support. You deserve an award for everything you've done to support me along the way_running to get me an emergency power cord during my exams, driving me from Seattle to Portland during a blizzard for my proposal defense, and reading early versions of this dissertation — thank you for being my number one fan. 


\section{Table of Contents}

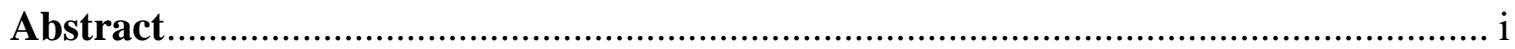

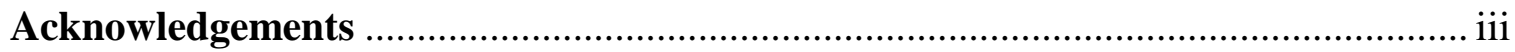

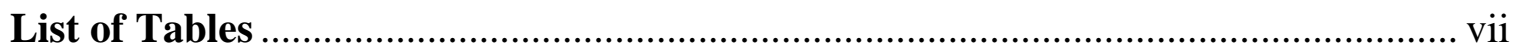

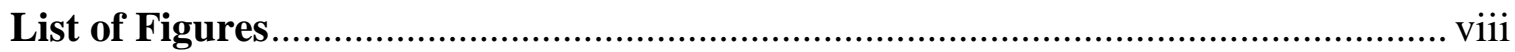

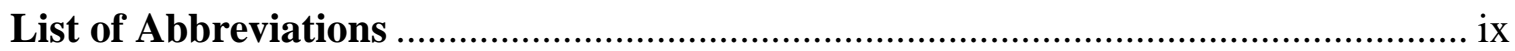

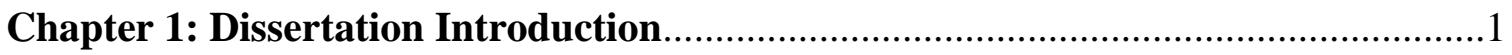

Chapter 2: Using Risk Ambiguity to Examine Sea Level Rise Adaptation Planning

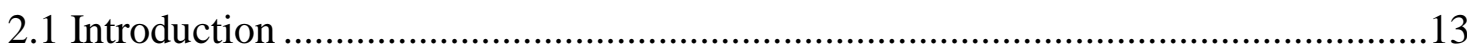

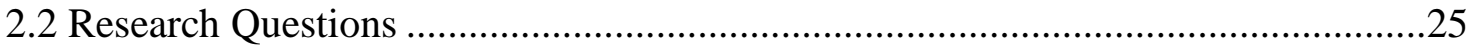

Chapter 3: Literature and Theoretical Review .....................................................2

3.1 Overview of Sea Level Rise Adaptation Science and Planning ............................27

3.2 Knowledge Co-production and Constructions of Risk ..........................................

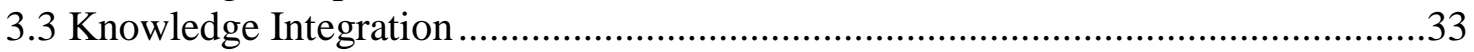

3.4 Connecting Literature and Theory to Sea Level Rise Adaptation Planning in

Miami-Dade County, Florida ...........................................................................51

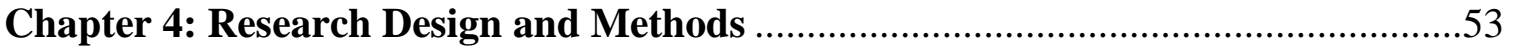

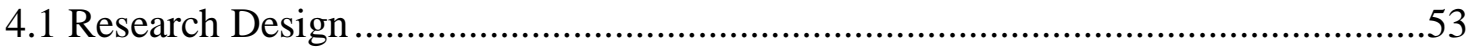

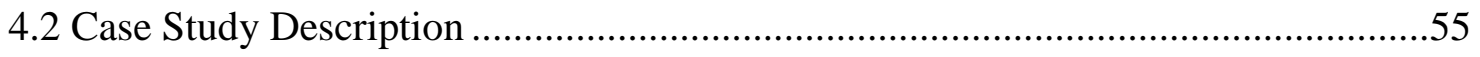

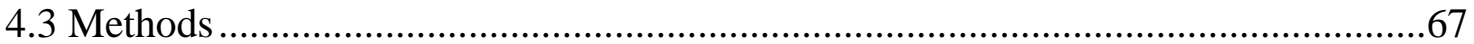

Chapter 5: Constructing Risk Knowledge in Sea Level Rise Adaptation Planning in

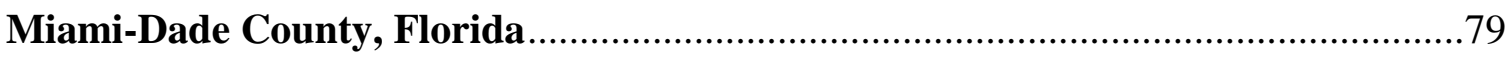

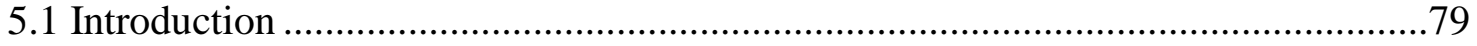

5.2 A relational Approach to Risk in Sea Level Rise Adaptation Planning..................82

5.3 Scientific Reticence, Political Uncertainty, and Confronting Denialism-Agreeing

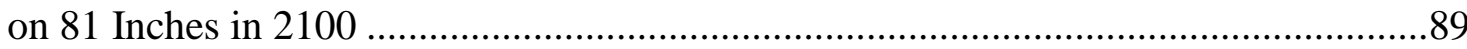

5.4 Risk Constructions of the Physical Landscape that Support an Economically Viable

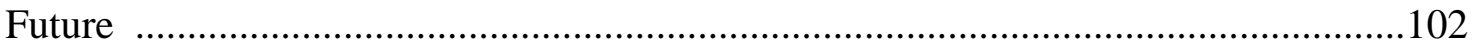

5.5 Prioritization and the Creation of Vulnerability and Adaptive Capacity .............117

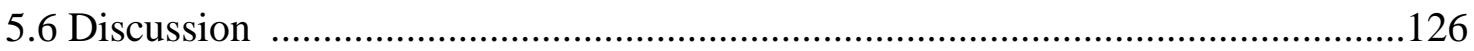

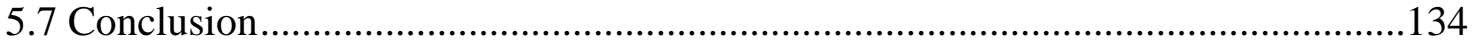

Chapter 6: Pathway for Change or Business as Usual? Discourses in Sea Level Rise

Adaptation Governance in Miami-Dade County, Florida

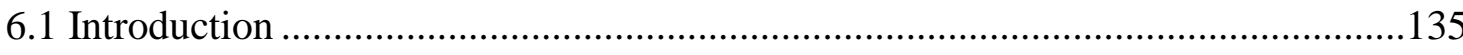


6.2 Institutional Discourse Analysis to Unpack Sea Level Rise Risk, Problem

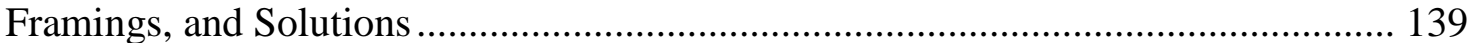

6.3 Institutions and Sea level Rise Adaptation in Miami-Dade County, Florida........ 143

6.4 Sea Level Rise Adaptation Storylines Discourses ............................................ 150

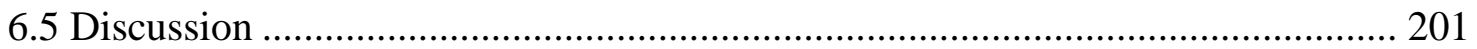

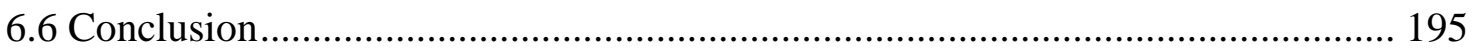

Chapter 7: Miami-Dade Case Study Conclusions, Theoretical and Planning Contributions, and Recommendations.............................................................. 203

7.1 Summary of Findings from Miami-Dade County, Florida ............................... 203

7.2 Situating Case Study Findings in Risk and Planning Theory and Practice........... 204

7.3 Strategies to Address Risk Ambiguity Challenges in Climate Change Adaptation

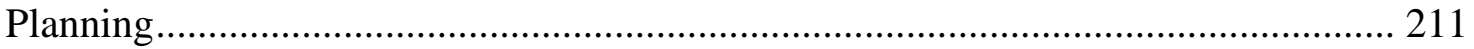

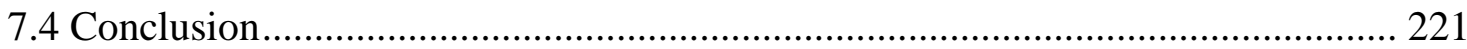

Chapter 8: Re-Scaling the Black Box of Decision-making: Global to Local

Knowledge Practices of Sea level Rise Risk in Coastal Adaptation Planning........ 223

8.1 Introduction ................................................................................................. 223

8.2 Scalar Politics of Risk in Sea Level Rise Adaptation Planning ......................... 227

8.3 Applying Scalar Politics of Risk ......................................................................... 236

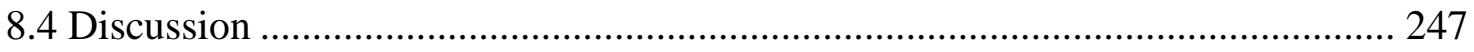

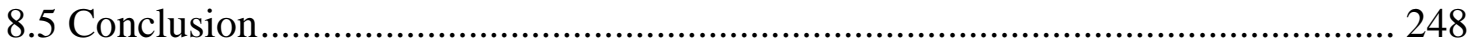

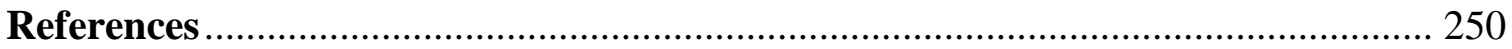

Appendix A: Timeline of events related to sea level rise adaptation planning in

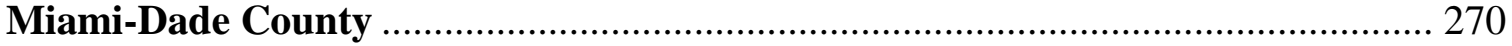

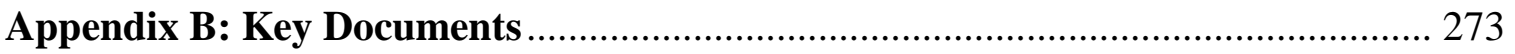

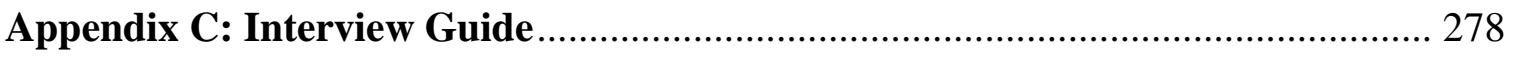

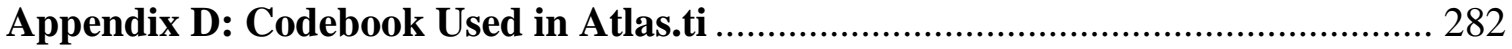

Appendix E: Events Attended During Field Research ..................................... 285 


\section{List of Tables}

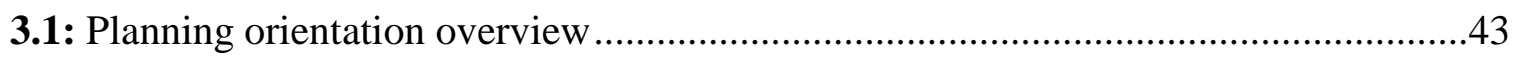

4.1: Key actions outlined in the preliminary resilience assessment from the 100 Resilient

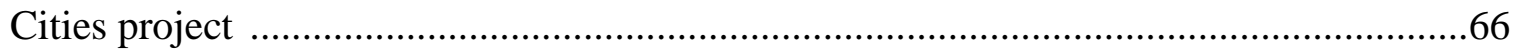

4.2: Summary of methods used in dissertation research ..........................................69

4.3: Institutions involved in sea level rise adaptation efforts in Miami-Dade County,

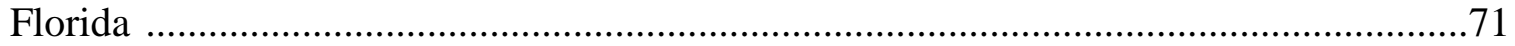

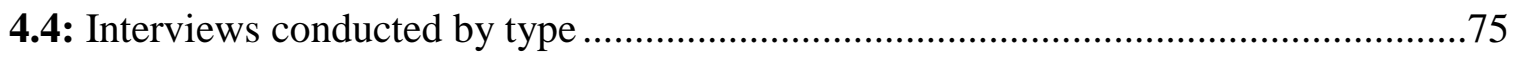

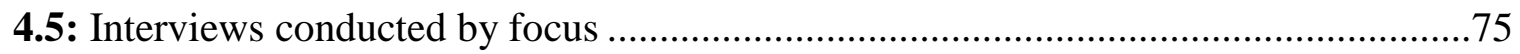

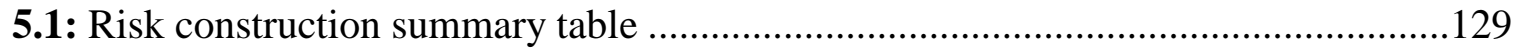

6.1: Rationality claims and implications for adaptation governance ............................142

6.2: Adaptation Pathways in Miami-Dade County, Florida .........................................150

6.3: Summary of four emerging discourses within sea level rise adaptation governance in Miami-Dade County, Florida...............................................................................192

8.1: Summary of definitions, processes, and key tensions within the five arenas of scalar

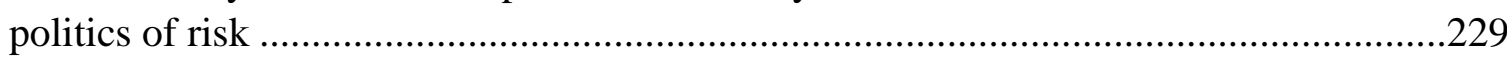

8.2: Pacific Island case study scalar work processes and key tensions ..........................241

8.3: Miami-Dade County, Florida case study scalar work processes and key tensions ..247 


\section{List of Figures}

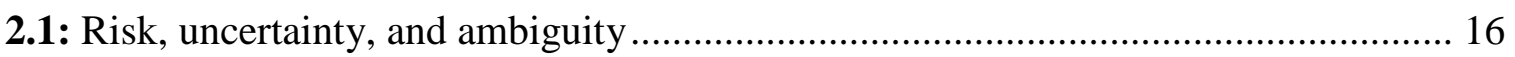

2.2: Dimensions of risk in sea level rise adaptation planning .................................... 17

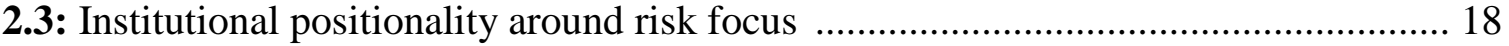

2.4: Governance, planning, and knowledge networks that address ambiguity............... 23

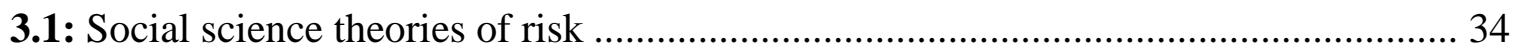

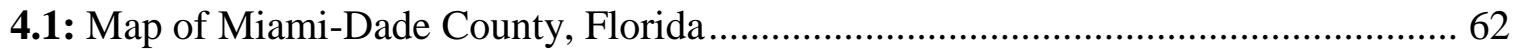

5.1: Two types of ignorance: nonknowledge and negative knowledge ......................... 87

5.2: Sea level rise projections adopted by Southeast Florida Regional Climate Change

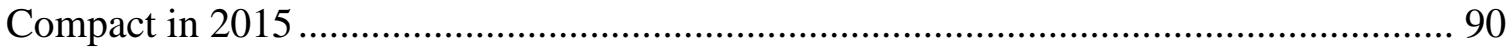

5.3: Representation of sea level rise trend in Miami-Dade County GreenPrint document

5.4: Map of sea level rise impacts, created by Miami-Dade County............................ 108

5.5: Map of percentage of individual poverty for Arch Creek project ......................... 112

5.6: Map created by Dr. Hugh Gladwin with community organizers to show climate gentrification in high elevation neighborhoods in Miami-Dade County, Florida .......... 114

5.7: Image of sea level rise impacts from Miami-Dade County's website.................... 125

5.8: Construction of risk knowledge in sea level rise adaptation planning in Miami-Dade

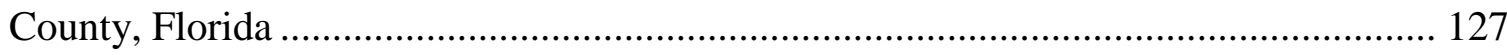

8.1: Distribution of the five scalar arenas across spatial, biophysical, and administrative

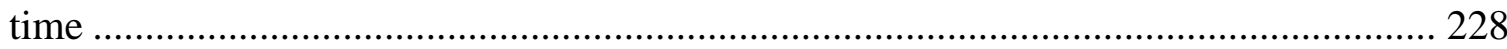




\section{List of Abbreviations}

$\begin{array}{ll}\text { Compact } & \text { Southeast Florida Regional Climate Change Compact } \\ \text { EPA } & \text { Environmental Protection Agency } \\ \text { FEMA } & \text { Federal Emergency Management Agency } \\ \text { GHG } & \text { Greenhous gas } \\ \text { IGERT } & \text { Integrative Graduate Education Research Traineeship } \\ \text { IPCC } & \text { Intergovernmental Panel on Climate Change } \\ \text { LiDar } & \text { Light Detection and Ranging } \\ \text { NFIP } & \text { National Flood Insurance Program } \\ \text { NOAA } & \text { National Oceanic and Atmospheric Administration } \\ \text { SETs } & \text { Social, Ecological, and Technical Systems } \\ \text { SFWMD } & \text { South Florida Water Management District } \\ \text { SLR } & \text { Sea level rise } \\ \text { USACE } & \text { United States Army Corps of Engineers } \\ \text { USGS } & \text { United States Geological Survey }\end{array}$




\section{Chapter 1: Dissertation Introduction}

On March 29, 2018 climate activist Maggie Fernandez addressed the City of Miami Sea Level Rise Committee in Coconut Grove at City Hall. Asking the committee and the city to discuss the possibility of joining the Miami Climate Alliance's effort in holding energy companies accountable for the cost of climate change impacts, the situation erupted into an argument over whether greenhouse gas emissions and mitigation efforts are under the purview of the committee (Harris 2018). Architect and Sea Level Rise Committee member, Reinaldo Borges, the most vocally opposed to Fernandez, argued to maintain the focus of the committee's efforts on adaptation solutions and not tap into the politics of responsibility. Fernandez argued back and pointed to the lack of diverse representation on the committee and the need to build a more inclusive planning arena in which more peoples' concerns could be addressed. The outfall of this outburst, which included personal attacks, ended in Mayor Suarez calling for Borges' resignation and potential reorganization of the Sea level Rise Committee into a resiliency committee to broaden its scope.

Like most outbursts in public settings, this one has multiple layers. There is the feeling of a lack of representation on a formal committee, boundaries that exclude topics that some view as relevant, as well as uneven power structures between a climate activist and a prominent architect. Debates surrounding the risks, or the anticipated dangers associated with sea level rise, are at the core of these issues. Contestations emerging from different views of what is considered relevant for sea level rise adaptation planning can be explored by examining how different groups (e.g. the development community and environmental organizations) construct and frame risk in the planning process. A climate 
activist, such as Fernandez for example, may be focused on a broad set of impacts from climate change and concerned with reducing emissions to mitigate all these impacts. While an architect may also be concerned with those things, they may be relatively more concerned with the impacts sea level rise will have on development and future growth within Miami. Neither Fernandez nor Borges are right or wrong in their views and priorities, yet some priorities carry more authority and political motivation than others, and may be embedded in assessments, policies, and planning documents. Within the planning context surrounding the existential threat of sea level rise in Miami, Florida, such dynamics emerge out of and simultaneously produce and construct the way in which risks are understood and addressed in the planning process. Finding ways to balance shifting priorities in this planning context around risk is a complex challenge.

This dissertation examines the way institutions, and individuals acting within those institutions, construct knowledge about risks and the social and governance processes surrounding the ways in which those different risk constructions are or are not embedded in planning activities. Broadly defined, the construction of risk encompasses the social process of selecting dangers for attention (Douglas and Wildavsky 1983). Though risks are often considered to be something that can be measured and formally assessed as a function of probability and consequence of a potential outcome, there is no one "correct" way to identify risks (Lupton 1999). The process of defining and assessing risks takes place in social settings by which people make decisions about what probabilities to assign and how to assign them, and what consequences to measure and how to measure them, among other factors that determine risk (Douglas and Wildavsky 1983; Lupton 1999). Often, guidelines and baselines surrounding these decisions are 
formalized in laws and policies. Uncertainty is a key component of risk because a world with perfect information about the future would suggest straightforward decision-making where outcomes of all decisions would be known, without the need to examine probabilities, unintended consequences, or risks (Gross 2010). The desire to reduce uncertainty is often paramount when managing risks, and how uncertainties are assessed and addressed are shaped by and shape our processes for how we deal with risks (Gross 2010). Since there is no one way to define risk, we must understand different planning contexts and the systems that determine and reinforce dominant narratives around risk.

The problem of risk construction and knowledge integration is not new to the topic of sea level rise because societies have long examined and managed different risks (Douglas and Wildavsky 1983; Wildavsky 1988; Winner 1989). For example, cities examine and attempt to reduce risks from crime, economic activities, and human and environmental health. Assessing risks and identifying strategies to mitigate those risks is ubiquitous to many urban environmental planning challenges (Gottlieb 1993; Fischer 2000). This is largely because we live in a society in which the risks resulting from industrialization often outstrip the benefits, and the dark sides of progress increasingly come to dominate social and political debates (Beck 1992). While cities have always grappled with risk management, modernization has transformed this relationship and new risks continue to emerge out of activities that are simultaneously viewed as technological, industrial, and urban achievements (Beck 1992; Latour 2012). Many modern risks are both more pervasive and harder to detect, requiring science and expertise to understand and interpret (Winner 1989; Beck 1992). Given the highly technical and invisible nature of risks, knowledge politics contested through expertise and counter expertise emerge 
from managing modern risks (Beck 1992; Fischer 2000). This serves to elevate the expertise and status of knowledge professions to a prime political position in the discourse of risk - often experts control the discourse around risk, leaving little or no room for the layperson (Wynne 1996). The central fault of the risk society is the growing tension between those with and those without formalized risk knowledge (Beck 1992). Understanding risk, science, and politics is complex, as is the way in which these knowledges become embedded in decision-making. While citizens depend on the knowledge produced by expert institutions, they can be simultaneously concerned that these institutions construct that knowledge to obscure or mystify them (Wynne 1996; Fischer 2000). Sometimes, knowledge about risks can be controlled and determined by certain policies, pre-existing goals, and decisions, which may benefit some while harming others (Tenenbaum and Wildavsky 1984).

From a theoretical standpoint, conventional work around risks has neglected two basic dimensions of the social processes that surround them. First, the social context in which risks are embedded is often ignored (Wynne 1992). Secondly, assumptions about the character of risk are often removed from the experiences of those at the actual site of the risk (Wynne 1992). For example, while institutions may conduct formal risk assessments, they may not be culturally relevant or reflect the risks that people experience in their daily lives (Wynne 2003). The danger of failing to recognize the social processes that construct and embed risk knowledge is that some knowledgeparticularly lay knowledge — can be left out, and risk management solutions can overlook critical knowledge to the problem at hand. 
Increasingly, we have multiple institutions, both formal and informal, governing knowledge production and implementation around risks (Leach et al. 2007). Each of these institutions has their own way of understanding risks. Institutions that govern decisions about risks shape risk knowledge in accordance with their own missions, priorities, ways of knowing, and boundaries (Douglas and Wildavsky 1983; Hilgartner 1992). Those institutions and individuals closest to decision-making, often adopt risk knowledge that most closely aligns with their cultural practices and preferences, which can differ from other institutions more removed from decision-making (Douglas and Wildavsky 1983). When not recognized and addressed, divergent and conflicting ways of constructing risk—known as risk ambiguity—can lead to barriers to implementation, communication, and knowledge integration (van den Hoek 2014). These processes can also reproduce social inequities (Adger et al. 2005; Adger and Jordan 2009; Wisner et al. 2014).

The way that risk knowledge is produced and governed in modern risk societies can hide who serves to benefit and who might be burdened by planning outcomes (Beck 1992; Wisner et al. 2014). Ultimately, risks are shaped by priorities, and within urban systems, priorities connected to both formalized and informalized systems of power and authority can shape planning outcomes in their favor (Fischer 2000; Leach et al. 2007). This can be either intentional or unintentional. The unintentional creation of risk knowledge that fails to address diverse dimensions of risk can be the result of institutional blindness to different problem framings and ways of measuring or knowing risks (Miller and Muñoz-Erickson 2018). Risks can also intentionally be ignored or misrepresented (Fischer 2000). This can occur when private interests dominate the policy 
design and evaluation around how risks are measured and managed (Fischer 2000). For example, United States policies on toxicants place most of the burden of proof on the public to demonstrate they are a risk, rather than on the companies producing toxicants to demonstrate safety (Fischer 2000).

This complicates planning for risk and suggests that modern societies managing risks are now trapped: risks are increasing but those responsible for their management are often blind to the complexity of those risks, and producers of risks are able to either avoid regulatory measures or possibly benefit from the ways that risks are constructed. The public must live with the obvious threats of uncontrolled technical industrial development and they often have little ability to account for the existence of threats or accurately identify the culpable individuals. However, such power dynamics and outcomes around winners and losers within a risk society are not guaranteed. Individual actors within different institutions and the community can change the system and ways in which risks are understood and managed. This has happened throughout history as communities have rallied against toxins in their neighborhoods, work environments, and food products (Gottlieb 1993; Fischer 2000). The environmental justice movement emerged out of the recognition that environmental harms are disproportionately experienced by communities of color and low-income communities (Gottlieb 1993).

So, while trends in modern risk societies present a gloomy image of those in power obfuscating risk in their favor, individuals can act within the system and institutions do change. The first step to changing top-down risk management practices is to create systems with a more complex understanding of the public's relationship to expertise and broader understandings of how multiple risks are understood and serve to 
be integrated into decision-making contexts (Fischer 2000). Expert's reductionist framings of both biophysical risks and evaluations of citizens responses to risks often fall short of achieving the necessary foundation for knowledge integration practices (Slovic 1992). We see an increasing recognition that ordinary people have valuable risk knowledge (Wynne 2003) and that city planning efforts seek out this knowledge for decision-making (Innes and Booher 2010). A restructuring of professional expertise towards a more reflexive approach to science (Wynne 2003), and a more democratic and integrative approach to measuring and addressing risks (Beck 1992; Fischer 2000; Innes and Booher 2010), can open-up knowledge practices around risk and create a more integrative approach to assessing and addressing environmental risk (Miller and MuñozErickson 2018).

This dissertation applies this planning challenge around assessing and addressing risks in the context of sea level rise adaptation planning. Impacts from climate change, including sea level rise, presents new emerging risks that are being understood and planned for by institutions governing the urban environment. Research on climate change risks, particularly the science to policy interface, demonstrate existing power structures around climate change mitigation and adaptation policies (Hulme 2009; Hulme 2010; Hulme 2013). Global climate knowledge and the institutions representing that knowledge come into conflict with local knowledge, sovereignty, and local power and authority (Jasanoff and Long-Martello 2004; Hulme 2009; Denton 2017). Researchers have also examined the uneven distribution of climate risks (Wisner et al. 2014) and community pushback and/or acceptance to different climate change policies and adaptation strategies (Humle 2009). While uneven distributions of risks are explored, the role of knowledge 
practices that result in those distributions is frequently unexamined, particularly in North America.

The risk of sea level rise is predominantly considered in future contexts and understood by climate models that both serve to reconstruct the past and project into the future. At the same time, decisions surrounding what to do about sea level rise impacts are affecting people now, and the way in which risk knowledge is constructed and integrated into the planning process can show us who may serve to benefit and who may be burdened by these planning choices. Ultimately it comes down to whose knowledge matters in terms of how risks are measured, and how is that knowledge used. The governance and production of risk knowledge is not static, people can work outside of the norms determined by their institutions and institutions can change in response to community and political pressure.

Sea level rise adaptation planning in Miami-Dade County, Florida is used as a key-case study for how knowledge about risks posed from sea level rise are both constructed and integrated into planning processes. In Miami-Dade County, planners and scientists have been examining sea level rise risks for decades and have begun to implement solutions to address inundation from changes to the sea level. The purpose of this dissertation research is to better understand how risks from sea level rise are constructed within a local planning context and the challenges and opportunities current governance processes present in integrating diverse knowledge about those risks. This will allow us to more closely examine risk challenges and how they are being reproduced and challenged in a real-world example. This dissertation is organized as follows: 
Chapter 2, titled, "Using risk ambiguity to examine sea level rise adaptation planning," applies the concept of risk ambiguity to the topic of sea level rise adaptation planning by emphasizing the way that risk knowledges are constructed in the planning process. Knowledge constructions around risk reflect institutional priorities, epistemologies, and boundaries in adaptation governance. This chapter provides a theoretical framework and research questions that guide the dissertation.

Chapter 3, "Literature and theoretical review" presents a literature review extending the theoretical frame around knowledge co-production, the social construction of risk, and knowledge integration theories around governance and planning. The purpose of this chapter is to connect these theoretical frameworks to the issue of sea level rise adaptation planning to provide more context for research gaps examined in this dissertation.

Chapter 4 "Research design and methods," offers an overview of the research design and methods. A single case study research design is used to understand the multiple, complex factors that shape how risks from sea level rise are constructed and integrated in planning systems. The case study was informed by document analysis and interviews. Interviews were transcribed and coded. Thematic analysis was used to identify emerging themes and discourses. Literature and theoretical reviews are also used to contextualize findings that emerge out of the case study.

Chapter 5, titled, "Constructing risk knowledge in sea level rise adaptation planning in Miami-Dade County, Florida" examines the process of how institutions select or ignore dangers for attention. I apply Gross's (2010) theory on the two types of ignorance - the uncertainties that get measured and further evaluated, and the 
uncertainties that are ignored - to understand how some risk knowledge is used in the planning process and uncertainties further examined while other risk knowledge is ignored. This chapter includes three findings of how sea level rise risks are constructed. First, that determining the physical hazards of sea level rise (i.e. rates, projections, and physical geographies) is a negotiated and contested process. Second that risk knowledge that supports an economically viable future is favored over knowledge that either threatens that future or is seen as insignificant to that future. Third, the production of knowledge about biophysical hazards shaped by certain economic and political framings are reinforced and reconstructed in the planning process as hazards are translated to their interaction with social, technological, ecological, and economic vulnerabilities. This research contributes to cultural theories of risk by identifying points of ambiguity among stakeholder groups in sea level rise adaptation planning. Findings from this research can be used to understand political processes around how constructions of risk are emerging in the context of climate adaptations in urban environments.

Chapter 6 titled, "Pathway for change or business as usual? Discourses in sea level rise adaptation governance in Miami-Dade County, Florida" examines institutional arrangements around adaptation governance through emerging narrative networks and storylines around problem framing and solutions to sea level rise adaptation planning. This chapter provides the interpretive planning context of sea level rise adaptation governance in Miami-Dade County, including an overview of roles and responsibilities of institutions involved or affected by sea level rise adaptation planning and the associated adaptation pathways. Four discourses around sea level rise adaptation planning in MiamiDade County emerge within the community. The first is a focus on the economic core of 
development and tourism, aligned primarily with the business community. The second discourse emphasizes infrastructure and is closely aligned with local governments and the desire to sustain a regional tax base to fund adaptation actions. Thirdly, a discourse around ecological impacts from sea level rise emerged among environmental nongovernmental organizations, some government employees, and private interest groups, primarily underpinned by scientific rationality. Finally, considerations for the people using infrastructure and that people also matter emerged out of cultural rationality with community organizations and others purporting initiatives that recognize distributive justice and the unevenness of socio-economic vulnerabilities. This research contributes to planning theory by opening-up governance processes around adaptations to climate change shape and are shaped by the ways different groups define and interpret risks to sea level rise. The planning and governance contexts are used to examine how these discourses interact with each other.

Chapter 7, "Miami-Dade County, Florida case study conclusions, theoretical and planning contributions, and recommendations" concludes the Miami-Dade County case study. This chapter draws on lessons learned from risk construction and governance in the Miami-Dade County case study to articulate principles for creating inclusive adaptation science and planning activities. Findings from chapters 5 and 6 suggest that baselines, projections, and the focus of risk rooted in economic principles have more authority as compared with counter arguments around ecological, social and cultural risks. Recommendations include the need for transparent adaptation decisions and the inclusion of diverse stakeholders in the production of regional climate science, sea level rise assessments, and adaptation planning. This work informs climate change adaptation 
science and planning practice by identifying barriers and opportunities for diverse knowledge integration in the planning process. These findings illuminate points within the planning system that can better facilitate the creation of shared meaning, trust, and relationships among different stakeholder groups.

Chapter 8 is a co-authored chapter titled, "Re-scaling the black box of decisionmaking: Global to local knowledge practices of sea level rise risk in coastal adaptation planning." As part of my National Science Foundation Integrative Graduate Education Research Traineeship (IGERT), I am required to co-author a dissertation chapter with other IGERT Fellows. We developed a framework that can be used to examine scalar issues of knowledge practices in identifying and planning for risks from sea level rise. As sea level rise risk knowledge is translated from global to site-specific scales, we identify five key moments in which politics of scale around risk knowledge emerge in adaptation work: 1) the construction of the global climate; 2) the regional downscaling of climate impacts; 3) the local definition of risks; 4) the transformation of on-the-ground socialecological-technical systems and infrastructures; and, 5) the evaluation of intervention efficacy. We apply this framework to findings from two case studies in the coastal areas of Florida, United States, and the Pacific Islands to exemplify scalar issues at work in adaptation governance. 


\section{Chapter 2: Using Risk Ambiguity to Examine Sea Level Rise Adaptation Planning}

\subsection{Introduction}

Impacts from climate change put pressure on cities' social, ecological, and technological systems (IPCC 2012; IPCC 2014). In response, cities around the world are transforming urban infrastructure to adapt to future climatic regimes and assuage potential threats posed to urban life. Across the country, coastal cities are developing and implementing a range of strategies to protect populations from the impacts of sea level rise. For example, the City of Miami Beach is currently raising street levels (Flechas 2015) and across the San Francisco Bay Area, groups are focused on restoring tidal wetlands in anticipation of climate impacts (King 2016). Planners in Seattle have begun working with community groups to better understand the ways in which sea level rise will affect urban residents (Stowe 2016).

Within these and other climate adaptation contexts, planners are confronted with the challenge of integrating diverse knowledge systems into adaptation strategies (Adger et al. 2009; van den Hoek 2014). Knowledge integration is particularly important to the ways in which risks surrounding sea level rise are understood relative to different stakeholder groups (van den Hoek 2014). Often, solutions to environmental problemslike confronting the challenge of sea level rise - are unproblematized and posed as requiring expert driven, technical solutions (Winner 1989; Jasanoff 2006). This framing, however, ignores the way in which the knowledge behind these solutions is produced and situated in political, economic, and cultural contexts (Jasanoff 2004; Shapin and Schaffer 1985; Miller 2008), and overlooks other knowledge systems relevant to the problem at hand (van den Hoek 2014; Brugnach and Ingram 2012). The failure to integrate diverse 
knowledge systems and constructions of risk into sea level rise adaptation strategies can result in barriers to implementation (Adger et al. 2005; Adger et al. 2009; Sabatier 2005) and outcomes that can reproduce social inequities (Adger et al. 2005; Adger and Jordan 2009; Wisner 2014).

In environmental planning, knowledge integration challenges can stem from several sources, including ambiguity and contestations around how environmental risks and solutions are framed (Brugnach and Ingram 2012; Fischer 2000) and institutional arrangements that may inhibit diverse involvement (Leach et al. 2007; Jasanoff and Long Martello 2004; Bogason and Musso 2006). This dissertation examines knowledge integration barriers in sea level rise adaptation planning and is guided by the question: how do different groups understand risk within sea level rise, and what planning and governance factors influence the way diverse dimensions of risk are integrated into adaptation strategies?

The climate change literature generally defines adaptation as the "adjustment in natural or human systems in response to actual or expected climate stimuli or their effects, which moderates harm or exploits beneficial opportunities" (McCarthy et al. 2001, p. 982). Sea level rise adaptation planning is predicated on predicting real world impacts and designing and implementing an adaptation strategy. In the wake of uncertain future conditions, cities depend on models, simulations, and expert opinions to make decisions about what adaptation measures to take and how to design and implement strategies. Knowledge claims about risks posed by climate change impacts are used to understand and promote climate adaptation (Hilgartner 1992), and the way risks are understood is ultimately linked to the design, planning, and implementation of proposed 
solutions (Sarawitz et al. 2000). These different knowledge claims are prioritized, ranked and privileged in the planning process (Gross 2010).

In environmental planning, risk is often conceived of as a function of the physical components of the hazard (i.e. rate of sea level rise), the vulnerability of the social and ecological system (e.g. topography, socio-demographic data), and the system's adaptive capacity_or ability to respond to shock (e.g. evaluated in terms of institutions and governance, information and resources, etc.) Planners conduct risk assessments which stem from a tradition of technical, scientific, and objectively rational approaches (Fischer 2000; Wisner 2014). The focus is on minimizing risks and it is often assumed that more information about the potential impacts of climate change on social, economic, and biophysical systems will result in better decision-making, and that the lack of information about risks is the main limitation in adaptation action (Adger et al. 2009; van der Hoek et al. 2014). This line of reasoning is understandable, given that predicting uncertain futures and impacts is at the core of many debates around how and when to take political action (Adger et al. 2009). However, scholars have identified multiple dimensions of uncertainty and while the focus tends to be on "not knowing enough" in terms of incomplete knowledge and unpredictability, ambiguity or "knowing differently" is equally important (see Figure 2.1) (Weick 1995; van den Hoek et al. 2012; Brugnach and Ingram 2012). 


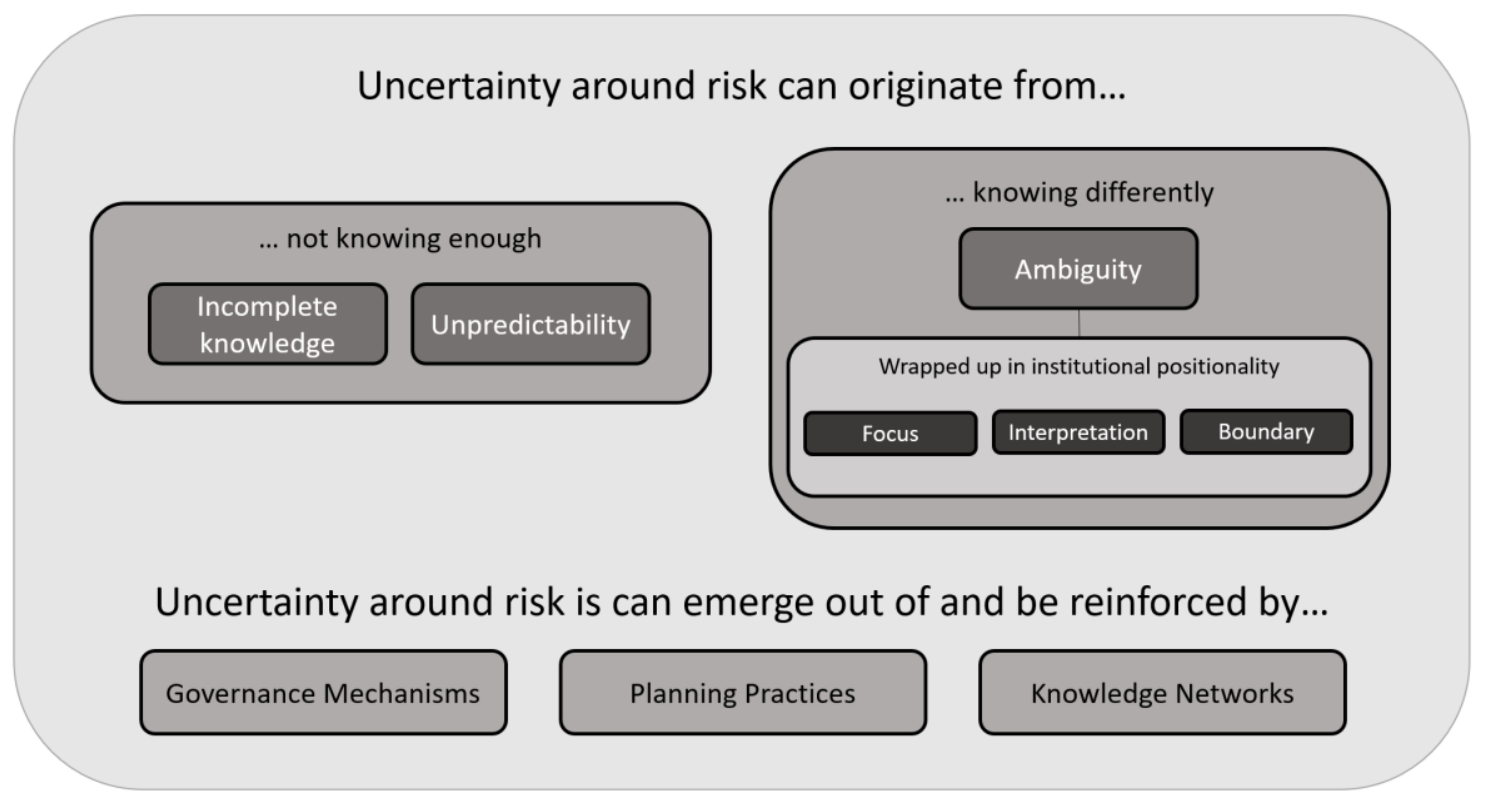

Figure 2.1 Risk, uncertainty, and ambiguity: Modified and expanded from van den Hoek 2014, depiction of how ambiguity, or "knowing differently" differs from incomplete knowledge and unpredictability, or "not knowing enough."

Ambiguity refers to a context in which there are different and sometimes conflicting views on how to understand the problem or system to be managed (Dewulf et al., 2005; Brugnach et al., 2008; Renn et al., 2011). Groups may have differing ideas of what to put as the focus, how to interpret information about the system, or how to bound a system (Brugnach et al. 2008; van den Hoek 2014). Often ignored in planning contexts and research on sea level rise adaptation, ambiguity — particularly around social riskscan be far more important for decision-making than the knowledge gaps of natural systems, since ambiguities can hamper project development and lead to conflicts over the facts (van den Hoek 2012). Within sea level rise adaptation, issues of ambiguity can take multiple forms: discretionary decisions resulting from the focus or problem framing, epistemological conventions or how knowledge is understood, and system boundaries that can restrict what knowledge is used. 


\section{Dimensions of Risk in Sea Level Rise Adaptation Planning}

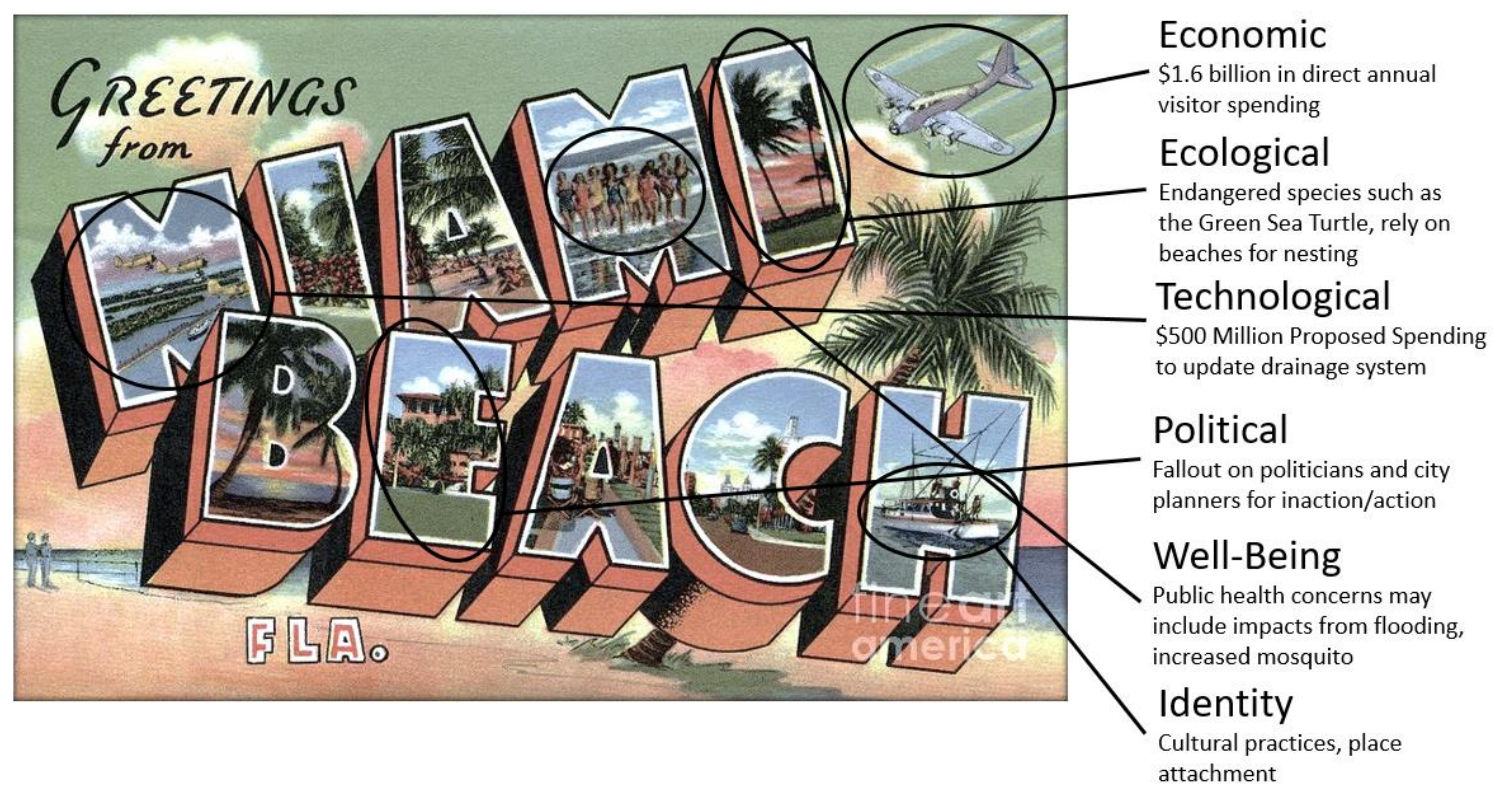

Figure 2.2 Within social-ecological systems, different contexts of risk emerge relative to the institution defining and making claims to those risks.

First, ambiguity can arise in what different groups place as the substantive focus of the risk definition (van den Hoek 2014). Institutions and groups create their own conceptions of risk stemming from different ontological perspectives from which institutions align themselves (Hilgartner 1992; Short and Clark 1992; Wisner et al. 2014). In understanding risk, cultural theory argues that risks are "defined, perceived, and managed according to principles that inhere in particular forms of social organization" (Rayner 1992). Figure 2.2 represents some of the ways risk may come to be thought of in terms of impacts from sea level rise using a post card from Miami Beach to illustrate various dimensions of risk. Adger et al. (2009) identify that within climate change adaptation planning, much of the focus for framing risk among the planning community surrounds ecological, economic, and technological dimensions of risk. There are other 
risks, however, related to sea level rise. There may be political risks involved in either addressing or failing to address sea level rise in a particular way (Giddens 2009; Adger et al. 2009). Environmental changes, such as those resulting from sea level rise, may impact community and individual identities (Clayton 2003) as well as elements of human wellbeing such as public health and livability (Fischer 2000). The way in which institutions come to define and interpret risk is shaped by their position in social, cultural, political and economic systems (Hilgartner 1992; Douglas and Wildavsky 1983). This institutional positionality can influence the focus of a groups definition of risk. Figure 2.3

demonstrates how different dimensions of risk may come to be important as the focus for different groups. The relationship between positionality and risk definitions are apparent in that people will often select those dimensions of risk that help to reinforce the social solidarity of their institutions (Douglas and Wildavsky 1983).

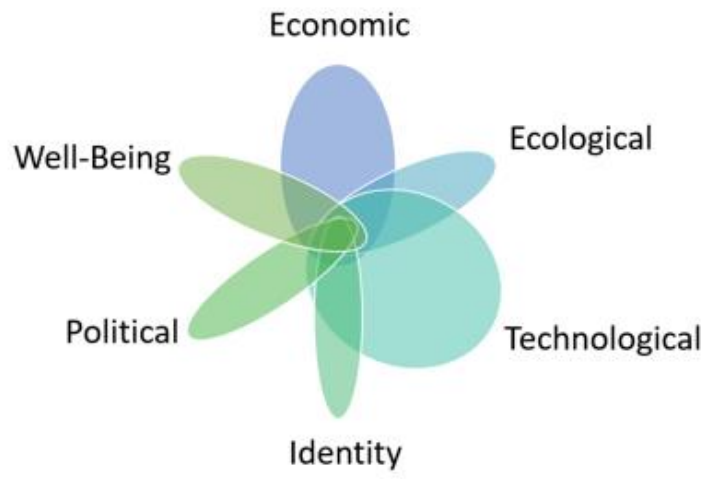

Engineers

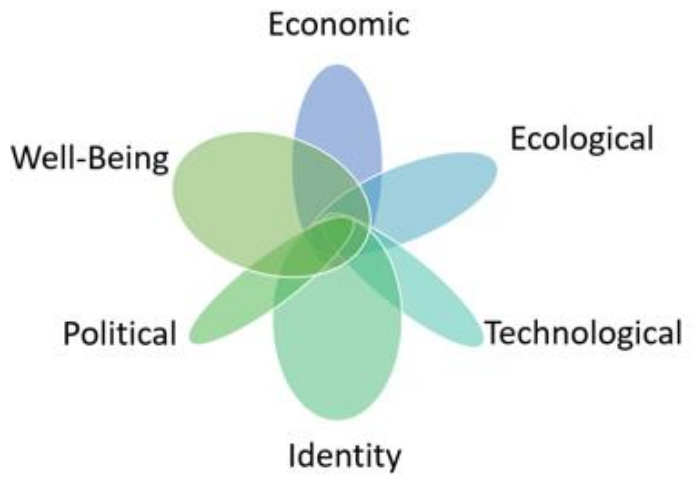

Community Organization

Figure 2.3 Institutional positionality around risk focus: Groups have different priorities that cause them to focus on different dimensions of risk. The first group on the left, representing engineers, may be more focused on technological risks to infrastructure. A community organization represented on the right may be primiarily focused on risks that threated well-being and identity. 
The second way ambiguity can manifest in sea level rise adaptation planning are in the ways groups interpret information about risk. Epistemological differences among institutions can create conflict around what knowledge is considered valid. As the conflict between the architect and the climate activist in the beginning of Chapter 1 demonstrated, the planning process can become political as different groups interact, determining the focus of sea level rise adaptation strategies (Sarewitz et al. 2000) It is not only important to consider the way knowledge claims around risk are constructed, but also how they are contested and used among different institutions in the planning context. These disagreements may emerge in public settings, such as the outburst at the City of Miami Sea Level Rise Committee meeting previously described. Sources of disagreement can stem from differences in methodological practices and different ways of measuring an unknowable future (Ozawa 1996). Constructions of risk are embedded in climate models (Edwards 2001), public policies (Fischer 2000), heuristics (Stirling 2009), organizational and individual behaviors (Short and Clark 1992), and lay knowledge (Wynne 1992). The process by which knowledge about risk is constructed in part lends it credibility in many planning arenas. For example, scientific representations of risk, such as those used by climate scientists, hydrologists, and geomorphologists may be considered more credible sources of information through a knowledge production system integrating testable and defensible biophysical laws (Latour and Woolgar 1986; Gieryn 2006). Rational and technical approaches to constructing knowledge around risk differ from other knowledge constructions. Community activists may use knowledge of placebased experiences, linking outcomes from previous climatic events within their communities to a changing climate as well as social, economic and political histories 
(Fischer 2000). As such, community groups may think of risk from climate change in terms of the complex arrangements surrounding their daily lives and worry about housing, future employment, health, and asserting their rights (see Stowe 2016). Ultimately, diverse ways of knowing risk are related to priorities of different groups. These priorities can be defined by and reinforced through institutional policies, laws, and social norms and help determine what types of information matters to whom. Disparate ways of knowing and ideas around what constitutes valid forms of knowledge within sea level rise adaptation planning may create conflicts among groups and impede the integration of diverse knowledge systems in proposed solutions. At the same time, conflicts can push against ideas of what is considered at risk from sea level rise.

Depending on how conflicts are handled, they can benefit the planning process and push things towards more integration. The outcome of the conflict between the architect and the climate activist, for example, called for the Sea Level Rise Committee to broaden its scope and begin addressing risks and solutions.

The third way issues of ambiguity emerge in sea level rise adaptation planning are in decisions surrounding how to bound the system (van den Hoek 2014). This could manifest in terms of scalar differences and in the way groups may emphasize different constraints on scope and project planning. Governing institutions have their own jurisdictional boundaries which may be related to borders (e.g. municipal, county, and state governments) or components of the social, ecological and technical system (e.g. United States Fish and Wildlife have jurisdiction over habitat, while the EPA may have jurisdiction over contaminants). Groups may bound the system differently in terms of both spatial and temporal scales, these differences may not only emerge in different 
constructions of risk, but also impact the planning process and knowledge integration. The perceived need to act quickly with sea level rise may result in actions that stem from narrow constructions of risk as opposed to taking the time to produce a more integrated approach, as time constraints can be barriers to collaborative and integrated processes. In addition to differences in scale boundaries of a system, groups may have different interpretations of political, environmental, and fiduciary constraints regarding the scope of possibilities. Some groups may bound the system based on limitations from historical trajectories and historical lock-in, while other groups may consider ideas outside of these boundaries. There may also be specific types of analysis and probabilities that groups use to bound the system (Kunreuther et al. 2013). In many widely-used systems for risk management policy analysists often focus on a narrow set of sources of uncertainty, and a narrow scoping of probabilities can influence how they bound the system (Kunreuther et al. 2013).

In addition to knowledge practices that create risk constructions, it is important to pay attention to the way in which diverse knowledge about risk are integrated into decision-making. Climate adaptation governance surrounding the decision-making context may help or hinder the integration of diverse constructions of risk into adaptation strategies. While some governance arrangements allow for creative linkages among institutional actors to help solve environmental problems, scholars have also identified several challenges. For example, decentralized environmental decision-making can lack transparency and blur the public participation processes, making it difficult for integrating local knowledge in decision-making (Leach et al. 2007; Jasanoff and Long Martello 2004; Bogason and Musso 2006). Further, rules and regulations may serve to 
reinforce certain ontologies, epistemologies, and system boundaries inhibiting knowledge integration (Jasanoff and Long Martello 2004).

In addition to examining governance, it is important to consider the planning process because it can help determine the degree to which views, values and interests of diverse communities are represented in the formulation of a problem and the development of its solution (Brugnach and Ingram 2012). While institutions may always differ in terms of where they place the substantive focus of risk, what information they use, and how they bound the system, conflict and uncertainty around ambiguity can be resolved through relationship building, trust, and creating shared meanings (see Figure 2.4) (Lengwiler 2008; van Asselt and Renn 2011). The planning process-and how the public and different stakeholders are included in particular - can help determine how diverse knowledge systems are integrated into planning outcomes and reduce barriers to implementation. 


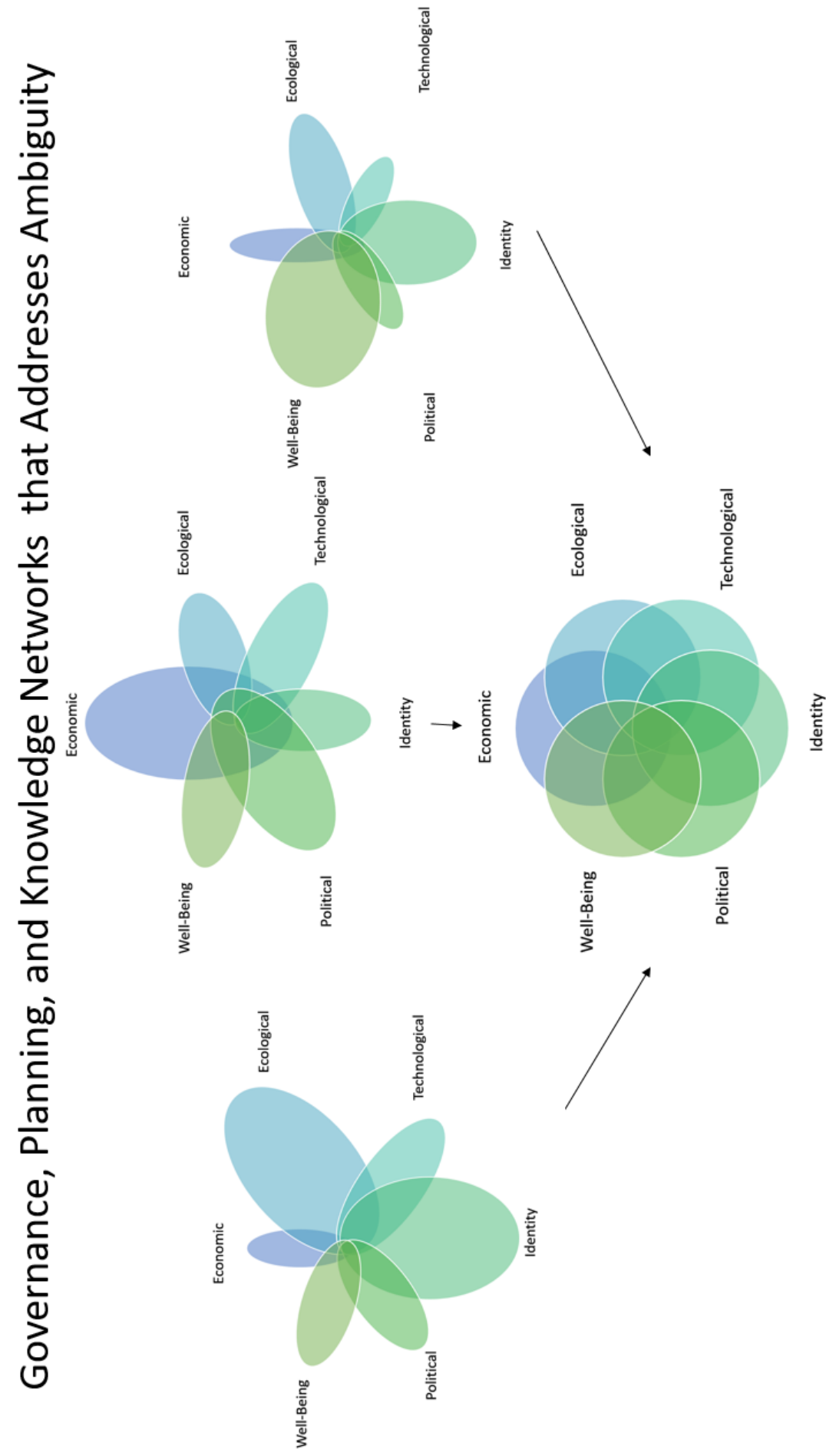

Figure 2.4 Issues of ambiguity emerge from and can be reinforced by the governance, planning, and knowledge network process. Issues of ambiguity can also be addressed through these processes with adaptation strategies that address diverse dimensions of risk in the outcome and produce a more holistic view. 
Finally, knowledge networks of different institutions (both formal and informal) may determine what types of knowledge — including lay knowledge - flow through the system and influence decision-making (Muñoz-Erickson 2014). Connectivity and information sharing can indicate a system in which there may be trust among organizations potentially leading to the creation of shared meanings around risks to sea level rise (Pietri et al. 2015). How connected different groups are may result in how their constructions of risk are integrated into adaptation strategies.

To summarize, within sea level rise adaptation planning there are several factors that may shape the way ambiguity is addressed. Addressing ambiguity can lead to the integration of diverse constructions of risk into climate adaptation strategies. The ontological focus of risk definitions and epistemological differences in how risk is understood are wrapped up in political dimensions of the decision-making arena. As such, knowledge politics surrounding different definitions of risk and adaptation strategies may in and of itself limit the integration of diverse knowledge systems. Different groups may bound the system in different ways and these boundaries may shape the way they construct risk around phenomena (van den Hoek 2014). Aspects of the planning process, governance mechanisms, and knowledge networks can negatively impact relationships, create distrust, restrict the creation of shared meanings, and ultimately, limit diverse knowledge integration. Conversely, these dynamics can also serve as an opportunity to foster relationships, build trust, create shared meanings, and result in diverse knowledge integration. 


\subsection{Research Questions}

This dissertation identifies how risk is being constructed among different groups within the sea level rise adaptation planning community in Miami-Dade County, Florida, and how those constructions of risk are embedded in design, planning, and implementation of adaptation strategies.

How do different groups understand risk related to sea level rise, and what planning and governance factors influence the way diverse dimensions of risk are integrated into adaptation strategies?

\section{$\underline{\text { Risk Construction }}$}

1. What do different institutions (both formal and informal) place as the substantive focus of risk and how do they generate knowledge claims and interpret information about risk surrounding the planning, implementation, and design of climate adaptation strategies? How are these knowledge claims contested? What shared meanings emerge out of these contestations?

2. How do different groups bound the system when considering risk of sea level rise and possible solutions? How do these boundaries shape how diverse dimensions of risk are both understood by different groups and integrated into adaptation strategies?

\section{$\underline{\text { Knowledge Integration }}$}

3. What characteristics of climate adaptation governance help or hinder the integration of diverse dimensions of risk into climate change adaptation planning, implementation, and design? 
4. How does the planning process shape the way diverse dimensions of risk are integrated into adaptation strategies?

5. What are the knowledge networks surrounding how institutions (both formal and informal) currently sharing knowledge in the knowledge production, planning, and or implementation phase? How do different types of knowledge — including lay knowledge - flow through the system?

Sea level rise adaptation is emerging in coastal cities across the United States and are transforming the built environment in Miami-Dade County, Florida, yet little is known about the political process, decisions, and knowledge systems going into their design, and the actors involved in planning. This dissertation contributes to the understanding of how sea level rise adaptation planning is being carried using a key case study of adaptation planning Miami-Dade County, Florida focusing on the political process and ambiguity around risk. By considering the way in which risks are constructed in sea level rise adaptation planning, this dissertation offers insight into how we can improve climate change adaptation science and planning and draws attention to the need to integrate the public at all stages of the planning process. 


\section{Chapter 3: Literature and Theoretical Review}

\subsection{Overview of Sea Level Rise Adaptation Science and Planning}

Sea level rise is the change of the height of the ocean relative to the coastline. It is caused by increases to the volume of the global ocean which come from warming of the ocean (thermal expansion), loss of ice by glaciers and ice sheets, and reduction of liquid storage on land (Church et al. 2013; Hine et al. 2016; Pilkey et al. 2016). Localized atmospheric conditions, tectonic land shifts and other hydrogeologic conditions of coastlines determine how sea level rise will impact specific regions (Hine et al. 2016; Sweet et al. 2017). And while sea levels change daily, global and regional mean sea levels have shifted drastically in the earth's history (Church et al. 2013; Hine et al. 2016; Pilkey et al. 2016). For example, 14,000 years ago geologists estimate that sea levels in Florida were 125 meters lower than they are today (Jarrett et al. 2005; Hine et al. 2016). In recent history, there is evidence that suggests global mean sea level rates are increasing (Sweet et al. 2017), with rates increasing by about 21-24 cm since 1880, with around 8cm occurring since 1993 (Church and White 2011; Hay et al. 2015; Nerem et al. 2010; Sweet et al 2017). Since 1900, the global mean sea level rise rate has been faster than during any comparable period over the last 2800 years (Kopp et al. 2016). Even if society were to drastically decrease greenhouse gas emissions, many scientists agree that sea level will most likely continue to rise for centuries based on persistent trends (Golledge et al. 2015; DeConto and Pollard 2016).

While benchmarks such as mean sea level and historical trends enable societies to monitor and assess potential threats posed by shifting conditions, mean sea level is not something that exists, it is a social construct (Hine et al. 2016). "Sea level" is never level, 
it slopes in different places and varies among ocean basins at any one time (Hine et al. 2016). Like measuring the global climate, the measurement of mean sea level is a modeled phenomenon comprised of multiple sources of data (Edwards 2001; Hine et al. 2016). Scientists come to "know" mean sea level and sea level rise through different ways. Because sea level rise only exists in relation to past conditions, understanding today's sea level requires reconstructing the past over long geological time periods. To do this, scientists use both direct and indirect indicators. Scientists rely on direct measurements of geological features that they know formed very close to sea level, such as elevated notches, shallow-water coral reefs, marshes, and preserved paleoshorelines (Hine et al. 2016). They use indirect proxy measures including chemical signals in rocks, sediments, and fossils (Hine et al. 2016).

To understand shifts in sea level, including past, current, and future projections, climate scientists look to the three main sources of increased oceanic volume: thermal expansion of water, loss of ice by glaciers and ice sheets, and loss of liquid storage on land, as well as various localized current and atmospheric conditions to assess historic changes and project future conditions (Church et al. 2013). For example, the 2013 IPCC Report on sea level rise, scientists have high confidence in the use of the earth's energy budget to model heat transfers to the ocean with physics to calculate thermal expansion of water (Church et al. 2013). They have varying degrees of confidence around different glaciers and ice melt and around potential feedbacks of accelerating land ice melt (Church et al. 2013). There are tradeoffs among different types of sea level rise models and decisions made during model construction which complicate sea level rise adaptation planning. 
Decisions regarding what resolution to use for collecting data and modeling, data differences from computing resources, the level of modeling complexity, and what duration (time-scale) to model are all made by those producing sea level rise knowledge with limited public oversight and involvement. These decisions are built on disciplinary conventions and "schools of thought" (Kuhn 1970; Edwards 2001). Different epistemic values, or values about knowledge, factor into these decisions around tradeoffs as well as other modeling choices that influence outcomes (Alder and Hadorn 2014). Sometimes the epistemic value choices that scientists make can be ethically relevant (Tuana 2013 and 2015; Alder and Hadorn 2014). For example, research around Antarctic and Greenland ice melt models suggest potential earth systems feedbacks that could drastically raise sea level and result in significant impacts to societies around the world (Hansen 2007). While these feedbacks are dynamic, they are represented as static in existing models because of the uncertainty around how those feedbacks will affect the system. Such a discretionary epistemic choice for modeling prudency has ethical implications around how best or worst-case sea level rise scenarios should be developed and presented by the scientific community and integrated in the policy arena (Hansen 2007). Because of the large scope of potential impacts the findings from climate change and sea level rise science poses to governments around the world, this knowledge can be suppressed, debated and politicized (Hulme 2009).

Issues of values and politics are relevant to the production of global climate knowledge. This political process becomes even more complex as knowledge moves from global to regional to local scales and how these projections are interpreted and used. The way that sea level rise projections are provided as ranges and with different carbon 
scenarios can create challenges for regional and local decision makers. For example, the most recent IPPC report on global mean sea level rise projects that the years 2081-2100 compared to baseline years of 1986-2005 will be 0.4 [0.26-0.55] $\mathrm{m}$ for RCP2.6 and 0.63 [0.45-0.82] $\mathrm{m}$ for RCP8.5 (Church et al. 2013). Information provided in this way leaves it to local decision makers to determine which rate to adopt and how to integrate that into planning. This process can be political as different actors will have different beliefs as to which projection to adopt. For example, local decision makers often interpret sea level rise as a slow process and can be dealt with in the future, but scientists suggest that it occurs in uneven and dramatic shifts (Hine et al. 2016). Further, scientists regularly point out that and even small changes to the sea level can have dramatic impacts on storm surge, high tides, and wave actions (Theuerkauf et al. 2014). Global sea level rise knowledge can intersect with local experiences, localized geographies and tide data that makes it difficult to apply at local scales.

The challenge of planning for sea level rise is like the challenge for planning for other climate change stressors in that local governments need down scaled climate data that are created in the context of regional and local conditions. The need for downscaled, and localized sea level rise projections have resulted in governments creating localized projections. For example, two United States Federal government agencies, NOAA and the USACE, have integrated local and regional data sets and processes to produce regional scale projections. Regional projections include the use of historical data from local tide gages, regional atmospheric processes, tectonic uplifting, and other processes (Sweet et al. 2017). Coastal regions must make decisions about what to do within this context around the state of knowledge about sea level rise. These decisions are 
commensurate with the way in which governing institutions understand the risks associated with unknown changing climatic and oceanic conditions. This understanding of risk is constructed by and reinforces planning decisions around how to deal with sea level rise impacts.

\subsection{Knowledge Co-Production and Constructions of Risk}

To better understand how risks are measured, understood and used in sea level rise adaptation planning, this dissertation uses the theory of co-production of knowledge from Science and Technology Studies and constructivist theories of risk to understand the way knowledge about risks from sea level rise are constructed by institutions and used in adaptation planning. The technical complexity of environmental challenges and reliance on scientific expertise to solve environmental problems creates barriers to public involvement and the integration of non-technical, lay knowledge in planning decisions (Fischer 2000). This knowledge integration barrier is problematic in how risk is understood in climate change adaptation planning (van den Hoek 2014). Using a coproduction lens offers "ways of thinking about power, highlighting the often invisible role of knowledge, expertise, technical practices, and material objects in shaping, sustaining, subverting, and transforming relations of authority” (Jasanoff 2004, p. 4). Because all organizations are "knowing" organizations (Choo 2007) and the way institutions know things shapes the material world (Jasanoff 2004), understanding how different institutions — both formal and informal — construct ideas about risk and how this knowledge shapes plans, designs, and implementation of climate change adaptation strategies is fundamental to unpacking barriers to diverse knowledge integration. 
We live in a time in which science and technology increasingly shapes our political system and daily life (Jasanoff 2004). More and more, science is called upon to predict occurrences that cannot easily be inferred from experiences and judgements alone (Sarewitz et al. 2000). Science and technology studies opens up the knowledge coproduction process - how the ways in which we understand the world and are inseparable from the ways we choose to live in it (Jasanoff 2004). When viewed through a co-production lens, all knowledge — including scientific knowledge — is produced through systems of social and material relationships and in turn that knowledge shapes the social and material world (Miller and Edwards 2001; Jasanoff and Wynne 1998; Jasanoff 2004). Sheila Jasanoff defines this relationship, "Knowledge and its material embodiments are at once products of social work and constitutive of forms of social life; society cannot function without knowledge any more than knowledge can exist without appropriate social support" (Jasanoff 2004, p. 2-3).

Knowledge refers to claims made by actors — either individuals or institutionsthat either serve to tell us something factual about the world (with varying degrees of certainty and consensus) or are taken by actors to tell us something factual about the world (Miller et al. 2010). It is an idea or belief that someone takes to be true, or at least relatively truer than other kinds of statements (Miller et al. 2010). As Miller (2008, p. 1898) defines it, "Knowledge is comprised not of simple statements of truth or fact but rather of complex judgments regarding how to identify multiple forms of evidence, assess their credibility and meaning, and integrate them together, based on appropriate evidentiary standards and weighting.” These judgments are often shaped by tacit skills and values (Collins 1974), problem framings (Miller 2000), and styles of reasoning 
(Hacking 2002). The forms of evidence are then accepted or rejected based on different disciplines and schools of thought (Kuhn 1970).

Knowledge claims are wrapped up in a decision-making context through $a$ knowledge-action-system (Muñoz-Erickson 2014). A knowledge system is a suite of interconnected individual, social, and/or institutional practices by which knowledge claims get formulated, validated, circulated, and used in making decisions (Miller et al. 2010). While science plays an important role in knowledge systems, there are many other actors, institutions, and networks which also play significant roles (Cornell et al. 2013; Irwin 1995; Irwin and Wynne 1996; Leach et al. 2005). Scholars have studied the ways knowledge systems relate to environmental decision-making and governance institutions. Knowledge systems determine what institutions know and what they do not know, based on what kinds of questions get asked, the methods used to gather information, and the standards by which to evaluate evidence.

For more than thirty years, social and cultural theorists have examined the way risk is understood in a knowledge co-production process (Schwing and Albers 1980), this work is summarized on Figure 3.1. Initially in this field, Mary Douglas and Aaron Wildavsky (1982) demonstrated that risk perceptions—once thought to be entirely created at the individual level—are socially and culturally mediated. In their work, they examined how community consensus relates some natural disasters to moral defects and how particular kinds of dangers come to be selected for attention. Risks that matter, therefore, are those seen as a threat to community order, and the social production of risks is a means of maintaining cultural boundaries. 


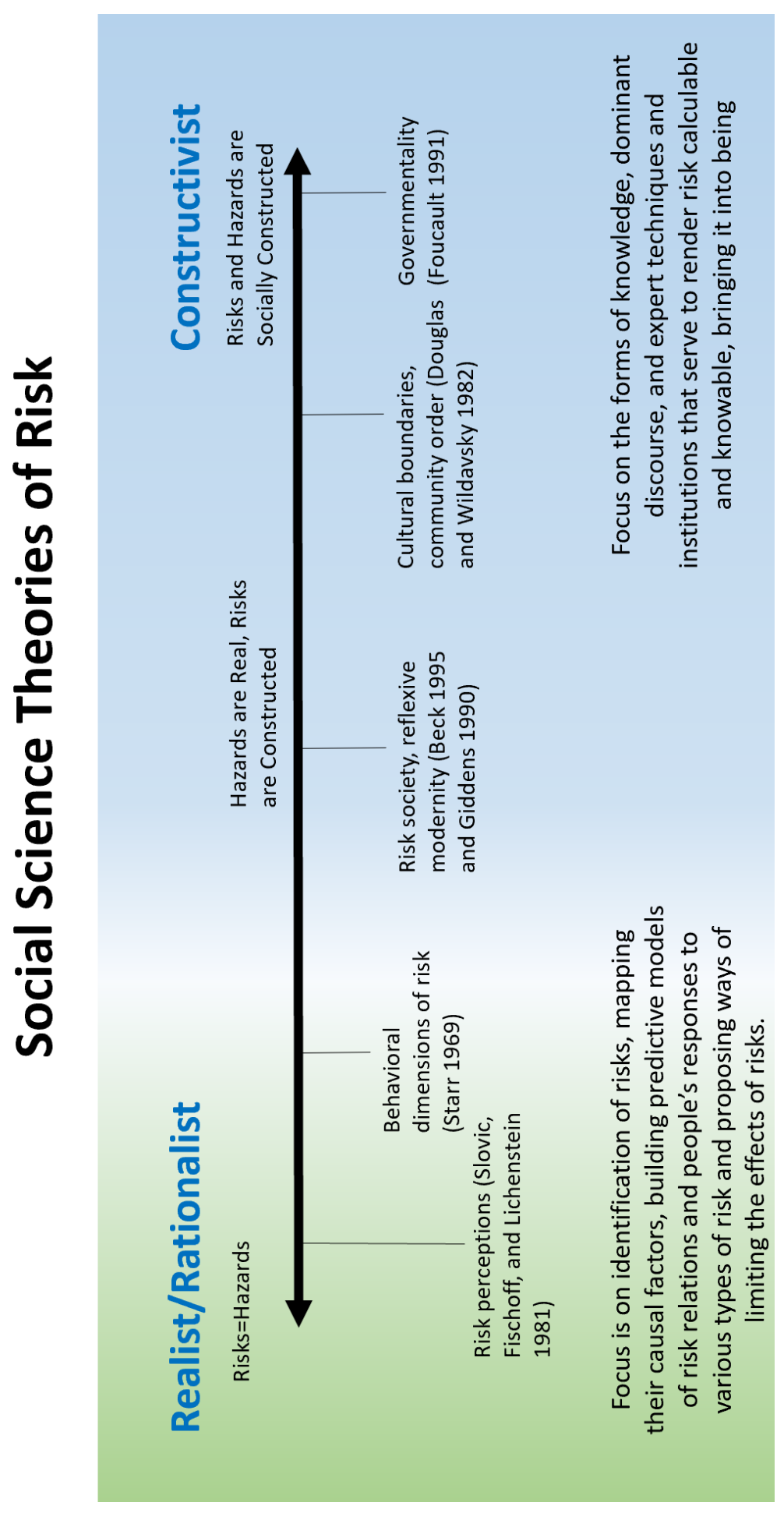

Figure 3.1 Social science theories of risk. Adopted from Lupton 1999, Fox 1999, and Krimsky and Golding 1992. In her assessment of the three-main contribution of social and cultural theories of risk, Lupton (1999) suggests that Giddens and Beck's understandings while constructivist, are sometimes realist. Douglas offers a relativist view and Foucault has the most constructivist view. 
Following the work of anthropologists Douglas and Wildavsky, sociologist Ulrich Beck published his work on 'risk society' which examines the process by which modern society has come to be encompassed by risk because of technological innovation. His work on modern instrumental rationality suggests that modern society seeks solutions to every problem through technology. But with this development of technology, there is also accumulation of risks in undesirable abundance because of technology. For example, the development of nuclear energy creates risks around accidents and how to deal with byproducts of the energy process. Risks, Beck argues, "only exist in terms of the (scientific or anti-scientific) knowledge about them. They can be changed, magnified, dramatized or minimized within knowledge, and to that extent they are particularly open to social definition and construction" (p. 23 in Beck 1992). Because of the uneven distribution of risks, Beck argues that the control of risk definitions and knowledge about risks becomes paramount in terms of how power is linked to knowledge in a risk society (Beck 1992).

Around the same time Beck was publishing his work, French philosopher Michel Foucault introduced his theory on governmentality and how the state and other governmental approaches work to govern (i.e. manage and regulate) populations via risk reduction discourses and strategies (Foucault et al. 1991). This work is the most constructivist of all three of these contributions to social and cultural theories of risk (see Figure 3.1). While Beck accepts the reality of hazards though views risks as socially constructed, Foucault is squarely constructivist, with both risks and hazards being mediated through social processes (Fox 1999). As Deborah Lupton writes about those who have followed Foucault's constructivist path, they are "not interested in investigating the nature of risk itself, but rather the forms of knowledge, the dominant discourses and 
expert techniques and institutions that serve to render risk calculable and knowable, bringing it into being" (Lupton 1999, p. 6).

While the work of Douglas and Wildavsky, Beck, and Foucault did not necessarily build off each other, these social and cultural theories are in clear contrast to techno-scientific approaches to risk by considering broader social, cultural, and historic contexts in which risk derives its meaning (Lupton 1999). Non-cultural theories of risk, such as those in economics and psychology, often begin with a statement of probability and consequences of an event or activity, followed by an assumption of an appropriate human response (Lupton 1999). Risk is largely treated as a taken for granted objective reality (Lupton 1999). In these realist theories of risk, the "focus is on identification of risks, mapping their causal factors, building predictive models of risk relations and people's responses to various types of risk and proposing ways of limiting the effects of risks" (Lupton 1999, 7). For example, in psychometric studies of risk people are often viewed as responding individually to risks per various 'heuristics', or frames of perception and understanding that structure judgement (Lupton 1999). In this line of research, lay people's judgments are often considered biased or ill-informed compared to expert, scientific assessments and very little attention is paid to the broader social, cultural, and historical contexts in which these heuristics are developed (Lupton 1999). Cultural theories of risk differ in that they assume an active rather than a passive perceiver of risk (Rayner 1992). This could be an individual or institution driven by their own cultural imperatives to select risks for management attention, or to suppress them from view (Douglas and Wildavsky1982). Institutional structure becomes the ultimate cause of risk perception, and risk management becomes the stimulus for risk rather than 
the outcome of risk (Rayner 1992). The focus, is therefore on "the forms of knowledge, dominant discourse, and expert techniques and institutions that serve to render risk calculable and knowable, bringing it into being" (Lupton 1999, p. 7).

Cultural studies of risk have spanned a variety of topics. Researchers have examined the organizational aspects of risk (Perrow 1984), analyzed risk distribution among classes and populations (Beck 1992), analyzed media coverage of risk (Lichtenberg and MacLean 1991), and followed the way knowledge about risk becomes legitimized (Jasanoff 1987). Institutions have their own ways of constructing knowledge about risks and part of the challenge in integrating diverse knowledge systems into climate adaptation planning rests in underlying assumptions of these disparate and sometimes conflicting knowledge systems. As Brugnach and Ingram (2012, p. 61) suggest, "Ambiguity is often the result of unrecognized contextual, methodological, and substantive differences among knowledge systems... Even when different knowledge systems share facts, there can be differences in the meaning and implications of the shared information." In cultural theory, risk communication, becomes more about the creation of shared meaning and trust to overcome the challenges of ambiguity (Rayner 1992).

Risk is a concept that when used to describe a population or situation can obscure who is bearing the costs and who is benefiting (Beck 1992). It is often a "black-boxed" term, where, although fundamental to how decisions are made regarding managing risks, the way risk is constructed in the planning process is often hidden from public attention (Lupton 1999). Planning processes often allude to straightforward measurements of risk and risk assessments. For example, the risk of harm from sea level rise can be 
geographically, biophysically, and socio-economically defined, and as such, solutions can be strait forward. In this realist perspectives, the risk of sea level rise, maps directly onto the hazard of increased flooding from sea level rise (Fox 1999). Yet, another argument would be that both risks and hazards are constructed through political and institutional processes. From a constructivist perspective, "hazards may be understood as the reifications of moral judgements about the 'riskiness' of choices, evoked discursively to support estimations of risk and those assessed to be "at risk"' (Fox 1999, p. 15). This could mean that solutions to sea level rise, grounded solely in realist perspectives of risk, may be blind to other ways of thinking about risk, and unpacking how risk is come to be understood can draw out the way these understandings are intentionally or unintentionally overlooking other perspectives.

\subsection{Knowledge Integration}

In addition to the need to understand risk knowledge construction practices, different governance, planning and network processes shape whether diverse understandings are integrated into decision-making contexts. Planners are confronted with the challenge of integrating diverse understandings of risk into sea level rise adaptation planning. There are several reasons why incorporating multiple knowledge systems — including non-western scientific knowledge — into integrated assessments of environmental and governance issues can be beneficial (Warren, Slikkenveer, and Brokensha, 1995; MA 2003; Pahl-Wostl 2003). The integration of local knowledge in decision-making can help overcome some of the limitations of science (Fabricius 2006) and increase the quality and amount of information available (Agarwal 1995). It can also contribute to understanding the relevance of a problem and how it is framed to an 
affected party, and it helps to empower groups that hold knowledge (Agarwal 1995).

Despite a variety of integrative approaches in the planning literature that consider multi-policy domains and stakeholder participation or adaptive management becoming increasingly common, changes in the substance of real-world decisions have remained elusive (Medema et al. 2008). Often, planning processes and policy choices fail to reflect the diversity of meaning and interpretations that the inclusion of multiple actors brings (Feldman and Ingram 2009). Several factors within contemporary knowledge production processes are inherently contradictory to knowledge integration (Brugnach and Ingram 2012). For example, the way that problems are framed may privilege credentialed experts that use formal scientific procedures (Brugnch and Ingram 2012). The subsequent technical solutions - like many climate adaptation strategies - are often considered objective, rational, scientific, and engineered solutions (Winner 1989; Jasanoff 2006).

There are three mechanisms that can affect the way in which diverse knowledge is integrated into adaptation strategies: governance, planning processes that incorporate public involvement, and knowledge networks.

\section{Governance}

First, governance, or broadly political processes and institutions, shape the future trajectory of social, ecological, and technological systems (Leach et al. 2007). In both intentional and unintentional ways, governance determines how scientific and technological processes are directed; how environmental and health issues are defined and addressed; and how social consequences become distributed (Leach et al. 2007).

Governance can be thought of in different ways. Broadly, it can be considered as rules and institutions for the authoritative organization of collective life (Donahue 2002). 
It is also considered as a way that different actors arrive at decisions by negotiating with each other and collaboratively implementing these decisions — or a multi-institutional networked decision-making frame (Schmitter 2001). Within sea level rise adaptation planning, governance processes such as funding streams, project selection criteria, and policies can shape the planning process and physical outcomes of adaptation strategies. It encompasses the system of institutions, including laws, norms, policies, organizations, and regulations involved in decisions surrounding the environment (Chaffin et al. 2014; Lemos and Agrawal 2006). The knowledge systems that shape and support governance processes - particularly surrounding how risk is defined, measured, and bounded — can serve to limit diverse knowledge integration (Miller et al. 2010).

In climate change adaptation, governance processes place much of the focus for identifying and framing risk surround ecological, economic, and technological dimensions (Adger et al. 2009). This framing can overlook local and lay understandings of risk that fall outside of these domains, which may matter to the public. Scholars have critiqued the dominant framings of risk prevalent in planning and policy in that they are narrowly defined, embed biases, overlook risks not easily captured within the accounting format, and ignore other risk factors which may matter to groups not involved in the risk assessment (Short and Clarke 1992; Fischer 2000; Wisner et al. 2014). Traditional risk framings are regarded through formal assessments of the hazard, vulnerability, and adaptive capacity. However, different groups and individuals construct their own knowledge about risk outside of these traditional framings (Douglas and Wildavsky 1983; Fischer 2000; Wisner et al. 2014). Yet, there is a widely-held assumption that the lay public does not possess the adequate amount of scientific knowledge needed for 
democratic processes around environmental governance (Miller 2008). Local knowledge bridging is not merely an epistemological challenge, but it is also wrapped up in a struggle over power and control (Agrawal 1999; Brosius 2006).

Governance mechanisms surrounding sea level rise adaptation planning tends to favor scientific knowledge, because it's considered objective and value neutral and can help provide credibility and authority to support institutional decision-making (Sarewitz et al. 2000). However, the argument that science is a translocally valid language through which to mediate normative policy conflicts has met increased scrutiny (Jasanoff 1998; Gupta 2001; Gupta 2004). The claim to value neutrality implies that science can be set apart from normative conflicts (Gupta 2004). Yet science can "camouflage" peoples' values, perspectives, and preferences (Sarewitz 2004). Although scientists claim to be value neutral, their efforts in defining concepts to draw attention to their interests and causes place them in the role of advocates for various agendas (Kuhn 1970; Takacs 1996; Miller and Edwards 2001; Reid et al. 2006).

In addition to governance mechanisms that bolster expertise, scale decisions impact the knowledge being created and can have implications on the governance outcomes from the use of such knowledge. Choice of scale in scientific assessments of environmental change, for example, may hide impacts experienced locally by lumping them in a bigger global picture (Wilbanks 2006). Scale choices are often wrapped up in governance processes and can be politically motivated (Lebel 2006). The "politics of scale" can be reproduced in environmental assessments, emerging in issue framing, use, and shaping of the analysis (Cox 1998; Swyngedouw 2000; Brenner 2001; Meadowcroft 2002; Lebel 2006). Knowledge constructions of risk cannot be disassociated with the 
governance arrangements surrounding sea level rise adaptation planning. Governance arrangements can shape whether diverse knowledge systems — including lay knowledge - can be integrated into the planning process.

\section{Planning Process}

The planning process is the second mechanism that can impact how knowledge is integrated into decision-making. This process is shaped by different planning approaches, how people are represented within plans, and levels of public involvement. Planning is a technical and political process concerned with the establishment of goals, policies and procedures for a social unit (Berke et al. 2006). When it comes to municipal activities, the planning process usually follows these steps: analysis and characterizing the state of the community; setting the direction, goals and objectives; preparing a plan; implementing a plan; and monitoring or evaluating the plan (Berke et al. 2006).

There are several different planning orientations articulated in planning theory, covering rational (e.g. McCarthy et al. 2001), consensus building/participation (e.g. Healey 1997), and urban design techniques (e.g. Barnett 2003). Each of these approaches has benefits and drawbacks for integrating diverse perspectives. Rational planning is premised on analytical thinking applied by social scientist and engineers and is often considered top-down. Consensus-based approaches incorporate more public participation, information sharing, and negotiation, which if done well can integrate many perspectives into decision-making. Planning processes utilizing urban design techniques often rely on a set of a priori design principles to guide planning and decision-making which may or may not integrate diverse perspectives. Planning orientation-whether it be rational, 
consensus, design focused, or something else — can influence different stages of the

planning process (see Table 3.1).

Table 3.1 Planning orientation overview. Adapted from Berke et al. 2006, this table highlights different stages of the planning process and how they might be shaped by three commonly used planning orientations: rational planning, consensus planning, and urban design. Both the stage of the planning and the planning orientation can impact the way different types of knowledge are used.

\begin{tabular}{|c|c|c|c|}
\hline Phase of Planning & Rational Techniques & $\begin{array}{l}\text { Consensus Building } \\
\text { and Participation } \\
\text { Techniques }\end{array}$ & $\begin{array}{l}\text { Urban Design } \\
\text { Techniques }\end{array}$ \\
\hline $\begin{array}{l}\text { State of the } \\
\text { Community: Identify } \\
\text { issues and } \\
\text { opportunities }\end{array}$ & $\begin{array}{l}\text { - use demographic info } \\
\text { to identify population } \\
\text { groups } \\
\text { - access existing } \\
\text { conditions and trends }\end{array}$ & $\begin{array}{l}\text { - establish organizing } \\
\text { committee } \\
\text { - create and execute } \\
\text { outreach plan } \\
\text { - council member as a } \\
\text { neighborhood liaison }\end{array}$ & $\begin{array}{l}\text { - translate vision into } \\
\text { hand-sketched } \\
\text { images of place } \\
\text { - use photographs to } \\
\text { visualize current } \\
\text { conditions of place }\end{array}$ \\
\hline $\begin{array}{l}\text { Setting the direction, } \\
\text { goals and objectives }\end{array}$ & $\begin{array}{l}\text { - analyze and prioritize } \\
\text { problems } \\
\text { - measure level of } \\
\text { citizen participation }\end{array}$ & $\begin{array}{l}\text { - use committee and } \\
\text { public involvement }\end{array}$ & $\begin{array}{l}\text { - run neighborhood } \\
\text { charrettes }\end{array}$ \\
\hline Preparing a plan & $\begin{array}{l}\text { - generate and test } \\
\text { alternative solutions } \\
\text { - measure level of } \\
\text { citizen participation }\end{array}$ & $\begin{array}{l}\text { - gather feedback from } \\
\text { community to } \\
\text { validate the plan } \\
\text { - coordinate with city } \\
\text { departments } \\
\text { - use conflict } \\
\text { resolution }\end{array}$ & $\begin{array}{l}\text { - prepare annotated } \\
\text { maps of future land } \\
\text { use in group } \\
\text { brainstorming } \\
\text { - use illustrations of } \\
\text { verbal design policies } \\
\text { in plan }\end{array}$ \\
\hline Implementing a plan & $\begin{array}{l}\text { - create action matrix to } \\
\text { prioritize, set timeline, } \\
\text { funding and assign } \\
\text { responsibility }\end{array}$ & $\begin{array}{l}\text { - use action matrix as a } \\
\text { negotiating tool with } \\
\text { city to amend city } \\
\text { plan }\end{array}$ & $\begin{array}{l}\text { - establish design } \\
\text { review board }\end{array}$ \\
\hline $\begin{array}{l}\text { Monitoring or } \\
\text { evaluating the plan }\end{array}$ & $\begin{array}{l}\text { - create indicators } \\
\text { - track changes in } \\
\text { outcomes/compare } \\
\text { objectives }\end{array}$ & $\begin{array}{l}\text { - dissemination of } \\
\text { reports }\end{array}$ & $\begin{array}{l}\text { - graphic display of } \\
\text { indicator trends }\end{array}$ \\
\hline
\end{tabular}

Understanding planning processes is important because they shape the physical

designs and outcomes of urban form. When plans become "fixed" they can determine and

limit future trajectories. For example, in some cities past stormwater planning may have

resulted in systems that transport stormwater to urban rivers and waterbodies, carrying 
contaminants into waterbodies. This planning process for dealing with urban flooding issues may have made sense at the time it was implemented, but later creates challenges for preventing urban pollution from entering waterways. Further, this existing infrastructure is now embedded in the urban form and subsequent stormwater plans are limited by the design and management of the existing infrastructure.

More recent planning strategies, such as adaptive management, have sought to overcome the challenge of "fixed" outcomes of plans. With adaptive management, planning strategies become implemented, monitored, evaluated, and adapted/altered to integrate findings from the monitoring and evaluation process (Holling 1978). With regards to stormwater management, for example, an adaptive management approach might include monitoring new approaches and continually updating the planning and implementation strategy. The flexibility, community involvement, and social learning components of adaptive management are increasingly called upon in planning for uncertainty in climate change (Lee 1999; Thompkins and Adger 2004).

In addition to adaptive management, other planning strategies have incorporated social and economic factors into risk and vulnerability assessments (Solecki et al. 2011; Wisner et al. 2014). Expanding the definition and analysis of how people become "vulnerable" and "at risk" to natural disasters has compelled many cities to integrate social and economic factors into their analyses for risk to flooding, sea level rise, extreme heat events, and other environmental hazards. These strategies seek to expand definitions of vulnerability, from purely geographical and environmental determinants, to incorporate social vulnerabilities—-for example, income, access to emergency services, etc. 
While cities may have plans preparing for environmental hazards, such as adapting to sea level rise, these plans may be limited by not having direction for what to do following an extreme event. Post disaster recovery planning is a new area that seeks to overcome this planning horizon limitation. This emerging area of planning examines what visions people have for their communities post environmental disaster (Berke and Campanella 2006). It offers another way to expand the conversation around risk beyond preparing to manage immediate risks and towards a conversation of regional goals for a longer-term vision of the community.

Efforts to create "actionable science" through co-producing science with managers and stakeholders is another approach some regions take with the use of boundary organizations connecting climate scientists to decision-makers (Vogel et al. 2016; Kjellström et al. 2016; Beier et al. 2017). There are varied ways in which this occurs, with some efforts primarily focused on formal managers and decision-makers and some projects integrating broader groups. Co-produced science with decision-makers may primarily serve to reinforce existing institutional knowledge structures while integrating broader stakeholder groups may serve to expand institutional knowledge structures (Innes and Booher 2010; Miller and Muñoz-Erickson 2018). This emerging style of planning can impact how diverse knowledge systems are integrated in sea level rise adaptations.

Procedural planning processes based on public participation techniques can impact the way in which different stakeholder groups are involved and ultimately shape planning outcomes. Public participation and involvement in planning, including environmental planning, emerged in the 1960s in response to conflict and challenges with 
top-down rational planning (Healey 1997). Scholars have studied the way in which the public can influence the planning process and shape outcomes through different public engagement strategies (Healey 1997; Fischer 2000; Innes and Booher 2010).

Opportunities for public involvement in planning processes include public meetings, public comment, budget hearings, community advisory panels, and other mechanisms.

The way the public engages in planning processes can draw out social contexts, diverse interests, values, forms of reasoning and uneven distribution of power, which in some planning settings can help shape outcomes which recognize and address these issues (Healey 1997). However, not all forms of public participation achieve full recognition and integration of diverse public experiences. The type of public engagement practices used and how they are carried out can impact the ability of planners to integrate diverse knowledge systems (Healey 1997). As Arnstein (1969) argues, public participation can play a "token" role to justify previously determined state action. In this way, public participation does not necessarily equate to influence in decision-making (Arnstein 1969). With environmental planning, this can get caught up in a struggle between state and scientific expertise claiming legitimacy over what actions to take, and public concerns over other issues overlooked by the state (Healey 1997).

Debates around how to define and implement public participation are wrapped up in normative ideas of who should have decision-making authority. For example, Arnstein (1969) argues that true participation achieves a high level of empowerment of the public and direct input into the decision process. Yet, Rowe and Frewer (2004, p. 515) argue that, "whether public information is elicited is an a priori characteristic of different mechanisms, though whether that information is used (to empower the public) depends as 
much on sponsor motives as intrinsic mechanism characteristics and may be determined only some period after the event." In this sense, any attempt on behalf of decision-makers to gather input from the public can be considered as public participation and as such evaluated on the basis of how that effort integrates diverse perspectives into those decisions.

There are many issues to evaluating public participation. Mentioned earlier is that public participation is a value-laden concept (Rosener 1981). From a democratic perspective, the most effective participation may be "fair" while decision-making perspective might focus on the quality of the decision outcome and how it addresses issues raised by multiple parties in the process. There are ongoing debates around the use of either process-oriented criteria and outcome oriented criteria (Rowe and Frewer 2004). Outcomes of participation are also relative to those participating-some people involved may consider the process very fair while others may consider it as disproportionately benefiting some groups over others (Fainstein 2000). One important debate within public participation literature is identifying the public and how affected parties are represented (Innes and Booher 2004). A representative participating on a panel representing a larger community of affected parties may or may not be able to capture all of the diverse opinions of that public (Innes and Booher 2004).

In considering aspects of public participation related to sea level rise adaptation planning and knowledge there are several evaluation dimensions worth considering. These can determine whether diverse perspectives are integrated in the decision-making process and outcomes. First, participants should comprise a representative sample of the affected population to achieve representation (Rowe and Frewer 2000; Fincher and 
Iverson 2008). The public should also be involved as early as possible, particularly when value judgements become salient (Rowe and Frewer 2000; Innes and Booher 2004). Public participation and planning procedures should be transparent, so the population can see what is going on and how decisions are being made (Rowe and Frewer 2000). Public participation should allow for genuine influence on policy outcomes and participants should have access to the appropriate resources to enable them to successfully contribute to the process (Rowe and Frewer 2000). During public participation processes, participants should be made aware of the nature and scope of the participation task as well as the structure of the decision-making and where participation fits in to the process (Rowe and Frewer 2000). What happens during public participation activities is an important component to understanding how diverse constructions of risk may—or may not be —integrated into the planning process (Rowe and Frewer 2000).

Tracking the planning process - particularly the role of the public —is important for understanding how sea level rise adaptation planning strategies are seeking input from diverse knowledge systems. Participation is not the same as influence and understanding the role of the public and planning procedures needs to be understood within the context of power dynamics, histories, and local complexities. Planning procedures that create opportunities for groups to construct shared meanings and build trust may result in more diverse knowledge integration into the adaptation strategy.

\section{Knowledge Networks}

The third knowledge integration mechanism surrounds the knowledge networks which may create formal and informal opportunities for groups to build shared meaning and trust. Transforming social-technological-environmental systems requires coordinated 
efforts and changes among different actors, institutions and artifacts (Elzen et al. 2005;

Leach et al. 2007; Meadows 1999). The rise of knowledge networks has been well documented both within general environmental governance and in climate change adaptation (Juhola and Westerhoff 2011). Knowledge networks are the actors and institutions that comprise a knowledge action system (using a related definition from the work of Muñoz-Erickson 2014). Planning and policy for various environmental activities — such as planning for sea level rise adaptation — can be represented by a constellation of different institutions working towards sometimes similar and sometimes conflicting goals (Leach et al. 2007). The way different types of knowledge flow through these networks shapes the decision-making process.

Sometimes, knowledge networks connect diverse types of institution, leveraging different types of information and can more flexibly and creatively solve environmental problems (Borzel 1998; Pietri 2014). Some decentralized knowledge networks have been shown to build trust, foster communication, information and knowledge dissemination, and mobilize resources (Bogason and Musso 2006; Borzel 1998; Pietri 2014). Such outcomes are not a given and uneven power within and among different knowledge networks can limit the integration of diverse knowledge systems (Ernston et al. 2008). Knowledge politics and boundary work are one possible outcome of various knowledge networks that can limit knowledge sharing and integration. Scholars examine knowledgepower systems in natural resource management, and the flow of knowledge can impact governance and planning (Crona and Bodin 2010; Muñoz-Erickson et al. 2010; MuñozErickson 2014). In her study of knowledge action systems in San Juan, Muñoz-Erickson (2014) found that institutions that dominate the knowledge about land use also make 
most of the land use decisions, suggesting that much of what we know about land use dynamics is filtered by the values and beliefs of the actors controlling city resources. This makes it difficult for alternative knowledge systems to influence decision-making as they are both outside the knowledge network controlling most knowledge and decisionmaking power (Muñoz-Erickson 2014).

Organizations tend to share information and connect with other similar organizations, for example, government organizations tended to work mostly with other government organizations, and private with private (Muñoz-Erickson 2014). Similarly, Ernston et al. (2008) found in their analysis of urban green areas in Stockholm, that garden collectives holding traditional ecological knowledge were outside of and disconnected to the dominant knowledge networks controlling most of the information and decision-making authority for urban green spaces.

Understanding knowledge networks and how it connects to decision-making is important because the decentralized nature may make them less democratic and accountable to the public (Bogason and Musso 2006). Lemos and Agrawal (2006) argue that in decentralized arrangements, those who are better able to integrate themselves into the network are better able to derive power from them. In practice the ability of the lay public and marginalized communities to exert power and influence is often limited because of this. This has implications for implementing climate adaptation strategies that serve both the powerful and marginalized members of the community. The inability to integrate diverse publics into climate adaptation invites a more nuanced and careful examination of how knowledge and governance networks take shape (Berkes 2007). 


\subsection{Connecting Literature and Theory to Sea Level Rise Adaptation Planning in Miami-Dade County, Florida}

The social construction of risk, or the process by which institutions and people select dangers for attention, risk theories from sociology and other fields suggest that risk knowledge is controlled by those with power and decision-making authority (Beck 1992), and that this knowledge is shaped by their own institutional positionality — or ways in which they understand and prioritize information (Douglas and Wildavsky1982). At the same time, however, this is a negotiated and contested process as multiple institutions are involved in climate science, adaptation planning, and urban governance, each shaping the way those risks are understood and constructed (Adger et al. 2009). The way in which institutions, both formal and informal, are connected to the governance process and what forms of knowledge are used to understand risks shape planning outcomes (Lupton 1999). While climate change research points to political and financial barriers to climate adaptation planning (Pilkey et al. 2016), some regions have been able to overcome these barriers and adopt adaptation strategies to mitigate the impacts from climate change.

Miami-Dade County, Florida, is one area that has overcome some of these challenges and adopted sea level rise adaptation planning as a key strategy for managing risk in the urban environment. Little is known about the political and planning process around how risk knowledge is used and constructed under these conditions and whose knowledge counts in adaptation decisions. Within Miami-Dade County, this includes how local decision-makers and planners determined what sea level rise rates to plan for, the process of determining what infrastructure to prioritize, and how they integrated multiple ways of understanding risks in the planning process. The lack of research on these social 
processes is in part due to the way in which the climate adaptation literature assumes that risks are "real" and can be understood and managed through scientific and technological assessments (Adger et al. 2009 ; Hulme 2009; van der Hoek et al. 2014). In general, the climate change literature fails to recognize how knowledge about risk is socially constructed and produced through social processes (Douglas and Wildavsky1982).

There is a need to open-up these processes, especially in Miami-Dade County, where local governments and other institutions have been examining and planning for sea level rise adaptation for over a decade. Within the City of Miami Beach, for example, planners have been able to implement major stormwater management projects that involve raising the roads three feet and installing expensive pumps, even with some local opposition from private landowners and businesses, and lack of support from State government. This puts the region ahead in terms of implementing sea level rise adaptation strategies. Miami-Dade County is an important case to examine because it represents a place where local planners are working to overcome political and economic barriers to be able to implement sea level rise adaptation planning, and where we can observe risk construction and knowledge integration processes. 


\section{Chapter 4: Research Design and Methods}

\subsection{Research Design}

This research was conducted using a case study of sea level rise adaptation planning in Miami-Dade County, Florida to examine how risk is constructed in the planning process and how diverse constructions of risk are integrated through the governance system. A case study is "an in-depth exploration from multiple perspectives of the complexity and uniqueness of a particular project, policy, institution, program or system in a "real life" context" (Simons 2009, p. 21). It offers a research design frame that incorporates different methods, rather it is "not a methodological choice but a choice of what is to be studied" (Stake 2005, p. 443). Compared with multiple case studies or other social science approaches that examine a few variables in multiple places, the single case study examines the complex interactions of many factors in a single place (Ragin 1992; Thomas 2011). While there is an analytical tradeoff for generalizing across a large sample, the single case is better suited for understanding complexity and contributing to theory around how social systems operate in relation to their political, economic, and social contexts (Thomas 2011).

Using Thomas' (2011) case study classification, the Miami-Dade County case study on how risk is constructed in sea level rise adaptation planning and governance is a "key-case" because of its ability to exemplify the analytical object of inquiry for examining the process of how regions construct knowledge about sea level rise and embed those into planning practice. Risks are being negotiated across scales and embedded in plans, designs, and physical adaptations. In addition, Miami is considered one of the country's most vulnerable regions to sea level rise and has a multi-decade 
history of related planning activities (see Appendix A for planning timeline of relevant sea level rise activities). Understanding the political and contextual dimensions that result in the way that risks are constructed requires a case in which this is occurring. The object for this case study are all the institutions involved or affected by sea level rise adaptation planning. This is a theory-seeking case study that uses the experience of institutions governing adaptations to sea level rise to understand how risk knowledge is produced and interpreted in this planning context.

Qualitative data is used to analyze how risk is understood by different groups involved or impacted by sea level rise adaptation planning. Qualitative methods are well suited to reveal a range of behavior and the perspectives that drive it. This fits the research questions which are focused on how groups construct risk and how these risk constructions are wrapped up in procedural elements of why they take this form and how these diverse constructs are integrated into planning. Qualitative methods allow researchers to draw out the diversity and richness of explanation, allowing for a "thick" description of actors, activities, and phenomena.

The case study is developed using multiple sources of evidence. I used content analysis for documents of sea level rise adaptation planning, policy, and programmatic documents, as well as meeting minutes, public testimony, and newspaper articles. Emergent themes from the document review was augmented with in-depth interviews with multiple stakeholders. Discourse analysis was used to understand the different ways sea level rise risks are understood and framed. Knowledge system dynamics around the construction of risks were paired with institutional and planning practices and outcomes (such as the creation of new programs, policies, or projects). In addition to the Miami- 
Dade County case study, Chapter 8 was developed using literature and theoretical reviews.

\subsection{Case Study Description}

A case study is used to analyze ambiguities around risk and the governance, planning, and knowledge networks surrounding planning for adaptation to sea level rise. This case studies follows "an empirical inquiry that investigates a contemporary phenomenon in depth and within its real-world context" (Yin 2014, p. 16). Case study research is useful for analyzing "how and why questions" when the researcher has little or no control over behavioral events and the study focuses on a contemporary issue (Yin 2014). Because knowledge around risks to sea level rise are constructed and articulated in a contemporary real-world setting, other methods such as purely conducting interviews or surveys, are inappropriate because they would fail to account for the diverse ways in which these constructions are made and interact in planning, governance, and knowledge networks.

Case study research is highly relevant in situations where the boundaries between the phenomenon and the context may not be evident. Context surrounding the research question is important in case study research (Yin 2014). It is not only the contemporary

processes that are important, but historical, political, and social context becomes a part of the case study research in shaping the "richness" of how decisions come to be made in the real world. In the proposed research, the context of both how sea level rise has grown to be a concern, as well as the context of other challenges regions face, is important to understand these research questions within the "bigger picture." 
The unit of analysis for this case study research includes all the institutions, both formal and informal, that are involved in or affected by sea level rise adaptation planning in Miami-Dade County. This research is bounded geographically, to include those activities within Miami-Dade County, Florida. This case study inquiry uses multiple sources of evidence, with data converging in a triangulating fashion (Yin 2014). Using discourse analysis, the case study development relies principally on document analysis and in-depth semi-structured interviews. Using multiple sources of evidence helps increase internal validity of these findings (Singleton and Straights 2010; Yin 2014).

\section{Miami-Dade County, Florida}

Miami-Dade County is on the southernmost portion of the East Coast of the State of Florida, covering approximately 2,400 square miles (see Figure 4.1 for a map). The coastal region is surrounded by barrier islands, including the City of Miami Beach, and Biscayne Bay to the south. Most of the inland portion of the county is in the Everglades National Park, a slow-moving river that drains from Lake Okeechobee around 100 miles to the north, to Biscayne Bay and other parts of the coast along south Florida.

When Florida was established as a state in 1845, it was primarily an agriculture economy with most of its residents living within 50 miles of the Georgia border. The establishment of railroads and the draining of the Everglades lead to broader expansion into southern Florida and present-day Miami-Dade County. Following the Great Freeze that struck the southeastern United States in the winter of 1894-1895 and ruined crops across the southeastern United States, the crops in Miami were unaffected (Dunn 1997; Grunwald 2006). Julia Tuttle, a prominent landowner, offered Henry Flagler half of her land holdings to convince him to expand the Florida East Coast Railway to Miami (Dunn 
1997). Flagler, Tuttle, and other wealthy speculators from the north established resorts in Miami-Dade County that could easily be reached when the railroad arrived in 1896 . The City of Miami was incorporated in 1896 and following its establishment, many farmers and farmworkers whose livelihoods were ruined by the Great Freeze settled in south Florida (Dunn 1997).

In addition to the railroad, land clearing and drainage of the Everglades took place first for agriculture and later for urban expansion. Settlers had hopes to drain the Everglades during the agriculture and homestead era of the $19^{\text {th }}$ century, but many farmers had issues with ongoing flooding (Grunwald 2006). Following the Civil War, privately funded efforts to drain large portions of the Everglades began in earnest with the construction of canals, but winter flooding continued to make this difficult. State driven efforts to drain the Everglades began in the early 1900s with the development of plans (Grunwald 2006). This coincided with the development and expansion of MiamiDade County. Though more canals were built to allow for development and agriculture, the Miami Hurricane of 1926 and the 1928 Hurricane caused enormous devastation to the areas early inhabitants. The 1928 Hurricane killed thousands of poor African Americans who were trapped by the rising waters of Lake Okeechobee, to the north of Miami-Dade County (Kleinberg 2003). This destruction supported already existing efforts for massive drainage and engineering control around the Everglades (Grunwald 2006). At this point, the federal government intervened and established the Okeechobee Flood Control District in 1929 in partnership with the State of Florida, marking a large transformation of the Everglades with over 60 miles of dike built along the southern edge of Lake Okeechobee in response to the flood devastation of the 1928 Hurricane (Grunwald 2006). These and 
other projects had major ecological impacts to the Everglades by restricting the flow of water and environmentalists, including the Audubon Society, fought for its protection and restoration (Grunwald 2006). At the same time, however, these drainage projects allowed for more agriculture and more urban growth in Miami-Dade and surrounding counties (Grunwald 2006). Sugar production soared in Palm Beach County and continues to this day. In response, environmental organizations fought to see the establishment of the Everglades National Park in 1947 to protect some of the ecosystem (Grunwald 2006).

The final period of major transformation of the Everglades ecosystem took place following hurricanes in 1947, when Congress approved the Central and Southern Florida Project for Flood Control and Other Purposes. This effort spanned roughly thirty years in which over 1,000 miles of canals, build pumping stations and levees were constructed (Grunwald 2006). This allowed for more growth and development in Miami-Dade County which further impacted the Everglades ecosystem and the region experienced its largest growth boom between the 1950s and 1970s (Grunwald 2006). Environmental movements strengthened in response to the sweeping growth and expansion of flood control (Grunwald 2006). Today, the region is undergoing both flood management and restoration efforts overseen by the United States Army Corps of Engineers and the South Florida Water District, in partnership with the National Park and environmental organizations. Environmental challenges such as flood management in the Everglades, restoration, challenges from climate change, and pollution runoff from agricultureprimarily the sugar industry — continue to be political issues to this day (Grunwald 2006). In addition to the development and environmental patterns of Miami-Dade County, there are important race relations that affect the present day (Bush 2016). Race 
relations between whites and the African American community have a tenuous history within Miami-Dade County and the State of Florida. Between 1890-1930, Florida had the highest rates of lynching in the country and many African Americans were given the most difficult and dangerous jobs with low wages and limited opportunity (Bush 2016). Early in the regions settlement, African Americans and black Caribbean immigrants cleared the land and built the railroad into Miami, jobs that many white settlers did not want to perform. Because of this, they largely settled along both sides of the railroad (Dunn 1997). The railroad corridor runs along some of the highest elevations within Miami-Dade County. During the 1896 incorporation of the City of Miami, African Americans who were living there had no political power, recognition, or influence (Dunn 1997). Yet, they were used as "pawns of Flager's interest" to make sure there were enough registered male voters to incorporate the city (Dunn, 1997, p. 57). Of the 367 voters who incorporated the city, 162 were black, and following the city's incorporation, these voting rights were removed (Dunn 1997). Racial covenants and redlining began in the early 1900s and continued up until the civil rights movement. Though the names of the neighborhoods have changed over the years, predominantly African American communities includes present day Liberty City and Overtown neighborhoods. These neighborhoods exist at some of the highest elevations in the county because African Americans were not allowed to live near the beaches and other desirable waterfront property. In 1955, the Miami City Planning Department routed the construction of Interstate 95 deliberately through the middle of Overtown, which displaced thousands of African Americans in that community and has had lasting impacts on the urban design, growth and development of the community (Dunn 1997). Up until desegregation laws, 
African Americans were only allowed in the City of Miami Beach, and other beach communities, if they were going there to work and they had to have special passes to enter the beach communities (Dunn 1997; Bush 2016). In addition, they were restricted from most city parks and the beaches until 1960 (except Virginia Key which was designated for African Americans) (Bush 2016). Resulting from these injustices, racial tensions have led to civil rights and other demonstrations over the years, including race riots. In many ways, Miami continues to remain a highly racially divided city (Bush 2016)

In addition to the hurricanes discussed above that intersect with development patterns in Miami-Dade County, Hurricane Andrew in 1992 transformed county building codes. Hurricanes Hurricane Andrew in 1992, landed as a Category 5 hurricane in south Miami-Dade County. Across the entire path, the hurricane destroyed more than 60,000 homes, and resulted in $\$ 27.3$ billion in damage and 65 deaths. In response to the hurricane's destruction in the southern part of the county, Miami-Dade County and several other counties across Florida adopted stricter building codes to withstand Category 4 hurricane wind speeds.

Florida is nicknamed, the "sunshine state" and known for its warm climate and sunny weather. Today, Miami-Dade County has 2.7 million residents and is the seventh largest county in terms of population in the country. With the different landscape changes the county land use is now roughly $70 \%$ Everglades National Park, $20 \%$ urban, and $10 \%$ agriculture. The top three industries are tourism, development and agriculture. Culturally, Miami-Dade County is very diverse. Following World War II Cuban and other immigrants began settling in Miami between the 1950s and 1970s. Different waves of 
immigrants from the Caribbean and South and Central America, make Miami-Dade County a highly diverse region. Several of the neighborhoods and regions within the county are known for the settlement of different immigrants, for example the Little Havana and Little Haiti neighborhoods in the City of Miami. From the 2010 United States Census, Miami-Dade County is comprised of 65\% Hispanic or Latino, $17.1 \%$ Black, 15.4\% White, and the remainder other races. 


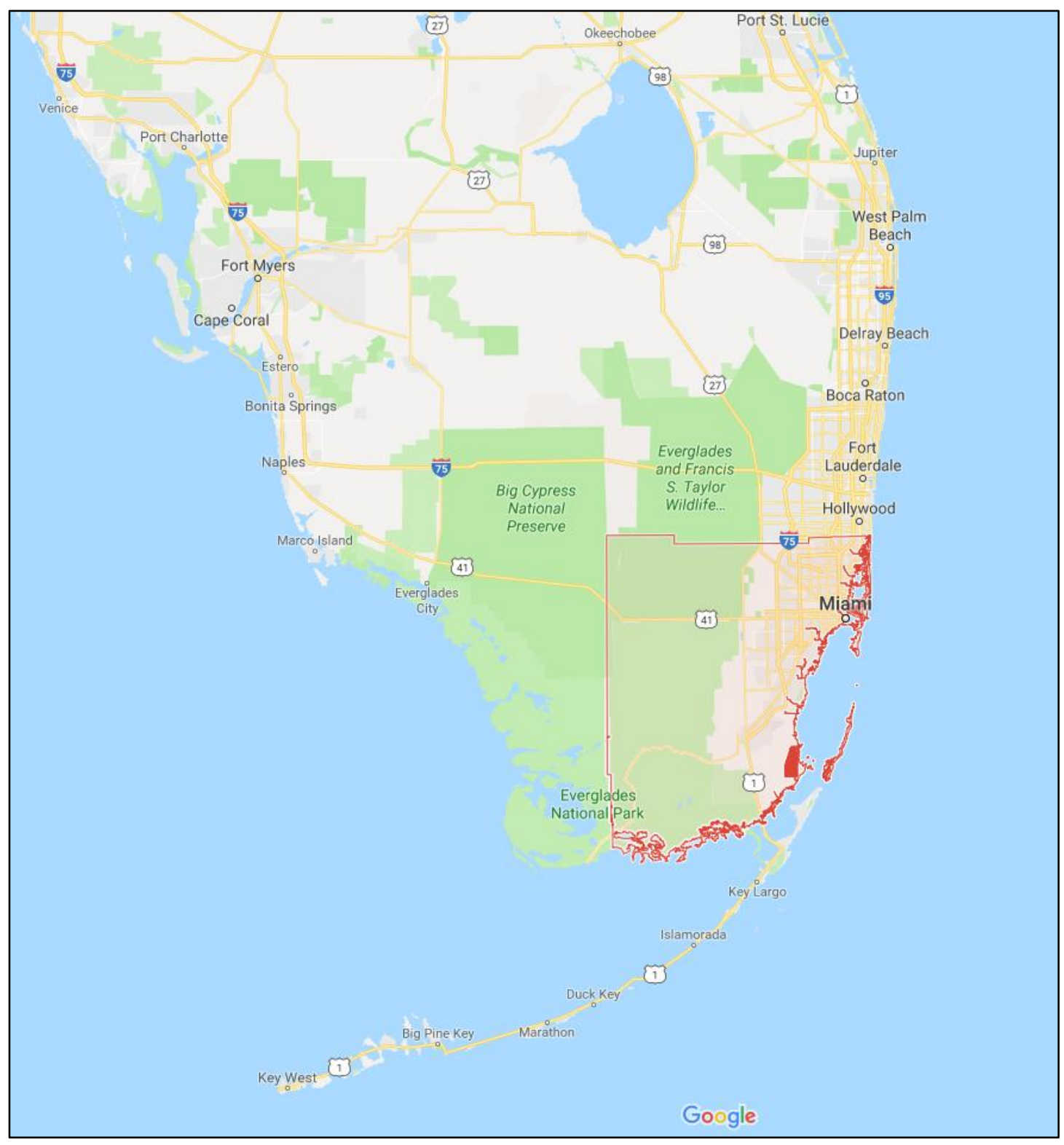

Figure 4.1 Map of Miami-Dade County, Florida. County boarder outlined in red. (Google 2018).

Geologically, Miami-Dade County is on porous limestone, which means that both surface water and groundwater travel quickly through the ground. Because the region is so flat, has a high groundwater table, and has the porous limestone the water systems have been heavily altered through engineered dikes, canals, and filling projects to allow for growth and development. Currently, the hydrologic system in Miami-Dade County is 
intensively managed with several canals, salinity controls, and pumps. The region is also highly susceptible to hurricanes and tropical storms, having experienced over thirty hurricanes since its incorporation as a county. Even with the efforts to drain the landscape for flood protection, Miami-Dade County and the municipalities within it regularly experience flooding challenges due to low elevations and porous limestone geology. In the past, these issues primarily occurred because of rain events, but now, it is increasingly common for them to take place during high tide events as water gets pushed up through storm drains and the porous limestone creating "sunny day flooding." Today, this occurs in different low elevation communities approximately 20 days per year (Sweet et al. 2014).

Climate projections suggest that Miami-Dade County will experience increased flooding from sea level rise as well as higher frequency and severity of extreme weather events. Despite this, the State of Florida has banned the terminology "climate change" from planning and policy. However, the State's comprehensive planning does allow local governments to consider sea level rise in planning (Florida Statutes 163.3178.2.f and Section 163.3177(6)(g)(10)). Miami-Dade County, municipalities within the county, and other non-governmental institutions have undertaken a variety of activities to mitigate current sunny day flooding and other anticipated impacts from sea level rise (Table 4.1 for a summary of activities by Miami-Dade County, City of Miami, and the City of Miami Beach). The City of Miami Beach, for example uses funding from stormwater bonds to install pumps and raise roads, as well as updating zoning codes and developing building requirements. The City of Miami recently passed the Miami Forever Bond, allocating funds to update stormwater management and planning. Due to a consent decree 
from the EPA, Miami-Dade County has made changes to their wastewater treatment facilities to account for future sea level conditions. In addition, the county, City of Miami, and the City of Miami Beach are a part of Rockefeller Foundation's 100 Resilient Cities initiative with sea level rise adaptation being a prominent component to that planning effort. There are additional examples of sea level rise adaptation efforts in this region, with many different institutions - both formal and informal—involved in the planning process.

Within this planning context, newspapers, planning websites, and other documents focus a lot of the attention around protecting real estate and other valuable assets. Yet, ecologists and environmental groups claim that pumping stormwater runoff into Biscayne Bay has deleterious impacts to the ecosystem (Flechas and Staletovich 2015). In addition, businesses complain that this new infrastructure is increasing the risk of flooding on their properties, forcing them to install expensive pumps to move the new source of water, and community members call for more thought out planning efforts rather than what seems to be a hastened approach (Flechas 2015, Flechas and Staletovich 2015). Part of this reaction may be in response to a lack of transparency and public accountability based on the city's decision to skip public bidding on the Sunset Harbor project. What originally started as a $\$ 2$ million awarded to Lanzo Construction, as a publicly bid project in May 2013, has since been expanded twice (once in 2014 and again in 2015) for an additional $\$ 10.4$ million with some questioning why these proposed project expansions were not open for either public input or a competitive bidding process (Flechas 2015). 
On the national and international stage, much of the commentary around climate change impacts to Miami-Dade County centers around impacts to affluent residents, in comparison to more disadvantaged low-laying coastal communities around the world. This framing of Miami-Dade County's climate change challenges overshadows discussions of vulnerable and marginalized communities. In February 2016 Catalyst Miami, a social justice organization that operates county wide, recently held their very first summit meeting around the issue of climate change adaptation planning. New claims suggest that it will not only be the low laying coastal neighborhoods that will experience inundation from sea level rise, but some of the inland communities will also be impacted due to the porous structure of the land (Weiss 2016). In response, Miami Commissioner Ken Russell announced at the end of May 2016 that he is introducing a resolution in early June that would mandate a representative from Miami's low-income and socioeconomically vulnerable population serve on the city's seven-person Sea level Rise Committee (Weiss 2016). He is quoted in the newspaper as saying, "The new member could be a liaison to low-income communities while at the same time influencing the city's planning, policy development, and implementation" (Weiss 2016). Prior to this the committee was comprised of representatives from real estate development, science, emergency management, and business. These and other dynamics have been occurring in Miami-Dade County on the topic of sea level rise adaptation planning for several years. Examining the way in which risks from sea level rise are understood can illuminate some of the underlying political processes and disagreements in this case and shed light on how this may take place in other regions as they undergo their own adaptation planning. 
Table 4.1 Key Actions Outlined in the Preliminary Resilience Assessment from the 100 Resilient Cities project (Resilient Cities Assessment 2017).

\begin{tabular}{|c|c|}
\hline & \\
\hline & Countr \\
\hline & $\begin{array}{l}\text { - Vulnerability assessment of key infrastructure and capital investments } \\
\text { - Water and Sewer Dept. investing billions on improving critical infrastructure with sea level rise part } \\
\text { of design } \\
\text { - Work with SFWMD and USACE on Comprehensive Everglades Restoration Plan } \\
\text { - Partner with Urban Land Institute on pilot Adaptation Action Area for Arch Creek drainage basin } \\
\text { - Rand Corporation to visualize how sea level rise and future land use decisions will affect flooding } \\
\text { - Working with SFWMD to understand how sea level rise will impact regional canal network } \\
\text { - Actively monitoring and managing saltwater intrusion into the aquifer } \\
\text { - Created sea level rise Task Force who recommended that the county prepare an Enhanced Capital } \\
\text { Plan for county's infrastructure }\end{array}$ \\
\hline & City \\
\hline & $\begin{array}{l}\text { - Established sea level rise Advisory Committee in } 2015 \text { and an interdepartmental Resilient } \\
\text { Infrastructure Committee in } 2017 \\
\text { - Partnering on a Resilient Redesign for Shorecrest } \\
\text { - Updating stormwater master plan while implementing stormwater upgrades in highly vulnerable } \\
\text { areas } \\
\text { - Strengthening flood risk mitigation in the Future Land Use and Coastal Management elements of the } \\
\text { City’s Comprehensive Neighborhood Plan } \\
\text { - Miami Forever General Obligation Bond ( } \$ 193 \text { mill for flood risk) } \\
\text { directly in the ground }\end{array}$ \\
\hline & ity of \\
\hline & $\begin{array}{l}\text { r drainage } \\
\text { orporate climate adaptation and resilience, } \\
\text {, roadway, ground, and seawall heights } \\
\text { City infrastructure } \\
\text { it sea walls } \\
\text { sk from storm surge and provide habitat } \\
\text { ion with sea level rise } \\
\text { community learn more, including an Adaptati } \\
\text { g }\end{array}$ \\
\hline
\end{tabular}




\subsection{Methods}

Discourse Analysis

This case study uses discourse analysis, incorporating document analysis and interviews. Discourse analysis is an interpretation of how social practices construct and contest shared meanings that constitute social reality (Howarth 2000). A discourse is a shared way of apprehending the world, which are embedded in language and "enables those who subscribe to it to interpret bits of information and put them together into coherent stories or accounts" (Dryzek 2013, p. 9). A discourse helps groups make sense of the world by constructing meanings and definitions while also legitimating knowledge (Dryzek 2013). Discourses, "rests on assumptions, judgments, and contentions that provide the basic terms for analysis, debates agreements, and disagreements" (Dryzek 2013, p. 9). They are bound up with political practices and power (Hajer and Versteeg 2005), and dominant discourses shape the physical reality through policy choices and implementation (Dryzek 2013).

Discourse theory begins with the assumption that all objects and actions are meaningful, and that their meaning is a product of historically specific systems of rules (Howarth 2000). Discourse analysis examines how social practices construct and contest the discourses that constitute social reality (Howarth 2000). This is well suited to research on constructions of risk in that it will help develop an understanding and interpretation of socially produced meanings (Howarth 2000). A discourse analysis will provide a "thick description" of understanding and explanation (Howarth 2000). As Howath explains: "Discourse theorists are concerned with how, under what conditions, and for what reasons, discourses are constructed, contested and change" (Howarth 2000, p. 131). 
Discourse analysis problematizes how certain topics and ideas are "closed off" to "open" them up. Discourse theorists must modulate and articulate their concepts to suit the problems they are addressing (Howarth 2000). This is relevant to this research on sea level rise adaptation planning, where there are many assumptions about risk, and these assumptions result in planning contexts and decisions that embed certain ways of knowing and priorities in the process. Discourse analysis can help unpack the discursive articulations of risk, for example if someone describes risk as being a calculation that is being made, it can help unpack the relations of power and assumptions embedded in such a definition of risk. Within discourse analysis, the theoretical framework must be sufficiently 'open' and flexible enough to be 'stretched' and restructured in the process of application (Howarth 2000). This conception therefore excludes essentialist and reductionist theories of society, which tend to predetermine the outcomes of research (Howath 2000). The overall aim of social and political analysis from a discursive perspective is to describe, understand, interpret, and evaluate carefully constructed objects of investigation (Howarth 2000). For this case study, there was no a priori understanding of what a "real" or "true" calculated sea level rise rate or risk, rather it was interpreted in the planning contexts and how different institutions articulated meaning around what they considered "risks."

Methods used in this study are summarized on Table 4.3 with a definition of the method and the purpose. Qualitative methods are used to generate and collect empirical material like historical, ethnographic, and anthropological forms of research. This includes a process of gathering information from a range of possible sources, including newspapers, official reports, unofficial documents such as pamphlets, organizational 
minutes and agendas, and supplementing document review with interviews and

observation.

Table 4.2 Summary of methods used in dissertation research.

\begin{tabular}{|l|l|l|}
\hline \multicolumn{1}{|c|}{ Method } & \multicolumn{1}{|c|}{ Definition } & \multicolumn{1}{c|}{ Purpose } \\
\hline $\begin{array}{l}\text { Discourse } \\
\text { Analysis }\end{array}$ & $\begin{array}{l}\text { Interpretation of how social } \\
\text { practices construct and contest } \\
\text { shared meanings that constitute } \\
\text { social reality (Howarth 2000) }\end{array}$ & $\begin{array}{l}\text { To develop an understanding and interpretation of } \\
\text { socially produced meanings }\end{array}$ \\
\hline $\begin{array}{l}\text { Document } \\
\text { Analysis }\end{array}$ & $\begin{array}{l}\text { Systematic review of relevant } \\
\text { planning, policy, and other } \\
\text { documents (Yin 2014) }\end{array}$ & $\begin{array}{l}\text { To examine how risk is being constructed in different } \\
\text { planning documents and media; to triangulate } \\
\text { observations from interviews and observation; to } \\
\text { support discourse analysis and case study } \\
\text { development. }\end{array}$ \\
\hline Interviews & $\begin{array}{l}\text { Guided conversations that } \\
\text { follow a line of inquiry (Yin } \\
\text { 2014) }\end{array}$ & $\begin{array}{l}\text { To examine how individual actors (who are a part of } \\
\text { organizations) construct knowledge about risk to sea } \\
\text { level rise and how these constructions interact with } \\
\text { planning, governance and knowledge network } \\
\text { processes; to triangulate findings from document } \\
\text { review and field observation; to support discourse } \\
\text { analysis and case study development }\end{array}$ \\
\hline $\begin{array}{l}\text { Thematic } \\
\text { Analysis }\end{array}$ & $\begin{array}{l}\text { Method for the systematic } \\
\text { identification, organization, and } \\
\text { providing insight to patterns of } \\
\text { meanings (themes) across a data } \\
\text { set (Braun and Clark 2006) }\end{array}$ & $\begin{array}{l}\text { To systematically identify patterns across documents } \\
\text { and interviews. To inform discourse analysis. }\end{array}$ \\
\hline
\end{tabular}

\section{Document Analysis}

This research used document analysis to inform case development. Document analysis is the systematic review of relevant planning, policy, and other documents (Yin 2014). It is important in both case study development and discourse analysis because documents can represent how organizations think and convey knowledge. This case study was informed by project and planning documents, vulnerability assessments, meeting agendas, newspaper articles, formal studies, and other documents relevant to sea level rise adaptation planning. Appendix B includes key planning and policy documents identified and used for this research. Documents were identified via institutional websites, through interviews, and as referenced in other documents. These documents 
were reviewed for historical context of how risk knowledge has changed overtime, how risks from sea level rise are measured and characterized, how assessment limitations are framed, and to identify who was involved in document production. In addition, news articles, organizational websites, meeting minutes, and other articles were reviewed to provide planning context. Document relevance was determined by how often it was referenced and used in the planning process. In some cases, documents with high relevance informed interviews. When documents were referenced during interviews as being contentious, further questions were asked about the process and sources of disagreement.

\section{In-Depth Interviews}

Interviewees were selected from institutions involved and/or affected by sea level rise adaptation planning, identified through an iterative process using expert opinions, semi-structured interviews, snowball sampling, document analysis and participant observation. Early in the research process I identified key documents used by the Southeast Florida Regional Climate Change Compact (Compact), Miami-Dade County, the City of Miami, and the City of Miami Beach from their organizations' websites. These documents include meeting minutes from different climate change and sea level rise committee advisory panels, proposed and analyzed sea level rise adaptation strategies, news articles, and other organizational websites of groups within the county that have information about sea level rise and/or climate change on their websites. I then identified institutions and individuals (when possible) who were involved in the document or activity. I also went to Miami-Dade County and met with some researchers at Florida International University and local contacts before beginning this research to 
learn more about the planning context. These informal meetings were used to learn more about the planning context and what organizations are viewed as key to the planning process. I compiled a list of organizations, summarized on Table 4.3, and identified their role in sea level rise adaptation planning as stated in the different documents and through formal interviews. I selected my interviewees based on this list, which also expanded during the interview process.

Table 4.3 Institutions involved in sea level rise adaptation efforts in Miami-Dade County, Florida

\begin{tabular}{|c|c|c|}
\hline Type of Institution & Name of Institution & Role in Sea Level Rise Adaptation \\
\hline $\begin{array}{l}\text { Community-Based } \\
\text { Organizations }\end{array}$ & $\begin{array}{l}\text { The CLEO Institute, New } \\
\text { Florida Majority, Catalyst } \\
\text { Miami, Urban Impact Lab, } \\
\text { Neighborhood Associations, } \\
\text { Miami Climate Alliance }\end{array}$ & $\begin{array}{l}\text { Organizations focus on community } \\
\text { education and organizing. Limited } \\
\text { participation on advisory panels, design } \\
\text { charrettes, and comprehensive planning, } \\
\text { though recent community organizing and } \\
\text { education programs have put pressure on } \\
\text { formal governing bodies to be more } \\
\text { inclusive. }\end{array}$ \\
\hline $\begin{array}{l}\text { Foundations, } \\
\text { Institutes }\end{array}$ & $\begin{array}{l}\text { Kresge Foundation, } \\
\text { Rockefeller Foundation, } \\
\text { Miami Foundation, Urban } \\
\text { Lands Institute, MacArthur } \\
\text { Foundation, First Street } \\
\text { Foundation, Rand } \\
\text { Corporation, Organizations } \\
\text { from the Netherlands (e.g. } \\
\text { Deltares) }\end{array}$ & $\begin{array}{l}\text { Support and fund analyses, design } \\
\text { charrettes, provide resources to community } \\
\text { organizations for education and outreach. } \\
\text { Share best practices in conferences, reports, } \\
\text { newsletters, and analysis. }\end{array}$ \\
\hline $\begin{array}{l}\text { Environmental } \\
\text { Organizations }\end{array}$ & $\begin{array}{l}\text { The Nature Conservancy, The } \\
\text { Everglades Foundation, Sea } \\
\text { Turtle Conservancy, Miami } \\
\text { Waterkeepers, Miami Climate } \\
\text { Alliance, The Audubon } \\
\text { Society, Florida Wildlife } \\
\text { Federation, Sierra Club, Urban } \\
\text { Paradise Guild }\end{array}$ & $\begin{array}{l}\text { Participate in collaborative processes and } \\
\text { serve on advisory committees. Work in } \\
\text { environmental education (including on } \\
\text { climate change) and advocacy organizing } \\
\text { around environmental issues. Some } \\
\text { purchase land and easements, conduct } \\
\text { restoration projects and monitoring. }\end{array}$ \\
\hline Academic & $\begin{array}{l}\text { Florida International } \\
\text { University, University of } \\
\text { Florida, University of Miami, } \\
\text { Florida Atlantic University, } \\
\text { University of Florida } \\
\text { Extension, Sea Level } \\
\text { Solutions Center, Sea Grant }\end{array}$ & $\begin{array}{l}\text { Serve on advisory committees, conduct } \\
\text { research on sea level rise and climate } \\
\text { change, provide expertise that influence } \\
\text { decisions, monitor changes to sea level rise } \\
\text { and updates to science, monitor water } \\
\text { quality and other impacts of sea level rise. } \\
\text { Work with government and non- } \\
\text { governmental orgs to educate on climate } \\
\text { change. }\end{array}$ \\
\hline $\begin{array}{l}\text { Private Firms (many, } \\
\text { listed a few) }\end{array}$ & $\begin{array}{l}\text { AECOM, Taylor Engineering, } \\
\text { CHM2Hill, David Mancini }\end{array}$ & $\begin{array}{l}\text { Hired by governments to produce } \\
\text { vulnerability assessments and other reports. }\end{array}$ \\
\hline
\end{tabular}




\begin{tabular}{|c|c|c|}
\hline & $\begin{array}{l}\text { and Sons, Duany Plater- } \\
\text { Zyberk and Company, Coastal } \\
\text { Risk Consulting, Dover, Kohl } \\
\text { and Partners, Rand } \\
\text { Corporation }\end{array}$ & $\begin{array}{l}\text { Contracted to help design and implement } \\
\text { adaptation strategies. }\end{array}$ \\
\hline $\begin{array}{l}\text { Business Interests } \\
\text { (many, listed a few) }\end{array}$ & $\begin{array}{l}\text { Greater Miami Chamber of } \\
\text { Commerce, South Florida } \\
\text { Builders Association, Latin } \\
\text { Builders Association, Miami } \\
\text { Association of Realtors, } \\
\text { Independent Insurance Agents } \\
\text { of South Florida, Terra Nova } \\
\text { (real estate development) }\end{array}$ & $\begin{array}{l}\text { Participate on advisory committees and help } \\
\text { set direction for action. Foster connections } \\
\text { between governments and industries they } \\
\text { represent. }\end{array}$ \\
\hline $\begin{array}{l}\text { City Governments } \\
\text { ( } 34 \text { Municipalities, } \\
\text { listed by population) }\end{array}$ & $\begin{array}{l}\text { Miami, Hialeah, Miami } \\
\text { Gardens, Miami Beach, } \\
\text { Homestead, North Miami, } \\
\text { Coral Gables, Doral, North } \\
\text { Miami Beach, Cutler Bay, } \\
\text { Aventura, Miami Lakes, } \\
\text { Palmetto Bay, Hialeah, } \\
\text { Gardens, Sunny Isles Beach, } \\
\text { Pinecrest, Opa-Locka, Miami } \\
\text { Springs, Sweetwater, Key } \\
\text { Biscayne, South Miami, } \\
\text { Florida City, Miami Shores, } \\
\text { North Bay Village, West } \\
\text { Miami, Surfside, Bay Harbor } \\
\text { Islands, Biscayne Park, Bal } \\
\text { Harbor, Virginia Gardens, El } \\
\text { Portal, Golden Beach, Medley, } \\
\text { Indian Creek }\end{array}$ & $\begin{array}{l}\text { Cities have different capacities to identify } \\
\text { and plan for risks from sea level rise. Some } \\
\text { cities are more actively involved in } \\
\text { updating their stormwater management and } \\
\text { other planning, while other cities lake the } \\
\text { resources. Use formal plans, comprehensive } \\
\text { planning, assessments, and set budgets for } \\
\text { adaptation and resilience strategies. Focus } \\
\text { on infrastructure and government owned } \\
\text { properties. }\end{array}$ \\
\hline $\begin{array}{l}\text { County Government } \\
\text { (Departments active } \\
\text { in sea level rise) }\end{array}$ & $\begin{array}{l}\text { Water and Sewer; Parks, } \\
\text { Recreation, and Open Spaces; } \\
\text { Regulatory and Economic } \\
\text { Resources (Resilience, Public } \\
\text { Works, Stormwater, } \\
\text { Planning); Transportation; } \\
\text { Emergency Management }\end{array}$ & $\begin{array}{l}\text { Oversee large region of unincorporated } \\
\text { county. Use formal plans, comprehensive } \\
\text { planning, assessments, and set budgets for } \\
\text { adaptation and resilience strategies. Focus } \\
\text { on infrastructure and government owned } \\
\text { properties. }\end{array}$ \\
\hline $\begin{array}{l}\text { Regional } \\
\text { Organizations }\end{array}$ & $\begin{array}{l}\text { Southeast Florida Regional } \\
\text { Climate Change Compact; } \\
\text { South Florida Regional } \\
\text { Planning Council, Florida } \\
\text { Institute for Health Innovation }\end{array}$ & $\begin{array}{l}\text { Coordinate multi-jurisdictional planning } \\
\text { activities to help prioritize adaptation } \\
\text { strategies and offer guidance to local } \\
\text { municipalities. }\end{array}$ \\
\hline State Agencies & $\begin{array}{l}\text { Florida Department of } \\
\text { Environmental Protection, } \\
\text { Florida Division of } \\
\text { Emergency Management, } \\
\text { Dep. of Transportation } \\
\end{array}$ & $\begin{array}{l}\text { Limited role in adaptation planning, not } \\
\text { allowed to use "climate change" in planning } \\
\text { documents. Existing policies shape local } \\
\text { strategies. Some highway projects to } \\
\text { mitigate flooding. }\end{array}$ \\
\hline Federal Agencies & $\begin{array}{l}\text { NOAA, Everglades National } \\
\text { Park, Biscayne National Park, } \\
\text { USGS, FEMA, EPA, USACE } \\
\text { and SFWMD (Quasi } \\
\text { Federal/State agreement) }\end{array}$ & $\begin{array}{l}\text { Emphasis on NFIP mapping, Everglades } \\
\text { restoration, and water conveyance systems } \\
\text { run by USACE. Set Federal sea level rise } \\
\text { projections used in local planning. }\end{array}$ \\
\hline
\end{tabular}


Fifty-nine people were interviewed in-person and on the phone between September 2016 and June 2017. In person interviews were primarily conducted in Miami-Dade County, though some were conducted in Broward and Palm Beach Counties. Some of these interviews were conducted jointly for people who worked together responsibilities requested to be interviewed together. This resulted in a total of 50 independent interviews. Forty-seven out of fifty of these interviews were recorded and transcribed and for three of these interviews detailed notes were taken as interviewees declined to be recorded. The average length of interview was 63.5 minutes with a range from 25 minutes to 214 minutes. Interviewees were purposefully selected and intended to cover the broad range of institutions active in this arena. This includes individuals from local and federal government, private consulting firms, environmental and community organizations, and research institutions (see Table 4.4 for a breakdown of interviewees by type). In some cases, a convenience sample was used to draw out groups who may be peripherally involved or impacted by sea level rise adaptation planning. The interviewees represent several different dimensions of sea level rise adaptation including: coastal and civil engineering, planning, public health, geophysical sciences, community development, ecological processes, agriculture, insurance, and development (see Table 4.5 for a breakdown of interviewees by focus). "Focus" is related to the institutions primary motivation. For example, the South Florida Water Management District is a regional governing body primarily concerned with managing water for municipal, agricultural, and other uses - their focus is "Water." A private business that has been hired to implement adaptation strategies is Type: "Private Sector-Consulting" and Focus: "Climate". The ten types of Focus were selected using both the literature and 
preliminary analysis of the different interests of institutions involved or impacted by sea level rise adaptation planning.

In case studies, interviews are guided conversations rather than structured queries (Yin 2014). While I followed a general set of core questions through a naturalistic conversation flow, I adjusted this interview guide as time went by (for interview guide, see Appendix C). After each interview, I reviewed my notes and reflected on emerging themes. I did not hesitate to ask follow-up questions that would lead me down unanticipated paths, and I made some changes to my guide following most interviews. I also asked specific subsets of questions that varied according to roles and experiences of each interviewee. For example, a subset of questions to scientists were different from those asked to community organizations. Often these subsets were uniquely tailored to learn about a committee, assessment, or plan an interviewee had experience with. I aimed to maintain a thread of common experiential and perception-oriented questions throughout. Interviews are semi-structured and open-ended with some more specific questions developed from document review. Interviews were transcribed and coded using Atlas.ti software (for code book, see Appendix D). 
Table 4.4 Interviews Conducted by Type

\begin{tabular}{|l|c|}
\hline Type & $\begin{array}{c}\text { Number of } \\
\text { Interviews }\end{array}$ \\
\hline Government- Federal/State & 4 \\
\hline Government- County & 12 \\
\hline Government- City & 10 \\
\hline NGO-Environment & 7 \\
\hline Private Sector- Business & 4 \\
\hline Private Sector- Consulting & 5 \\
\hline Community Organizations & 7 \\
\hline Elected Officials & 4 \\
\hline Scientists & 6 \\
\hline Total & 59 \\
\hline
\end{tabular}

Table 4.5 Interviews Conducted by Focus

\begin{tabular}{|l|c|}
\hline Focus & $\begin{array}{l}\text { Number of } \\
\text { Interviews }\end{array}$ \\
\hline Environment & 13 \\
\hline Engineering/Hydrology & 9 \\
\hline Climate Change & 13 \\
\hline Health & 1 \\
\hline Insurance & 1 \\
\hline Planning & 4 \\
\hline Community Development & 5 \\
\hline Business & 3 \\
\hline Agriculture & 6 \\
\hline Political & 4 \\
\hline Total & 59 \\
\hline
\end{tabular}

\section{Thematic Analysis}

Documents and interview transcriptions and notes were coded and analyzed according to the methods outlined in Braun and Clark (2006). The coding could best be described as manifest content coding, where coding was used to identify the tangible interpretation of the text. Using Atlas.ti software I created the following meta-categories 
(parent codes): Focus of Risk; Interpret Information About Risk; Risk Boundary;

Planning Process; Governance; Knowledge Networks; Solutions; and Other. These parent codes were determined a priori and based on the research questions around risk construction and knowledge integration. From there, I created 93 sub-categories (or child codes). Some of these child codes were identified in literature and preliminary document review a priori, and some of them were identified during the coding process. I used codes mainly as a system of indexing to sort and retrieve data for future analysis. This kind of coding is common in many techniques of qualitative analysis including thematic analysis, as schematized by Braun and Clarke (2012). My process mirrored their suggested steps: I immersed myself in the data, coded, identified themes (identifying themes throughout data collection, not just following transcription), refined and finalized themes and then began writing. A specific description of how codes were used, organized, and interpreted for analysis are included under the analytical approach for each chapter.

\section{Field Observation}

Some field observation was used to contextualize case study development and identify interviewees. This dissertation defines field observation as the witnessing of realworld activities taking place that are relevant to the case study. I attended fourteen events for field observation to contextualize case study development and identify interviewees. These events include public workshops on sea level rise adaptation planning, a communitybased course, and public meetings (for a full list with descriptions see Appendix E).

\section{Analytical Approach for Chapter 5:}

This chapter is primarily concerned with how risk knowledge is constructed in the planning process. Thematic analysis was primarily inductive with the identification of 
emerging themes around formal assessments that address sea level rise. Planning documents were reviewed with the purpose of identifying how sea level rise rates and projections, knowledge of the physical geography, infrastructure vulnerability, and knowledge about social and economic contexts were produced. Interviews provided more information as to the process of how these studies were put together, the contestations among different authors and participants, and how they have been used to inform decision-making. Early on during document review and interviews it became clear that identifying a baseline for sea level rise was an important and political issue. In addition, both experts and planners discussed the challenge of interpreting sea level rise risks across the physical landscape. These themes identified early in the research process were explored in greater detail using thematic analysis. This chapter primarily relied on the codes that fell under Focus of Risk; Interpret Information About Risk; Risk Boundary; and Planning Process. Child codes under these categories were compared across groups. Codes were then compared across themes to construct the planning history and use of different key ideas around the way risks are understood in sea level rise adaptation planning.

\section{Analytical Approach for Chapter 6:}

This chapter addresses research questions related to knowledge integration. Documents and interviews were used to determine the institutional context and roles and responsibilities of institutions involved or affected by sea level rise adaptation planning. I also identified the different adaptation pathways, which organizations are involved, how are they are involved, how the institutions and adaptation pathways relate to each other. This chapter also used thematic analysis to characterize the four emerging discourses 
shaping sea level rise adaptation governance. These discourses were identified inductively as emerging themes from the data. Sub codes from the Focus of Risk; Interpret Information About Risk; Governance; Knowledge Networks; and Solutions were primarily used for this chapter. Using Atlas.ti I first identified emerging themes around the four discourses. I then examined the codes using co-occurrence tables and based on the different types of institutions to understand patterns around the emerging discourses, what types of rationalities and authority they draw on, and how they interact with other discourses. This analysis helps identify the dominant narratives and where they sit in terms of adaptation planning strategies.

Analytical Approach for Chapter 8:

This chapter uses a literature and theoretical review to propose a framework of how sea level rise risk knowledge and expertise is negotiated and enacted across scales through the science policy interface. We developed the framework through literature and theoretical reviews. We then applied two case examples from South Florida, United States, and the Pacific Islands, to contextualize this scalar framework. 


\section{Chapter 5: Constructing Risk Knowledge in Sea Level Rise Adaptation Planning in Miami-Dade County, Florida}

\subsection{Introduction}

Sea level rise adaptation planning is predicated on understanding risks from changing and uncertain future conditions and identifying strategies to mitigate those risks (McCarthy et al. 2001). Risk knowledge is wrapped up in sea level rise discourses, projections, regional assessments, maps, and other planning tools created and used by governments, private firms, NGOs, and other organizations. These adaptation planning efforts often follow a hazards assessment and approach to determine risks, in which risks are considered a function of the physical components of the hazard (i.e. rate of sea level rise) and their interaction with social, ecological and technological vulnerabilities and adaptive capacity (e.g. topography, infrastructure, human life) (Wisner et al. 2014). Because there would be no risks without incomplete knowledge of future outcomes, knowledge gaps are often addressed through improving measurements and techniques to predict and identify uncertainties in anticipation of modeled future conditions (Gross 2010). Indeed, planning requires some idea of what that future might look like, and such future knowledge around risks are primarily focused on the physical, economic, and ecological impacts of climate change (Adger 2005). At the same time, however, knowledge about climate risks do not represent objective "facts"; the process of identifying and measuring risks is constructed, produced, and situated in political, economic, and cultural contexts (Shapin and Schaffer 1985; Jasanoff 2004; Miller 2008). The emphasis placed on physical and economic future conditions can create a planning 
arena that overlooks other risks and knowledge relevant to the problem at hand (Brugnach and Ingram 2012; van den Hoek 2014).

Scholars point to risk construction challenges of hazards assessments and anticipatory planning, required for sea level rise adaptation planning. Identifying how risks from climate change are likely to emerge and implementing presumably — though not guaranteed - effective responses inherently "picks winners" where decisions made based on how risks are understood can favor some people while causing harm to others (Wildavsky 1988; Barnett 2001). While uneven impacts of climate change are widely recognized (O’Brien and Leichenko 2000; Shi et al. 2016), uneven knowledge practices and problem framings which affect planning outcomes are often unexamined. The way that knowledge around climate risks is constructed shapes decision processes. As McCubbin et al. (2015) found in their study on sea level rise planning in Tuvalu, the emphasis on modeling and scenario-based climate impacts draws attention away from pressing challenges on livelihoods in the community and ignores effective points for adaptation. Climate change planning can emphasize physical hazards that are related to economic and political interests, rather than vulnerabilities that matter to the community, and by focusing on future conditions can potentially distract from current challenges (Kelman 2014; McCubbin et al. 2015). Additionally, constructions of biophysical hazards and their relation to social and technological systems, may favor technocratic and economic styles of reasoning and embed these value structures in risk knowledge while excluding and/or ignoring social and cultural values that may also be at risk (Adger et al. 2009; Brugnach and Ingram 2012; van der Hoek et al. 2014). 
Risk knowledge about sea level rise is at the core of how decisions are made regarding prioritizing and implementing adaptation strategies, yet the knowledge production practices around how those risks are determined is often left unexamined in the climate change adaptation planning literature, particularly in North America. This chapter addresses the call for research to open-up knowledge practices around identifying risks in climate change adaptation planning (Adger et al. 2009; Brugnach and Ingram 2012; van der Hoek et al. 2014). Using a case study of sea level rise planning in MiamiDade County, Florida, this chapter addresses the first part of my research question by unpacking the social process of how particular dangers come to be selected for attention (Douglas and Wildavsky 1983). I do this by uncovering the dominant framings, styles of reasoning, and political context that are embedded in the way risks are understood (Lupton 1999). Building off the work of Gross (2010), Ignorance and Surprise, I open-up planning and knowledge practices that create two types of ignorance: nonknowledge and negative knowledge. Nonknowledge is the knowledge gaps around what is considered relevant. Negative knowledge is blind spots, or knowledge that is unknown and considered unimportant, often thought of as "undone science." In this chapter, I connect Gross's work on ignorance to the concept of "risk ambiguity" as used by Brugnach and Ingram (2012) and van der Hoek et al (2014) to understand how contestations around the focus, interpretations, and boundaries of risk shape knowledge practices. Through this analysis, this chapter articulates three findings around knowledge constructions of risk in sea level rise climate adaptation planning:

1. Determining "objective" knowledge around the hazards (i.e. calculated rates, projections, and physical geographies) of sea level rise in Miami-Dade County 
is a negotiated and contested process. Sea level rise rates and projections are shaped by political debates surrounding relevant science and processes, which are enrolled to justify minimizing risks at the local scale.

2. Sea level rise risk knowledge that supports an economically viable future is favored over knowledge that either threatens that future or is seen as insignificant to achieving goals of that future. This creates knowledge practices that address ignorance within those arenas (e.g. through improvements to modeling accuracy around physical hazards) and precludes planners from other ways of thinking about risk.

3. Problem closure around risk knowledge occurs to drive action and decisionmaking, specifically around infrastructure and the economy. Actors more closely connected with decision-making subscribe to problem framings around infrastructure that serve to reinforce bureaucratic and "expert driven" institutional path dependency around knowledge and decision-making. The outcome is the reproduction of a system in which some communities gain more attention and authority over risk knowledge and adaptation solutions, over others.

\subsection{A Relational Approach to Risk in Sea Level Rise Adaptation Planning}

Applying theories from Society and Technology Studies and cultural approaches to risk can open-up the knowledge production of risk and ground that process in social reality (Latour 2004). While non-cultural theories of risk, such as those in economics, psychology, and hazards planning, largely treat risk as a taken for granted objective reality (Lupton 1999; Fox 1999; Wisner et al. 2014), cultural theories of risk differ in that 
they assume an active rather than a passive perceiver of risk (Rayner 1992). This could be an individual or institution driven by their own cultural imperatives to select risks for management attention, or to suppress them from view (Douglas and Wildavsky1983). Institutional structure becomes the ultimate cause of risk perception, and risk management becomes the stimulus for risk rather than the outcome of risk (Rayner 1992). Risks, therefore, are determined by the process of how an individual or institution comes to define, measure, understand, and construct knowledge about associated dangers in relation to what they care about (Douglas and Wildavsky 1983; Fox 1999). In this way, even hazards — or measured physical impacts associated with the changing environment — are determined in relation to what an institution values and how the institution constructs and validates knowledge (Fox 1999).

In this framing, knowledge refers to claims made by actors-either individuals or institutions - that either serve to tell us something factual about the world (with varying degrees of certainty) or are taken by actors to tell us something factual about the world (Miller et al. 2010). It is an idea or judgement that someone takes to be true, or at least relatively truer than other kinds of statements (Miller et al. 2010) and are often shaped by tacit skills and values (Collins 1974), problem framings (Miller 2000), and styles of reasoning (Hacking 2002).

Knowledge about risks are co-produced in the planning process by individuals and institutions, where those involved in adaptation planning shape knowledge about risks, and that risk knowledge shapes the social and material world (Jasanoff 2004). The way risks are understood is ultimately linked to the design, planning, and implementation of proposed solutions (Sarawitz et al. 2000). To build an analysis around risks, the focus, 
is therefore on "the forms of knowledge, dominant discourse, and expert techniques and institutions that serve to render risk calculable and knowable, bringing it into being" (Lupton 1999, 7). Risks that matter are those seen as a threat to community—or institutional — order (Douglas and Wildavsky 1983), and, because of the uneven distribution of risks, the process of determining risk definitions and knowledge, and adopting those into formalized governance processes is inherently political (Beck 1992). Ultimately, knowledge practices around risk determine what institutions know and what they do not know, what kinds of questions get asked, the methods used to gather information, and the standards by which to evaluate evidence (Lupton 1999).

Gross's (2010) classification of ignorance offers a particularly useful approach to understanding how knowledge is constructed in sea level rise adaptation planning in Miami-Dade County, Florida (Figure 5.1). Sea level rise adaptation planning is predicated on multiple forms of knowledge produced at different spatial, temporal, and administrative scales, with variegated actors involved in different contexts (addressed in Chapter 8 on knowledge politics of scale). Scientific knowledge is the primary means by which global and regional sea level rise rates and impacts are understood, and the emphasis of scientific uncertainty often becomes the focus of where to produce new knowledge. Gross offers another way of thinking about this process using the concept of ignorance which points to the limits of knowing, including the intentional and unintentional bracketing out of information (Gross 2010). He points to two forms of ignorance: nonknowledge and negative knowledge.

The first type of ignorance is called nonknowledge, which encompasses uncertainties around scientific knowledge where actors lack sufficient knowledge about a 
certain problem, however, they know the point of reference of that uncertainty. Within sea level rise, future conditions can never be fully knowable and actors from different institutions work toward identifying knowledge about those uncertainties. For example, sea level rise is understood as a process that is affected by currents, thermal expansion of water, tectonic activity, glacial ice melt, and other factors (Hine et al. 2016). While scientists recognize glacial ice melt as a crucial factor, they lack complete certainty and confidence as to how fast glaciers will melt with climate change (Hansen 2007). Therefore, under Gross's classifications of ignorance, rates of ice melt acceleration are characterized as "nonknowledge" and scientists work to better understand those processes. This practice makes up knowledge claims that are recognized and debated in the institutional and planning structure. The development of new or extended knowledge, results from further assessments, planning, tinkering, or acting in the face on nonknowledge. New knowledge connects back to ignorance, by addressing some of the initial ignorance and uncertainties and also creating new forms of ignorance and uncertainties (Gross 2010). To address issues of scientific uncertainty in sea level rise adaptation planning, scientists and planners continue to explore known uncertainties born out of climate modeling, ecological and geological science, and other knowledges that are used in decision-making (Hine et al. 2016). The uncertainties are known and identified, and new knowledge seeks to address those uncertainties.

The second type of ignorance is negative knowledge which is the active consideration that to think further in a certain direction will be unimportant. This occurs as some consequences of an activity might be anticipated but are deemed unimportant or unlikely to be severe. This is also related to Tannert, Elvers, and Jandrig's (2007) idea of 
the Galileo effect which refers to Bertolt Brecht's play during which a cardinal refuses to look through a telescope to avoid having to accept the knowledge that the planets revolve around the sun. Negative knowledge can lead to what Hess (2007) calls "undone science" where knowledge could be produced based on clearly defined ignorance, but it is not pursued further (e.g. science is driven towards results that are patentable, and away from other pursuits). Hess goes so far to argue that there is a "systematic nonexistence of selected fields of research" (Hess 2007, p. 2). Frickel (2008) applies this thinking to the term knowledge gaps to situate organizational outcomes of undone science in his work on the social determinants and effects of Hurricane Katrina on New Orleans. Such undone science may result in social movement organizations lacking potentially helpful research results because they are undone, a consequence of lack of funding based out of knowledge avoidance practices by funders and planners who would have the capacity to support this research (Hess 2007; Frickel 2008). 


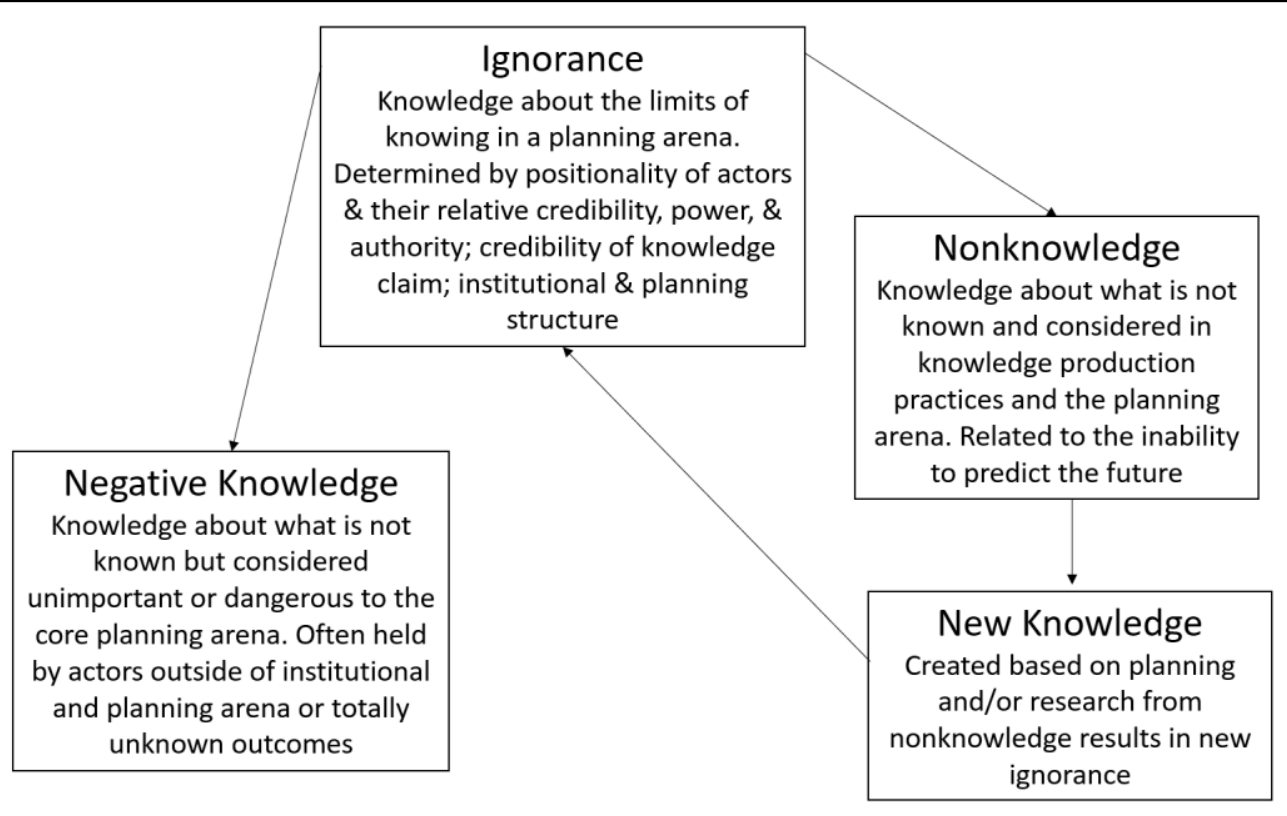

Figure 5.1 Two types of ignorance: nonknowledge and negative knowledge. Nonknowledge results in the production of new knowledge to try and reduce the ignorance. However, negative knowledge is ignored by the system and no new knowledge is created to address this form of ignorance. (Figure adapted from Gross (2010) Ignorance and Surprise)

Complementary to Gross's work on ignorance, the concept of institutional positionality can be used to explain these two forms of ignorance. Applied to risk, institutional positionality determines what institutions place as the substantive focus of risk, how institutions interpret information about the system, and how institutions bound a system regarding climate risks (Brugnach et al. 2008; van den Hoek 2014). Risk constructions stem from different ontological perspectives from which institutions align themselves and what values they prioritize on the landscape (Hilgartner 1992; Short and Clark 1992; Rayner 1992; Wisner et al. 2014). Different institutions come to understand, validate, and interpret risks and those epistemological differences can create conflict around what knowledge is considered valid (Bocking 2004). For example, there are 
different scientific representations of risk, such as those used by climate scientists, hydrologists, versus geomorphologists. These representations are often considered credible sources because of their knowledge production system integrates testable and defensible biophysical laws (Latour and Woolgar 1986; Gieryn 2006). At the same time, however, these "facts" may be contested based on the epistemic choices made during their production (Ozawa 1996). Finally, risk knowledge encounters different system boundaries which can shape which knowledge is used and integrated in a planning system, and which knowledge is ignored or discarded (van den Hoek 2014). Institutions may bound the system differently in terms of both spatial and temporal scales and these differences may not only emerge in different constructions of risk, but also impact the planning process and knowledge integration (Adger 2005). Each of these risk knowledge construction processes related to institutional positionality can determine which form of ignorance is produced in the planning system.

Communities facing risks from climate change, such as Miami-Dade County, address those risks by first creating knowledge about them. In Miami-Dade County, this knowledge process primarily follows a format of a combination of the physical hazard, the vulnerability and adaptive capacity. The following three sections discuss the knowledge practices and contestations within the way risk has been understood in MiamiDade County with a discussion of how sea level rise rates were adopted locally (physical hazard), how this interacts with conditions on the landscape emphasizing knowledge that supports economic growth (vulnerability), and how this is understood in a vulnerability and adaptive capacity context. 


\subsection{Scientific Reticence, Political Uncertainty, and Confronting Denialism-}

\section{Agreeing on 81 Inches in 2100}

To plan for sea level rise risk, governments adopt regionally relevant rates and projections. Currently, Miami-Dade County and municipal governments within the county recognize and plan for sea level rise projections up to 81 inches by 2100 (Figure 5.2 shows projections currently used in adaptation planning in Miami-Dade County). Determining the use and application of different sea level rise rates and projections has been a contested process with scientists from academic institutions, federal agencies, and local governments interacting with planners, policymakers, and other stakeholders to identify relevant global processes and knowledge to apply to Miami's context. Three processes underscore the contestations around which rates and projections to apply locally: scientific reticence surrounding the role of ice melt acceleration, political uncertainty, and climate change denialism. 


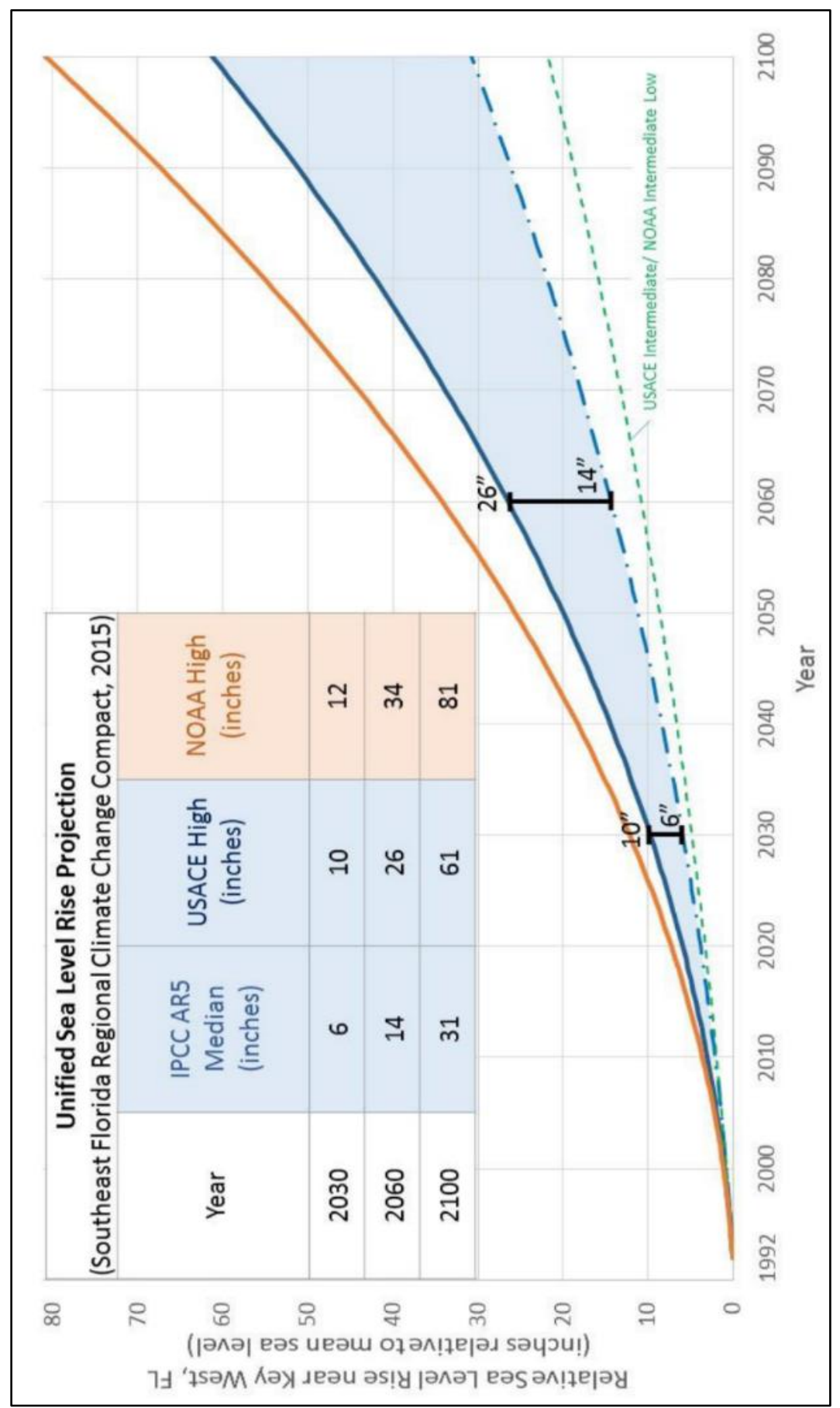

Figure 5.2 Sea level rise projections adopted by Southeast Florida Regional Climate Change Compact in 2015. 
The local government's first formal instance of identifying sea level rise projections in the county was in 2006 when the Board of County Commissioners established the Miami-Dade County Climate Change Advisory Task Force which included a Science and Technology Committee. ${ }^{1}$ Collectively this committee produced and signed the Science and Technology Committee's Statement on Sea Level in the Coming Century. ${ }^{2}$ This statement presented an argument that the 2001 and 2007 IPCC sea level rise projections, recommended for use by the US Government and project 1-3 feet of sea level rise over the coming century, underrepresented the risk by failing to incorporate the accelerated melting of the Greenland and Arctic Ice Sheets. Building their own sea level rise model that integrated Arctic and Greenland ice melt, the committee projected a 1.5-foot increase in the coming 50 years and a total of at least 3-5 feet by the end of the century, and formally presented their recommendations to the county government in report published in 2008 (Recommendations 2008).

The incorporation of ice melt acceleration in this projection was questioned by county planners and policymakers, discussed by interviewees from both the scientific community and local government planners. Although the county formally adopted the Climate Change Advisory Task Force Recommendations (Resolution: R-48-15) two key planning documents produced following this adoption, the Comprehensive Development

\footnotetext{
${ }^{1}$ Legislation number 06-113 sponsored by commissioners Seijas (lead), Diaz, Gimenez, Edmonson, Jordon, Rolle, and Sosa. The committee included 10 scientists (specializing in oceanography, sedimentology, coastal processes, chemistry, ocean-atmosphere interaction, paleoecology, hydrology, and ecology), two county employees (including the Deputy Director of Miami-Dade County Water and Sewer), and a biodiesel and public policy specialist.

${ }_{2}$ Drawing on oceanography, geology, and other sciences to reconstruct thousands of years of coastal history and use contemporary data to identify ongoing shifts and changes in sea level rise in recorded history (e.g. Dr. Hal Wanless Presentation April 22, 2008-Wanless 2008)
} 
Master Plan 2010 Evaluation and Appraisal Report and the sustainability plan called, "GreenPrint: Our Design for a Sustainable Future" did not include sea level rise projections and instead reference incremental changes of sea level rise observed by the Key West Tide Gauge since the early 1900s (see Figure 5.3). While some scientists shared that knowledge about accelerating ice melt is disregarded as an extremist perspective, others expressed that the disagreement stems from scientific uncertainty around ice melt acceleration having never been recorded or documented in human history. Because there is no baseline, scientists are learning about this as it is happening and using geological indicators to reconstruct the past. While many geologists focusing on sea level rise agree on the importance of ice melt acceleration, there is disagreement as to how much to include and how well the instruments are measuring the rate of ice melt. Additionally, challenges with global datasets and measurement instruments and technologies creates debates around how to model and predict sea level rise. This scientific reticence around ice melt acceleration and other gaps in sea level rise processes playing out among climate scientists at the global scale (see Hansen 2007) is called into question by planners at the local scale; while some scientists may be more comfortable with a wider band of possibility—or nonknowledge — surrounding rates and projections, planners wanted a narrower target. 


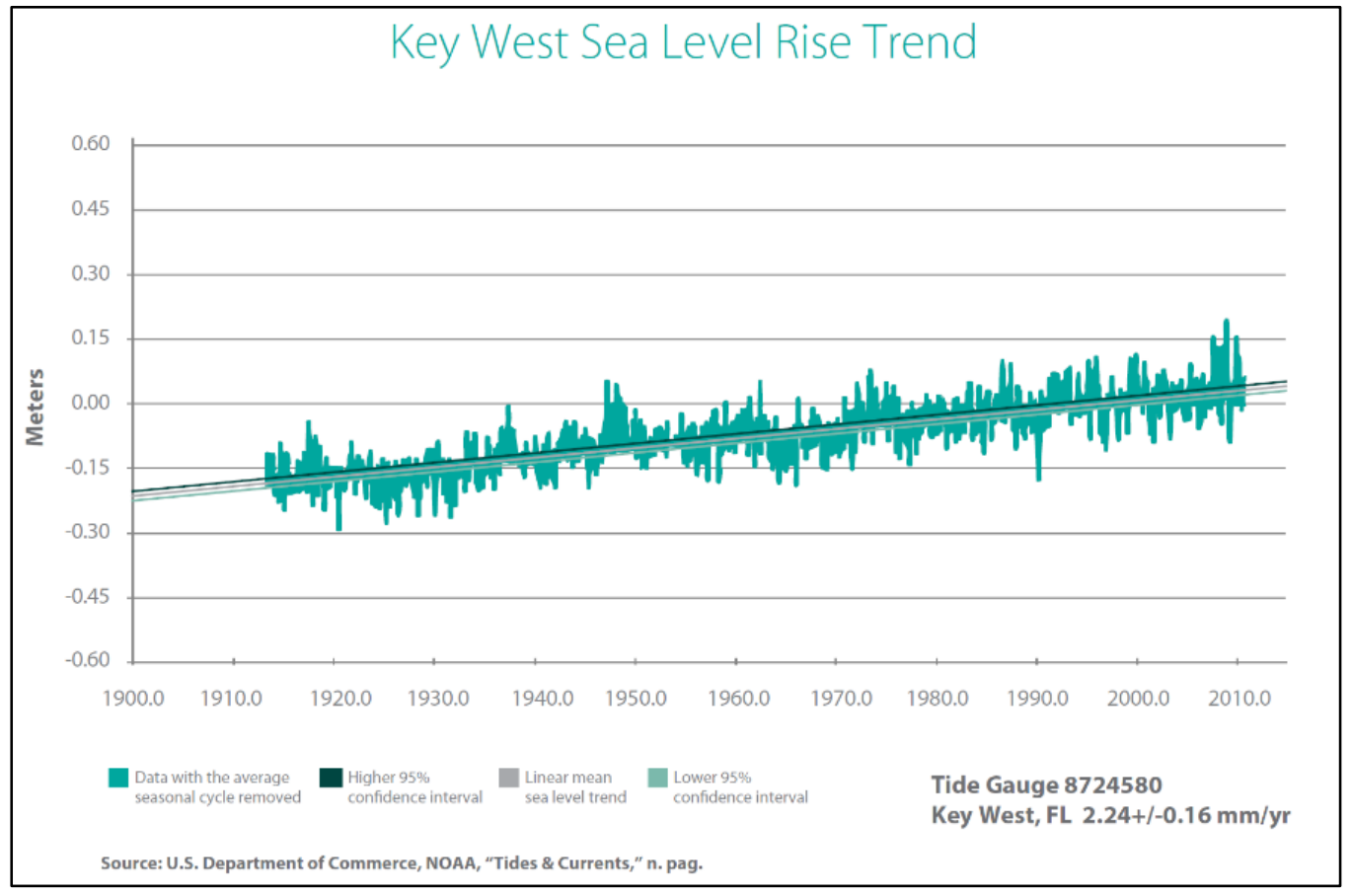

Figure 5.3 Representation of sea level rise trend in Miami-Dade County GreenPrint document. Did not include projections, focused on recent historical changes observed at Key West tide gauge

The failure of the county to address the Climate Change Advisory Task Force's recommendations resulted in ongoing pressure from scientists, environmental organizations, and growing concerns in the media. In 2013, five years after the Climate Change Advisory Task Force's recommendations were presented to the county, county Commissioner Sosa introduced resolution R-599-13 to create a Miami-Dade Sea Level Rise Task Force. While the 2006 Climate Change Advisory Task Force examined multiple dimensions of climate change and had several committees and dozens of members, the Sea Level Rise Task Force was focused on sea level rise and had seven members, with one scientist. Some planners shared that the idea behind focusing only on sea level rise was to avoid more political issues of greenhouse gas mitigation that had 
slowed down the Climate Change Advisory Task Force and the GreenPrint. The scientist selected for the Task Force was met with skepticism as other scientists expressed that the committee chair purposefully selected a scientist who was not vocal about ice melt acceleration and higher projections. As one scientist shared in talking about the hurricane scientist selected for the second task force, "You know, one of the first things he said on the committee was, 'I'm not a sea level scientist,' yet he was in charge of it. But the whole thing in fact was a total farce of a committee, the second task force." Another scientist commented on the reluctance of this scientist to view ice melt acceleration as a factor for determining rates of sea level rise:

So now the second committee was a problem because of David Enfield. And a few others... And like I said, David's a hurricane guy that sees everything as decadal and other cycles. Even today, and he said 'We don't know until it's already past if something really changed.' Because he's so dedicated to that.

While scientists discussed how their knowledge around ice melt acceleration was discarded and ignored, planners shared that during the early years of determining projections there was reluctance to incorporate projections into planning and share the information with the public because of political uncertainty as to how the public would respond. As one interviewee expressed when talking about the county planner in charge of the Climate Change Advisory Task Force and Sea Level Rise Task Force Committee Chair:

Harvey had in his mind from day one the need for a major vision on how it needed to be instilled that was commensurate with his view of the risk...The numbers started the pile up, the different projections... There were a couple really key reports that Harvey said look, we're underestimating the potential of sea level rise. We could be looking at two or three feet... In fact, we're now [today] looking at numbers of six feet... I 
think if we look back honestly everybody was afraid to say that. We didn't know what the reaction would be to saying 6 feet.

Part of this reluctance to adopt higher rates was wrapped up in planners stating they were ill-prepared to plan for and deal with the impacts of sea level rise. As one planner shared,

They were starting to see these tools that you can look at it in a computer, I said show me three feet on Miami beach. All of a sudden Ocean Drive buildings are, water is up there, up to the top bar stool... So, you know they were fairly elementary tools. But they are not talking about a storm surge, they are talking inundation that doesn't go away. That's scary because there is frankly no known experience for dealing with this. People have had tidal waves they've had what do you call the big waves, coming from tsunamis. We've seen those pictures. But they always recede.

In talking about why sea level rise experts were left off the second county task

force, one scientist expressed that the drive for individuals to want to create positive environmental change in the county requires the idea that it is possible to save the environment and region, and high sea level rise projections could limit action. As one scientist expressed frustration about an influential local planner that blocked the adoption of higher projections:

He's been an environmentalist from before there was any environmental stuff, in the 70 's... he wants his life to be success, that's why I'm convinced of this... he wants us to plant a tree and buy a Prius and maybe in a few years it will all be okay. Well the problem is, that $93 \%$ of global warming heat is transferred to the ocean. We're not turning this around, there is no way. Almost all the heat of global warming is in the ocean. And that's with us for centuries. And the residence time of carbon dioxide in the atmosphere is something like 4,000 years. You know, we're in for this. We've really done something. And [he] just can't buy that. He feels he's been a failure... And they're almost more problem than a denier, because they're coming to you as one of the people involved in climate change and sea level rise, and then they don't want to face the reality. 
Similarly, several shared that rates and projections are shaped by the possibility of adapting. Smaller sea level rise rates are favored to allow for an economy to grow around building those adaptations. If the rates are too high, it will be impossible to plan to adapt to those risks.

While Miami-Dade County was trying to reach agreement on sea level rise rates and projections, similar debates around which sea level rise rates to adopt were taking place in neighboring counties and cities. Philip Levine had just been elected to serve as the Mayor of Miami Beach, running on a campaign to save Miami Beach from sea level rise and sunny day flooding. Broward, Monroe, Palm Beach and Miami-Dade County were all referencing different sea level rise projections for State and Federal lobbying and funding proposals. In response, these county governments formed a four-county regional effort beginning in 2009, called the Southeast Florida Regional Climate Change Compact (Compact) to create a unified projection and recommendations for addressing vulnerability. The Compact's science and technical committee oversees reviewing current government projections and scientific research to determine which projections to use. The first unified projection was published in 2012 used USACE guidance and projected 9-24" of sea level rise by 2060 (Compact 2012). Following the publication of NOAA and updated USACE regional projections for planning guidance for federal agencies, the Compact reevaluated this initial unified projection. The second unified projectioncurrently being used — was published in 2015 and projects up to 6.6 feet of sea level rise by the end of the century, much greater than the original 1-3 feet the federal government was recommending in 2006 (Compact 2015). 
While there was Federal precedence for determining rates of sea level rise at the regional scale, the effort for adopting projections was interrupted by local politics and climate change denial. Several people involved in this effort pointed to representatives from Palm Beach County as being the primary barriers to adopting higher projections. As one scientist expressed, "That was a fight... Again, it was scientists in Palm Beach, we got a few. One of the guys from Palm Beach... said, 'I'm not authorized to project more than two feet [by the end of the century]."' Several sea level rise scientists expressed that they would have pushed for higher projections, however, they saw a "big fight" with climate change deniers in Palm Beach County and internally with some of the scientists on the committee and instead pushed for the United States Government projections, even though they expressed these projections were too conservative. For example, one scientist expressed an interaction they had with another scientist who did not agree that Arctic and Greenland ice melt acceleration models should be included in sea level rise projections early in the Compact's effort to unify projections:

He came up to me the first meeting and he said... Because we were talking right off, this was the second time we had the compact see over it. And he said 'Are you agreeable not to go above 6.6 feet?' And I said 'Yeah. I mean I think it's going to be more, but I think for planning 6.6 feet is so severe for coastal communities that it drives home the reality and you start planning.' That's been my goal. And if we get on our high horse and say 'It's going to be 25 feet'... Then they're just going to buy a bottle of Jack Daniels and forget it. Which, they can't. The government's supposed to be Protecting their people. And you can't protect your people by ignoring this.

Some scientists stated that the decision to have a smaller projection for the county was in the political expedience of a lower rate. As one shared,

The politicians, most of them, are interested in reducing the projections. In fact, the Four-County Climate Compact was too aggressive, so, Harvey 
Ruvin, who's an environmental guy who's on the Dade county... and he's been involved in sea level rise and things of that kind for a very long time. He suspected, or he hypothesized, that if the rate of rise was too aggressive, the people on the County Commission would just tune the whole thing out and not do anything. And so, he started another sea level rise group in order to moderate the forecast by the Four-County Climate Compact so he could get by the Dade County Commission.

When the Compact was trying to adopt unified projections, many on the committee wanted to at least suggest a sea level rise projection of 100 years because infrastructure projects are expensive and built to last longer than 60 years. Several interviewees involved in this process indicated that this was a struggle, but attributed agreement to a USACE employee who shared that USACE planners are required by law to plan to the 100-year mark to make sure that infrastructure projects will last their lifetime. While the science committee used refereed publications, IPCC reports, and other scientific and credible data to suggest rates of sea level rise, some shared that the USACE was viewed as being the most politically expedient. As one scientist shared, ... politically, it's easier for the people in Palm Beach to acquiesce to something that a military group puts forward because they're heavily Republican, and if a military group like the US Army Corps of Engineers says that something is happening that gives it credibility, whereas if a scientist were to say it, even though the Corps of Engineers projections are based on what the scientists have said, it's the politics of the whole thing. The people in Palm Beach were always holding out for minimal projected rises.

Currently, the county, city, and local governments use the agreed upon Compact projections published in 2015 which include the NOAA High, USACE High, and IPCC AR5 Median, for a projected sea level rise range of 6-12" by 2030, 14-34" by 2060, and 31-81 inches by 2100 (Figure 5.2) (Compact 2015). While some sea level rise adaptation planning took place within the county prior to the Compact finalizing their projections 
(e.g. City of Miami Beach ${ }^{3}$ ), presently, nearly all locally produced plans and assessments that include sea level rise reference the Compact's unified projections. At the same time, the range of projected rates of sea level rise do not provide an exact number for municipalities to plan for, rather the suggestion is for planners to use this information to determine the specific level of risk their project can support. For excessive cost infrastructure upgrades, for example waste water treatment facilities, the idea is that erring on the side of caution and aiming for the higher projection makes fiscal sense as those systems are expensive and built to last a long time. Although this flexibility is by design so that municipalities have guidelines for determining design standards, some view these guidelines as a mechanism to focus attention on short-term adaptation strategies while avoiding longer-term challenges. For example, the City of Miami-Beach is planning stormwater infrastructure adaptations for 2 feet above the current hightide mark, which corresponds to roughly a 30-year planning horizon. Several critics shared that they consider this a "band-aid" solution and that local governments are using the short-term projections to avoid discussing longer term strategies.

Sea level rise scientists and environmental organizations continue to be active in the community, sharing both the Compact projections and higher projections from scientific publications at different community meetings and with the public. Many of these scientists as well as environmental organizations and community activists expressed

\footnotetext{
${ }^{3}$ When determining how high to raise roads for the initial stormwater projects, the City of Miami Beach decided to use current high tide as a baseline and add a foot (later two feet) on top of that baseline to use for the design standard for road elevation. The reason being that they shared they could not wait around for the compact to agree so adopted their own rates
} 
concern that the adopted projections from the federal government and recent IPCC should

be looked at as a minimum, as one scientist explained in an interview:

But those are government projections, and they do not incorporate either the accelerating feedbacks, mostly accelerating feedbacks we're seeing with ice melt. There are about 15 of them that are really important. That are speeding up ice melt beyond what the models are projecting. And those aren't in those models. So, those have to be really looked at, at the low end. This is where people that don't take the time to truly understand this, sort of blow off any of us that are projecting higher rates as extremist. But we're not. We're taking the models that they use and say "Okay, but it's gonna be faster than that, because you don't have these things in the models." Somebody last year, put out a publication adding three of the models. Three of the feedbacks. Just looking at Antarctica, and they added another meter or two.

These individuals expressed that local governments are not doing enough to communicate the projections and the risks of climate change to the public. Some of these scientists call on local government to initiate transparent planning. For example, as one shared:

Let's take the high projection, and let's not put a date on it, but let's realize this may well happen this century. And what you do is, you say 'Okay. These are the things we're going to have to do at six inch more sea level rise, or a foot, or a foot and a half, to maintain the integrated infrastructure. All these things. And then to keep the water sort of out of the way and stuff. And then you figure out how much each part of that costs, and then when you do that, all of the sudden you're going to realize that a foot and a half, this whole part of your city, you won't be able to afford maintaining the infrastructure... You're going to be on your own with your infrastructure.' That would be really nice to know, if you're buying down here. Or if you're trying to sell, I mean it would be nice to know this.

Several scientists shared that governments are afraid to be transparent about sea level rise projections because of the tax base and not wanting to scare people. Many were vocally opposed to this lack of transparency. As one scientist shared, 
But what I'm trying to do is just get people to honestly, transparently plan. Because I truly believe that the only purpose of government is to protect your safety, your welfare, your health, your risk, you know... Reducing risk for you. One of the problems with sea level rise is storm surges are gonna become exponentially more devastating as they push farther in. Because they're a horizontal horror of water pushing in. And those are the things that are gonna move us on, but it's going to be devastating at some point... Just figure out what's going to happen, because it will happen. At each step and figure out what it's going to cost to maintain the infrastructure.

Some of the scientists actively involved in aiding local governments with their modeling and project planning shared that they communicate to managers and planners that the highest government rate may be a bottom line. In addition to rates of sea level rise, several scientists and planners pointed to unknowns around climate change impacts to rainfall and storm surges, which will also create future inundation and flooding challenges. As one government planner shared,

I think we have a very good handle on the sea level rise projections although there is some more work needed for storm surge projection. The biggest science gap is this climate model for rainfall, highly uncertain for this region because a lot of models... they cannot capture the kind of dynamics of climate like sea breeze and other things. In terms of extreme rainfall there's a big gap in what will happen to like hundred-year rainfall for example. The other issue is that even the average rainfall the question is if rainfall averages go down or go up what are the implications for the Everglades Restoration?

Further examining rainfall and other biophysical climate dynamics that may worsen the impacts of sea level rise appears to be the next frontier of nonknowledge and new knowledge. The emphasis on ignorance surrounding biophysical hazards emerges out of interviews and documents as key uncertainties or unknowns surrounding sea level rise risks. 


\subsection{Risk Constructions of the Physical Landscape that Support an Economically}

\section{Viable Future}

Part of the drive for local governments to present rates and projections that minimize risks is wrapped up in the desire to portray an economically viable future for the region to investors, residents, insurance brokers, and others. Many scientists and interviewees expressed that part of what shaped the adoption lower projections and rates of sea level rise over those that incorporate ice melt acceleration and result in higher rates, is the focus on the way different projections affect buildable land in the county. As one scientist expressed:

And from my view, 6.6 feet by the end of the century is catastrophic for a place like south Florida. If you wanted to build houses at 6.6 feet ... Sea level rise in areas that were say, more than two feet above just normal high tide, not the king tide, just normal high tide, you're down to less than $10 \%$ of Miami-Dade County that's still buildable. We're so low, we're just ridiculously low. This is a real problem. And let's say sea levels at five feet by the end of the century. With this accelerating ice melt. It will be rising at a foot per decade and accelerating.

By adopting a smaller sea level rise projection, several planners suggested that private companies can innovate building, design, and engineering techniques to address the issue and make a profit. Many scientists and practitioners shared that private, economic interests shaped adopted rates and projections. Planning for projections of more than a few feet means that adaptation work would be prohibitively expensive, and it would not attract economic growth.

This idea of constructing risks that commensurate with a viable economic future is reinforced in knowledge about the physical geography and how projections will interact with the landscape and infrastructure. Several interviewees expressed that in the 
early years of the planning process the county and local governments were hesitant to acknowledge and share information about sea level rise because of the threat to property values. For example, despite this being a formal recommendation from the county's Climate Change Advisory Task Force ${ }^{4}$ there was a reluctance on part of the county to produce high resolution elevation maps to identify impacts of sea level rise projections. ${ }^{5}$ And today, contestation occurs between actors that seek to minimize the location of where sea level rise risks occur and those that try to determine hyper-local risk knowledge for planning solutions, despite having somewhat similar goals of maintaining developable property and allowing for economic growth to continue.

Generally, a modified bathtub model ${ }^{6}$ is used to assess where sea level rise inundation will occur. The county, the Compact, and other municipalities acknowledge

\footnotetext{
${ }^{4}$ In 2008 the Climate Change Advisory Task Force Science and Technology Committee made a second recommendation to the County to get high resolution elevation maps, stated: "The County should commission detailed maps for all Miami-Dade County created from calibrated LiDAR (Light Detection and Ranging) surveys (or other elevation survey technology that employs best known practices). These maps will show mean high, with water (MHHW) levels for 1-foot through 6-foot rises in sea level. (MHHW level is the spring high tide level which occurs every 14 days around full moon and new moon.) The maps will allow identification of which areas will become flooded in association with different sea levels and will provide a basis for assessing risk to the County's development and infrastructure." (Recommendations 2008). The rational provided for this recommendation is to obtain higher resolution elevation data to determine vulnerability to infrastructure, roadway elements, the susceptibility of coastal, wetland, and artificial fill areas to erosion, areas of potential pollution and contamination release, changing drainage and storm surge risks, assess structural viability of buildings and levees with changing groundwater levels and saline water intrusion, and assess future fresh potable water sources.

${ }^{5}$ One scientist shared that there was opposition within the local government to create those maps, as expressed: "And there was a commissioner... that made sure those maps never appeared." In response to the County's reluctance one FIU scientist used the State's LiDAR data to produce and share maps showing inundation across the county up to 12 feet of sea level rise (Harlem 2008). Several people shared that the scientist's maps strongly influenced public opinion on sea level rise and resulted in more action and awareness, particularly in the environmental community for calling for GHG emissions reduction, concerns over sea level rise risks to a nuclear power plant, and natural systems restoration and protection. And while by 2010 , the county did update a digital elevation model using 2003 LiDAR data, they were not made publicly available.

${ }^{6}$ The bathtub approach consists of overlaying current high-tide levels and different increments of sea level rise on existing water and elevation maps, simulated by intersecting the land surface with a water surface that includes the added water of a given sea level rise scenario linearly superimposed over the baseline reference ( 0 -ft sea level rise tidal water surface).
} 
the limitations of bathtub modeling because it assumes that land geomorphology, tidal surface variability and other conditions remain constant as the landscape is "inundated", and it does not consider additional hydrodynamic effects during storm surges. For example, though they show future conditions of sea level rise projections, bathtub models fail to account for land use changes, higher groundwater levels, coastal barrier island migration, changes in sedimentation rates and deposition patterns, changes in tidal hydraulics due to land geomorphology changes and physical barriers, and other weather/ocean factors (e.g. storm surge, wave activity and anomalous events) (Vulnerability Assessment 2012; NOAA CSC August 2010b; NOAA NOS September 2010).

Based on these limitations, several managers shared that the bathtub modeling completed for the first sea level rise vulnerability assessment for the Compact, underrepresented the risk and pointed to known areas of flood complaints that were not showing up as flooded in assessment. One modeler associated these complaint areas with older housing stock, in an area considered higher elevation but that still floods due to precipitation, land use, and other factors. Shortly following the Compacts initial vulnerability assessments in 2012 different modelers from county government, City of Miami Beach, agencies and others began expanding their practices to ameliorate bathtub model limitations. Both Miami-Dade County and the City of Miami Beach, are working on dynamic groundwater/surface water model and well monitoring to address this uncertainty. For Miami-Dade County, this took place with a plan to integrate sea level rise into updates to the Stormwater Master Plan as well as modeling in the Water and Sewer Department. 
Within the county, part of this focus on groundwater came from a top-down mandate from the South Florida Water Management District, an agency that oversees water resources in the region. When the county sought to increase their municipal water supply to allow for more regional growth through additional drawdown of the Biscayne Aquifer, the South Florida Water Management District required the county to prove this would not impact canal water (i.e. surface water) and water flow in the region (assessment published in Hughes and White 2016). The county applied this groundwater and surface water model to sea level rise bathtub models and more locations became flooded based on this additional information. While county stormwater and water and sewer managers utilize modeling that incorporates this model of groundwater and surface water interactions, getting these updated maps in the county's comprehensive land use plan to inform land use policies, building codes, and published for the public to view has been an ongoing challenge. As one interviewee shared,

So the problem is, is that some internal departments aren't comfortable with releasing information, because it could be wrong. And because ... so, part of it's really valid, in that... so when you do the bathtub model, you inundate the coast. But that's underestimating the risk, because our ground water also rises, and there will be areas on the west, and on the canals, and then the south, that also are soggy. They're like, the ground water's so high that basically, they're not that livable. So when you do just the coastal bathtub model, you miss this other component. So from, like, a very valid science perspective, they say like "You know, that's not really a great map, cause you're missing these other pieces"...

But then what we have is just different departments that are in charge of different things, and seaming those together is difficult. And then, truth be told, there are people within the department that are deniers, that don't want to publish this information... even the bathtub one. And so, they use all their excuses to say why we can't publish it, and it's confusing to everybody, and no one understand why... really it's a moot point. [Other] maps are publicly available, you know, they're on TV, they're in the news, it's whatever. But we haven't been able to get all of the departments to 
agree on, sort of our uniform... like, what we want to present [the bathtub model]... Which is, again, it's gonna underestimate the risk. But you gotta start somewhere. [Others] may object to our map. But, you know, we've gotta start somewhere.

One of the primary concerns for publishing comprehensive maps that show the full extent of where sea level rise inundation may occur is connected to the risk of these sea level rise maps devaluing property. As one informant shared, "The real fear, from one person, is that providing this information we may devalue homes, it may devalue property by releasing this information." While the threat of devaluing land is at the core, this gets wrapped up in debates over other uncertainties of mapping, as another informant shared,

The problem is, is that you can't really map out into the future. Because... so let's just take for example, we go to 2060, we've two more feet of water. So then we could do, okay, well if the sea is this much higher than the ground level will be this much higher, but then that's assuming that the canals are operating the same way. But they'll be flowing... they won't be flowing anymore, to the sea, and so that's not really a valid assumption. So then what do you map for 2060? Depends on what the district does, and how they manage the system, and... so it loses, sort of, meaning as you go out that far.

While there is no local government produced map that is publicly available map that shows where inundation from sea level rise might occur given ground water and surface water dynamic modeling, the county does present a map using bath tub modeling (Figure 5.3). In this online interactive map made in partnership with NOAA and the county, areas in blue are considered hydrologically connected, either by the coastline or the canal system, whereas areas in green are low-lying areas in relation to a 3-foot mark of sea level rise, but not considered hydrologically connected using the bath tub modeling approach. The green areas on this map represent much of the regions that several 
interviewees were concerned are not being addressed in current sea level rise assessments. 


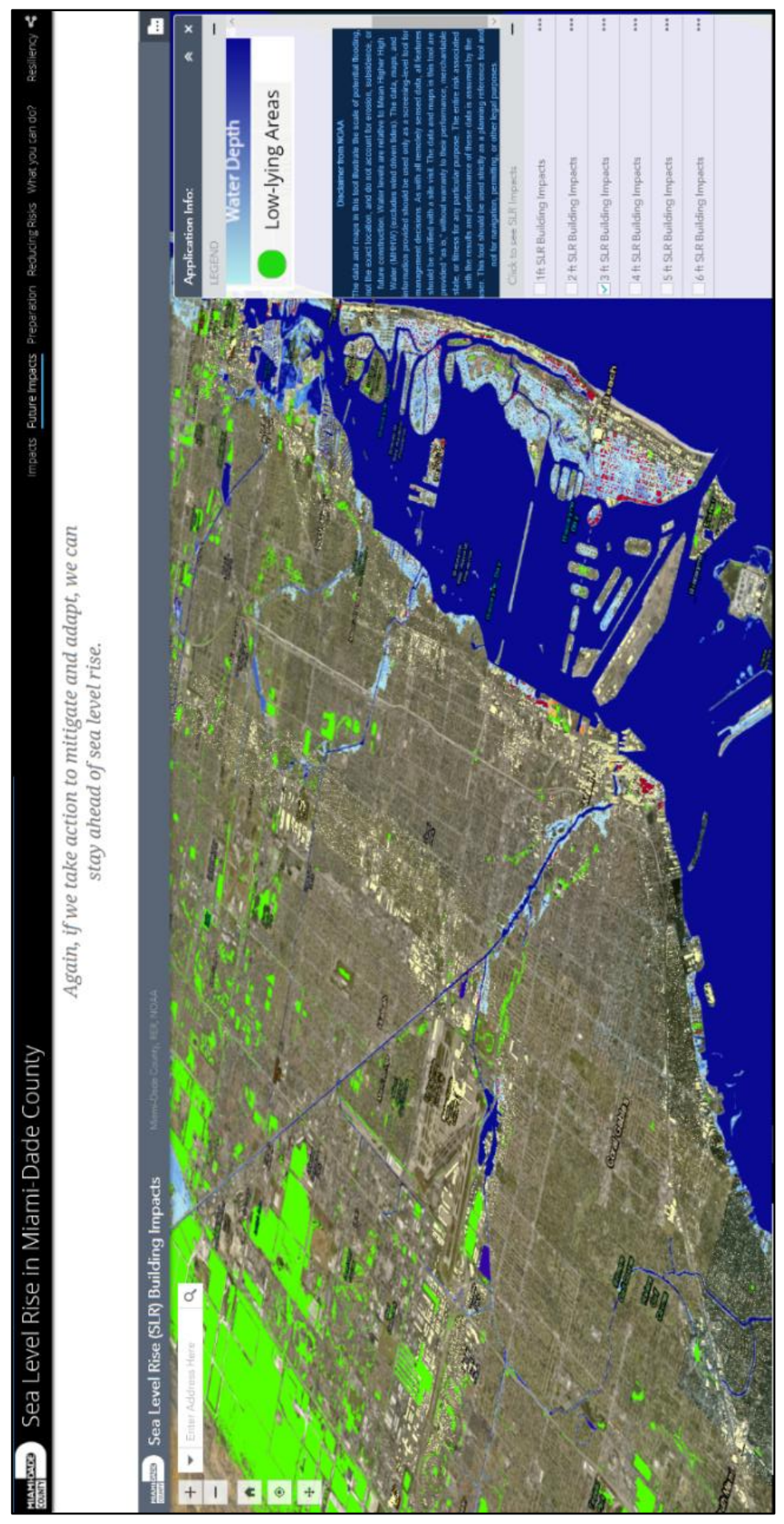

Figure 5.4 Map of sea level rise impacts, created by Miami-Dade County: Miami-Dade County created this map adapted from NOAA's Sea Level Rise Viewer, Miami-Dade County shares a map of possible sea level rise inundation based on bath tub model and elevation. Areas in blue are considered possible sea level rise inundation regions based on hydrologic connectivity of coastlines and canals. Ground water surface water dynamic modeling is not included, but the green areas represent low elevation regions (below 3 -feet). 
To lessen the risk of economic impacts to the region, many interviewees discussed the need to support projects that will help keep insurance costs down and protect continued investment in the region. Several planners and interviewees shared efforts designed to "get ahead of the issue" of risk from sea level rise by focusing on infrastructure vulnerability and adaptation solutions. Because local governments are responsible for supporting infrastructure the link between infrastructure vulnerability and property is not surprising. In 2012, the Compact was one of the first organizations to publish a vulnerability assessment, publishing "Analysis of the Vulnerability of Southeast Florida to Sea Level Rise"'. The physical features identified for vulnerability include: ports and airports, railroads, miles of road, water and wastewater treatment plants, landfills, hospitals, schools, emergency shelters, evacuation routes, and marine facilities. In addition, analysis was conducted to determine taxable value of property ${ }^{8}$, acres of future land use, and acres by habitat type/land use that would be impacted by sea level rise. The link between infrastructure and property values is underscored by vulnerability assessments that emphasize property values as a driving force to measure risk in the region. Part of this is shaped by the need to maintain local property taxes to support infrastructure upgrades, and another component of this is driven by external policies,

\footnotetext{
${ }^{7}$ This document used 1,2, and 3-foot sea level rise scenarios and a bathtub model to identify where sea level rise would intersect with infrastructure. The Compact facilitated discussions and used surveys and workshops to develop planning parameters that would be part of the regional sea level rise vulnerability assessment. While this assessment was based on land and sea elevations only and does not consider flooding related to existing drainage issues, associated with rain or tropical storm surge, they suggest that additional analysis and more sophisticated models is needed to better understand the hydrologic connections and surface water response to rising sea levels

${ }^{8}$ When putting together this report, Miami-Dade County would not include property value information. It was shared by several interviewees that this was because bathtub modeling underrepresented the risks, other interviewees expressed that there may have been internal pushback within the county to not want to publish those maps to scare developers.
} 
development investments, and insurance priorities. The emphasis gets placed on design standards and building codes around how the region builds, without discussions of where growth should happen. As one insurance expert shared,

[Building standards] are not a bad thing to discuss. My quibble would be that it's the only thing we discuss, and that's the problem. The analogy in coastal management from my perspective is... and resilience in the built environment, is that we spend all this time talking about how we build. The sacred cow, or the elephant in the room, whatever you want to call it, is that we will not discuss where we build. That's the real problem. It's not just how, and that's because legally, it's really easy to just keep increasing building standards. Comparatively speaking, I mean, sure you get pushed back from the building industry, but that's nothing compared to the property rights implications of starting to look at serious, where we build.

The importance of property value as a proxy for vulnerability shows up in assessments that address socio-economic conditions. For example, the "Sea level Rise and Health Vulnerability Assessment" published in 2016 provides another example of how the focus of risk knowledge is underscored by physical and economic conditions. This planning document, produced by the Florida Institute for Health Innovation used bath tub modeling, state LiDAR, and socio-demographic data to measure vulnerability to sea level rise from a public health perspective. This technical, expert driven assessment looked at vulnerability and income in two, competing ways. It addressed low-income communities of color as socio-economically vulnerable, while at the same time factored property values into the assessment — where high-valued assets on the landscape are considered more vulnerable. The assessment found that low-income communities of color are less vulnerable to sea level rise than high income areas, because those communities are at higher elevations. Similar logic was used by several interviewees that acknowledged low-income communities and historically marginalized communities of 
color will experience impacts from sea level rise based on their socio-economic status, but that these impacts are no different or less so than those experienced by wealthier communities, because wealthy communities have financial assets at risk. Community organizations contest this idea and contend that low-income and marginalized minority populations are at greater risk of displacement from climate gentrification, storm surge and hurricane events, and public health and economic impacts of climate change. Yet, aside from limited assessments being conducted by academic institutions, the risks these organizations are concerned about are largely un-recognized in formalized risk assessments used for planning purposes.

It could be argued that socio-economic vulnerability should be examined on a more local scale, during project specific planning and design. Several planners shared that it is more appropriate to consider social factors in the hyper-local scale that they exist. In this way, socio-economic vulnerabilities are considered during pilot case studies and design charrettes. In the Arch Creek Adaptation Action Area design charrette organized in partnership with the Compact in 2016, for example, Census block data is used to look at poverty rates (see Figure 5.4). Yet this and other design charrettes serve as pilot assessments and have been completed with little involvement of local communities and assessing other information related to priorities and risk understandings experienced by those within these communities. Instead, a limited number of stakeholders and experts examine things like municipal codes, ecological functions, planning tools, and infrastructure projects that could be used in this region. What we see are contradictions surrounding how some planners view integrating communities — including socioeconomically marginalized communities - into planning. On the one hand, interviewees 
shared the importance of this when it comes to developing comprehensive plans, and on the other hand, some of these same planners expressed that it may not be appropriate for the public to comment specific technological roles of governing infrastructure, such as stormwater management planning.

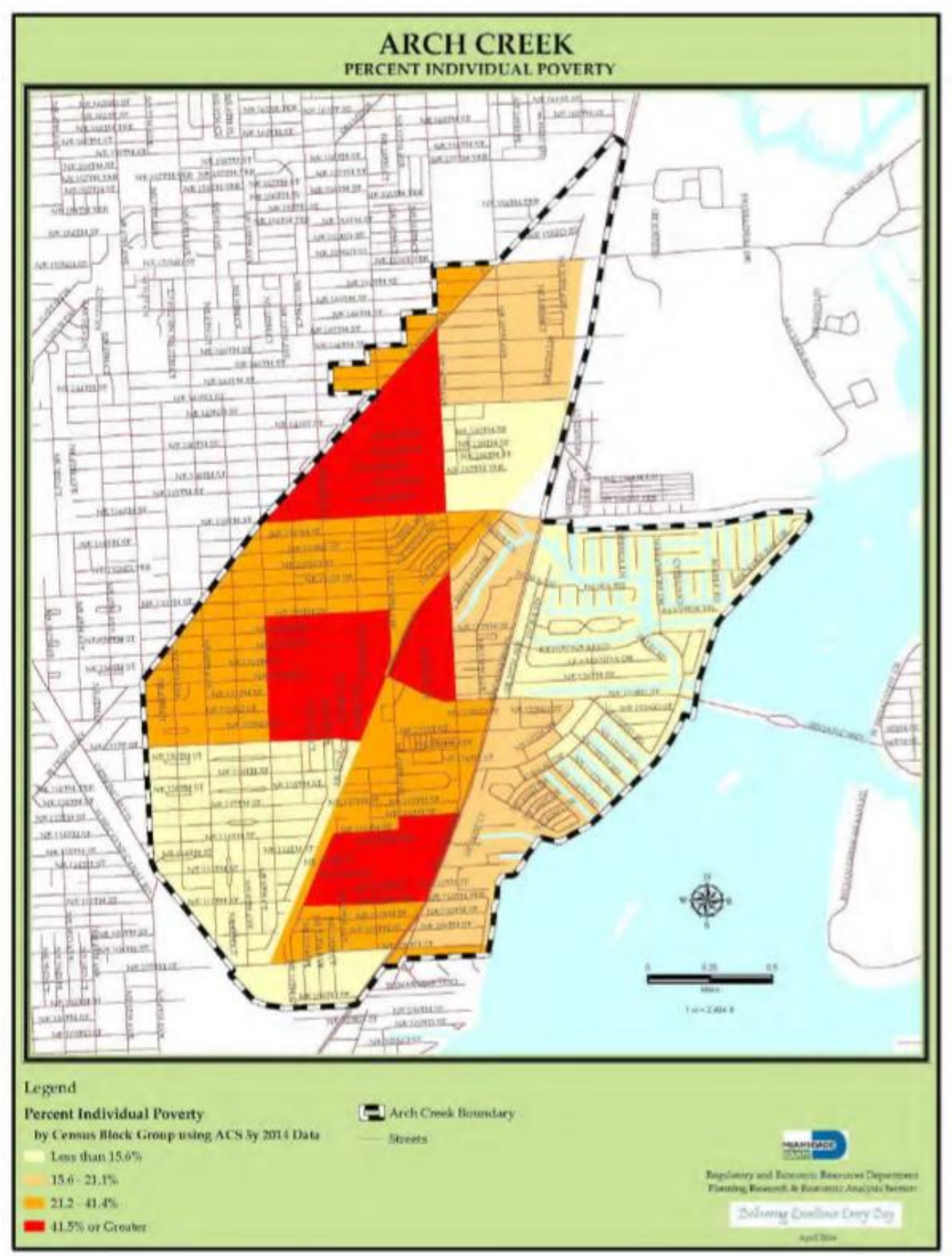

Figure 5.5 Map of percentage of individual poverty for Arch Creek project: Included in assessments for Arch Creek Adaptation Action Area design charrette in addition to other sources of information around stormwater, sea level rise inundation, and planning and zoning. The design charrettes are often pilot studies and done in a short period of time with little community involvement. 
While issues of poverty, public health statistics, and other formal assessments can tell part of the story of socio-economic vulnerability, they fail to capture the diverse ways in which those communities themselves frame the problem. For example, many community organizers brought up their concern over climate gentrification, where they are experiencing developers coming into their high elevation communities and purchasing property. While community members shared they were discussing this issue for over a year prior, it was in 2017 when geographer Dr. Hugh Gladwin was attending a community organized listening session that they came up with the idea to produce a map that shows which developers have been purchasing land in high elevation areas (see Figure 5.5 for the map). Despite community organizing around issues of gentrification and other issues related to climate change vulnerabilities, these concerns are poorly integrated into formal planning efforts. Some planners questioned whether climate gentrification was really because of sea level rise or if it was just "normal" gentrification. At the same time, many of these high elevation areas are frequently discussed by local government planners as areas to promote growth because they are less vulnerable to sea level rise, running counter to concerns from people in those communities about displacement. 


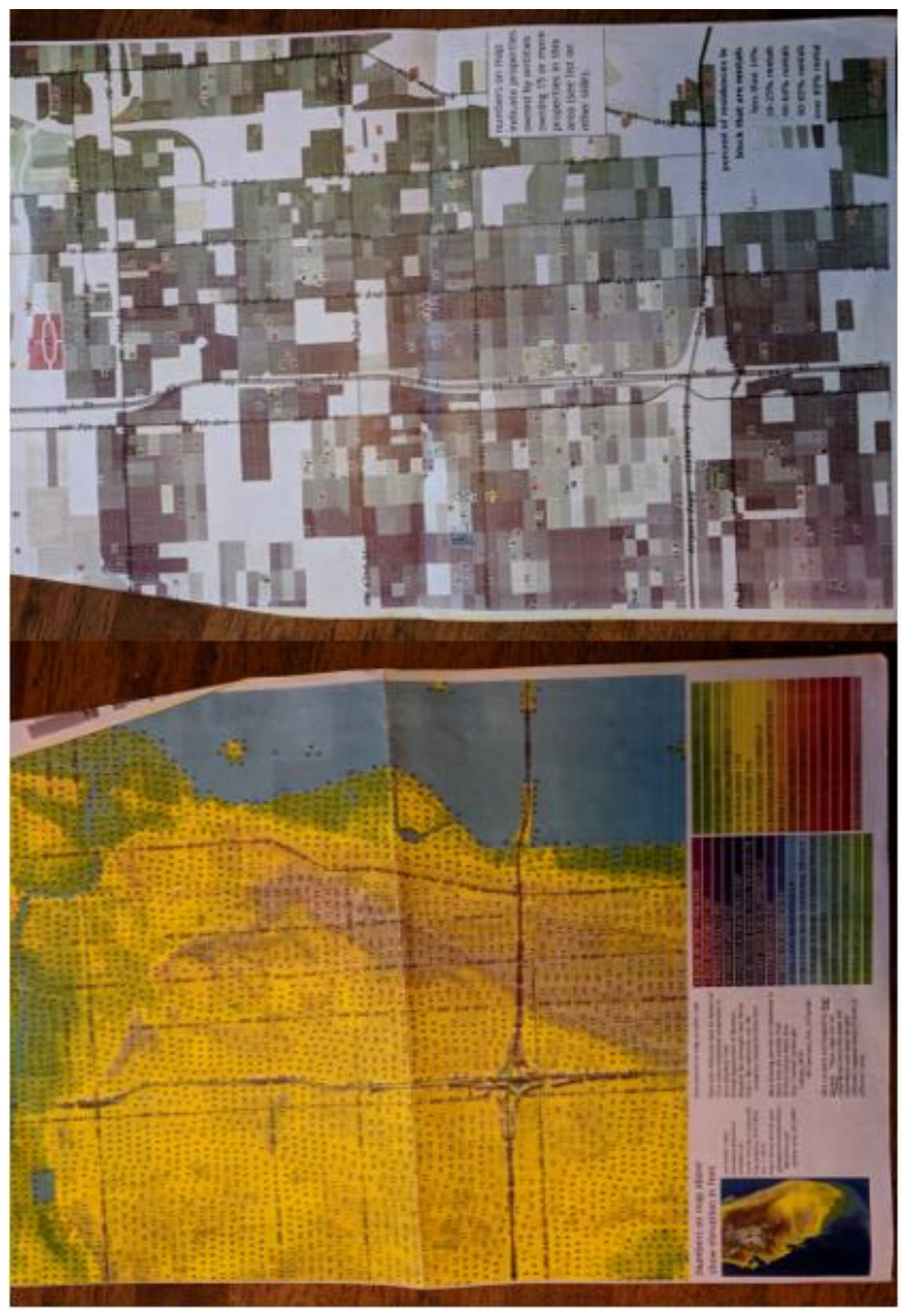

Figure 5.6 Map created by Dr. Hugh Gladwin with community organizers to show climate gentrification in high elevation neighborhoods in Miami-Dade County, Florida. The image on the left shows elevation and the image on the right shows where parcels have recently been sold and the developer and/or bank they were sold to. 
In addition to minimizing knowledge from socio-economically marginalized communities, risk knowledge that runs counter to an economically viable future, or that points to issues and concerns about the way in which risks are being measured and addressed were marginalized and often ignored in the planning process. For example, many community and environmental organizations discussed the political inertia towards addressing sea level rise with the nuclear power plant owned by Florida Power and Light. As one interviewee suggested,

The Florida Power and Light [are] persisting in the myth that their power plant won't be affected by sea level rise, and that they've got a plan to deal with two feet of sea level rise and it's what they're counting on.

This private sector sea level rise knowledge avoidance persisted in attitudes towards the development community and real estate community. Policies and regulations often fail to integrate sea level rise and thus shape the conversation away from regional economies.

For example, when discussing the challenge of getting realtors on board with understanding and sharing sea level rise risks, one interviewee shared,

And then, in real estate... regard to flooding has a don't ask, don't tell policy, so their standard of conduct for the realtors is don't ask, don't tell. So, if the realtor did not see the flooding, they have no obligation themselves to tell a buyer about tidal flooding. All they have to do is say, "Here's the FEMA flood map. Find your home. Figure out where you are. Have a nice life. Buy it, don't buy it, whatever." But, they have no obligation because the sea level rise flooding is not covered by FEMA maps, and I'll admit, the realtors know about it because they're not stupid. And they drive their cars through seawater, and they're going like, "I never saw that property flood. Never." Of course, they didn't go there in September, October, November when it was flooding.

And while private sector avoiding the issue of risk due to financial strain is not entirely surprising, in some cases, environmental and community organizations challenge the way that risks are understood and addressed in infrastructure adaptation planning. 
Several environmental organizations express concerns over the county's proposed adaptation to use inland injection sites that send treated wastewater to an area below the Floridian aquifer in the boulder zone, including uncertainty from taking water out of the water cycle and the impacts the treated wastewater will have on the aquifer. As one informant expressed their concerns,

It's taking hundreds of billions of gallons of water out of the water cycle and putting it into a hole, which I think is not sustainable. It's also a somewhat untested technology. What's going to happen to that water down there? Is it just going to stay down there forever? Is it going to migrate, is it going to contaminate the aquifer, is it going to create a methane bubble and become anoxic? It's becoming more and more clear that, particularly in Miami, where we have porous limestone, things are not very well contained underground... There are fissures even into the boulders now that we don't even know about.

Additionally, some interviewees expressed uncertainty around stormwater pumps installed in the City of Miami Beach, and that they create more concentrated pollution into the waterway. As expressed by one individual:

Well, it has been effective in short term lowering of the water in the streets. The downside of it is that the stuff is pumped into the bay without any real treatment. They might strain out a few chunks or something like that, but it's... So, North Biscayne Bay sea grasses are dying off, and it probably relates to turbidity in the bay, and it started to happen about the same time that the pumps were turned on. That's not proof that that's the case but... It's an observation, and one of the obvious candidates. Florida International University did measurements of the nutrient loading in the plumes of stuff going into the bay, and the mayor of Miami Beach, Levine, was outraged because they were finding there were some problems with the amount of nutrients, and so, instead of working with them, basically a politician often attacks the messenger. ${ }^{9}$

\footnotetext{
${ }^{9}$ In response to this testing and community pushback, the City of Miami Beach is now testing different methods to treat stormwater at these pump sites.
} 
And community organizations question whether the focus on infrastructure is ignoring the people that rely on that infrastructure and call for other adaptation approaches to support low-income and historically marginalized communities. Knowledge that addresses several ecological and social components of sea level rise risks remains as negative knowledge, and "undone science" while knowledge about sea level rise impacts transportation, wastewater, water treatment, and stormwater take priority.

\subsection{Prioritization and the Creation of Vulnerability and Adaptive Capacity}

The way that risk knowledge is constructed is connected to adaptation project selection and prioritization. In Miami-Dade County the production of knowledge about biophysical hazards shaped by economic and political values leads to a path dependency around knowledge and decision-making and creates a system in which some communities gain more attention and adaptation solutions, over others. During interviews, planners focused on two types of decisions related to vulnerability (primarily of infrastructure) that they make and how they use sea level rise risk knowledge to make those decisions which reinforce this finding. The first type of decision is where to invest in adaptations, and the second type of decision is how to integrate sea level rise projections into the infrastructure adaptation designs.

Currently, planners within Miami-Dade County and city governments are working towards developing different criteria for determining where to invest. Several managers reported how difficult adaptation decisions are to make. One stormwater manager commented,

There are some difficult decisions to make in that, [we] had this vision of like are there neighborhoods that we leave as is and we let them flood. Are there neighborhoods we protect? Well if you make a decision like that, 
how do you do that? How do you make a decision that this neighborhood is going to get protected, this one is not? Kind of developing that criteria like well is it about severity of that risk or potential vulnerability.

Much of this is already established in policies around flooding and stormwater management. For example, the South Florida Water Management District holds the most authority over flood control and water infrastructure management in the region. In analyzing the risk associated with sea level rise they apply formulas for storage capacity based on level of service which inherently prioritizes dense urban areas over rural regions in the southern portion of the county. Similarly, though the NFIP does not consider future sea level rise conditions in modeling, it determines a lot of how the region understands and addresses current risks and is connected to prioritization. Stormwater management and prioritizing projects is based on a combination of modeling components (NOAA Historical High Tide Data, the groundwater table, existing land use, elevation data, and different flood event data), FEMA insurance claims, and complaints. The county, for example, prioritizes drainage capital improvement projects in areas with most repetitive losses, flood complaints, and low-lying areas, with flood protection levels of service (integrating sea level rise projections) below the threshold identified in the Comprehensive Development Master Plan. Because many shared that insurance rates are a major concern for homeowners, the focus of mitigating risk is related to projects that can reduce insurance costs for homeowners. Much of this takes place using flood risk management activities that are included in FEMA's Community Benefits Rating System. In this way, FEMA flood insurance and local government actions that address those risks are building people into more risk. At the same time, the local governments have no real information around how flood insurance rates or not having flood insurance impacts low 
income and historically marginalized communities — who tend to live in older houses that may not require insurance. Despite these challenges around insurance, it still drives a lot of the focus and attention for how sea level rise adaptation planning is taking shape. As one interviewee shared,

Well, it's all about insurance at the end of the day. There's two main users, insurance and then the local flood plan administrators are the guys who are really using it to then mitigate disasters and risks. But the insurance drives a lot of the conversation with the homeowners. Homeowners aren't concerned with mitigating risk, they're concerned with, what am I paying. Just bottom line. And so the insurance drives a large part of that.

And while several planners discuss the need to create objective approaches to avoid favoring some regions over others, several of these same planners shared how the outcomes of these efforts favor those who have flood insurance - which are primarily in low-lying coastal areas that also represent more affluent parts of the county. Nearly all informants expressed that areas like Miami Beach and other affluent communities will have the most resources available for adaptation and protecting infrastructure. Beach renourishment, for example, is funded in part by the USACE, the State of Florida, and local municipalities and several people expressed that Miami Beach receives the most funding for this, as expressed by one planner:

They [Miami Beach] get lots of funding for beach re-nourishment projects which are helpful to sea level rise. But in some of those areas like Miami River and some of those back areas, they're not going to get any funding to do anything on theirs. So they're just going to be more susceptible to the sea level rise... Anywhere that doesn't have a beach and tourist dollars, is probably in trouble.

From the USACE's perspective, the purpose of beach re-nourishment is to protect building structures and prioritizing funding is based on exposure and cost benefit analysis 
of property values and number of human lives, again favoring low-elevation, densely crowded and high-property value regions.

In addition to differences in external funding sources and prioritization, there are also differences in internal funding and tax base to support adaptations. Floodplain administrators for small and under-resourced cities and municipalities may lack the ability to influence planning decisions, shaping how risks are distributed across the landscape. As one planner shared,

Most [Floodplain administrators] have a very challenging job. Because [Miami-Dade County] obviously has a lot of resources and we go down to many of these other communities they have one person and they're also doing whatever. Ten other jobs, and so it's a very small piece of their job. So imagine if you had something like this [flood map] and you wanted the community to be more resilient in the coastal areas, so you said hey to your board of commissioners, hey we really need to change our code to enforce this. And she's a little nobody down in the middle of some organization. The board is going to be listening to all their developer friends and anybody else that wants to develop in those areas and doesn't want those stricter regulations and so they're going to fight it. She has an uphill battle to even convince her board of county commissioners that this is a good thing.

Both current and future loss of property values becomes one of the key ways risk is understood and in adaptation planning. When discussing wastewater treatment and hooking septic systems up to the sewer system as a sea level rise adaptation, one interviewee shared that it is a difficult decision because some of the areas on septic systems are low elevation areas that may not be ideal for development because of sea level rise impacts. So, the question is whether or not it makes sense to invest in those areas that may be abandoned in the future. In this way, infrastructure vulnerability gets caught up in debates and decisions regarding the economic and social values across the region, in determining what is and what is not worth investing. As one insurance industry 
expert shared, "The way we fund government is part of what's driving how our

organizations see risk. Because for local governments, their property value is what they

need to operate." Informant interviews corroborated this with their emphasis on needing

to protect the economic core to fund future adaptation efforts. As one interviewee shared,

Well, the city and the area around Little River and Shorecrest, they were talking about basically allowing the areas that are low to flood and become more marsh like, and, just accept the water coming on to the land. Well, my own personal feeling is that the water front areas are the high value areas and they are the economic drivers that would finance the changes that we need to make, so we need to... For example, if you go to Fort Lauderdale and you drive around, you'll notice that there are a lot of big yachts and so forth that are up there next to very opulent water front homes that are on top of fill pads, and basically if you made the North Bay more accessible to upscale yachts, then it would be possible to raise the money to elevate the bridges, to do the... Whatever is necessary.

Another reason people suggested prioritizing areas that are high property value is that wealthier people can afford adaptation strategies on their property. While at the same time, others expressed the challenge with aiding lower-income communities with addressing the risk of sea level rise. This is wrapped up in who's responsible for adapting private property, as one respondent shared,

So that's one of the big challenges, is that... rightfully so, people say we should focus on the most vulnerable areas, and we should focus on the most socially vulnerable areas, these, sort of, economically vulnerable areas, which makes sense. But then, again, when you get into those communities, what is the solution? The solution, in Florida, is that you have to elevate your homes, and you have to elevate the roadways, and you need to connect the septic systems to sewer, and those are expensive... So then, if you take no action, you get into a blighted condition, or exacerbating the housing disparity.

In line with what this individual shared, several other interviewees recognize that socioeconomic conditions can shape peoples' experience of climate risks. At the same time, many interviewees across sectors expressed concern that these communities will be 
ignored in the planning process. As one person shared regarding how adaptation planning

will take place within low-income communities,

They are not even gonna talk to those people. They're gonna ignore them, and the developers are gonna develop. That's how it works... it's gonna be business as usual. It's [sea level rise] playing a... It's a big forcing function, and so it's stimulating people to move, and so the relocation, there are plans for big buildings in the Overtown area. Maybe they haven't been put out in public yet, but I'm sure... I've been in some of the climate marches, and those people are marching. They're literally beating the drum about this... I haven't talked to the development side about it, it's mostly either outside of town money. Miami is a speculator's paradise, always has been.

And part of this is linked to the way in which vulnerability is understood, when discussing one key vulnerability assessment being created for county planning an interviewee shared, "Purely economic." Planning documents use inundation maps of sea level rise combined with property value and demonstrate the estimated costs of sea level rise to these assets. This takes place in diverse ways including, beach re-nourishment programs focused on protecting coastal properties, the attention to building codes and developing differently.

Yeah, they [different committees] seem to be sort of fixated on building code changes, and asking for money to get surveys, or risk assessments, or experts, or things like that. That has been slow in coming.

However, this same individual elaborated on the challenge of focusing on building codes and other economic priorities in that it can shift attention away from things that the region could be doing now, for example, fixing sewer overflow and investing in green infrastructure.

It's very slow and difficult to get changes to the building code. It takes years. The City of Miami just did this Miami 21... new building codes. They don't cover resiliency but they're more modern than they were before. And then Miami is a very developer driven town economically, 
and so adding additional burdens onto developers for doing things with sea level rise in mind is slow going. Because it's going to cost them more money to build their buildings differently, or elevate them, or so on and so forth. Because right now most of the costs are pushing on people who are buying apartments and things like that, because developers sort of engage for three to five years, and then they sell them.

[Things we could be doing instead of focusing on building codes and infrastructure] Holding up the dune infrastructure, restoring mangrove habitat. New infrastructure needs to be built with sea level rise in mind. Stormwater master plans. Making sure that there are storm water master plans, that the water can percolate, that there are enough impervious surfaces around that we have areas that can flood. That the sewage infrastructure is well maintained so that it doesn't flood when it rains.

Other interviewees expressed their frustration with calls to spend $\$ 100,000$ for high resolution studies to create a fine detail elevation map of downtown Miami. While proponents argue that this will help the city better understand where to invest in stormwater management and change building codes, several respondents expressed that those funds could instead be used to support socio-economically vulnerable communities to prepare for hurricanes.

In addition to decisions around where to adapt there, planners shared approaches for how to integrate sea level rise projections into adaptation strategies. The concept of "design life" has been used and integrated into water and sewer infrastructure planning and discussed widely among different institutions governing infrastructure. When designing infrastructure projects, the projection used is based on the length of the useful life of infrastructure and the cost of that infrastructure upgrade. The risk that is embedded in talking about "design-life" are the risks of the physical impacts from sea level rise, the risk of the infrastructure failing and causing harm to property values and human life, as well as the risk of the investment of the infrastructure falling short of meeting its goal. 
For example, wastewater treatment infrastructure that both costs a lot and has a long useful life would adopt the sea level rise curve showing a higher rate of projection for the year that the infrastructure would be expected to be used for. This is compared to infrastructure that may only have a useful life of 20-30 years and not cost as much, which would be designed for one of the more conservative projections at 20-30 years in the future. Many of the reports on infrastructure suggest or explicitly recommend a cost benefit analysis or optimization for prioritizing and designing projects.

Ultimately, the way local governments portray information around sea level rise risks shows us how they are choosing to "get ahead" of the issue and construct risk in the planning process. Despite individual efforts among some planners, community organizers, and scientists to address socio-economic and broader ecological risks around how sea level rise will be experienced, these areas of vulnerability have been somewhat ignored to different degrees. On the one hand, issues such as socio-economic vulnerabilities are brought up during design charrettes, while on the other hand, they are left out of local government information surrounding impacts from sea level rise (see Figure 5.6). 


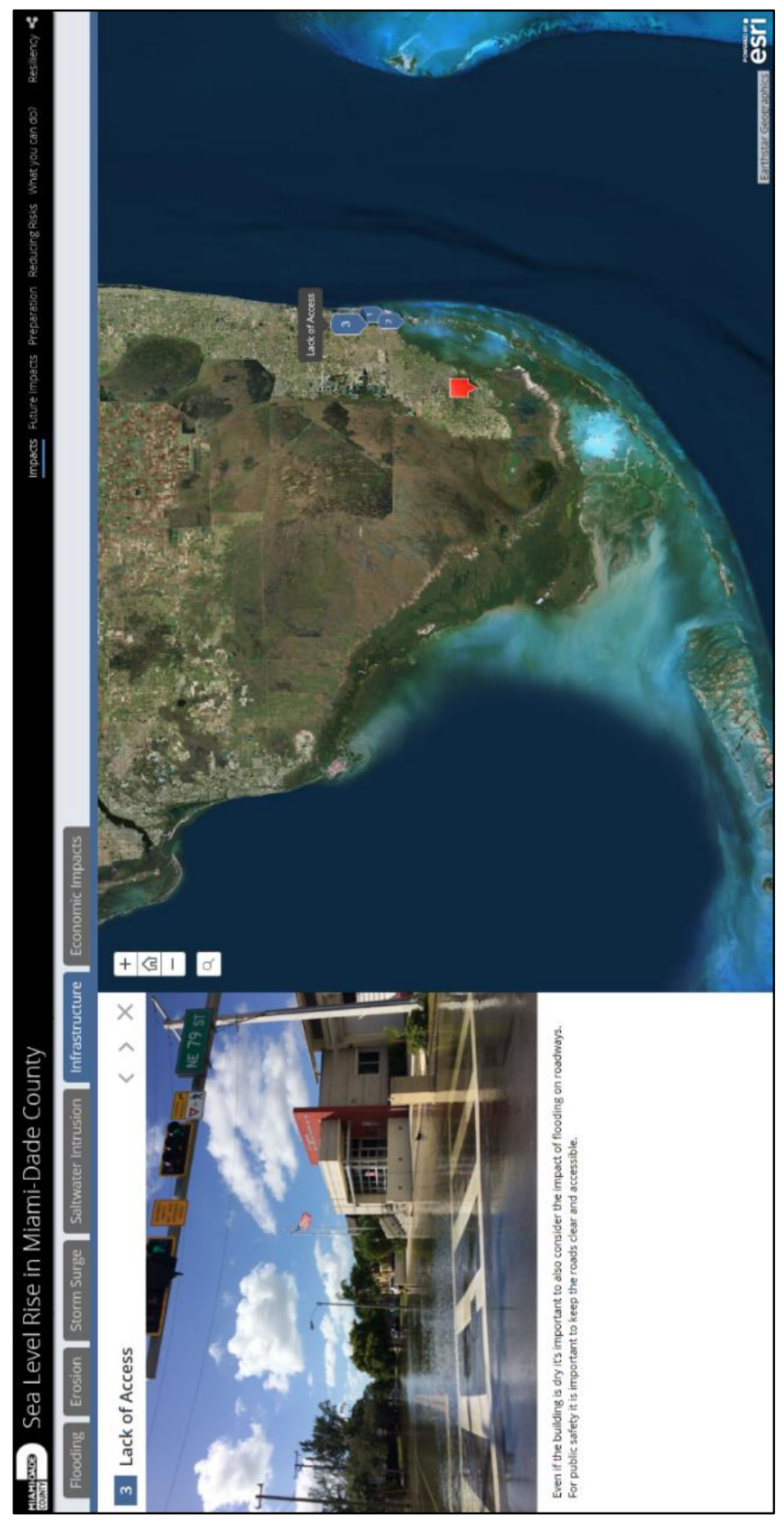

Figure 5.7 Image of sea level rise impacts from Miami-Dade County's website: Represents how most municipal governments frame the issue of sea level rise risks and adaptation strategies. While some planners shared the need to integrate socio-economic vulnerabilities into planning, representations of the risk fall short of integrating those considerations. Here we see the emphasis is on flooding, erosion, storm sure, saltwater intrusion, infrastructure and economic impacts. Economic impacts emphasis property loss, insurance costs, and business interruption, not vulnerability from socio-economic marginalization. 


\subsection{Discussion}

Sea level rise adaptation planning in Miami-Dade County is predicated in identifying objective facts and hazards about sea level rise rates and projections as well as knowledge about the hydrogeology of where water will flow, and how this will interact with the built environment. Bocking (2004) argues that regions focus on physical aspects and scientific assessments of risks and hazards in order to wrap decisions in the authority of science and avoid choices that would be deemed arbitrary and capricious. While identifying sea level rise risks, including anticipated projections and measurements is fundamental to planning, Carlo Jaeger et al. (2001, p. 24) summarize a common view of measuring risk, “Approaches for objectively quantifying risk, actuarial analysis, probabilistic risk assessment, and epidemiology/toxicology all assume that risks can be assigned a value of harmfulness independent of the social, economic, political, or cultural context." Bocking (2004) elaborates on this drawing out common assumptions of risk in environmental planning. First, that risks are an objective property of the physical world and therefore freely amenable to measurement. Second, that people everywhere perceive hazards the same way, and third, that this can be revealed by science which override historical and cultural differences (Bocking 2004). Like the work of Bocking (2004), and other scholars who challenge these assumptions (e.g. Perrow 1984; Liftin 1994; Jasanoff and Long Martello 2004), the process of determining sea level rise hazards in MiamiDade County is shaped by political, social, and economic contexts. While actors within Miami-Dade County are driven towards identifying a sea level rise projection that represents "objective truth," given uncertainties around climate change and sea level rise projections these same actors recognize the complexity and challenges of identifying 
those risks. The presence of deliberative, science and policy panels to determine what sea level rise projections to adopt for the region demonstrates the recognition of this complexity, as does the decision to officially include three projections (Figure 4.2). At the same time, however, this case study shows how political processes shaped what sea level rise projection knowledge was accepted and what knowledge was discarded, demonstrating how sea level rise rates and projections are shaped by political debates surrounding relevant science and processes, which are enrolled to justify minimizing risks at the local scale (summarized on Figure 5.7).

\begin{tabular}{lll}
\multicolumn{1}{c}{$\begin{array}{c}\text { Rates and } \\
\text { Projections }\end{array}$} & \multicolumn{1}{c}{$\begin{array}{c}\text { Physical } \\
\text { Landscape }\end{array}$} \\
$\begin{array}{l}\text { Adoption of more conservative } \\
\text { projections are shaped by scientific } \\
\text { and political uncertainty and } \\
\text { climate change denialism. }\end{array}$ & $\begin{array}{l}\text { Knowledge that threatens } \\
\text { economically viable future is } \\
\text { discarded, while knowledge that } \\
\text { protects that future is favored. }\end{array}$ & $\begin{array}{l}\text { Emphasis on affluent coastal } \\
\text { communities reinforced via } \\
\text { intersection of hazards with social, } \\
\text { ecological, and techno system. }\end{array}$
\end{tabular}

Figure 5.8 Construction of risk knowledge in sea level rise adaptation planning in Miami-Dade County, Florida

To this point, Gross's (2010) theory on the link between nonknowledge and newknowledge, as well as negative knowledge (or avoided and ignored knowledge), can be used to explain path dependencies around risk knowledge practices in Miami-Dade County (summarized on Table 5.1). For example, interviewees shared that there are disagreements as to how ice melt acceleration factors into sea level rise rates and how water moves through physical geographies. On the surface, these disagreements appear to be about relevant science, yet findings from this case study show how debates around science are enrolled to control and shape risk knowledge is to protect the regional economy. The focus on the economy (and by proxy infrastructure that supports that 
economy), continues to put pressure on identifying additional and more detailed risk measurements. For example, the emphasis placed on high-resolution elevation and LiDAR data to understand where risks will be at a finer resolution. Within each of the type of risk knowledge there is a cadre of actors and institutional structures that prioritize some risk knowledge over others. While this process is expected, it also leaves out other potential risks (expressed as negative risk knowledge), and instead can build a path dependency around nonknowledge, new knowledge, and feeding back into new ignorance. Many scholars discuss the importance of paying attention to the agglomeration of uncertainties when climate models are compiled. Those uncertainties are often only expressed in scientific terms of findings and associated uncertainties and without consideration of how the process of framing those uncertainties can exclude some risks from the planning process. But we also need to pay attention to the way in which those uncertainties are socially determined. 
Table 5.1 Risk construction summary table. The findings examine what knowledge uncertainties are prioritized for further exploration and what knowledge uncertainties are ignored.

\begin{tabular}{|c|c|c|c|}
\hline $\begin{array}{l}\text { Dimension of } \\
\text { Risk } \\
\text { Construction }\end{array}$ & Description & $\begin{array}{l}\text { Explored Knowledge } \\
\text { Uncertainties and New } \\
\text { Knowledge }\end{array}$ & $\begin{array}{l}\text { Ignored Knowledge } \\
\text { Uncertainties }\end{array}$ \\
\hline $\begin{array}{l}\text { Rates \& } \\
\text { Projections }\end{array}$ & $\begin{array}{l}\text { Regional SLR models incorporate } \\
\text { downscaled global climate data } \\
\text { with regional and localized } \\
\text { processes affecting sea-level, as } \\
\text { well as regional and local data } \\
\text { points. Agreement for which } \\
\text { projections to use came out of } \\
\text { collaborative effort with external } \\
\text { Federal precedence. Adoption of } \\
\text { more conservative projections are } \\
\text { shaped by scientific and political } \\
\text { uncertainty and climate change } \\
\text { denialism. }\end{array}$ & $\begin{array}{l}\text { Impacts of global } \\
\text { processes (e.g. ice melt } \\
\text { acceleration); } \\
\text { measuring errors and } \\
\text { uncertainty } \\
\text { Technological } \\
\text { advancements for } \\
\text { measurements }\end{array}$ & $\begin{array}{l}\text { Rates that } \\
\text { incorporate ice melt } \\
\text { acceleration and } \\
\text { higher emissions } \\
\text { scenarios }\end{array}$ \\
\hline $\begin{array}{l}\text { Physical } \\
\text { Landscape }\end{array}$ & $\begin{array}{l}\text { Bathtub models assume uniform } \\
\text { landscape and static } \\
\text { environmental processes. } \\
\text { Government institutions address } \\
\text { uncertainties via data gathering } \\
\text { and modeling around } \\
\text { groundwater-surface water } \\
\text { interactions. Yet this knowledge } \\
\text { is restricted in use, as is other } \\
\text { knowledge regarding the physical } \\
\text { landscape that impacts how SLR } \\
\text { will affect the region. }\end{array}$ & $\begin{array}{l}\text { Limitations of bathtub } \\
\text { approach (i.e. } \\
\text { groundwater surface } \\
\text { water interactions; } \\
\text { changes to } \\
\text { precipitation) } \\
\text { Additional monitoring } \\
\text { instruments for } \\
\text { hydrologic shifts in } \\
\text { aquifer, groundwater } \\
\text { and surface water } \\
\text { interaction } \\
\text { Water flow for canal } \\
\text { drainage; stormwater } \\
\text { management; } \\
\text { wastewater and water } \\
\text { supply; storm surge; } \\
\text { low-elevation coastal } \\
\text { neighborhoods }\end{array}$ & $\begin{array}{l}\text { Enviro impacts from } \\
\text { sewer overflow and } \\
\text { deep well injection; } \\
\text { health impacts of } \\
\text { stormwater; } \\
\text { community } \\
\text { baselines of } \\
\text { acceptability; } \\
\text { salinization on } \\
\text { agriculture lands; } \\
\text { impacts to areas } \\
\text { outside of low- } \\
\text { elevation areas }\end{array}$ \\
\hline $\begin{array}{l}\text { Vulnerability \& } \\
\text { Capacity }\end{array}$ & $\begin{array}{l}\text { While understandings of the } \\
\text { physical landscape reinforce the } \\
\text { focus of risks along coastal } \\
\text { affluent parts of the county, the } \\
\text { economic focus to protect tax- } \\
\text { base and insurance costs also } \\
\text { emerge out of how vulnerability } \\
\text { and adaptive capacity is } \\
\text { understood. Other concerns } \\
\text { around how SLR will affect } \\
\text { communities, including } \\
\text { displacement and extreme events, } \\
\text { exist on the planning periphery. }\end{array}$ & $\begin{array}{l}\text { Incomplete knowledge } \\
\text { of the hazards, potential } \\
\text { for infrastructure } \\
\text { failures } \\
\text { Parcel level information } \\
\text { for elevation } \\
\text { assessments } \\
\text { Impacts to insurance } \\
\text { and populated coastal } \\
\text { regions }\end{array}$ & $\begin{array}{l}\text { How people interact } \\
\text { with infrastructure } \\
\text { in their daily life, } \\
\text { infrastructure needs } \\
\text { in less populated } \\
\text { regions }\end{array}$ \\
\hline
\end{tabular}


The self-fulfilling process of scientific inquiry to identify and address risks shaped through a system that prioritizes economic, technological, and political factors, itself prevents adaptation planners from addressing social inequities and risks that could be addressed. This echoes Gross's (2010) argument that the lack of acknowledgement and addressing the different forms of ignorance in knowledge practices, creates a system where knowledge production favors narrowly defined uncertainties while either intentionally or unintentionally ignoring areas that some groups shared need further exploration. Such knowledge practices are reinforced by institutional positionality (Douglas and Wildavsky 1983), how organizations identify and measure risks (Haas 1992), and the emphasis on preparing for the future rather than dealing with things now (Barnett 2001). In sea level rise adaptation planning in Miami-Dade County, the way that risks are understood, broken down into their most basic components, is connected to prioritizations and adaptation planning outcomes.

Within climate adaptation planning in Miami, there is a push to capture more information at hyper-localized scales to better map climate risks. Being hyper-focused on addressing nonknowledge creates knowledge practices that address scientific uncertainties around rates, projections, and biophysical components the planning process. At the same time, this emphasis within Miami can serve to limit the integration of diverse risk constructions that exist on the periphery as negative knowledge around risk (Barnett and Cambell 2010). While hazards identified are often considered neutral and apolitical, they form the basis for how risks are determined on the landscape and can affect planning dynamics and processes (Wisner et al. 2014). This can create what Hajer (1995) calls "problem closure," in which solutions are born out of well-developed but often 
unquestioned problem framings (Hajer 1995). Within Miami-Dade County, problem closure around sea level rise risks being focused on where water goes and how it intersects with infrastructure and property values and ignores other ways in which sea level rise can impact the broader landscape and community functioning that it supports. In Miami-Dade County, the way in which risks are constructed support sea level rise problem framing as a technical issue in which more information about these physical and economic systems are needed to make technical engineered solutions. These problem closures are related to Stirling's notion of technological commitments, in which the way the problem is appraised can "close down" the range of different technologies and approaches to solving the problem (Stirling 2009).

The process of constructing risks and prioritizing certain risk knowledge in the planning arena, can limit policy options and the space for democratic debate over adaptation strategies, or opening-up ignorance to include more unrecognized risk knowledge and more integrative risk knowledge prioritized in the planning arena (Hajer 1995). Within Miami, climate risks that exist outside of the dominant way in which the problem is framed are left on the margins, rather than integrated into assessments, projections, and adaptation strategies themselves. Barnett and Cambell (2010) extend this idea to scientific models of climate change which they argue are mechanisms of "problem closure" and one approach to a "well-defined problem" that, "Have the effect of rendering climate change as an environmental fact against which actors can do little but suffer. They deny the agency of people at risk: to define the problem in their own terms; to apply their own systems of knowledge; to implement the solutions that are appropriate to their needs and values and which accommodate uncertainty; and to make 
knowledge claims of equal value to those of science." (2010, p. 2) Through this idea of problem closure, based on the way in which hazards and risks are understood, some communities have more attention and access to adaptation planning decisions than others (Barnett and Cambell 2010).

While incorporating multiple knowledge frames into integrated risk assessments can be beneficial (Warren et al. 1995; MA 2003; Pahl-Wostl 2003), these efforts remain limited by risk constructions that favor biophysical and economic dimensions. As in other cases, this case study in Miami-Dade County demonstrates that knowledge around sea level rise adaptation risks favor credentialed experts that use formal scientific procedures (Brugnch and Ingram 2012) and the subsequent technical solution-like many climate adaptation strategies - are often unproblematized and considered objective, rational, scientific, and engineered solutions (Winner 1989; Jasanoff 2006). In Miami-Dade County, technical rationality_ —or the idea that risk decisions are made based on empirical evidence, gathered and evaluated by experts and expressed in universal, quantitative terms (Bocking 2004) — is favored over other forms of rationality, including communicative or cultural rationality. Communicative and cultural forms of rationality suggests that people do not calculate risks the way experts do, that is, by evaluating the expected consequences of a course of action and by multiplying them by the probability of their occurrence. Instead, they proceed more intuitively by recognizing patterns, classifying alternatives in terms of clusters of values, applying rules of thumb (Fischer 2000). In doing so, they take a broader view of environmental hazards, a view that encompasses aspects of the hazards themselves and how they are encountered (Fischer 2000). 
Conflicts are common outcomes when governments or companies apply a narrow technical perspective to risks, ignoring broader concerns, including awareness that this perspective itself incorporates tacit political and moral assumptions (Bocking 2004). Within Miami-Dade County, there are both conflicts that happen during public meetings, and conflicts that were discussed during interviews. Rational and technical approaches to constructing knowledge around risk differ from other knowledge constructions. For example, when determining climate change projections at the global scale, the process can be highly contentious and shaped by competing economic and political discourses (Hulme 2009). Adopting rates and projections at the local level is also politicized as local governments may be unwilling to recognize sea level rise as a problem because they would have to act or are concerned about devaluing property (Hulme 2009). While scientists may determine risks with quantified data and models, community activists may use knowledge of place-based experiences, linking outcomes from previous climatic events within their communities to a changing climate as well as social, economic and political histories (Fischer 2000). As such, people may think of risk from climate change in terms of impacts and changes to their daily lives and worry about housing, future employment, health, and asserting their rights (Fischer 2000; Jasanoff and Long Martello 2004). These different forms of rationality rooted in discourse are further explored in Chapter 6 where I focus more explicitly on sea level rise adaptation governance and emerging discourse storylines among different institutions coming together to address the risk of sea level rise. 


\subsection{Conclusion}

In this chapter I articulate the social process of how risks are selected for attention in sea level rise adaptation planning in Miami-Dade County, Florida. Using Gross's (2010) notion of ignorance, I examine how some risk knowledge is included in the planning process while other knowledge is either ignored or deemed unimportant. This risk construction process is underscored by the political process of identifying sea level rise rates and projections; the favoring of risk knowledge that supports an economically viable future; and the path dependency of how these risks constructions can become embedded in adaptation strategies themselves. 


\section{Chapter 6: Pathway for Change or Business as Usual? Discourses in Sea Level Rise Adaptation Governance in Miami-Dade County, Florida}

\subsection{Introduction}

Managing sea level rise adaptations is inherently contentious. Regions must make decisions around whether to limit or regulate development in low-lying areas, how to prepare socio-economically vulnerable communities, how to change design or building standards and transform infrastructure, among other choices and tradeoffs of how to address risks from climate change (Adger et al. 2005; Taylor et al. 2012). Planning activities like these take place in multiple arenas with diverse approaches and ideas of how to prepare and prioritize actions, bringing diverse interests together on the topic of adaptation (Adger et al. 2009; van den Hoek et al. 2014). This is in part due to the multiple ways that risks are experienced and understood (Dewulf et al., 2005; Brugnach et al., 2008; Renn et al., 2011) and different priorities and politics embedded in urban environments, policies, and institutions governing adaptation planning (Hilgartner 1992; Hommels 2005; Heynen et al. 2006; van den Hoek 2012). This decentralized planning arena mirrors theory on environmental governance, which suggest that decisions surrounding the urban environment take place through systems of shared authority and decision-making power among multiple organizations with different mandates and agendas (Jasanoff and Long Martello 2004; Leach et al. 2007). Climate adaptation governance is defined as the system of institutions, including laws, norms, policies, organizations, and regulations involved in decisions surrounding how to understand and respond to challenges posed by climate change (Lemos and Agrawal 2006; Leach et al. 2007; Chaffin et al. 2014). In both intentional and unintentional ways, governance 
determines how scientific and technological processes are directed; how environmental issues are defined and addressed; and how consequences of these decisions become distributed (Leach et al. 2007). Each of these processes shape the future trajectory of social, ecological, and technological systems (Leach et al. 2007). Marking a departure away from considering governance as being directed solely by government and top-down mandates, decentralized approaches recognize a networked understanding of all the institutions - both formal and informal - involved in making decisions for the urban environment (Schmitter 2001; Lejano et al. 2013).

Many scholars view this form of governance as being nimble and more responsive to local context with multiple organizations integrated across different scales (Healey 1997; Sabatier et al. 2005). Relationships among the different organizations are viewed as offering institutional flexibility necessary to achieve principles of adaptive management and planning under uncertain conditions (Elzen et al. 2005; Smith et al. 2005). In many ways, cities have embraced this form of planning within climate change adaptation because of these benefits and engage in partnerships and promote strategies that connect and collaborate across formally bureaucratic siloed departments, between public and private sectors, and across various levels of governance to promote resilience strategies (Leach et al. 2007). Divergent perspectives and approaches to address impacts from climate change come together in a unique way where diverse interests converge around the topic of sea level rise to address a variety of issues in the urban landscape. This shift mimics calls for holistic planning approaches that emphasize planning for cross-sector resilience and point to problems with narrowly defined approaches (Leach et al. 2007; Adger et al. 2009; Taylor et al. 2012). 
While decentralized governance arrangements may connect groups across scales to decision-making, there is no guarantee that they will offer democratic, participatory, or collaborative approaches (Cooke and Kothari 2001). With aspects of unequal power and authority in the planning process, decentralized governance arrangements can create dynamics where rights, responsibilities, and who bears the benefits and burdens are controlled by those with the most influence over decision-making, acting within the system (Cooke and Kothari 2001; Jasanoff and Long Martello 2004; Agrawal 2005). Although conflicts within network governance are expected, they can result in power struggles that further separate and entrench ideals (Fischer 2000; Bäckstrand and Lövbrand, 2006). One reason for these challenges is because institutions have different levels and types of power, authority, and rationalities (Rydin 2003; Bäckstrand and Lövbrand, 2006; Dryzek 2013). Some groups are more connected and have more power and authority over decision-making than other groups (Rydin 2003; Bäckstrand and Lövbrand, 2006). At the same time, other groups may justify their decisions with economic rationalities which often carry more weight within decision-making contexts than other forms of rationality (Healey 1997; Fischer 2000; Bäckstrand and Lövbrand 2006). Along these lines, several scholars have pointed out that the rationale and practice of urban planning and policy within diffuse governance arrangements have been dominated by concerns of economic efficiency, deregulation, and privatization (Thorns 2002; Low 2008; Gleeson 2010; Taylor et al. 2014).

In response to these challenges, a growing body of scholarship now exists around discourses, or shared meanings, among actors and institutions governing urban planning and climate change policy (Rydin 1998 and 2005; Hastings 1999; Bulkeley 2000; Lees 
2004; Lindseth 2005; Jacobs 2006; Bäckstrand and Lövbrand 2006; Lovell et al. 2009; Taylor et al. 2014). Most of these studies examine how global discourses around climate change interfere with local narratives, power, and knowledge (Hulme 2009). Few studies have examined discourses surrounding sea level rise adaptation planning, especially within the United States. This chapter addresses this gap and uses institutional discourse analysis to better understand how institutions—-both formal and informal—shape decision-making around sea level rise adaptation planning in Miami-Dade County. This chapter focuses on examining the process by which diverse risk knowledge are integrated into adaptation planning. I use discourse storylines (Hajer 1995) and rationality claims (Rydin 2003; Taylor et al. 2014) around key institutions involved in sea level rise adaptation planning in Miami-Dade County, Florida to shed light on knowledge integration practices. As new institutional arrangements emerge to plan for risks posed by sea level rise, this chapter asks, what are the different storylines and forms of reasoning around sea level rise and how are those connected to different adaptation pathways and planning processes. This chapter considers the basis of rationality within adaptation planning, the role this plays in legitimizing strategies, and the interplay of discourses promoted by governing institutions. The analysis seeks to identify the storylines alongside the interplay of interests and to explore the role that these discourses fulfill. This chapter contributes to planning theory around how institutions frame the problem and solutions with sea level rise adaptation, and how those problem framings are connected to institutional structures, power and authority within the system. 


\subsection{Institutional Discourse Analysis to Unpack Sea Level Rise Risk, Problem Framings, and Solutions}

An institutional discourse approach can be applied to sea level rise adaptation governance to identify areas of divergence and convergence surrounding ways that different groups understand the problem in relation to different systems, power, and authority that exist in a particular place (Rydin 2003). This approach suggests that "discourses are the product of institutional practices and individual activities that reflect types of knowledge claims - different accounts of what is true and what counts as a representation of reality" (Taylor et al. 2014, p. 6). In this way, a discourse can be understood as a grouping of ideas, concepts, and categorizations that are produced in a set of practices, and which meaning is given to social reality (Hajer 1995).

One approach that has been widely used is to understand discourses through storylines of shared terms and concepts (Hajer 1995; Lejano et al. 2013). Narrative storylines do the task of creating shared meaning; actors that subscribe to a particular storyline and place themselves into the network of a particular discourse (Lejano et al. 2013). Through storylines, meaning given to physical and social processes around how the problem is framed (Hajer 1995; Lejano et al. 2013). While competing storylines may highlight possible challenges and disagreements, they can also offer opportunities for policy change by uniting actors across domains and with different values into "discourse coalitions" through their adherence to shared terms and concepts (Hajer 1995; Mander 2007; Lovell et al. 2009).

Storylines align actors by which they ascribe credibility to the claims of certain groups (Taylor et al. 2014). One approach to doing this is by paying attention to the way 
in which storylines are rationalized (Rydin 2003; Taylor et al. 2014). Claims to various forms of rationality embody assumptions about appropriate courses of action and are central to legitimizing planning policy and practice (Rydin 2003; Taylor et al. 2014). There are five rationality claims that are important to climate adaptation governance and these can be used to examine storylines (Healey 1997; Fischer 2000; Rydin 2003): procedural, scientific, economic, cultural, and communicative rationalities. Each of these can be used to legitimate policy decisions (Healey 1997; Fischer 2000; Rydin 2003). (1) Procedural rationality is based on the idea that there is advantage from "categorizing, listing and breaking up the policy process into steps and stages" (Rydin, 2003, p. 78-79), and that this process legitimizes the activities and centralization of public sector planning activities which strive to optimize for the public interest.

(2) Scientific rationality stresses the scientific knowledge and processes related to the problem, focuses on reducing uncertainty, and the translation of scientific knowledge into the policy process.

(3) Economic rationality considers concerns about the environment and urban sustainability from the perspective of economic decision-making, determining which policy choices have the greatest economic impacts, and/or results for the cost. This rationality views the environment as something that can be commodified and promotes the use of market-based solutions to resolve problems associated with externalities and other policy issues.

(4) Cultural rationality sees environmental problems as hyper localized and related to peoples' quality of life and daily lived experiences (Fischer 2000). This form prioritizes 
personal and familiar experiences as a basis for knowledge, over detached and calculated forms of knowledge.

(5) Communicative rationality recognizes the potential for groups with diverging interests to come together and co-construct knowledge and meaning relevant for decision-making (Healey 1997). This form views participation and inclusion in the policy process as the key to the informed acceptance of environmental risks.

Framing institutional discourse analysis from a rationality perspective allows us to examine what forms of discourses may be aligned with rationality claims, highlighting points of tension and areas for opportunity (Rydin 2003; Taylor et al. 2014). Discourses can be connected to an institutional analysis around how institutions act within a system, in relation to their political power and authority (Ostrom 1990; Rydin 2003). It enables us to look across the system of institutions governing various aspects of sea level rise adaptation problem framings and solutions and identify places where coalitions may form between actors or conflicts may remain entrenched (Sabatier and Jenkins-Smith 1993; Taylor et al. 2014). Using Rydin's rationality approach, we can identify how actors frame and reason their arguments within planning and policy debates around sea level rise (Rydin 2003; Taylor et al. 2014) and connect this to their political position and type of authority within the governance arena (Ostrom 1990; Rydin 2003) (summarized on Table 6.1). This can also allow us to look at how those meanings connect and possibly influence the political and material outcomes of the planning process (Taylor et al. 2014). 
Table 6.1 Rationality claims and implications for adaptation governance. There is no one "best" or "optimal" form of rationality claim to a particular discourse, each has its own benefits and drawbacks within a diffuse governance system and approach to understanding and managing risks. For example, scientific rationality provides information for decision-making regarding the natural world, but it can be uncertain and overshadow other forms of knowledge. Further, economic rationality is an important consideration for maximizing benefits for cost, but it can also leave people out who are not represented within this framework. The purpose of an institutional discourse analysis is to understand how rationality claims are being made and where there are points of integration and synergies as well as tensions.

\begin{tabular}{|c|c|c|c|c|c|}
\hline Rationality & Location & Authority & Knowledges & $\begin{array}{c}\text { Benefits for } \\
\text { Adaptation } \\
\text { Governance }\end{array}$ & $\begin{array}{c}\text { Consequences for } \\
\text { Adaptation } \\
\text { Governance }\end{array}$ \\
\hline Procedural & $\begin{array}{c}\text { Federal, } \\
\text { Regional, } \\
\text { City } \\
\text { Governments }\end{array}$ & $\begin{array}{c}\text { Rational- } \\
\text { Legal }\end{array}$ & $\begin{array}{c}\text { Norm and } \\
\text { definition } \\
\text { construction }\end{array}$ & $\begin{array}{c}\text { Procedures are } \\
\text { streamlined } \\
\text { and efficient }\end{array}$ & $\begin{array}{c}\text { Limited } \\
\text { democratic access } \\
\text { to sites of } \\
\text { decision-making }\end{array}$ \\
\hline Ecientific & $\begin{array}{c}\text { Epistemic } \\
\text { Communities }\end{array}$ & $\begin{array}{c}\text { Expert } \\
\text { (Miller }\end{array}$ & $\begin{array}{c}\text { Authoritative } \\
\text { Science } \\
\text { (Bocking 2004) }\end{array}$ & $\begin{array}{c}\text { Provides } \\
\text { needed } \\
\text { information } \\
\text { about the } \\
\text { natural world }\end{array}$ & $\begin{array}{c}\text { Costly, time } \\
\text { consuming, } \\
\text { uncertain, and can } \\
\text { overshadow other } \\
\text { forms of } \\
\text { knowledge }\end{array}$ \\
\hline Private Firms, \\
Businesses
\end{tabular}


In this chapter, I provide the interpretive governance context for emerging discourses among institutions involved in sea level rise adaptation planning in MiamiDade County (Lee 2004). This includes an overview of roles and responsibilities of institutions involved or affected by sea level rise adaptation planning and the associated adaptation pathways, or proposed strategies to adapt to sea level rise. I then use storylines to examine the emerging discourses that surround how the problem of sea level rise is framed, how it is understood, and proposed solutions (Tonkiss 1998; Rydin 2003; Lee 2004). The institutional framework coupled with storylines around problem and solution framing are used to capture the dynamic processes by which risks are broadly interpreted in the planning process. How different groups understand risk is ultimately connected to their priorities on the landscape and how they rationalize problem and solution framing.

\subsection{Institutions and Sea level Rise Adaptation in Miami-Dade County, Florida}

\section{Local Governments}

Local governments are central to decision-making around land use planning, zoning, stormwater management, and other infrastructure. Because of their position in overseeing municipal infrastructure, they are key decision-makers with adapting to sea level rise and hold formal authority over infrastructure design. Design codes around infrastructure and the built environment are embedded within municipal codes and regulations. These codes are set through comprehensive planning and other mechanisms, then adopted into plans by elected officials. In Miami-Dade County, the three largest local governments involved in sea level rise adaptation planning are Miami-Dade County, the City of Miami, and the City of Miami Beach. 
- Miami-Dade County has a mayor form of government with an elected county mayor serving as the chief executive and the county commission serving as the legislative body. The county has 34 independent municipalities and oversees a population of over 1 million people in unincorporated Miami-Dade County.

- The City of Miami is the county's largest municipality and has an executive mayor who appoints a city manager to serve as the chief administrative officer while the City Commission is the legislative body.

- Because of its role in tourism, the City of Miami Beach has a significant amount of regional influence and is viewed both nationally and regionally as a leader in adapting to sea level rise. The City of Miami Beach has a council-manager system, with the mayor and six commissioners setting city policy and the city manager serving as the chief executive.

Property taxes serve as a large source of revenue for Miami-Dade County and city governments, and a recent report produced by local governments for the Rockefeller Foundation's 100 Resilient Cities Initiative claimed that the greater Miami region is strong financially (Resilient Cities Assessment 2017). Each of the three jurisdictions uses comprehensive planning which includes short and long term economic, social, physical, environmental and fiscal goals, with resilience being integrated into their next comprehensive plan updates (Resilient Cities Assessment 2017). Each of these municipalities either currently have or have had different sea level rise, resiliency, and climate change advisory committees to advise on policies and prioritizing work to varying degrees. These panels have comprised of business interests, environmental 
interests, scientists, and government employees, with community-based organizations mostly absent from the process, though this has recently shifted in the City of Miami. Three cities within Miami-Dade County, Coral Gables, South Miami, Key Biscayne, and Pine Crest, have also been actively involved in sea level rise adaptation planning with their respective Mayors leading many of the efforts. Financial, scientific, and other resource limitations are a challenge for many of the municipalities, especially smaller and/or resource poor governments that do not have significant tax revenue from tourist dollars and property taxes. Maintaining and providing infrastructure and accessing resources needed to plan for sea level rise (financial and technical) are highly uneven across jurisdictions.

\section{Regional, State, and Federal Oversight}

Regional, state, and federal agencies and authorities have regulatory oversight over water quality, floodplain management, regional water management, the Everglades conveyance and restoration, and other areas. Each of these organizations has roles and responsibilities related to sea level rise adaptation planning. Sometimes these organizations work together and sometimes they have distinct agendas.

- The South Florida Water Management District (SFWMD) and the USACE are key water governing entities in Southeast Florida, responsible for overseeing Everglades restoration, in partnership with the National Park Service and other organizations, and the primary canal infrastructure that carries water from the Everglades out to Biscayne Bay and other regions across South Florida. Their water management strategies play a significant role in water supply, water quality, 
and flood control in the region, and consequently shape Miami-Dade County's and other municipalities water management strategies. These agencies collaborate closely with Miami-Dade County on issues of water management and supply, as well as Everglades restoration.

- FEMA oversees the NFIP and has recently been updating the flood insurance maps and storm surge modeling for Miami-Dade and surrounding counties. In addition, local governments incorporate the Community Benefits Rating System, a component of the NFIP, into stormwater management planning to lower flood insurance rates for residents. The NFIP program operates locally through floodplain administrators that sit at each municipal government.

- NOAA oversees much of the tide gage data on sea level rise trends, provides data on hurricanes, and offers planning support to local governments. Both NOAA and the USACE have regional sea level rise projections used by local governments in Miami-Dade County.

- USGS primarily serves in a supporting role to local governments offering research services on the hydrology, hydrogeomorphology, and other aspects of the region's geology.

- The EPA and the Florida Department of Environmental Protection agencies are responsible for oversite of the Clean Water Act, including stormwater permitting, which has some overlap with sea level rise adaptation planning, particularly around wastewater treatment facilities.

Non-Governmental Entities 
There are numerous non-governmental institutions involved or affected by sea level rise adaptation planning. These include community-based organizations, foundations, environmental NGOs, academic institutions, private consulting firms, and various business interests. Diverse institutions operate at different scales, with differing levels of coordination, and on both distinct and overlapping adaptation strategies. In general, locally based community organizations are funded by two primary foundations, The Kresge Foundation and The Miami Foundation, along with donor and grant support. Individuals from environmental organizations, academic institutions, private firms and business interests are connected to the formal planning process through advisory roles, partnerships and contracts with departments in both city and county government. Some community organizations are connected to the Rockefeller Foundation's 100 Resilient Cities planning and with the City of Miami on the Miami Forever Bond's by serving on community advisory panels. There is also one community representative on the City of Miami's Sea Level Rise Committee, with the city yielding to political pressure to include community representation. Private firms comprised both of business that work in the environmental and adaptation fields and of businesses working in development, insurance, tourism, and other industries with different priorities and interests in adaptation. In general, the development and insurance community has been closely connected to sea level rise adaptation planning by serving on advisory roles to local government. Environmental and engineering firms have also been closely involved by conducting contractual work for local governments. Environmental organizations have a long history working in the region, primarily on issues related to the Everglades and 
Biscayne Bay. They participate on several advisory committees and collaborative efforts related to sea level rise adaptation planning.

\section{Adaptation Pathways}

Within Miami-Dade County, there are several adaptation pathways, or strategies for preparing the region for the impacts of sea level rise (summarized on Table 6.2). Changes to urban infrastructure is the primary focus of adaptation efforts followed by updates to building and landscape design, collaborative efforts, and emergency preparations. Beach re-nourishment, which is the replacement of sand along the shoreline, and Everglades and Biscayne National Park restoration activities are two dominant ecological strategies, while the focus on social capacity remains fairly limited in terms of resources and efforts. A recent report from the 100 Resilient Cities effort summarized the key actions that Miami-Dade County, the City of Miami, and the City of Miami Beach has taken towards addressing sea level rise (summarized in Chapter 4 on Table 4.2). The projects these governing bodies are undertaking reiterate the focus on infrastructure, design, and the environment. The City of Miami Beach includes their recent outreach activities which are project specific to road and stormwater drainage upgrades.

There are two primary collaborative efforts in the region related to sea level rise adaptation planning: the Southeast Florida Regional Climate Change Compact (Compact) and the Rockefeller 100 Resilient Cities initiative. The Compact is led by county governments and involves a diverse set of partners including, environmental organizations, city governments, the SFWMD, and recently has expanded to include some community organizations from Miami-Dade County. This organization operates as 
a support role for local governments and to create a unified voice for the region to lobby for funding and climate adaptation support. The Compact hosts an annual meeting that brings together scientists, planners, private firms, NGOs, and others to share the state of knowledge around climate change in the region. In 2017 they published their second report, Regional Climate Action Plan 2.0 with strategies suggested to guide regional planning and individual municipal planning efforts. Since the first iteration published in 2012, the new Regional Climate Action Plan has expanded to include public health, public outreach and engagement, and social equity. The Rockefeller 100 Resilient Cities effort is led through a partnership between Miami-Dade County, the City of Miami, and the City of Miami Beach, with the City of Miami expected to follow the prescriptive approach given that their Chief Resilience Officer is funded through a grant from the Rockefeller Foundation, where as the Chief Resilience Officers from the county and Miami Beach are funded through their respective governments budgeting. 
Table 6.2 Adaptation Pathways in Miami-Dade County, Florida. The responsibility of formalized processes around sea level rise adaptation planning has largely been that of local government, especially Miami-Dade County, the City of Miami, and the City of Miami Beach. Formalized roles and responsibilities are not the only source of power over the sea level rise adaptation process, as private firms, community organizations, and environmental groups are also involved in adaptation planning efforts.

\begin{tabular}{|c|c|c|c|}
\hline Pathway & Activities & Description & Institutions Involved \\
\hline Infrastructure & $\begin{array}{l}\text { Stormwater and Canal } \\
\text { System; Drinking } \\
\text { Water and Wastewater } \\
\text { Treatment; Critical } \\
\text { Infrastructure Planning }\end{array}$ & $\begin{array}{l}\text { System adaptations include } \\
\text { increasing capacity, } \\
\text { installing new and/or more } \\
\text { pumps, moving electrical } \\
\text { equipment out of flood area, } \\
\text { identifying "critical } \\
\text { pumping stations" }\end{array}$ & $\begin{array}{l}\text { SFWMD, City and County } \\
\text { Governments, USGS, } \\
\text { FEMA, Firms }\end{array}$ \\
\hline Design & $\begin{array}{l}\text { Comprehensive } \\
\text { Planning; Sustainability } \\
\text { Planning; Design } \\
\text { Charrettes; Adaptation } \\
\text { Action Areas }\end{array}$ & $\begin{array}{l}\text { Both for new developments } \\
\text { and retrofitting existing } \\
\text { communities. Includes ideas } \\
\text { for localized retreat and re- } \\
\text { development }\end{array}$ & $\begin{array}{l}\text { City and County } \\
\text { Governments, Firms, } \\
\text { Business Interests, } \\
\text { Academic, Institutes, } \\
\text { Compact, SFWMD, Env. } \\
\text { Orgs }\end{array}$ \\
\hline $\begin{array}{l}\text { Emergency } \\
\text { Preparations }\end{array}$ & $\begin{array}{l}\text { Transportation routes; } \\
\text { Local Mitigation } \\
\text { Strategy (LMS); } \\
\text { Building Codes }\end{array}$ & $\begin{array}{l}\text { LMS in response to } \\
\text { Hurricane Andrew and } \\
\text { FEMA insurance policy. } \\
\text { Also, projects for } \\
\text { transportation facilities and } \\
\text { critical infrastructure for } \\
\text { emergency response }\end{array}$ & $\begin{array}{l}\text { FEMA, emergency } \\
\text { services, transportation, } \\
\text { County and City } \\
\text { Government, Business } \\
\text { Interests, Firms }\end{array}$ \\
\hline $\begin{array}{l}\text { Social } \\
\text { Capacity }\end{array}$ & $\begin{array}{l}\text { Education and } \\
\text { Engagement; } \\
\text { Grassroots Organizing } \\
\text { and Community } \\
\text { Development, Public } \\
\text { Health }\end{array}$ & $\begin{array}{l}\text { Preformed primarily } \\
\text { through non-profit } \\
\text { community organizations, } \\
\text { individual community } \\
\text { leaders, public meetings }\end{array}$ & $\begin{array}{l}\text { Community-based } \\
\text { organizations, } \\
\text { Foundations, } 100 \text { Resilient } \\
\text { Cities, County and City } \\
\text { Government }\end{array}$ \\
\hline $\begin{array}{l}\text { Collaborative } \\
\text { Efforts }\end{array}$ & $\begin{array}{l}\text { Southeast Florida } \\
\text { Regional Climate } \\
\text { Change Compact, } 100 \\
\text { Resilient Cities } \\
\text { Rockefeller Foundation }\end{array}$ & $\begin{array}{l}\text { Primarily focused on } \\
\text { government, regional } \\
\text { collaborations among } \\
\text { different municipalities to } \\
\text { coordinate efforts and use a } \\
\text { unified sea level rise } \\
\text { projection }\end{array}$ & $\begin{array}{l}\text { County and City } \\
\text { Governments, Federal } \\
\text { Agencies, Firms, } \\
\text { Foundations, Env. Orgs, } \\
\text { Business interests, } \\
\text { Community Based Orgs } \\
\text { (more recently) }\end{array}$ \\
\hline $\begin{array}{l}\text { Ecological } \\
\text { Restoration, } \\
\text { Protection, \& } \\
\text { Adaptation }\end{array}$ & $\begin{array}{l}\text { Beach Re-nourishment, } \\
\text { Mangroves, Everglades } \\
\text { and Biscayne NP } \\
\text { Restoration }\end{array}$ & $\begin{array}{l}\text { Emphasis is on ecological } \\
\text { community in part because } \\
\text { the regional economy is so } \\
\text { dependent on a functioning } \\
\text { ecosystem }\end{array}$ & $\begin{array}{l}\text { USACE, SFWMD, County } \\
\text { and City Government, Env. } \\
\text { Orgs, Firms, USGS, } \\
\text { NOAA }\end{array}$ \\
\hline
\end{tabular}

\subsection{Sea Level Rise Adaptation Storylines Discourses}

Case study findings point to four discourses around risk of sea level rise used in

the planning process and shaping adaptation priorities in Miami-Dade County. The first is 
a focus on the economic core of development and tourism. This discourse arises out of an economic rationality for basing adaptation planning decisions in support of protecting the dominant economic drivers in the region. The emphasis is on "A city of the future" and what some call, "the future Miami." The second discourse emphasizes infrastructure and is closely aligned with local governments and the desire to sustain a regional tax base to fund adaptation actions. This discourse is closely aligned with procedural rationality and is based in local governments efforts to understand and address sea level rise impacts through infrastructure. The economic and infrastructure discourses are reinforced by risk assessments and reports emphasizing and framing economic and infrastructure risks, that emerged in Chapter 5. Thirdly, a discourse around ecological impacts from sea level rise emerged among environmental non-governmental organizations, some government employees, and private interest groups, primarily underpinned by scientific rationality. Finally, considerations for the people using infrastructure and that people also matter emerged out of cultural rationality with community organizations and others purporting initiatives that recognize distributive justice and the unevenness of socio-economic vulnerabilities. In addition to the four discourses, there are examples of both individuals and organizations seeking to span boundaries and build connections across these storylines. Both from governmental and non-governmental entities, these individuals and actions of institutions represent opportunities for building and expanding collaborative approaches, based on claims for communicative rationality. For each discourse, I provide a thematic description of the problem framing, the actors involved, and the proposed adaptation approaches being discussed or implemented. I also include points of 
contention and points of shared meanings, as they emerge within and among the different risk discourses.

\section{Economic Discourse: The Business of Sea Level Rise and the Future Miami}

Under the "Business of sea level rise and the future Miami" discourse, people representing private business interests, politicians, and others emphasize the economic risks sea level rise poses to development and tourism, the two largest economies in the county. The risk of sea level rise is framed in an economic context and financial risks are prioritized through planning and vulnerability assessments that focus on the monetary assets at risk of inundation and coastal beach erosion. Such a focus is reinforced formally in the planning process through different task forces and advisory panels largely comprised of people from building, real estate, insurance, and banking industries. A large reason behind the economic framing is it reflects the priorities of those involved. It is also used to motivate political action and will to adapt. This is in part due to the notion among several people that economic considerations are the primary roadblock to adaptation. As one elected official shared when discussing the political sentiment around sea level rise risks and adaptation, “Elected officials aren't discussing. They aren't. It's all about our economic engine, which is development. That's why they're not talking about it." And as a business leader in the region shared,

Well, the big concern in the Business Community, mainly, is creating panic where it lowers property values. Starts lowering property values to such a degree that it creates this whole disaster... Yeah, disaster.

People within this discourse framed the problem around how impacts from sea level rise on property values are inevitable, and that the loss of property value is the largest risk to the region. As this business leader expressed with the example of the housing market, 
But it's inevitable. It's going to happen. People are going to start saying, "Does this house flood?" If I'm a buyer in Miami Beach, that's what I would ask... There's other people that say, "Well, insurance will happen first and that will destroy the market." Regardless, water will destroy the market.

The notion that sea level rise will destroy the market was shared by some government employees and elected officials. Many of the government officials expressed that market failures would occur via anticipated impacts of sea level rise through the insurance industry. As one county employee expressed,

I think we generally expect that, at least I do, that insurance will be a major driver... What starts to happen with property values will end up providing some influence. If there's a major storm and people are impacted, that's going to have an influence on whether people decide to stay or not.

The fear for many within this storyline is that insurance companies will either stop insuring people or costs will be so high that they will result in local economic disasters, and that an ultimate risk would be having to retreat. An elected official elaborated on this point and discussed it in the context of someone bringing up the idea of planned retreat.

What we all understand is the reinsurance industries, the Swiss Re and other reinsurers are warning us and have been warning us for the last couple years that we need to mitigate against the damage that's going to come from all this flooding. Yeah, to limit and reduce known hazards and known losses. It's billions in known losses. Nobody is doing anything about it. They're just raising the dollar value of known losses by allowing more and more. One of the scariest comments I heard about two or three, maybe three years ago... there was a gentleman from Army Corps of Engineers doing a presentation... He said, "At some point soon, you'll have to develop an exit plan.”

Another part of the problem framing in this discourse is that the drive for short-term gains in the development industry is creating problems for adapting to sea level rise. As one elected official shared, 
... here we are, just looking the other way and letting them keep building these multi-million, billion-dollar..." Developments are reliant on our foreign money still coming in, developers making a buck, a lot of construction going on, so helps the economy, and it's all short-term gain.

Narratives around economic risks are structured around the loss of the economic core and the loss of the tax base needed to finance adaptation measures going forward. In addition, risks are viewed as the possibility that there will not be a federal or state bailout for these market driven failures.

Both current and future loss of property values becomes one of the key ways the problem is framed under this storyline. The focus placed on the economic core manifests in the way risks are understood and measured. For example, with the Compact, risk maps are presented in terms of inundation levels and property values, embedding assumptions about risk as being the places where the greatest property loss occurs (Vulnerability Assessment 2012). Informant interviews corroborated this with their emphasis on needing to protect the economic core to fund future adaptation efforts. In this way, maintaining property value, protecting the economic core, and planning for a future economy in the region become the focus of adaptation efforts in the region. This takes place in diverse ways including, beach re-nourishment programs focused on protecting coastal properties and the attention to building codes and urban design.

Linked to the problem framing around economic risks, is the emphasis on economic gains and emerging economies around adaptation actions. Business opportunities were expressed in-terms of both consulting firms that can take advantage of the emerging adaptation industry, but also in-terms of the need for ongoing development that will secure investments in the region. This second point was expressed in terms of 
the risk of not building and how sea level rise will create slums in existing low-elevation

areas. Development is viewed as a necessary adaptation solution for raising base floor

elevations and protecting economic investments. As one private sector individual

described the relationship between developers and adaptation planning,

When Barret Houseman and Napoleon III tore out Paris, they said they were doing it to stop the possibility of more revolution and violence. This was breeding ground for rebellion and revolt. They tore down Paris, and they built a new Paris, but that new Paris made a lot of developers really, really wealthy. It's the same thing. It also made Paris a city of the middle class, whereas the city was a city of poor before they started their work.

Similarly, North Beach is an area of poverty. There's always been a reason to tear down places the poor live, whether it's put in highway or a stoplight, or to stop concentrations of poverty, or whatever. The newest reason is sea level rise and climate change. Just like those other reasons, there's a validity to it. You're talking about a Barrier Island in Florida.

Several interviewees that represent this view shared that there are no physical limits to adaptation, that the limits to adaptation are economic limits, that the land must be worth enough and the concern is if the region waits too long to adapt, the land will no longer be worth enough to save. This sentiment is commensurate with problem framings and solutions that are engineered and adapt the physical landscape to allow for growth in the era of sea level rise. One government employee shared that sea level rise risks will not limit future growth, it will just change the way the region grows,

We are not thinking about abandoning any areas at all. We already live on reclaimed land so we will keep reclaiming. It doesn't really matter. It's all reclaimed land anyways so it's not an issue. So then, you have to abandon this area and say 'Why? China can make an island in the middle of the ocean, we can build some more.' So the thing is that abandonment is going be more related to areas that are already difficult to live, because they're too low so they need to be redeveloped. And [those areas are] going to be redeveloped with more focus on how we're going dispose of the water because it's going to be harder for us to drain... So there are 
some areas that are going to look very different to what they look now. That doesn't mean that there are not going to be houses there.

Another government employee shared this sentiment and discussed a link between the economic framing of sea level rise adaptation with an engineered perspective. In this way, economic framings are matched with ideas for re-grading the city to solve the problem of sea level rise. As this individual shared,

One thing that I suggested is you can fix everything with enough money. But the land needs to be worth the money... you know there's a cost benefit analysis to that... if you ask me what's the best thing that could happen from the engineering standpoint to get rid of the problem not necessarily about the individual people who are living there but from... If some developer will buy everything out fill it two and a half feet and rebuild it. You know, and that would make the problem literally go away.

Many in this discourse echo this individual and bound the problem of sea level rise by the financial constraints to solve the problem. In this risk discourse around the economic core, risks are expressed via a monetary lens. As one city employee shared when discussing future growth and development in the region,

It's all land value. It's not really the buildings and that's what we talk about. Saving the building. I said the buildings are worth very little, it's where they sit is what the value is.

The risk of sea level rise is bound by the ability of the region to be economically prosperous as to be able to afford the adaptations needed to support cities in Miami-Dade County. Several interviewees used economic reasoning to discuss prioritization for adaptation strategies, as one elected official shared,

There's economic activity to happen and there's places where they need to be reinforcing, elevating structures and land to keep that happening. There's an area, very high economic activity in the Jackson Hospital area, along the Miami river. That area is a big job engine and the area is pretty low. They need to be paying attention there. 
With the problem framed around developers serving as a major roadblock to adaptation planning, the logic follows that this stakeholder group needs to be included in planning activities. Several people from the development community have been involved in sea level rise adaptation planning via participating on committees and proving input in assessments. Because of the presence of the business community on these committees and their involvement, the conversations that take place in those arenas often surround the need to update codes, building materials, and emerging business opportunities around adaptation planning. Several interviewees from outside this discourse commented on the focus on building codes and new growth for sea level rise adaptation and resiliency strategies. These outsiders expressed that these building code changes can be slow because of political challenges and detract from activities that could take place in the nearer term. As one individual from an environmental organization shared when discussing private sector organizations involved in adaptation planning efforts, Yeah, they seem to be sort of fixated on building code changes, and asking for money to get surveys, or risk assessments, or experts, or things like that. That has been slow in coming... Economic impact studies, like GIS surveys... Financial, and elevation perspective, and flood maps... And building code changes... It's very slow and difficult to get changes to the building code. It takes years... And then Miami is a very developer driven town economically, and so adding additional burdens onto developers for doing things with sea level rise in mind is slow going. Because it's going to cost them more money to build their buildings differently, or elevate them, or so on and so forth. Because right now most of the costs are pushing on people who are buying apartments and things like that, because developers sort of engage for three to five years, and then they sell them.

While those within the economic discourse emphasize the need to focus on building design and code challenges, this individual from outside the economic discourse discussed an alternative framing. Understanding how slow moving changes to building 
codes can be, this individual shared that there are alternative solutions that could be done in the nearer term, including green infrastructure and emissions reduction.

Within the economic discourse, several people representing private sector interests discussed the new economy emerging out of building adaptation strategies. This new emerging economy is part of how those within this discourse frame adaptation solutions and focus on infrastructure investments. For example, one private sector individual discussed recent changes to Miami-Dade County's sewer treatment in terms of a positive economic driver,

They were slapped with a consent order, and so now they were forced to basically upgrade their infrastructure to accommodate for the growth, and also to protect sewage issues into our ecosystem. Therefore, that's been good for business... The economy is the environment, and the environment is the economy in South Florida... \$20 billion dollars over... well, over 20 years, so you do the math. There's a lot of contracts out on the street already, and big global firms are down here hiring small firms. My firm benefits from that as well, because they hire me to help them.

This notion of emerging economies out of the need to engineer and transform the built environment was discussed among several others. In relation to the business community an elected official discussed how some in the business community discuss the need to focus on the new economies around adaptation to sea level rise. This individual shared,

[The business community] talks about new economies that we should be focusing on. One is the ability to bring in engineers and state-of-the-art to help with planning, and to help with infrastructure. There is an economy waiting to do that. Renewable energy, solar, all of those things. There is a new green economy, but we aren't involved in it as a county, at the chamber... or any of those levels. We are solely invested in tourism development. These developers come in, and they're building in the most vulnerable coastal areas, which is still the most valuable property, because they know they'll be able to take the money and run within the next fiveyear spread. 
Economic benefits are also discussed in terms of longer-term improvements to the region.

As some business and homeowners in Miami-Beach have expressed frustration with infrastructure projects at public meetings, one adaptation proponent from the business sector reframes this issue in the context of economic gains.

Guess what? We're going to bust up your street... But it's all for the greater good, and you're going to have better services, and we're improving the system. There are temporary impacts to greater benefits, and it's also helpful for the economy. The [business community] comes in and understands that and wants to build... that conversation.

Economic Discourse Summary: The link between the economic framing of the problem with the economic opportunities surrounding new growth and an adaptation economy are produced out of and reinforced by an economic rationality. Miami as a development driven town with political leaders and officials closely connected to developers lends more political weight towards this discourse. The long-term involvement of the development and business community participating on sea level rise and climate change committees for the different municipalities lends the business community some level of administrative authority, shaping the development of plans and assessments. Further, insurance programs, flood protection, and beach nourishment activities create a direct pathway for economic considerations to have formal positions within the planning arena. This storyline is used by local politicians and the business community to reframe the problem of economic barriers to sea level rise adaptation as an economic opportunity. Infrastructure Discourse: Risks are Technological and can be Managed with Infrastructure

Regional, county, and city planners and managers primarily frame the problem of sea level rise around the physical impacts to infrastructure that result from inundation and 
associated physical changes to the landscape. Part of this is understood in relation to protecting the regional economy and tax base, overlapping with the economic framing of risk. This framing is rationalized through procedural rationality, where those within this group justify action and problem framing in the context of what they perceive as logical and apolitical assessments and prioritizations. A large emphasis around the framing of the problem of sea level rise is around the roles and responsibilities of local government, and the need to address their own issues and risks before asking others to do the same. This places some focus around roles and responsibilities of local governments and not wanting to infringe on property rights. As one federal employee suggests,

I think that local governments in general they are trying to work on things they can do... You know the things that involve public infrastructure are going to be more feasible to start working on than anything that impacts private property... That is something that you see a lot of the emphasis is on public infrastructure.

In addition, government employees shared the desire to get their own assets prepared for sea level rise before asking the public to do theirs. The question of public and private responsibility is brought up in the context of when landowners should adapt and whether to wait for the government to adapt the infrastructure first. As one scientist and county resident explained this question of public and private action,

If they're gonna charge me tax on my parcel of land with my house on it, I should have access to my parcel of land. That's my feeling... I mean, I can afford to elevate my house, and do those things. I mean it'd be kind of fun, but, before I make the investment, I want to be sure that I can get to my house.

And while the procedural logic around adapting infrastructure is wrapped up in roles and responsibilities of local governments, there are several outspoken critics of this discourse. Critics from the environmental discourse shared that ongoing infrastructure 
investments in low-elevation areas encourages additional growth in vulnerable regions.

As one scientist shared,

And so what we're doing is we're putting all our money into this basket of infrastructure protection, and it's going to keep driving our property values down and keep more social inequity, higher cost, poor quality of life, and then finally, we're going to start get hit with serial Katrina and Sandy style events because it won't take that big a storm at some point where when that system finally gets swamped, it's going to be bad... We're going to build ourselves into a disaster. That's my fear... And once it gets to that point, I think what we're going to end up with is... this kind of... apocalyptic shoreline where you're going to have abandoned infrastructure and cities, squatters living in places that don't have any sewer or water, maybe they have hi-jacked electricity or something.

Logic around adapting infrastructure is to approach it from an incremental perspective. In Miami Beach, for example, the city has been installing stormwater pumps and raising roads based on a 30-year planning horizon. Several people shared that this is in part because raising roads higher than that would kill the local economy. While the logic behind planning this way is based on procedural and economic elements, there were several outspoken critics that expressed this planning was too short-term and parochial. For example, as an environmentalist and critic shared about infrastructure adaptation in Miami Beach,

I kept saying, "Good guys, but what happens when you've raised the streets 3 feet and you put the pumps in and you're pumping the water out 24 hours a day pumping it out? You put sea walls all around Miami Beach and the rest of Miami-Dade County looks like that?" There is no causeway to drive across because it's under water. Great, and good, you have built a 1 mile wide, 7-mile-long island, with a wall around it. You can't call it Miami Beach anymore because there is no beach here. What quality of life is that? Is that where you want to live? Are we slowing down and building? Hell no. We're building billions and billions of dollars' worth of stuff all along this. Something's wrong with people. 
This individual as well as other critics favor planned retreat as a strategy for adaptation planning. Interviewees representing the infrastructure arena discuss encounters with outspoken critics of adaptation who favor planned retreat. In these scenarios, those that subscribe to the infrastructure storyline - especially those working in local governmentargue that planned retreat is not an option. This is in part because people want to continue living in the region and it's the local governments role to provide infrastructure. As one government employee shared,

A planned retreat, which, you know, is a totally valid argument when you look at the whole scale of the problem. But then their individual plans for their own family are not in accordance with that. And you think, "Okay, I understand why, because you like where you live." And that is also true of your neighbors, so it's not really possible to assume that these other people should pack up and leave, while you maintain your particular home and community. So people, not everywhere, but a lot of people wanna maintain their community, and they wanna maintain their house... which is what we're, as a government, you know, what the community wants is what we're trying to provide.

Local government employees do discuss some hyper-localized retreat in the general sense when speaking on panels but have yet to formally address this issue in policies, plans, and official public forum. They emphasize small scale retreat within low-lying parts of neighborhoods, not mass planned retreat. Beyond the moral argument around the purpose of local governments to provide a certain quality of life and maintain communities, the emphasis on hard infrastructure projects is embedded in policies and mandates.

Emergency management and FEMA become one lens for how the region views infrastructure risks from sea level rise. Often, these policies direct investment towards what was referred to as "hard" infrastructure projects, meaning infrastructure projects that are built to withstand disturbance. As one government employee shared, 
One of the other collateral things I was involved in was called "Local Mitigation Strategy." Which was part of the emergency management office. FEMA is really the driving force on that. The county was very aggressive, probably one of the leading counties in the country, on developing this Local Mitigation Strategy on how to harden vulnerable facilities. They have taken advantage of a lot of grant money through FEMA. A lot of programs that they have to help communities, both municipal government and county agencies. A lot of other entities get funding to protect, harden their resource. Whether it is hurricane impact windows, doors, or generators. Raise a facility or build a new facility. Kind of drainage, pumping facilities to pump water.

Some government employees discussed wanting to explore more flexible infrastructure projects, for example green infrastructure, which are designed to take on some of the impact of disturbance and dissipate that across a larger system for impact. This notion of infrastructure flexibility was contested among different people within this discourse, particularly in discussions about green infrastructure. Many proponents of more flexible infrastructure did not see it as a replacement for hard infrastructure, but to augment and alleviate disturbances to hard infrastructure.

With local governments, the emphasis of the risk is framed around public infrastructure and the solutions are centered around developing a detailed understanding of risks and engineering solutions to those physical risks. This is supported with logical, decision-making and represents a procedural rationality, backed up by scientific assessments and economic rationalities around costs and benefits specific to infrastructure design and investments. The work of developing criteria and prioritization for projects is most often done by consulting firms and government employees and mandated by different state and federal policies. As one planner shared,

The first task that we gave them [the consultant] under that contract was to assess climate impacts. They did extensive evaluations. They did storm surge modeling. We did rainfall projections. Because part of that program 
is also to calculate what our future flows will be. If a rainfall is going to be more intensive, we may have higher peak flows in the future. They did that assessment. We look at wind also. Based on all that, we came up with a criteria.

Prioritizations and solutions become embedded in the infrastructure themselves.

Several people within this discourse discussed the role of the useful life of infrastructure in determining what science to apply, what the costs and benefits are, and how to prioritize different strategies. In some cases, people described this process as being represented as a formula around weighting different decisions. As one planner shared,

Basically, we have this formula for allocating those stormwater utility dollars to improve flooding. So objectively, this basin was the most flood prone area that we had, so it's pretty standard.

Even though the system is currently set up to strive for procedural approaches to decision-making and prioritization, some within this discourse challenged the efficacy of standardized approaches to prioritize adaptation actions. For example, some government planners within this arena shared the challenge in coming up with standards for determining "Adaptation Action Areas." "Adaptation Action Areas," are supported by State land use policies as an official designation (Section 163.3177(6)(g)(10), Florida Statutes), which can be used to as a land use zone to support adaptation actions. There are different approaches to designating Adaptation Action Areas and some planners question the ability to come up with calculations to identify these priority areas. For example, one individual shared that they used a standard calculation used for allocating stormwater utility dollars to determine a pilot area for an Adaptation Action Area. This planner describes the tension between an official systematic 
process for designating Adaptation Action Areas using a standard stormwater calculation verses a more flexible approach,

....when we selected the area... obviously we didn't know that much about the area when we chose it... the most flood prone area was just off the map, it was this mobile home facility, basically. It's just a little bit off the map. It's literally across the street. Anyway, it's just off the map, and it's like, as soon as you start to speak to people, and you go up there, and you learn more about the area, and you're mapping it et cetera, you're like "Oh man, this is just outside the boundary." Which isn't a problem for us in this particular sense, cause we just say "Okay, this is part of it." Yeah, it's just a part of it. It's not a big deal. But if it's officially designated, I don't know... It wouldn't be in there. So I don't know. I guess some of the benefits of being designated is that you might be able to direct funding towards those places.

This view of systems being too complex to have strict criteria for prioritizing and determining adaptation actions was linked with people who shared the need to work on hyper-focused projects that explore the complexities and nuance of place. Such a concept is emerging in some areas around pilot projects sponsored by different foundations, and design charrettes have been performed in this way. However, currently this approach and the logic behind this approach exists more on the periphery of this discourse. Most that subscribe to the infrastructure discourse emphasize the need to have prescribed assessments and approaches to determine prioritization and adaptation solutions.

Part of the concern around having standardized approaches to prioritize adaptation planning based on physical risks of sea level rise surrounds how to address complex issues experienced by low-income communities. The response to the concerns of lowincome communities within this discourse is varied. Some planners shared that while there are vulnerabilities unique to these communities, the bigger picture of the risks from sea level rise do not make those vulnerabilities worse than vulnerabilities to more affluent 
communities. "Risks do not discriminate between rich and poor" was a common

argument made to rationalize the inclusion of low-income communities in the

conversation. As one planner shared,

Well, I think the big takeaway is the same as it is in lots of other communities, I mean, like, this is an existential threat to Miami, and people are informed about the severity of the threat, and that, basically, regardless of emissions, the amount of sea level rise the community will encounter is probably more than the community can absorb. We're not talking about inches, we're taking about feet. And such a huge percentage of the community is below six feet. So, I think the challenge is that, you know, the concerns that you hear in Liberty City and the concerns that you hear from big developers, affluent developers... Key Biscayne, an affluent community... they're the same. People are like, "This is a serious problem. What you said, it sounds very serious, I haven't heard you say what we can do about it." And like, "What are we gonna do about it and why isn't it already happening?"

And really I think that they're the same... you know, the content is different, like, in Key Biscayne residents brought up that... one woman asked this room full of people, like "Who knows Donald Trump?

Someone pick up the phone." Obviously, in Liberty City, those kinds of comments don't come up. People are talking about New Orleans a lot more, and they're talking about storms, and savings getting wiped out, so the impacts are the same, but I would say that the tenor, and the real fundamental concern, is pretty similar. You know, it's like "What you've just told me is that this sounds really serious and irreversible. Like, what are we gonna do about it? And why haven't you, like, come up with a plan?

When discussing solutions, some planners shared that infrastructure adaptations will benefit rich and poor alike, that there is no distinction. In this way, the focus on the elevation and infrastructure is used as a tool to depoliticize the planning process. Some interviewees shared that they view infrastructure adaptations as an apolitical, technological solution that provides equal opportunity and benefits to those within the 
regions the infrastructure serves. When discussing equity issues with climate change, one city employee suggested that,

Every neighborhood will have different [socio-economic] levels like we mentioned. North Beach is kind of a lower income but at the same time some other neighborhoods are mixed. Any project that is developed will end up benefiting them, any level of society because they're a part of those neighborhoods... but basically when it comes to lower income population they'll also benefit... We have homeless all the way to billionaires as you heard. As in any city, is it always challenging to provide and tailor things to everybody... It was like I mentioned, [the city] really does a lot of communication to the public, a lot of outreach and education on the things that are being done. Those meetings are public, and anybody can attend and learn more.

At the same time, some planners were more vocal about the different challenges among different communities. These planners expressed that possibility of sea level rise adaptation planning addressing a plurality of issues related to low-income communities. As one planner shared,

... sea level rise planning really if it's done well... there's a real opportunity to address many other stresses and potential shocks hitting our community so I think that holistic resilience one is really, it bodes well particularly given socio-economic vulnerability so much of our... city. $70 \%$ of the city's population is struggling to make ends meet.

While views like this may offer the seeds for innovation around integrating social considerations outside of economic and biophysical drivers into infrastructure planning decisions, current planning remains focused on physical hazards for prioritization. There are different framings around how to support low-income communities with adapting to sea level rise. In considering sea level rise as a physical problem with high cost solutions, some interviewees within this infrastructure discourse were highly vocal about the challenges of supporting low-income communities. As one government representative 
shared when discussing why conversations around adaptation do not focus on how to

support low-income communities,

We're not discussing how to support them, because there is no supporting them. It's people mostly just waving their arms up and down saying, "Hey this is going to be unfair." That's are things are, things are unfair. Right now, ironically the rich people are in the way of the problems, but rich people can relocate themselves to their Swiss chalet or whatever...

Two meters by the end of the century...The slope is like that, so now it doesn't stop at two meters. Two meters, okay I got to figure out what to do with two meters... It's accelerating. You can't catch up with it. You never catch up with it and finally it overtakes you. You're out of money and you're out of rock. The sea level isn't quitting. It's still cranking up on you... Then what? You're going to worry about gentrification and Liberty City at that point? I don't think so... Yeah, by the time the water finally gets up to... Makes Liberty City's property valuable... This is going to be a very different place.

Infrastructure Discourse Summary: Within the infrastructure storyline, sea level rise poses risks to infrastructure. The emphasis is on local governments to address those issues. Local governments primarily rely on procedural rationalities and also use economic and scientific rationalities to bolster procedural elements in relation to infrastructure costs, design and prioritization. The emphasis is on considering threats from sea level rise as being physical and economic, and solutions are framed in a similar context. Counter arguments around the need to consider retreat are ignored by this planning arena, primarily because of the moral and legal obligations local governments must maintain communities. At the same time, considerations for how to integrate challenges experienced by low-income communities remain mixed with some expressing visions for integration and others focused on the challenges and impossibility of integrating them into planning due to the perceived prohibitive costs of adaptations on private land. 


\section{Ecological Discourse: Ecological Complexity and Longer-term Processes and Impacts}

The third discourse storyline that emerged surrounds ecological complexity and longer-range impacts from climate change. This discourse is primarily supported by environmental organizations and scientists with some government employees who work in environmental focused programs. In this discourse, risks to sea level rise are understood in relation to the environment and the solutions consider the role of the environment in adaptation. This arena is primarily based on scientific rationality. Individuals from environmental organizations discussed their close relationships with scientists from local and regional universities, and often talked about the biophysical impacts from sea level rise in longer-term with higher projections and more severe impacts than other groups.

Environmental sea level rise impacts are often discussed in the context of broader climate change impacts to the environment and emphasize inundation of the Everglades, salinity issues within Biscayne Bay, coastal erosion and warming impacts on the living shoreline (including mangroves, eel grass, and coral bleaching), and water quality challenges that are worsened by sea level rise. For example, as one an individual from an environmental organization shared,

All the mangroves will be gone, all the grasslands will be gone. Flats are going to die. All the grass flats, all the mangroves are going to die. They can't take sea level rise more than nine inches a century. They cannot migrate quick enough.

Several people linked regional vulnerability to the overall health of the ecosystem. Many focus on the Everglades, in part because of the longstanding environmental focus 
on connecting regional systems with Everglades restoration. As one individual from an

NGO shared,

I think people are seeing that our vulnerability to a great degree is affected by the health of our natural systems. I think that one thing we could do a better job of is conveying to people that we have been regulating this system, this aquatic system in our backyard going back to the late 1940s and providing flood control in a system that receives a lot of water. If we can manage this Everglades ecosystem, and also restore it, put more water out there and still keep our developed areas relatively dry in what is otherwise a flat, low lying landscape, then we might have the capacity to do really what people think is the impossible.

Many that subscribed to this discourse talked about the multiple threats to the environment and often discussed these threats in the context of broader climate change risks to the ecosystem. Sea surface temperature and ocean acidification were frequently added into interviews in the context of risk from sea level rise. One government employee focused on ecological protection shared,

... there's going to be significant impacts to the natural resources. I don't think that our resources will maintain the same homeostasis that they historically had with potentially accelerated sea level rise. Impacts potential to benthic resources, corals which we're seeing right now. Sea surface temperature, ocean acidification, coral disease. The coral reefs off Miami-Dade County are not in great shape. Also, we are seeing a largescale sea grass die-off in certain parts of Biscayne Bay which may be attributed to land-based sources of pollution.

In terms of impacts, baselines and reference points often follow an ecological time scale. Several people within this arena focus on whether the ecological systems can keep up with the impacts from sea level rise. For example, several shared that one key uncertainty is how the mangrove system will be able to keep up via soil accretion rates.

In addition to these direct impacts, this discourse discusses indirect water quality impacts from failed infrastructure surrounding sewerage system and stormwater 
infrastructure failures. Several interviewees and documents also discuss ecological risks from adaptation strategies themselves, including from sea-walls, well drilling, and stormwater pumps. One informant shared, "They'll [individual homeowners] start hardening yep, along the coastal areas. The problem then is, is you lose your inner tidal zone. There is no inner tidal zone, it's just two lines on a wall." Another environmentalist expressed, "You lose your inner tidal and you lose your inner tidal life. It's a temporary fix. Also of course when the water tops your sea wall then you're in big trouble. It gives you a false sense of security."

Many within this discourse framed part of the problem around ecological risks being rooted in decisions that support economic benefits to the region. Many were outspoken critics of short-term economic gains at the expense of the environment and considerations for the impacts of sea level rise. As one interviewee from an environmental organization shared,

We have the port dredging to bring in mega cruises. You're damaging coral reef and marine life. It's like, "We need coral reefs. You're killing them. What are you doing?" It's brutal. Money is... It's a monster.

In addition to framing the risks and the problem around climate change and sea level rise to ecological systems, many discussed that risks (both to the environment and to the economy) can be addressed using ecological systems. Most within this arena link the economy to the environment and identify synergies between the environment and sea level rise adaptation solutions. These include: living shorelines restoration, sand dune restoration, stormwater treatment, green infrastructure, Everglades and Biscayne Bay restoration, sending water south to prevent saltwater intrusion, and green space. As such, environmental protections and funding are often driven by the need to protect the 
environment for the economy. This is linked to the connection between the environment and the economy, expressed by one individual, "It's like the quality of our water. The availability of our water. The health of the ecosystem, which is at the center of our economy." Groups use this framing to make a case for restoration and the role of the environment in adapting to sea level rise. As one individual from an environmental organization shared,

I think one of the most compelling things that we can do, and we're working toward that, is making a strong economic case for Everglades restoration. That includes understanding the economic impacts of the existing system, and being able to project what restoration will do, not only in terms of avoiding those impacts, but also improving the system on some trajectory back to what it may have been. We've done economic studies. We know that people pay a lot of money to fish, people pay a lot of money to bird watch.

The importance around protecting the environment because it's tied to the economy was shared by some local government officials. As one municipal employee shared, ... we have a lot of money and political backing for the environment and an understanding of how important it is because it's tied to our economy. The same way and that's why people move here and that what funds all our programs. In the end if we don't have a pleasant environment to enjoy and live in, we and all these other items don't really matter because nobody is going to want to live here. Everybody is going to be like oh you know this area is doomed okay we might as well just leave because it's not even worth living. We don't ever want to get to that point.

In extending the role of the environment for protecting the economy, the environment also gets brought into discussion around protecting the region from impacts of sea level rise. The environment is enrolled in conversations about solutions for adapting to sea level rise, solving some of the proximal impacts of sea level rise. For example, one individual from an environmental organization shared, 
Yeah, living shoreline is not going to solve sea level rise. That's more about sort of proximal effects, like flooding and erosion. Sea level rise exacerbates those things... It takes not so much mangroves to really stop a lot of waves... So that protects from erosion and flooding... And provide all kinds of other benefits; habitat for fish that people love to catch, and water filtration, wildlife habitat, a million other things.

At the same time, some within this discourse express a strong scientific argument around climate change impacts being insurmountable and call for discussions of planned retreat and political movements towards greenhouse gas reductions. The challenge of addressing these longer-term impacts is the lack of political motivation around emissions reduction. As one individual from an environmental organization shared when discussing the risk Miami Beach took in discussing and addressing sea level rise, ... you potentially put your region in the cross hairs for bad press with this issue that you don't have a solution to. It's a really expensive, intractable problem. I don't think people want to talk about it without knowing what to do about it. The sort of logical end to these conversations is sort of reducing emissions, and I don't think people want to talk about what that means. There's political and economic pressure to not talk about those things... It's insanely expensive to do adaptation and it's insanely expensive to... or is going to shift our economic structure to do the mitigation. Neither thing is particularly palatable.

Like both the economic and infrastructure storylines around the problem framing, people within the ecological discourse discussed barriers to implement adaptation strategies posed by private landowners. This was discussed in the context of trying to get private landowners onboard with some of the ecological adaptation strategies, for example, sand dune restoration. As one person from an environmental organization shared,

Most of the governments want dunes... It's really private homeowners, and the government can't put a dune in front of a home until they sign paperwork, so sometimes they build a big project and they have to put gaps in the dune, because there are certain homeowners that don't want a 
dune on their property... There's nothing bad about a dune. They're protective, they're a good wildlife habitat... From like an, other than not being able to see over it, there's nothing bad about a dune.

Several among this group suggested that the adaptation strategies themselves will have environmental impacts that are not being considered. For example, one individual from an environmental discussed environmental concern for drilling into the aquifer to treat wastewater as part of a sea level rise adaptation strategy. They shared,

I know they're doing this deep well injection process now that makes me quite nervous... Yeah, so they're just sticking all the dirty water down a hole basically... It's taking hundreds of billions of gallons of water out of the water cycle and putting it into a hole, which I think is not sustainable. It's also a somewhat untested technology. What's going to happen to that water down there? Is it just going to stay down there forever? Is it going to migrate, is it going to contaminate the aquifer, is it going to create a methane bubble and become anoxic? It's becoming more and more clear that, particularly in Miami, where we have porous limestone, things are not very well contained underground, and... there are fissures even into the boulders now that we don't even know about.

People within the environmental discourse differed in their opinion of how impactful the high profile stormwater pumps and elevated streets in Miami Beach are to the environment. Some expressed concern that the pumps concentrate stormwater pollution and create more problems in Biscayne Bay that existed prior to the pumping. For example one scientist shared,

Well, it has been effective in short term lowering of the water in the streets. The downside of it is that the stuff is pumped into the bay without any real treatment. They might strain out a few chunks or something like that, but it's... So, North Biscayne Bay sea grasses are dying off, and it probably relates to turbidity in the bay, and it started to happen about the same time that the pumps were turned on. That's not proof that that's the case but... It's an observation, and one of the obvious candidates. FIU [Florida International University] did measurements of the nutrient loading in the plumes of stuff going into the bay, and the mayor of Miami Beach, [Mayor] Levine, was outraged because they were finding there 
were some problems with the amount of nutrients, and so, instead of working with them, basically a politician often attacks the messenger.

At the same time, some people from this discourse, including from environmental organizations, feel that the pumping is no worse than what's been going on in the past and that the real concern is a lack of stormwater infrastructure in general. As one individual shared,

On the scale of massive pollution issues I'm much more worried about the sewage infrastructure getting overwhelmed and getting millions or billions of gallons of sewage... Yeah, the bigger problem is we don't have good stormwater management, we have a shallow water table, we have too much water. Every time it rains we end up with infiltration in the sewage infrastructure. There's lots of storm water pollution, we don't have enough green spaces to let it percolate. I think that problem is only getting worse with sea level rise and salt water intrusion issues. It's like the pumps are very visible, and sort of high profile, so people are sort of fixated on them, but it's a much bigger problem than just for the Miami Beach where they have pumps.

While people working within local governments also share ecological goals, the pressure from those that are more central to the ecological discourse is pushing local governments towards those considerations. For example, within Miami Beach, government and nongovernment employees discussed how the pressure from scientists sampling water quality has resulted in additional sampling programs and efforts to design stormwater infrastructure to address bacteria and contamination at the water pump stations. Some interviewees shared that many of the activities proposed by the environmental community are long-standing issues. One consultant expressed,

The environmentalists in this county were the first adopters of the sea level rise and climate change. Environmental goals that were being pursued anyway are being strengthened. Restoration of habitat... of the Everglades protection. Things that were happening anyway. 
Most of what was already "happening anyway" center around Everglades restoration efforts aligned with sea level rise risks and adaptation. Restoring the natural flow of the Everglades and maintaining the brackish characteristic needed to sustain ecological processes in Biscayne Bay have long been ecological goals among environmental organizations and local and federal governments in the region. Among those within the environmental discourse, this goal of sending water south and "growing the bubble" is seen as preventing salinization of the Biscayne aquifer, an important water supply. The risk of salinization comes both from not enough aquifer recharge and from saltwater intrusion from sea level rise. This argument is also linked to other ecosystem needs for the Everglades and Biscayne Bay. As one individual shared,

But anyway, that natural flow that goes through the Everglades, that reestablishes freshwater flow there to the extent that it then continues into Florida Bay. The fresh water is important to Florida Bay because without it, the bay dies. It's that brackish water, the fresh water that collides with salt water, that creates these amazing estuaries for fish and natural life. But these other fish, it ends up being part of this whole fishing economy, that you hear about in the Florida Keys. That hydration needs to then continue to Biscayne Bay because there's evidence that the bay might be dying off in certain areas. Sea grasses are not there like they used to be. You don't want the bottom of the bay to be muddy. You want it to be filled with sea grass.

This issue framing around sea level rise and the Everglades restoration has historical context which impact modern conflicts and present challenges for restoration. In Palm Beach County, for example, the sugar industry has long been considered by environmental organizations as a big polluter and political power against sending the water south, which is viewed as necessary for Everglades restoration, and now for sea level rise adaptation. 
Ecological Discourse Summary: Within the ecological discourse, the problem is framed in relation to direct and indirect impacts of climate change and sea level rise on the environment. These include how inundation rates affect different species, ecological impacts of adaptation strategies, and the broader human impacts on the environment which places sea level rise among multiple threats. The role of private property rights and developers are also framed as part of the problem, with ongoing development in the region both producing ecological harms and long-term challenges for sea level rise adaptation. The environment is linked to the economy in that it supports tourism, quality of life, and the reason people are drawn to live in the area. Within this problem framing, there are different problem solutions that emerge, many focusing on the role of the environment in protecting infrastructure. Risks from climate change are considered much longer-term and more severe and calls for mitigation and planned retreat emerge from this framing.

\section{Community Discourse: People also Matter, and Risks are Not the Same}

The fourth discourse storyline emerged out of cultural rationality and emphasizes the need to consider the people who use infrastructure and the importance of including the public in adaptation planning. The emphasis is on low-income and historically marginalized communities which have a history of being left out of planning decisions in the city. As one community organizer expressed, "If you don't have a seat at the table you're on the menu." In addition to urban community organizations, people from South Miami-Dade County and the agricultural community expressed similar sentiments around being left out of planning efforts and had less awareness of sea level rise impacts to their 
region. The problem of sea level rise risks is framed both in terms of impacts to day to day life, the situatedness of historical and contemporary socio-economic factors, exclusion from the planning process, displacement from adaptation practices, and health and economic risks to the community from flooding and other impacts of sea level rise. Emergency preparedness for hurricanes and flooding events is another major concern for this group. Heat and other climate stressors factored into the risk understandings, as did other social and economic stressors, as interviewees articulated that they cannot be separated.

While some in this arena discussed flooding impacts and potential inundation from sea level rise in low-income communities, most focused on how sea level rise and climate change present a complex problem that extends beyond physical inundation. Within this context, the problem is framed not only around the impacts but also the inability of some communities to be able to bounce back. One community organizer shared,

As you know... low income communities, when you're having conversations about any kind of stress, like sea level rise or gentrification, the issue is not how they'll be affected, but the fact that they can't bounce back. They don't have the same ability to adapt to changes or stresses.

Several interviewees discussed this issue of not being able to bounce back in the context of public health challenges that will emerge from sea level rise and climate change. During interviews, several people within this group used Zika as an example and the role that the disease played in impacting low-income verses affluent communities. As one interviewee shared when discussing the variegated effects of Zika:

Sea level rise will present a whole new generation of public health threats, and when you don't have the money to adapt to those threats, you're 
uniquely affected. Zika is a great example because, when Zika came to Miami, many of the affluent or even just middle-class women that I knew that were pregnant. Yes. They were like, "Oh, I'll be in Canada. You have a blessed life. I'm going to have my babies Zika-free, wait until this all dies down, and then come back." Obviously, that's a privilege that a lot of women did not have. Especially, when Zika moved to Miami Beach, which is a very high affluent community compared to this area and to Little Haiti... So, Zika was just a prime example. But there's going to be other threats, and Zika's not completely eradicated yet. Let's not forget, mosquito season died down, but it's coming back...

Evoking the 2016 Zika crisis in relation to impacts from sea level rise and climate change is indicative of considerations for public health, socio-economic disparities creating different risk exposure, and different abilities to bounce back from risks. Similar logic was used to contextualize the issue of urban flooding from sea level rise, which is understood in a largely economic context among local governments. However, under the community storyline public health and different challenges in the community are emphasized. As one community organizer from this group shared,

We can talk about other public health threats, such as flood water exposure. You saw some of the pictures of the flooding during the tidal events in Shorecrest. They're just now trying to get shuttles that will transport residents down these roads. But if you lived there before, and there's articles that show, residents in knee, waist high water having to wade through... Now, there was a study done showing that, in the pumps that funnel the water into Biscayne Bay, there was traces of human fecal waste. Those studies haven't been replicated with the actual water that people are exposed to, but can you imagine wading through water that is clearly contaminated? There are probably floating animals and all kinds of things in there. There is the issue of trash and trash then being released into this water, that's moving and carrying things with it, so that's an issue.

Among those in this group, it was widely expressed that the local governments and planning arenas are not discussing public health issues and the concerns of low-income communities. People shared that because these issues only affect some people, and those 
people tend to have minimal political power and access to decision-makers, these issues are ignored. In discussing why no one is talking about public health issues including heat and increased frequency of diseases such as Zika, one person shared that,

Nobody talks about it... Because it's not affecting everybody. People think, well, we have A/C [air conditioning] units. People in low-income communities don't always have A/C units. The fact that we lack vegetation in most of our low-income communities. It's really, really hot... And I'm almost sure Liberty City and Little Havana are [hot]. I know down in Coral Gables and different places, they have these huge canopy trees.

Several shared how the dominant planning circles call Miami Beach and other low-laying coastal communities as "frontline" communities and related this terminology to the communities they are a part of and represent.

Yeah. So, why we call it frontlines is because, you know, they call it frontline communities that would be affected by climate... So, Miami Beach is definitely a frontline community, right? You can't deny that. But a place like Little Haiti, where they don't have money to pay a light bill. They don't have money to evacuate. They don't have money to buy hurricane supplies. So, that puts us in a more vulnerable situation than other communities.

One of the major concerns from institutions primarily focused around this discourse, is that people in the communities they represent and work with are very uninformed about sea level rise and the impacts that are coming. When a foundation became involved in sea level rise and resiliency planning they worked with local community organizations to understand the perspectives from the communities those organizations work with. People involved in that organizing shared that those community members were largely unaware of sea level rise being an issue. As one individual shared,

I mean, their concerns were that they had no idea. A lot of these people that came, this was new information. They had heard of climate change, but they didn't know that sea level rise was as big of a threat. They didn't 
know that climate change was a threat multiplier. With sea level rise it's heat, it's vector-borne diseases. It's food and water vulnerability.

People in this discourse also shared their concern for representational justice and having their voices heard. In different efforts by community organizations and foundations to gather and share information, several expressed the view that community members wanted more information and more contact with government representatives. Some people also talked about the challenge of bridging these connections because of distrust on part of the community for local government and non-government organizations from past injustices. For example, one person shared,

The African American community is not necessarily on good terms with the Red Cross, with government, because they feel that they are slighted, in obvious ways. So, I wouldn't say it's the best relationship, but I feel like creating these platforms is the first and best step to, I guess, like placating that kind of tension, I would say. I would say it's a little tense. They don't hate each other... but it's not the best.

Equity issues were viewed as not being included in conversations about sea level rise risks and adaptation strategies. When discussing what's not included in formal planning efforts one community organizer responded, “Equity. That's it, in a nutshell... we've seen the results of cities who don't plan for everybody. You have people sleeping on the highway for a week, waiting for assistance. Or living in a stadium." While those in this discourse shared that this is changing slowly and pointed to the Rockefeller Foundation 100 Resilient Cities initiative, they also shared that progress is slow. Many shared they have not seen changes in policies or the way decisions are made based on their participation.

Within this discourse, risks are understood to differentially affect low-income communities because they will not have the means to adapt, pay for damages to their 
homes, and fight displacement from climate gentrification. In addition, development and the focus on the economy are also part of the problem framing around risk. However, the difference in this framing is that developers are viewed as a threat to their communities from gentrification. In the context of development, one individual shared,

Miami has a development problem that we don't know how to balance. We don't know, really, how to redevelop for a community. We redevelop for a new community instead of redeveloping with a community. That's why I mentioned the hyper-gentrification. It's not regular gentrification where there's a few apartment buildings, some people come in, and then it's like mixed income. No. It's like, "All of ya'll have to go... It's like, "Here's the new crowd in this neighborhood" ...

Many people frame the challenge of gentrification as an economic problem with the city prioritizing economic interests over community interests. As one person shared,

Well, it's economics because we want to bring more money into the city. So these developers come with these mega projects, and we're like, "Yes!" What we don't think about is the fact that, as soon as that development is even approved, the property values in that neighborhood skyrocket.

Another part of the problem framing is that existing adaptation planning efforts focus on the economy, development, and things that both displace people and fail to address needs of low-income communities. For example, one individual discussed how conversations focusing on development ignore low income communities:

Planning and zoning is... I mean, they're a huge department. They cover a lot. One conversation, for the greater part of three hours, revolved around changes that can be applied to new developments. Now, there are not a whole lot of people in Miami that can afford the new developments that are being built, but you know who definitely can't afford them? People under a certain income. So, to me, it was another example of them addressing something that's not very important [to low income communities]. 
While this individual and many within this arena recognize the point of exploring building codes and economic components to address sea level rise, they argue that the policy and planning work around sea level rise cannot be purely economic. As one person elaborated on this:

A lot of the ways that you spur an argument, or you start the conversation and inspire action, is economic. You're going, "Look, you're going to lose your city, so whether or not you agree with me, this threat is coming. Do you want to be ready for it or not?" That doesn't mean that the conversation should stay economic though... Once you've started the conversation, and you've gotten the resources, then there's your opportunity to redirect it back too... Infrastructure matters. People also matter. We can have these conversations concurrently.

The economic context reads like three risks: a risk of communities being ignored, not having the resources to bounce back, and the risk of displacement from climate gentrification. Several situate this high elevation development pressure in a historic context. As one community organizer shared,

We had to have special passes to get over the causeway to go to the beach during segregation... So, when we had the conversation, all of those things came up. It was just so crazy how they pushed us to this one area because they didn't want us by the beach. And now the beach is flooding. Now they want to push us out and they want to come to the center of the city.

Community organizers share that people are experiencing climate gentrification as developers are buying land in low-income high elevation neighborhoods such as Liberty City and Little Haiti. This framing is based on personal experience. While referring to the woman who coined the term "climate gentrification," one community organizer shared, And she coined the term and every resident when you first hear the term. You're like, that's exactly what I've been hearing. Like, immediately you put two and two together. She didn't have any science behind it. But she just knew that we're starting to see this trend of developers from the beach coming into Liberty City. Buying up property. Buying up lots. 
In addition to personal observation within their communities, several organizers also referenced how they see newspapers quoting developers about this issue. In this way, the problem framing of risks from sea level rise includes private greed. One community organizer shared,

When you have certain developers. Peter Erlich, who was quoted saying that he's buying up Little Haiti because it's gonna be beach-front property. That furthers the evidence for us, right. And this guy despises Haitians. Real racist man. I don't like him at all.

Several outside this arena, while pointing to issues of gentrification experienced in these communities argue that it's not possible to prove that it is due to sea level rise. People within this group respond to such criticisms with examples of things they have heard developers say and that whether or not it can be "proved" is irrelevant because they see it happening. As one community organizer shared,

Well people will say we can't prove that's why they're doing it because they never said that's why they're doing it. They actually might not-it might not be a factor, or it could be... because they're very short-term thinkers, developers. Because they get a short-term buyout. So they could just be gentrifying it. But it doesn't matter to me because it's happening, so it doesn't matter what their intention is.

In response, community organizations point to the work of a geographer at Florida International University who has mapped out elevations and recent purchases by land developers across gentrifying communities (discussed in chapter 5, see Figure 5.5). When discussing this map and critics of the climate gentrification argument, one person shared,

This map here. Everybody shuts up now, because we have proof to show that it's trending. Maybe it's not happening as fast or as in-depth as we think it is. But it's happening. Right? It's real.

For solutions and sea level rise adaptations, those within this discourse focused on the need for hyper-localized approaches, efforts for distributional justice, and community 
organizing and education. This is like some of the views shared within the infrastructure discourse who shared the need to conduct localized planning to address social issues not captured by large-scale planning. To overcome issues of climate gentrification, for example, community organizing and education around issues of displacement are being used. People are also drawing attention to these community issues to get government spending on adaptation to support these communities. Many community organizers are focused on distributional justice and making sure communities get what they need in terms of adaptation to sea level rise and climate change. This was often independent of references to infrastructure investments and prioritizations. As one individual from a community organization shared,

And I don't know all the science and everything, but I'm more than sure, like, if you don't get rid of the water first, the water's not going to go anywhere. So, throughout all of that, I just really focused on making sure low-income communities get what they need.

During interviews about sea level rise, the problem was often discussed in relation to other climate stressors, for example heat waves. The problem around heat is partially framed in terms of distributional differences and inequities. This was discussed in relation to spending on sand dune restoration, resilience development, and infrastructure adaptations. As one community organizer shared when discussing how some of the resources could be redirected,

You should be pouring those millions of dollars into these houses so that these kids are not passing out from heat exhaustion in their own house. Instead, you're building a multimillion dollar skyscraper when there's ten other ones around you. So it's frustrating. It's very, very frustrating.

Surrounding community development and education, much of the focus is on preparing for storms and extreme events. As one person from a community organization shared, 
My work usually focuses on educating low-income communities and preparing us for storms and things like that... Hurricane preparedness and any other things I do there. Because the way things are going, we gotta expect more than just a hurricane, if we're not careful... also, I'm going to try to do a big push on heat.

While much of the storyline around people center around urban areas, there are similar storylines emerging in the southern, more rural part of the county. The agriculture community and community leaders in South Miami-Dade County expressed concern with being left out of planning conversations about many issues, including climate change and sea level rise. Though the agriculture community in South Miami-Dade County is new to this topic and currently lacks a cohesive problem framing around the issue, several from South Miami-Dade County shared that they do not have information on the impacts of sea level rise to their communities. These interviewees focused on how their unique experiences and needs are regularly ignored from planning processes. For example, several people shared that formalized climate change planning ignores issues relevant to the agriculture community. Some from the agricultural community took this further and shared that policies fail to support and at times cause greater challenges to agriculture communities. For example, land use policies that allow for development on agriculture land are resulting in increased development pressure and further loss of agriculture land. At the same time, several managers and government employees expressed that there is little that can be done to address sea level rise issues in the agriculture community because of inundation and salt water intrusion. While there are differences around storylines and problem framings between urban communities and agricultural communities, the general cultural rationality claims underscore both. Both express unique 
social challenges surrounding the way risks are experienced and being left out of planning processes.

Community discourse summary: Community based organizations and foundations within the community discourse frame risks of sea level rise around impacts to daily life, including housing affordability, health concerns, transportation, and more. Risks framed under the community discourse emphasize the social risks in how low-income and historically marginalized communities are uniquely at risk because they do not have the ability to bounce back. The storyline is based on cultural rationality claims as much of the reasoning behind it comes from peoples' daily lived experiences. The problem is also framed around issues of justice and being left out of decision-making related to climate change planning. Individuals within this discourse expressed their concern that many people from low-income and historically marginalized communities are unaware of sea level rise. Efforts to address these risks take place through building social capacity. This includes education and community organizing efforts.

\section{Seeds for a Communicative Approach}

The four discourse storylines offer an assessment of the primary modes by which institutions and individuals acting within those institutions frame the problem of sea level rise and adaptation planning. At the same time, however, institutions are not static and some individuals acting within the system do work towards integrating some of these disparate and at times opposing views. During the interviews, some individuals discussed different integrative approaches and expressed frustration with the challenge of trying to span certain discourse boundaries. Though not well enough established to be its own discourse, these boundary spanning activities offer places where there may be a more 
communicative turn in adaptation governance. This has occurred primarily through resiliency planning, community organizing and education, and efforts of the Compact.

Rockefeller's 100 Resilient Cities initiative has brought groups together who had previously been left out of climate change and created an official platform for the City of Miami, Miami-Dade County, and the City of Miami Beach to work together on resilience issues. While issues of equity had previously been ignored, the 100 Resilient Cities advisory committee was required include community organizations representing those issues. The 100 Resilient Cities framework also requires that local governments work to understand issues pertaining to the community to determine what planning assessments and efforts are needed. Most of the public participation was done via public polling and committee discussions. While these mechanisms have limitations in integrating the public into decision-making, nonetheless the 100 Resilient Cities initiative represents a government supported, broad public engagement effort around issues of resilience, including sea level rise. Some planners within local government as well as community organizers expressed that they are hopeful about the outcomes of this planning being able to integrate more perspectives into issues of climate change and sea level rise. At the same time, however, some were skeptical and shared that resilience planning is too broad and would distract the region from needed sea level rise adaptation planning. Several skeptics shared their frustration with local governments now claiming that everything they do is resilient planning, often referencing the Mayor of Miami-Dade County who made such proclamations.

Some environmental and community organizations work with regional universities and scientists to engage stakeholders, including the public, in discussions 
about climate change. For example, the CLEO Institute, a Miami based nonprofit organization dedicated to climate change education, engagement and advocacy, was discussed by people across all four discourses. Several interviewees shared that the "listening sessions" hosted by the CLEO Institute bring people with diverse interests into the same space. These listening sessions take place at the neighborhood scale and invite members from the community to share their concerns and experiences with climate change. Local government staff, primarily from resilience offices, attend these as do scientists and other stakeholders. People who may have otherwise not become involved in climate change and sea level rise learn about the issues and share their experiences in these listening sessions. Some of those individuals have become community organizers and participate on panels and committees. For example, based on their participation at listening sessions and other educational activities, several community organizations successfully made a case for having someone on the City's Sea Level Rise Committee representing their interests. Many interviewees noted that the presence of someone representing socio-economically marginalized communities on the City of Miami's Sea Level Rise Committee has broadened the dialogue towards more issues.

The Compact has been the longest collaborative effort in the region but has primarily focused on collaboration among local governments and to some extent environmental organizations. The Compact supports design charrettes which take place at very local scales. These charrettes may serve to model some of the hyper-local scale planning approaches that a few people from the infrastructure, community, and ecological discourses suggested are needed. Many interviewees from institutions that exist primarily outside this effort shared that the Compact is primarily for local 
government. However, recently this organization has been broadening its scope, in response to some of these criticisms and the acknowledgement of including more stakeholders. In the updated Regional Climate Action Plan 2.0 they added issues of public health, public outreach and engagement, and social equity, which many pointed to as a reflection of the change in who is involved. However, some still expressed their frustration with the Compact for being disconnected to issues that matter to different stakeholders. Several people from the agriculture community shared that the Compact emphasizes things (such as urban agriculture) that have little to do with the issues facing the agriculture industry.

While these efforts offer opportunities for boundary spanning, those individuals working in these efforts also express frustration with the current governance system limiting knowledge integration. For example, some within the environmental community vocalized that they would like to see local governments more actively pursuing green infrastructure for stormwater, integrating both ecological and infrastructure goals. Several also expressed frustrations that they do not have access to how local governments, including Miami-Dade County and the City of Miami, conduct their stormwater management planning. Those wishing to be able to comment or contribute different approaches and ideas to managing stormwater-primarily from the environmental discourse - expressed their frustration with not having access to this information or being able to provide input. At the same time, however, some from the community discourse shared that they think the experts should make decisions around how to design stormwater systems, and that it may not be appropriate for the community to provide input on engineering decisions. 


\subsection{Discussion}

Efforts to plan, design, and implement radical changes to the urban form—such as sea level rise adaptations - are often confronted by obdurate social, economic, and political systems embedded in physical structures (Hommels 2005). To overcome obduracy in the city, institutions make knowledge claims in support of new infrastructure and connect with other groups to garner political backing (Hommels 2005). Cities are contested spaces with different economic, social, and political interests vying for space and resources (Heynen et al. 2006). While urban transformations require an efficacious political process to take hold, the way these planning efforts are carried out - and the knowledge that goes into making these decisions - shapes social, political, economic, and biophysical aspects of the city and the overall outcomes of adaptation efforts. Within urban transformations, such as adapting to sea level rise, the process by which dominant ideas take hold is " practically accomplished and politically constructed... inherently, if not exclusively', by discursive means (McGuirk, 2012, p. 260). Discourse storylines about risk are not only used in the political planning process promoting climate adaptation, but become embedded in physical designs, plans, implementation efforts, strategies, and technologies (Hilgartner 1992). The discourse storylines that emerge in sea level rise adaptation planning in Miami-Dade County characterize the current governance system around this issue (summarized on Table 6.3). Once integrated into new technologies they transform those institutions and groups encountering the new proposed and implemented solution (Hilgartner 1992). 
Table 6.3 Summary of four emerging discourses within sea level rise adaptation governance in MiamiDade County, Florida

\begin{tabular}{|c|c|c|c|c|}
\hline & $\begin{array}{l}\text { Problem Framing and } \\
\text { Focus of Risk }\end{array}$ & Interpretation & $\begin{array}{l}\text { Boundary of } \\
\text { Problem Framing }\end{array}$ & $\begin{array}{l}\text { Adaptation } \\
\text { Strategy }\end{array}$ \\
\hline $\begin{array}{l}\text { Economic } \\
\text { Discourse } \\
\text { Economic } \\
\text { rationality } \\
\text { Actors: } \\
\text { Business } \\
\text { interests, } \\
\text { politicians }\end{array}$ & $\begin{array}{l}\text { Negative impacts to the } \\
\text { economy by via } \\
\text { property value, } \\
\text { business, insurance, } \\
\text { reducing investment, } \\
\text { and blight devaluing } \\
\text { property. Business and } \\
\text { private property } \\
\text { interests viewed as } \\
\text { roadblock to adaptation, } \\
\text { so framing the problem } \\
\text { around economy. }\end{array}$ & $\begin{array}{l}\text { Made legible } \\
\text { through formal } \\
\text { industry reports (e.g. } \\
\text { banking, insurance), } \\
\text { government } \\
\text { assessments, } \\
\text { advisory panels, } \\
\text { local meetings and } \\
\text { events. Emphasis is } \\
\text { sea level rise } \\
\text { inundation and } \\
\text { property values. }\end{array}$ & $\begin{array}{l}\text { Dev. short-term } \\
\text { profit thinking, } \\
\text { but re-frames this } \\
\text { and consider } \\
\text { resilient } \\
\text { development to } \\
\text { maintain } 30 \text {-year } \\
\text { mortgages and } \\
\text { lower insurance } \\
\text { costs (near-term). } \\
\text { Primarily along } \\
\text { the coast. }\end{array}$ & $\begin{array}{l}\text { Update building } \\
\text { standards, urban } \\
\text { design/planning } \\
\text {, new economy } \\
\text { around } \\
\text { adaptation, } \\
\text { focus } \\
\text { infrastructure } \\
\text { adaptations to } \\
\text { affluent areas to } \\
\text { use future tax to } \\
\text { pay for } \\
\text { adaptations. } \\
\end{array}$ \\
\hline $\begin{array}{l}\text { Infrastructure } \\
\text { Discourse } \\
\text { Procedural } \\
\text { rationality } \\
\text { (primary); } \\
\text { Econ. and Sci } \\
\text { (secondary) } \\
\text { Actors: Gov, } \\
\text { private firms }\end{array}$ & $\begin{array}{l}\text { Sea level rise will } \\
\text { impact already } \\
\text { overstretched and aging } \\
\text { infrastructure. This } \\
\text { includes: stormwater } \\
\text { management, canals, } \\
\text { wastewater treatment, } \\
\text { drinking water, } \\
\text { transportation routes, } \\
\text { evacuation corridors, } \\
\text { government buildings } \\
\text { and important sites. }\end{array}$ & $\begin{array}{l}\text { Government } \\
\text { assessments, } \\
\text { advisory panels, } \\
\text { meetings, and } \\
\text { events. Emphasis on } \\
\text { physical impacts to } \\
\text { infrastructure, } \\
\text { maintaining levels } \\
\text { of service set out in } \\
\text { policies and laws, } \\
\text { and political support } \\
\text { and funding. } \\
\end{array}$ & $\begin{array}{l}\text { Municipal } \\
\text { boundaries around } \\
\text { decision-making } \\
\text { authority; } \\
\text { temporal } \\
\text { dimensions of sea } \\
\text { level rise are } \\
\text { primarily } \\
\text { understood in the } \\
\text { relation to how } \\
\text { long infrastructure } \\
\text { is designed to last. }\end{array}$ & $\begin{array}{l}\text { Calculate } \\
\text { localized and } \\
\text { specific impacts } \\
\text { and design new } \\
\text { systems that can } \\
\text { withstand those } \\
\text { impacts. } \\
\text { Integrate sea } \\
\text { level rise } \\
\text { projections into } \\
\text { infrastructure } \\
\text { planning. }\end{array}$ \\
\hline $\begin{array}{l}\text { Ecological } \\
\text { Discourse } \\
\text { Scientific } \\
\text { rationality } \\
\text { Actors: Env. } \\
\text { orgs, } \\
\text { scientists, } \\
\text { Fed agencies }\end{array}$ & $\begin{array}{l}\text { Impacts of sea level rise } \\
\text { and climate change to } \\
\text { ecosystems, risks from } \\
\text { infrastructure failures } \\
\text { because of climate } \\
\text { change, and ecological } \\
\text { risks from adaptation } \\
\text { strategies themselves. } \\
\text { Concern with impacts } \\
\text { from ocean heat and } \\
\text { acidification. }\end{array}$ & $\begin{array}{l}\text { Assessments, } \\
\text { scientific monitoring } \\
\text { and reports, as well } \\
\text { as community } \\
\text { organizing around } \\
\text { climate change } \\
\text { mitigation. }\end{array}$ & $\begin{array}{l}\text { Geographically, } \\
\text { the problem spans } \\
\text { the entire region } \\
\text { and far into the } \\
\text { future. The } \\
\text { primary emphasis } \\
\text { is bound by places } \\
\text { experiencing } \\
\text { water quality and } \\
\text { habitat loss. }\end{array}$ & $\begin{array}{l}\text { GHG emissions } \\
\text { reduction, use } \\
\text { the environment } \\
\text { and ecological } \\
\text { restoration to } \\
\text { adapt to sea } \\
\text { level rise, to } \\
\text { protect } \\
\text { infrastructure, } \\
\text { water supply, } \\
\text { flood risk. }\end{array}$ \\
\hline $\begin{array}{l}\text { Community } \\
\text { Discourse } \\
\text { Community } \\
\text { rationality } \\
\text { Actors: } \\
\text { Comm. Orgs, } \\
\text { foundations }\end{array}$ & $\begin{array}{l}\text { People using } \\
\text { infrastructure also } \\
\text { matter. Risks of } \\
\text { exclusion from } \\
\text { planning. Distributional } \\
\text { justice concerns of not } \\
\text { getting resources and } \\
\text { displacement. Concerns } \\
\text { over extreme events } \\
\text { and socio-economic } \\
\text { vulnerability, not being } \\
\text { able to bounce back. }\end{array}$ & $\begin{array}{l}\text { Not all the risks are } \\
\text { biophysical, there } \\
\text { are also social and } \\
\text { economic risks } \\
\text { related to climate } \\
\text { gentrification. Also, } \\
\text { risks to public health } \\
\text { understood from } \\
\text { heat impacts, sea } \\
\text { level rise, and new } \\
\text { diseases (e.g. Zika). }\end{array}$ & $\begin{array}{l}\text { Bound in the } \\
\text { context of what is } \\
\text { occurring in local } \\
\text { communities and } \\
\text { often temporally } \\
\text { restricted to } \\
\text { challenges } \\
\text { communities are } \\
\text { experiencing now. }\end{array}$ & $\begin{array}{l}\text { Community } \\
\text { organizing and } \\
\text { education to be } \\
\text { included in } \\
\text { planning } \\
\text { activities, } \\
\text { inform people } \\
\text { of the issues, } \\
\text { and create } \\
\text { platforms for } \\
\text { elevating } \\
\text { voices. }\end{array}$ \\
\hline
\end{tabular}


By examining discourse storylines, it is possible to identify places where groups are in alignment and where tensions may emerge in a diffuse governance arena. Across all discourses, problem framing is tightly linked to proposed solutions. For example, ecological problem framings are linked with the use of ecosystem processes to mitigate impacts from sea level rise. Likewise, impacts to the community are matched with the need to educate people and create opportunities to integrate diverse voices into adaptation decisions. Similar patterns follow the economic and infrastructure framings. Further, the role of private property is brought up in all four discourses though intersects with problem framings and storylines in different ways. For each, private property is seen as an impediment to adaptation solutions and/or as a source of risk. In the ecological discourse, for example, private property is viewed as a barrier to implementing ecological adaptations such as sand dunes and mangroves. Those in the community discourse view the focus on risks to private property as something that excludes their interests from the planning process. For the economic discourse, private property is used to frame the problem of sea level rise, with risk shaped by property values and threats to private property. This has similarities with the infrastructure discourse which complicates the issue of private property surrounding service delivery.

The two most closely aligned discourses are the economic and the infrastructure discourses. Within the economic discourse, part of the problem is framed around existing and ongoing high-value development within low-lying areas that are viewed as being vulnerable to sea level rise. Because local governments (the primary group involved in the Infrastructure Investments discourse), are concerned with maintaining their tax base, 
this gives individuals within the economic discourse practical authority in the governance arena. There is evidence for this in that several members from the business community are represented on sea level rise and climate change task forces and advising groups. Of course, not all interests are aligned and those within the infrastructure discourse are responsible for addressing non-economic factors to maintain quality of life, ecological processes, and other goals. At the same time, people from the business community and others shared how businesses push back against local governments for regulations that create barriers to economic growth. From the infrastructure discourse, the emphasis on risks to infrastructure and the link between infrastructure and tax-dollars creates a further justification to engage with the business community. In addition, both the business and the infrastructure groups view risks from sea level rise from a highly biophysical and engineered perspective, framed in the context of risks to property value and insurance rates. This framing places the focus of sea level rise solutions on engineered, technical solutions while avoiding challenges around land use and social and environmental impacts from those solutions_-including new, resilient urban development. Local governments primarily emphasize infrastructure to stabilize the risks of sea level rise and ensure ongoing investments and insurance stabilization in the region. This emphasis placed on infrastructure creates a knowledge arena that favors engineered, technical knowledge and solutions and serves as a barrier to other interests, primarily ecological and community based.

Within the ecological discourse, there is some alignment with the economic and infrastructure discourses in that many evoke the role of the environment in protecting the economy and built environment. Some ecologically based activities, for example beach 
re-nourishment, demonstrate this link. While beach re-nourishment comes out of infrastructure protection, many from the ecological discourse pointed to it as a "win-win" solution, that it is good for the environment, infrastructure, and economy. At the same time, economic and infrastructure impacts to the environment are viewed in tension. Longer term and more complex impacts of climate change and sea level rise are connected to calls for retreat and greenhouse gas emissions reduction.

There is also some overlap between the ecological discourse and the community discourse. Both discourses frame part of the problem around the emphasis placed on economic growth in the region at the expense of their interests. There has been some alignment around calls for greenhouse gas emissions reduction and community organizing around improvements to the local environment. At the same time, these discourses are largely distinct with the environmental discourse focused primarily on "traditional" ecological concerns such as Everglades and Biscayne Bay restoration activities and the community discourse emphasizing hyper local and contextual experiences.

The four discourse storylines around sea level rise adaptation governance that emerged out of Miami-Dade County, Florida share commonality with other studies and work on discourses around the environment. In terms of the tensions among the different groups, this case study demonstrates how those are linked to different forms of rationality and power dynamics (Hajer 1995; Fischer 2000; Bäckstrand and Lövbrand 2006; Dryzek 2013; Taylor et al. 2014). Although conflicts between competing discourses will happen — different sides of a conflict interpret the issues at hand in different ways and the way an issue is dealt with depends partly on the balance of competing discourses (Dryzek 
2013). Within Miami-Dade County, the economic and infrastructure discourses are primarily aligned with the most decision-making authority and power around adaptation strategies. The infrastructure and economic discourses embody power which can advance economic and growth interests while suppressing others (Foucault 1980). This is not surprising given the privileged position of business in city planning because of tax revenue (Lindblom 1978) and urban growth machine politics (Logan and Molotch 1976).

In considering the economic discourse, problem framings are born out of the inevitability of financial impacts and the political inertia created by the business community. This problem framing shapes much of the emphasis around planning activities that support economic growth, reframing the issue around creating economic opportunity. While climate adaptation studies have pointed to the way in which risks from climate change are often understood in economic terms (Adger et al. 2005), it is more complex than that. In Miami-Dade County, these risks to the economic core relate to a view that they are also an opportunity to reshape the economy around an adaptation and resilient development economy. Echoing calls for ecological modernization, in which the economy is reshaped to support the environment (Bäckstrand and Lövbrand 2006), business leaders and politicians that evoke the economic discourse storyline in MiamiDade County emphasize opportunity in the context of economic risks. Like critics of ecological modernization theories, critics of this framing in Miami-Dade County point out the contradiction: that the same economic rationality used to justify adaptation planning is also creating the economic problem (Dryzek 2013). Critics of this logic point to the ways in which ongoing development in the region-no matter if striving for resilience from sea level rise-will continue to grow economic risks. 
Local governments that primarily emphasize the infrastructure discourse latch onto the economic framing to overcome political inertia and advance future growth in the region. Within both discourses, large-scale retreat is not considered a viable option, and local governments emphasize infrastructure to adapt the physical landscape to protect and encourage economic investment. The combination of the emphasis on infrastructure and the economy offers problem and solution framing to support ongoing growth in the region. While this tactic is focused on maintaining community function in the region, the primary underlying objective seems to be either in protecting assets from physical impacts or from changes and risks of the insurance industry. The emphasis on having formal assessments to base planning choices on are situated in procedural, economic and certain scientific rationalities, leaving out and conflicting with community-based interests. At the same time, the science used for infrastructure decisions often ignores ecological science and debates in longer-term and more climate change complex impacts on the environment. The divergence of these discourses is not perhaps surprising. In other regions, pro-growth discourses have been shown to run in opposition of adaptation planning and greenhouse gas emissions reduction. For example, Taylor et al. (2014) examine the tensions between urban growth and climate adaptation discourses in Queensland, Australia with pro-growth largely in conflict with GHG emissions reduction and adaptation. The shift away from greenhouse gas emissions reduction and towards the economy around adaptation is connecting what may otherwise be divergent discourses in Miami-Dade County. However, the emerging discourses around the economy and infrastructure shut out some discussions of retreat and greenhouse gas emissions—and science used to inform those arguments - in favor of a pro-growth future. 
The tendency for economic and procedural rationalities to be tied to formal and contextual forms of power and authority within institutional arrangements governing the urban environment is being re-produced in the context of sea level rise adaptation planning. While such linkages have a long history in planning theory and practice, the threat of sea level rise is primarily viewed as a highly expensive and engineering challenge, places more emphasis on those rationalities. What this case study suggests, is that although there are calls for integrative approaches that consider social and ecological risk factors within the governance arena, these occur on the margins. Community groups expressed feelings of being left out of planning processes and not having their interests represented or discussed. Part of this is because of the view that sea level rise threats are largely economic and physical, it seems to those that subscribe to these dominant discourses believe that there is little need for attention to other interests. Interests within the ecological and people-centric discourses are often infringed upon and go unconsidered by the dominant narratives around problem and solution framing.

While the divergent storylines and interests create numerous planning challenges, this case study also points to actors and activities that strive for more integration. These places of integration represent seeds for where more communicative rationality efforts can start to lead the way and help address many of the challenges discussed above. A collaborative process can be communicatively rational "To the extent that all the affected interests jointly engage in face-to-face dialogue, bringing their various perspectives to the table to deliberate on the problems they face together... all participants must also be fully informed and able to express their views and be listened to, whether they are powerful or not. Techniques must be used to mutually assure the legitimacy, comprehensibility, 
sincerity, and accuracy of what they say. Nothing can be left off the table. They have to seek consensus." (Innes and Booher 2010, p. 6). Based on ideas from Habermas (1984) and Dewey (1927) and brought into the planning field by Healey (1997) and Forester (1999), collaborative processes designed to generate collaborative rationality can produce effective options for how actors can move forward together, and allow for collective learning that will help make communities more adaptive and resilient (Innes and Booher 2010). In the Miami-Dade County case study, the 100 Resilient Cities initiative, community outreach and involvement practices by local organizations, and the Compact have certain elements that offer possible direction for collaborative planning. For example, each of these initiatives is bringing diverse interests and people into the planning process and opening the conversation around sea level rise to other perspectives and problem framings. While some of the divergent interests have yet to be formally addressed in planning processes, the connections being made are bringing stakeholders that had been left out of sea level rise into the planning process.

Design charrettes and activities looking at neighborhood scale have begun to build these connections. The Compact has played a large role in supporting these efforts which bring together universities, governments, scientists, and stakeholders for short, design charrettes to look at a small area. This type of work could be expanded and formalized by local governments. Broader public engagement efforts are needed around resilient community design activities. Because existing efforts have tended to be on shorter planning timelines, they have been limited in public engagement.

Within Miami-Dade County, building off the existing collaborative approaches could move the region into a more communicative approach. One mechanism would be 
to adjust the role of the Resiliency Officers, supporting the 100 Resilient Cities Planning Effort, from one that is primarily internally focused as cross bureau relationship managers to a position that incorporates communicative planning. Resilience Officers could work integrate communicative planning process into all dimensions of infrastructure and planning choices by creating education and outreach materials, establishing community advisory committees, and creating an equity and justice division to provide oversight. There is currently a lack of community dialogue being integrated into infrastructure adaptation planning decisions. Establishing the role of Resilience Officers as one that expands public engagement around cross-bureau planning activities could help address this issue.

These cross-sector efforts show early signs of groups working together to find more holistic and joint problem framings around the risks of sea level rise. Another potential mechanism to integrate a more communicative approach could be to use joint fact finding to frame the problem of sea level rise (Susskind et al 1999; Innes and Booher 2010). The approach connects diverse stakeholders to the process of identifying risks and creating and using different forms of knowledge to frame problems and solutions (Innes and Booher 2010). In Miami, this could occur with community derived baselines of acceptable risks that currently exist outside of mainstream activities and instead be integrated into existing assessment processes. This practice can be a powerful tool where even if the outcome was not what the group predicted, they may still be happy with the decision that was made. For example, Inness and Booher (2010) point to a case in which stakeholders brought together by the CALFED Bay-Delta Program agreed to close off one channel to allow more flow into the delta in fear of drought conditions. All the 
participants agreed, including the Los Angeles Metropolitan Water District, which was significantly harmed by the decision. These participants testified that though the result was unsatisfactory, and there was a mistake in judgement (the drought did not occur) that the decision was right. Collaborative approaches can help uncover issues of dubious findings, opens-up assumptions, identifies biases, and dismisses unsupported claims and ultimately, the "truth" is whatever the group agrees upon (Innes and Booher 2010). More participatory activities around different infrastructure projects could produce similar results in Miami. This would require a restructuring of the way infrastructure is assessed and planned for from one that is predominately expert driven towards a process that is more open and engaged with the broader community. Efforts by the City of Miami Beach to provide public information surrounding adaptation planning are a good start, but more mechanisms for public engagement and integrating diverse perspectives would help the city and the region overcome some of the current conflicts and challenges.

\subsection{Conclusion}

This chapter used an institutional discourse approach to examine sea level rise adaptation governance in Miami-Dade County. Within Miami-Dade County, there are several governmental and non-governmental institutions involved with sea level rise adaptation planning, and these activities take place across a variety of adaptation strategies. The four emerging discourses — around the economy, infrastructure, environment, and community - mirror other findings around discourses related to environmental changes and risks. The economic and infrastructure discourses are at the core of adaptation governance while discourses around the environment and communities exist on the periphery. Though the case study shows that the region has yet to achieve 
integrative approaches across divergent discourses, these institutions and the governance arrangements are not static. The case study also demonstrates that some activities and individuals are actively working to address these issues. It is in those activities where communicative approaches may expand and integrate broader aspects of the system. 


\section{Chapter 7 Miami-Dade Case Study Conclusions, Theoretical and Planning Contributions, and Recommendations}

Some people are very gloom and doom, but that's also sort of by necessity, because we don't really know what to do about it. There isn't one easy silver bullet that's going to fix it like, "If we just paid for this thing it would fix everything." The geology here is very difficult, we have so much infrastructure along the water, and we have a state that won't talk about climate change. We have cities and counties that are relatively recently talking about this as an issue, and we don't have great plans.

-Environmental Organizer in Miami-Dade County, Fl

\subsection{Summary of Findings from Miami-Dade County, Florida}

In Miami-Dade County risk construction around sea level rise generally follows a hazards assessment approach. Local governments, scientists, and other institutions seeking knowledge about the risks from sea level rise emphasize reducing uncertainty around rates and projections and how that will interact with the local landscape and hydrogeologic conditions. The process of determining what risks to select is a negotiated and contested political process underscored by climate change denialism, scientific reticence around ice melt acceleration, and political uncertainty as to how people would react to higher projections. The need for a narrow range of sea level rise projections comes from local governments requiring specific numbers to design and implement adaptation planning activities. Part of the desire for local governments to strategically identify solutions is in response to the scientific uncertainties and tendency of some people to be very "doom and gloom" as described in the quote from an environmental organizer at the beginning of this chapter. Local governments strive to create hope and present a future for people in Miami. To do so, they promote risk knowledge that can allow them to present a secure future for people in the region. At the same time, 
knowledge suppression practices may also present minimized risks to the landscape to continue allowing economic growth in the region.

Considering sea level rise adaptation governance, there are several governmental and non-governmental institutions involved with sea level rise adaptation planning, and these activities take place across a variety of adaptation strategies. These diverse groups frame the risks of sea level rise around four emerging discourses-focused on the economy, infrastructure, environment, and community. Economic and infrastructure discourses are at the core of adaptation governance while discourses around the environment and community exist on the periphery. This privileged framing connects with risk construction and knowledge practices around risk.

In linking the findings from Chapters 5 and 6, narrative discourse storylines that frame risks from sea level rise in the context of the current and future economy and infrastructure closes-down knowledge production practices and serves to limit diverse knowledge integration around risks. The self-fulfilling process that frames risks from sea level rise as a threat to the future of Miami's economy places much of the emphasis on knowledge practices and identifying solutions to minimize risks to the economy. While the case study shows that the region has yet to achieve integrative approaches across divergent discourses, it also demonstrates some activities that are currently trying to address the lack of integration. It is in those activities where communicative approaches may expand and integrate broader aspects of the system.

\subsection{Situating Case Study Findings in Risk and Planning Theory and Practice}

Within environmental planning, theorists examine the way in which institutions understand risk and how diverse understandings can lead to conflicts, barriers to 
implementation, and uneven benefits and harms (Beck 1992; Fischer 2000; Bocking 2004). This work has been applied in several different planning contexts. When applied to environmental toxicants, for example, local communities, environmental organizations, and other affected parties are often less willing to accept government and industry standards for "safe" levels of exposure, advocating instead for stricter regulations and "cleaner" environments (Fischer 2000). Standards around allowable levels of contaminants in the environment that favor economic interests over community interests can result in community pushback in the form of protests and lawsuits at best, and public health crises at worst. Risk literature on hazards shows how risks are disproportionately distributed across the landscape, often with low-income and historically marginalized communities exposed to more hazards (Wisner et al. 2014). What these and other studies point to is that although there are multiple ways to understand and come to "know" risks, the planning arena often prioritizes risks that are understood through a top-down government driven process that favors some knowledge over other knowledge. Part of this is based on the role of uncertainty, and the drive for governments to present certainty and confidence in their ability to manage risks (Innes and Booher 2010). The desire to represent risks as measured and manageable is wrapped up in the need to establish trust and confidence among the public (Beck 1992). At the same time, however, such top topdown knowledge practices are often disconnected with other ways of understanding risk, and the desire for certainty in a complex and uncertain world can backfire. This can occur through community pushback, distrust, and with the reproduction of social inequities through risk management. Because of these challenges, risk theorists regularly call for 
integrative approaches to incorporate social and cultural components into the production of risk knowledge, prioritization, and planning (Wisner et al. 2014).

From knowledge systems literature, we know that either intentionally or unintentionally ignoring different forms of knowledge—especially around risks—can result in barriers to risk knowledge integration and disproportionate planning outcomes that favor some communities over others (Miller and Muñoz-Erickson 2018). The MiamiDade County case study on sea level rise adaptation planning points to similar processes around risk. At the same time, however, institutions governing risk are not static and even if limited, risk knowledge is leaning towards more integration going forward.

Applying risk construction and knowledge integration to the context of climate change adaptation planning expands theories and practice around risk in key ways. While the risk literature often focuses on a hyper local scale, risks from climate change are understood at a global scale and are dependent on models compiled from local scale data sets (Edwards 2001). There is also a temporal mismatch on how risks from climate change are understood, in that risks that are understood as possibly occurring in the future are measured, prioritized and planned for now. These future risks also shape present day discourses around how the problem is framed, understood, and different solutions for addressing those risks. Projecting climate into the future and at global scales has several uncertainties that are debated, politicized, and lead to additional scientific research to reduce those uncertainties (Edwards 2001).

Although the global and temporal distinctions surrounding climate change risks create new risk construction challenges, there are several components of climate change adaptation planning that are like other risk construction and planning contexts. Primarily, 
global and temporal constructions of climate risks are interpreted and adopted at regional and local scales (Adger et al. 2005). Such localized processes mirror other risk practices in which global, scientific knowledge (i.e. around contaminants, technologies, hazards) are debated and brought to bear in local settings. Like these other risks, knowledge about the biophysical hazards of sea level rise are constructed and then converted into risks by governments and non-governmental institutions in the way that those hazards are understood to intersect with social, ecological, and technological systems (Adger et al. 2005). The centrality of both decision-making authority and knowledge production practices around risks echo Muñoz-Erickson's (2014) findings on knowledge practices around land use in San Juan Puerto Rico. Like Muñoz-Erickson's (2014) findings, in Miami-Dade County, institutions that dominate knowledge about risks from sea level rise also make most of the decisions. This suggests that a lot of what we know about risks from sea level rise are filtered by values of actors controlling adaptation resources (Muñoz -Erickson 2014). At the same time, from the experience of Miami-Dade County identifying, prioritizing, and planning for risks from sea level rise, we see that risk knowledge is also contested. It is through the different contestations that we see how future and current uncertainties around sea level rise risks create a planning arena in which risks are open to social construction (Beck 1992). The local governments' perception for a need to identify tangible risks and to mitigate these risks creates problem closure around risk construction rooted in biophysical and economic framings (Hajer 1995). The question then becomes how to situate these findings in the context of risk and planning theory and practice, how this links back to the problem of planning for sea level rise adaptation, and what actions can be taken to address these issues. 
The case study on knowledge practices and sea level rise adaptation governance in Miami-Dade County contributes to the theoretical and planning literature around risk knowledge production and governance in three important ways: 1) Risk knowledge about sea level rise is constructed and prioritized in a primarily top-down approach;2) This construction of knowledge for action is created in political, social, and economic contexts and shaped by the idea of taking action and what is possible to manage; and 3) The way in which risk knowledge is constructed, favoring certain political and economic values over other values on the landscape, creates a planning arena in which the "facts" are already stacked against groups representing other interests.

First, risk knowledge constructed and prioritized in a primarily top-down approach produces knowledge that is situated in plans connected to drive action. Risk is a concept that is fundamentally connected to uncertainty. If societies knew the exact outcomes of a situation or decision, there would be no risk because they would have perfect information of how to act to mitigate that risk. Climate change risks are understood in different ways and shaped by different knowledge practices and epistemic choices that can drastically change their significance, level of uncertainty, and magnitude of the outcome. While the exact rates and impacts of sea level rise can never be known, institutions create knowledge around what they think those impacts might be, and this knowledge is shaped by institutional positionality as well as interactions with outside pressure and knowledge acting on those institutions. This process in Miami-Dade County continues to unfold as a system of complex relationships and forms of knowledge and is bound by codified institutional arrangements and power structures. 
Risk knowledge that falls outside of what can systematically be planned for is ignored in dominant problem framings, planning documents, and formal public forum. In the early 2000s, knowledge of impacts from climate change began to reach the mainstream media and concerns over sea level rise placed Florida—a very low-lying state - at the center of these narratives. Former Vice President Al Gore and others were discussing the vulnerability of South Florida and cities within Miami-Dade County early in this process. Locally, geologists, other scientists, and environmental groups mobilized around climate change and sea level rise impacts. At the same time, king tides, rain events, and the threat of storm surges put pressure on local governments to address flooding issues. Local governments in Miami-Dade County began to pay attention to issues of sea level rise and wanted to "get ahead of the issue" to change the global narrative of doom and gloom. In the mid and late aughts, local governments began assembling committees, task forces, and adopting ordinances for how to understand and address these issues. This organization was partially in response to the global narratives of the insurmountable risks that cities within Miami-Dade County would suffer including destruction and economic loss if they took no action to adapt.

Based on this risk of economic loss via changes to the insurance and reinsurance industries, flooding, and loss of investments, local governments have been the primary focus for actions deemed necessary to change the global narrative around destruction, towards a narrative of continued growth. To do so, knowledge about risks were shaped in a way commensurate with the ability to act and systematically identify risks and plan to mitigate those risks. To control the narrative around action, risk knowledge about sea level rise has been and continues to be constructed and prioritized in a primarily top- 
down, technocratic approach. This produces knowledge that is situated in plans connected to drive action. Because much of the knowledge about sea level rise risks comes from technocratic planning activities by local governments, that knowledge is primarily constructed in relation to priorities and actions of local government. The emphasis on infrastructure, building codes, and insurance are rooted in a system that prioritizes the primary roles and responsibilities of local government.

By understanding risks via what institutions governing risk care about, we also see that the risk knowledge is shaped by the constraints around what can be done to mitigate those risks. Within Miami-Dade County, we see this in that most of planning activities that are designed for no more than 30 years—or 2 feet of sea level rise-into the future. The idea that planning for any more than that would "kill the economy," as several planners shared. Knowledge suppression practices around the hydrogeologic connections between groundwater, surface water, and broader impacts from climate change take place to minimize risks on the landscape. This is in part because acknowledging these impacts would render future land use planning as currently envisioned impossible, since more of the region would be deemed undevelopable. Risk knowledge that falls outside of what can systematically be planned for is also ignored in dominant problem framings, planning documents, and formal public forum.

While this case study also points to places of intervention, where individuals acting within the system are seeking more integrative approaches, the present trajectory around knowledge production practices around risk suggest that these attempts will continue to fall short. This is because most of these strategies to integrate diverse perspectives take place following the knowledge production process, and this risk 
knowledge already embeds values that may not align and may run counter to other interests on the landscape. The way in which risk knowledge is constructed, favoring certain political and economic values over other values on the landscape, creates a planning arena in which the "facts" are already stacked against groups representing other interests. Drawing on recent knowledge systems work by Miller and Muñoz-Erickson (2018), collaborative planning work of Innes and Booher (2010), and others, for regions to integrate diverse constructions of risk, they must pay attention to the design of their knowledge system and integrate more stakeholders into the planning process.

\subsection{Strategies to Address Risk Ambiguity Challenges in Climate Change Adaptation Planning}

While it is often thought that planning is about linking knowledge and action (Friedmann 1987; Innes and Booher 2010), we now extend this to question the nature of that knowledge and its purpose for action (Miller and Muñoz-Erickson 2018). The quality of knowledge reflects the process of how knowledge was made (Miller and MuñozErickson 2018) and who participated in the production of that knowledge (Innes and Booher 2010). Unfortunately, institutions often lack a clear understanding of how their knowledge is constructed and based on the organization's own values, routines, assumptions and other factors which can be both explicit and hidden (Miller and MuñozErickson 2018). The different ways in which institutions construct risk knowledge can create ambiguity emerging out of different problem framings and ways to understand the problem. Overall, reflexivity, or self-confrontation and self-reflection, provides an opportunity to change this practice. The call for reflexivity in the biophysical and social 
sciences urges scientists to examine how the knowledge they produce, and the methods used to produce it, are influenced by political, historical, cultural and social processes (Harding 1987; Boström et al. 2017). Interest in reflexivity emerged from concern about how "truth claims" serve particular political and private interests. More recently, scholars have extended the call for reflexivity to environmental governance (Dryzek and Pickering 2017), to examine the politics of knowledge, public discourse, and institutions to improve policy outcomes. Others have begun to develop models for institutionalized reflexivity where environmental institutions develop mechanisms for examining their own political commitments, constraints and assumptions, opening these issues to public debate (Boström et al. 2017).

I echo the call for reflexivity to the practice of identifying and planning for risks from impacts and climate change. While some of the knowledge practices within MiamiDade County point to the overshadowing of diverse representations of risk in framing the problem and identifying solutions, there are also actors working towards knowledge integration. In this vein, I use the findings from Miami-Dade County-both the challenges and the opportunities - to offer recommendations to create more integrated ways for regions to assess and manage risks from climate change, overcoming challenges related to risk ambiguity.

Train experts in areas outside of their disciplinary boundaries

Part of the challenge around risk knowledge integration in Miami-Dade County are the epistemological conditions surrounding expertise. Within sea level rise adaptation planning, it is often engineering expertise that is relied upon for decision-making. This expert knowledge has epistemic rules that influence the construction of risk knowledge. 
In Miami-Dade County, for example, engineers and experts producing most of the knowledge about risks are not necessarily trained to account for social and ecological system components. Several shared that the risks are primarily physical and saw engineering analysis and solutions as being equal across socio-economic conditions. This problem is not unique to sea level rise risks, but other work points to epistemic challenges around how risks are measured, and experts having certain rules of their field (Miller and Muñoz-Erickson 2018). Because this problem is ubiquitous across different types of risks, scholars have begun to identify ways to shift the epistemic rules guiding expert disciplines. For example, Jack Ahern (2011) presents an argument to change engineers thinking from "fail safe" to "safe to fail" to incorporate ecological processes and dynamic natures into engineered systems. Engineers often place the emphasis on over designing systems so that they will not fail, similar to the findings in Chapter 6 around policies that emphasize "hard" infrastructure. While fail safe designs are important in many contexts, natural systems are dynamic and impacts from climate change introduce additional uncertainty into the system. In response, the call to transition thinking to "safe to fail" introduces more flexibility into engineering epistemic views (Ahern 2011), similar to the calls for flexible infrastructure in Chapter 6. This is only one example, experts that represent the dominant knowledge framings around risk can be trained outside of their disciplinary boundaries to reframe the epistemic conditions which guide those knowledge practices. This can occur with climate scientists working with philosophers, engineers intersecting with social scientists, and other forms of disciplinary integration.

\section{Create multi-faceted risk assessments}


Most of the formal risk assessments used in Miami-Dade County emphasize economic and infrastructure risks, including property value, stormwater infrastructure, and transportation infrastructure. There is a critical need to expand this to integrate social and ecological risks into core municipal government planning assessments. A goal for regions undergoing adaptations to climate change should be to create multi-faceted risk assessments. While these currently exist on the fringe in Miami-Dade County, local governments have most of the decision-making authority over how to prioritize actions and they rely on risk assessments that ignore social and ecological components. Recent advances in hazards literature incorporates social dimensions of hazards (e.g. Solecki et a. 2011; Wisener et al. 2014), which can include different socio-economic characteristics such as income level, number of minorities, different health indicators, and other characteristics that relate to social vulnerability (Solecki et al. 2011; Wisener et al. 2014). Integrate an equity lens into planning

Local governments could conduct assessments that relate to those who are the most socio-economically vulnerable and address some of the concerns and questions raised by community organizations. For example, rather than only examining the impacts on changes to the insurance industry, local governments could conduct assessments of how those who do not carry flood insurance will be affected. Another concern that could be assessed includes climate displacement due to inhospitable living conditions and adaptation policies. In addition to conducting a formal assessment of this issue, local government could track where people are being displaced to and the risks that surround their new location. Researchers are integrating these kinds of approaches, called coproduction of science and actionable science (Vogel et al. 2016; Kjellström et al. 2016; 
Beier et al. 2017). While this has largely focused on better establishing relationships between scientists and managers, this field is expanding to incorporate broader stakeholders in the production of science that can be directly used in decision-making (Innes and Booher 2010; Miller and Muñoz-Erickson 2018). There are many ways local government could use these approaches to create integrated risk assessments or assessments for interests currently on the fringe. For example, during the CLEO Institute's listening sessions, communities highlight issues of pressing concern. Local governments and researchers could build assessments framed by these concerns, putting resources to answering and solving problems that matter to the community. The climate gentrification map that came out of a Florida International University professor attending a listening session is a good example of knowledge co-production. Local governments better connected to decision-making and resources could work with the existing community organizing efforts and relationships to allocate funding for assessments that seek to understand risk from diverse perspectives, including assessments framed by the community. This can also be paired with more participation in risk evaluation and setting baselines for management.

\section{Broaden adaptation measures with plausible scenarios approach and incremental} planning

Risk theorists argue for increased participation in decision-making that surround knowledge production and governance of risk (Beck 1992; Fischer 2000), applied to climate change adaptation planning this means broader participation in risk evaluation and setting baselines. Within Miami-Dade County, most of the decisions surrounding how to measure, assess, and prioritize risks take place in a closed off arena of experts and 
decision makers. This process has served to limit broad representation and integration of risks. In addition to ecological and social risks existing largely on the periphery, planned retreat is primarily ignored. This is in part due to current accepted baselines and risk framings demonstrating the possibility of continued growth. However, many scientists and even some planners argue that these baselines are a minimum and that actual sea level rise rates and impacts will be far greater.

Incorporating broader participation into decisions surrounding baselines and risk evaluation would enable civic dialogue and engagement around risk (Beck 1992; Fischer 2000). There is very little information regarding public perspective on rates of sea level rise, because the regionally adopted government projections are assumed to be the "real" rates from which peoples' perspectives are measured against. These "real" rates could either be wrong, or as many scientists suggest in the case study, should be taken as a minimum. This suggests that broader adaptation measures should be taken to capture more plausible futures, or futures that wider stakeholder groups view as plausible, including the upper boundaries of the risk.

Presenting upper boundaries of the risk for planning can have its own challenges because addressing large scale change is difficult in any planning context. One approach to include the upper boundary of the risks would be through looking at incremental changes overtime using plausible scenarios that look at several planning horizons. Broader participation in decisions surrounding what different incremental planning horizons to include along with the upper boundaries of the risk would help the region identify incremental planning solutions to address issues at different stages. A plausible futures scenarios approach with different temporal increments of potential change can 
engage communities to consider ways to address the issue of uncertainty around different climate futures at different planning horizons (both short term and long term) in the future. This would entail planners to open-up the climate projections they have currently selected when they engage with diverse stakeholders. Rather than assume the regionally adopted sea level rise projections, stakeholders could engage in planning activities to examine impacts from a range of possible climate scenarios to determine different adaptation responses.

\section{Identify visions for post environmental disaster}

Current knowledge practices that close off debates around baselines and projections allow local governments to present a vision for the future of Miami that allows continued resilience, growth and prosperity. While not mal intended, this framing potentially minimizes the current risks and given more knowledge on the topic and more ability to influence decisions, civic epistemologies may or may not change this perception (Miller 2008). The intentions of local governments to present an optimistic future are important, but optimism and retreat do not run counter to each other as local governments project. Though decisions about community and individual retreat are highly political and deeply personal, there are examples of voluntary retreat programs following Hurricane Sandy in New York and New Jersey. In Miami-Dade County, discussions of retreat are shut out of local government, though interviewees from federal government agencies brought up the need for the region to begin this conversation. There are multiple ways to look at retreat. Retreat can symbolize the death of community or the death of place or, it can allow for risk avoidance (financial, personal, and human life). This is an area where post disaster recovery planning can be beneficial (Berke and 
Campanella 2006). Public engagement practices that address community values, politics, and what visions people have for their communities post environmental disaster offer a way to build conversation around regional goals for a longer-term vision of the community (Berke and Campanella 2006). Within Miami-Dade County, this could allow for opening-up the conversation around planned retreat rather than economic disaster forcing retreat.

Reframing the issue to broaden scope and create more public involvement

In Miami-Dade County, current modes of public involvement in adaptation planning center on climate change and sea level rise focused advisory panels, which the City of Miami Beach and the City of Miami both currently have, and Miami-Dade County had in the past. Within this planning context, the focus is primarily on sea level rise, with less engagement in broader climate change issues including heat waves, changes to hurricane patterns, other climate stressors, and mitigation. Several individuals from the ecological and community discourses expressed these limitations and shared that they want to see the planning issues broaden to include more aspects of climate change. This would expand the planning conversation around different risks—-not just sea level rise risks - and also to different solutions, including more mitigation and solutions that address these additional risks. Mitigation was framed by many in the environmental discourse as a necessary part of adaptation to slow-down and limit the problem of sea level rise.

In addition, a re-framing around resilience currently underway via the 100 Resilient Cities initiative is one approach to broadening the scope to create a more inclusive dialogue. The planning efforts that are framed as sea level rise adaptation 
planning are primarily expert driven and limit public involvement. Perhaps a re-framing of sea level rise adaptation planning to the context of reducing harm to communities could help broaden scope (e.g. to include crime, safety, hurricanes, heat, etc.) and increase participation. Additionally, while the Southeast Florida Regional Climate Change Compact (Compact) provides easy online access to planning assessments and documents, several planning activities remain out of public view. For example, while the county provides access to generalized risk assessments, publicly accessible information around stormwater infrastructure and decisions regarding how stormwater projects are prioritized is lacking. Interviewees from outside of government expressed frustration with not having information regarding stormwater planning in Miami-Dade County. Similar frustration occurred among City of Miami Beach residents as adaptation projects were implemented. When newly installed stormwater pumps failed and flooded a local business, residents and business owners began to demand more transparency around planning. This resulted in the City of Miami Beach hosting open houses about project development. This activity helps address issues of transparency but at the same time is primarily a one-way flow of information. Reframing these infrastructure adaptation planning activities around reducing harm to communities could open up this planning process from expert-driven towards broader inclusion.

Increase transparency and actively solicit input from groups

Other approaches to increase transparency and public involvement would be to require community engagement strategies be developed for each plan, have community advisory panels for different infrastructure planning divisions, and have an environmental justice and service equity division. The Seattle Public Utilities in Seattle, Washington, for 
example, uses these tools to both create more transparency in their infrastructure planning activities and increase public involvement in decision-making. Within Miami-Dade County, local governments could provide information that emphasizes how infrastructure and flood management decisions are assessed and create direct pathways for involvement. The budgetary oversight committee being established for the Miami Forever Bond is a good place to start. It is also possible to imagine a service equity oversight committee reviewing codes for project selection criteria and propose criteria around environmental justice and equity. Within Miami-Dade County, the Resilience Officers primarily focus on building connections across sectors of government to work towards creative resiliency planning. Their role could be expanded to also promote transparency and public engagement in all infrastructure planning decisions. In this way, they could help serve as a boundary organization or integrate existing boundary organizations between infrastructure, environmental and social justice communities. They could be engaged in organizing and institutionalizing oversight committees across multiple layers of municipal planning and representing multiple interests. A formalized climate justice committee could review planning related to climate change adaptation, including changes to zoning that may lead to displacement. This would move position of the planner from internally facing to outward facing and a turn towards a more communicative approach to resilience planning.

\section{Reflexivity in climate adaptation planning}

While much of the risk knowledge and governance practices come out of an expert and decision-maker space focused on infrastructure and the economy, there are elements of the current planning process that bend towards more integration. This is 
evident in the Resilient Cities initiative, activities of the Compact, and community organizations seeking to incorporate broader groups through education and organizing. Expanding these communicative processes to more aspects of sea level rise adaptation planning can serve as a point of reflection for planners embedded in the process. For example, a communicative process around stormwater adaptation planning could expand knowledge practices from just favoring scientific-technical knowledge, to one that recognizes multiple types of knowledge and the values embedded within them. Climate adaptation planners can build more reflexivity in the planning process by examining knowledge biases in current decision-making frameworks, identifying how diverse public views are integrated into planning decisions, and assessing modes of participation and ensuring that everyone has a seat at the table for all adaptation planning activities. These reflexive practices must extend beyond the communicative approaches and towards activities governing decisions around infrastructure, a predominantly expert and decisionmaker space. Opening-up these predominantly technocratic planning spaces towards a reflexive and communicative approach can foster trust and create shared meaning and problem framing around risks from sea level rise.

\subsection{Conclusion}

On October 22, 2018, WLRN Public Radio and Television in Miami hosted a sea level rise adaptation expert panel to share their perspectives and where they view the region headed. The four panel members each represented the following categories, closely aligned with the discourses identified in this dissertation: an environmentalist, a community activist, a local developer, and a government planner. As if it were choreographed, each spoke of the problem in relation to what they prioritize and value on 
the landscape. The environmentalist emphasized the need for carbon reduction and possible planned retreat, while the community organizer discussed the impacts to lowincome communities and the responsibility of others to support those who cannot afford to adapt. The developer discussed innovative building solutions and the need to secure investments in economic hot spots and high tax base areas. Finally, the planner recognized the importance of all these issues but emphasized adapting infrastructure to secure investment. This was explained as a necessary first step to stabilize the situation and attract external investments to be able to afford the necessary adaptations that would be needed. While this planner kept coming back to acknowledging the variety of ways people are impacted, this planner is also confronted by the risk of major physical impacts on municipal infrastructure, and the obligation to provide services to citizens. Such shortterm planning, addressing the immediate needs for infrastructure and investment, cannot preclude the region from finding more integrated solutions. Although the current planning trajectory around risk appears to leave people out, the region can build off the existing communicative strategies to create a more integrated planning future for the region.

While this chapter offers a conclusion and recommendations for the Miami-Dade County case study, the following Chapter 8 offers an integrated approach to how this might be applied to sea level rise knowledge practices from global to local scales. More work on knowledge and governance practices around climate change adaptation planning is needed to understand how those practices help or hinder diverse knowledge integration. 


\section{Chapter 8: Re-Scaling the Black Box of Decision-making: Global to Local}

\section{Knowledge Practices of Sea level Rise Risk in Coastal Adaptation Planning}

Mary Ann Rozance ${ }^{\mathrm{a} *}$, Ashlie Denton ${ }^{\mathrm{a}}$, Zbigniew Grabowski ${ }^{\mathrm{b}}$, Marissa Matsler ${ }^{\mathrm{b}}$, and Wendy Mayhugh ${ }^{\mathrm{c}}$

${ }^{a}$ College of Urban and Public Affairs, Portland State University, Portland, United States;

${ }^{b}$ Cary Institute of Ecosystem Studies;

${ }^{C}$ Department of Geography, Portland State University

\subsection{Introduction}

Over the past century, changes in mean sea level and increased tidal fluctuations have been recorded around the world and modeled projections show the potential for sea level rise to significantly impact cities' social, ecological, and technological systems (IPCC 2012) here termed SETs (Grabowski et al. 2017). In two particularly vulnerable regions - the South Pacific and South Florida USA — sea level rise is expected to be around 80 inches by 2100 (Compact 2015; Sweet et al. 2017); this rise is expected to contribute significantly to extreme weather-related risks (IPCC 2012). In response, coastal governments work to manage threats posed to urban life (e.g. raising roads and expanding stormwater drainage in Florida and discussing plans for retreat and relocation in Kiribati). These sea level rise adaptation strategies vary in their underlying value systems, spatial scales, and forms of institutional collaboration. While part of a seemingly innocuous technical planning processes, sea level rise transitions are inherently political in their processes, indicators, and outcomes, often reinforcing long-standing unequal development and power relations (Kaika 2017), because the types of knowledge and 
expertise used in decision-making inherently ignore some risks and favor others (Gross 2010).

Scholarship on community and urban resilience continues to rapidly evolve, encompassing prescriptive and descriptive analyses (e.g. Cutter et al. 2008), as well as process-based approaches that frame resilience as an emergent property of risknegotiating social, environmental, and infrastructural systems (Adger et al. 2005). Here we expand this work by asking how different socio-political arenas describe and frame the risks of sea level rise at different temporal, spatial, and administrative scales. We use knowledge systems analysis to expose linkages between global and local knowledges and transformations of irreducibly complex social, ecological, and technical systems (SETs) of the city (McPhearson et al. 2016) and beyond. Drawing upon field work with urban and regional managers and engaged communities, we propose the concept of 'scalar politics of risk,' i.e. the ways in which scales explicitly frame and channel interactions between knowledge systems that define and manage risks. Here we provide a theoretical grounding for this approach, explicate five distinct arenas of 'scalar politics,' and illustrate the utility of this conceptual framework (Figure 1) by examining results from interviews with practitioners and communities engaged in sea level rise adaptation in Miami, USA and the Pacific Islands. By exploring the scalar politics of risk, we present a framework for exploring sea level rise (and other) governance that can make more explicit the knowledge systems and politics at play within multi-scalar governing bodies.

\section{Theoretical Grounding of the Scalar Politics of Risk}

The notion that systemic forms of knowledge are developed and often problematically deployed by governments and municipalities to manage territories, 
populations, economic activities, and infrastructures have long been studied by scholars of science and technology studies (Scott 1998; Graham and Marvin 2001, Pritchard 2011), including those explicitly examining city level adaptations to climate change (Miller 2004; Muñoz-Erickson 2014). We draw on these works, as well as fundamental concepts of coproduction of knowledge and social order (Foucault 1980; Jasanoff 2004), knowledge systems analysis (Miller and Muñoz-Erickson 2018), and the social and scientific production of risk (Beck 1992) to examine sea level rise.

First, of particular importance to understanding sea level rise adaptation is the literature examining the totalizing potential of seemingly apolitical scientific knowledge production (Porter 1996), which can erase the social and political contingencies of its production, or the 'power knowledge relationship' (Foucault 1980). Powerful actors often frame specific knowledges as inherently apolitical, obscuring the actual political and subjective elements of knowledge creation (Hajer 1995; Jasanoff 2004; Agrawal 2005). Jasanoff (2004) describes this power/knowledge relationship as coproduction. She explains, "Scientific knowledge, in particular, is not a transcendent mirror of society. It both embeds and is embedded in social practices, identities, norms, conventions, discourses, instruments, and institutions" (Jasanoff 2004, p. 3). Thus, looking through a coproductive lens clarifies the ways in which particular understandings of the world are privileged in questions of what is being studied, why it is being studied, and how it is being studied (Porter 1996; Scott 1998; Jasanoff 2004). These considerations are not only theoretical, but also inherently practical as local climate adaptations form the basis of the urban experience of sea level rise, and misalignment between framings at different levels 
of decision-making about adaptation can lead to less equitable and less effective outcomes.

Second, to help expose the underlying coproduction of sea level rise adaptation, we utilize knowledge systems analysis. Organizations often focus on examining policy outcomes rather than the values, assumptions, and routines that go into their policy decision-making processes in the first place. Knowledge systems analysis, instead, examines how knowledge is conceived and constructed for decision-making, rejecting the concept of the "logic of discovery" that assumes knowledge is found, pre-formed and ready for use (Miller and Muñoz-Erickson 2018). Knowledge systems analysis builds on the concept that different disciplinary practices designate rules, standards, and norms for producing legitimate and useful knowledge (Foucault 1980; Gieryn 1999; Wynne 2003), as well as defining what constitutes the 'public' for whom such knowledge is relevant (Rogers and Hall 2003; Rancière 2015). This is key to holistically understanding sea level rise adaptation and its consequences.

Lastly, we specifically seek to examine how risks are conceived and constructed by different knowledge systems, both shaping and being shaped by the social and material world (Jasanoff and Wynne 1998; Miller and Edwards 2001; Jasanoff 2004). In following this coproduction of risk, we examine the processes by which dominant discourses, expertise, and institutions render risk calculable and knowable. And while risks are most often understood from a material point of view (i.e. risk is the probability of a consequence), a constructivist point of view unpacks this process and asks: whose experience counts, who bears the consequences, and who determines the probabilities (Beck 1992; Lupton 1999), making institutional structure the ultimate cause of risk 
perception (Rayner 1992). These theoretical foundations-power/knowledge, knowledge systems analysis, and risk construction—ground our work in multi-scalar sea level rise.

\subsection{Scalar politics of risk in sea level rise adaptation planning}

While humans have certainly dealt with rapid climate change throughout their evolutionary history (Calvin 2002), anthropogenic climate change presents two novel considerations. First, human decisions surrounding SETs and resource consumption has directly produced climate change and its corollary, rapid sea level rise, both of which are clearly visible in the geologic record (Zalasiewicz et al. 2017). Secondly, and more importantly for our purposes here, climate change has for the first time in the human story been understood as a truly global phenomenon rather than a local or regional event, as well as a phenomenon requiring coordinated global responses (Edwards 2001;

Demeritt 2001; Miller 2004). However, insufficient attention has been paid to the various intermediate scales between the construction of global knowledge systems and local experiences of climate change. To fill this gap, we argue for understanding feedbacks between five scalar arenas within which knowledge is co-produced and turned into actions (Muñoz Erickson 2014). Between each arena—which correspond to distinct spatial and temporal scales (Figure 8.1) - knowledge must be translated (Latour 2012) into forms relevant for decision-making within each political arena. Below, we define the scope of each arena (summarized in Table 8.1), briefly describe existing work that has uncovered each arena, and identify key tensions within each. 


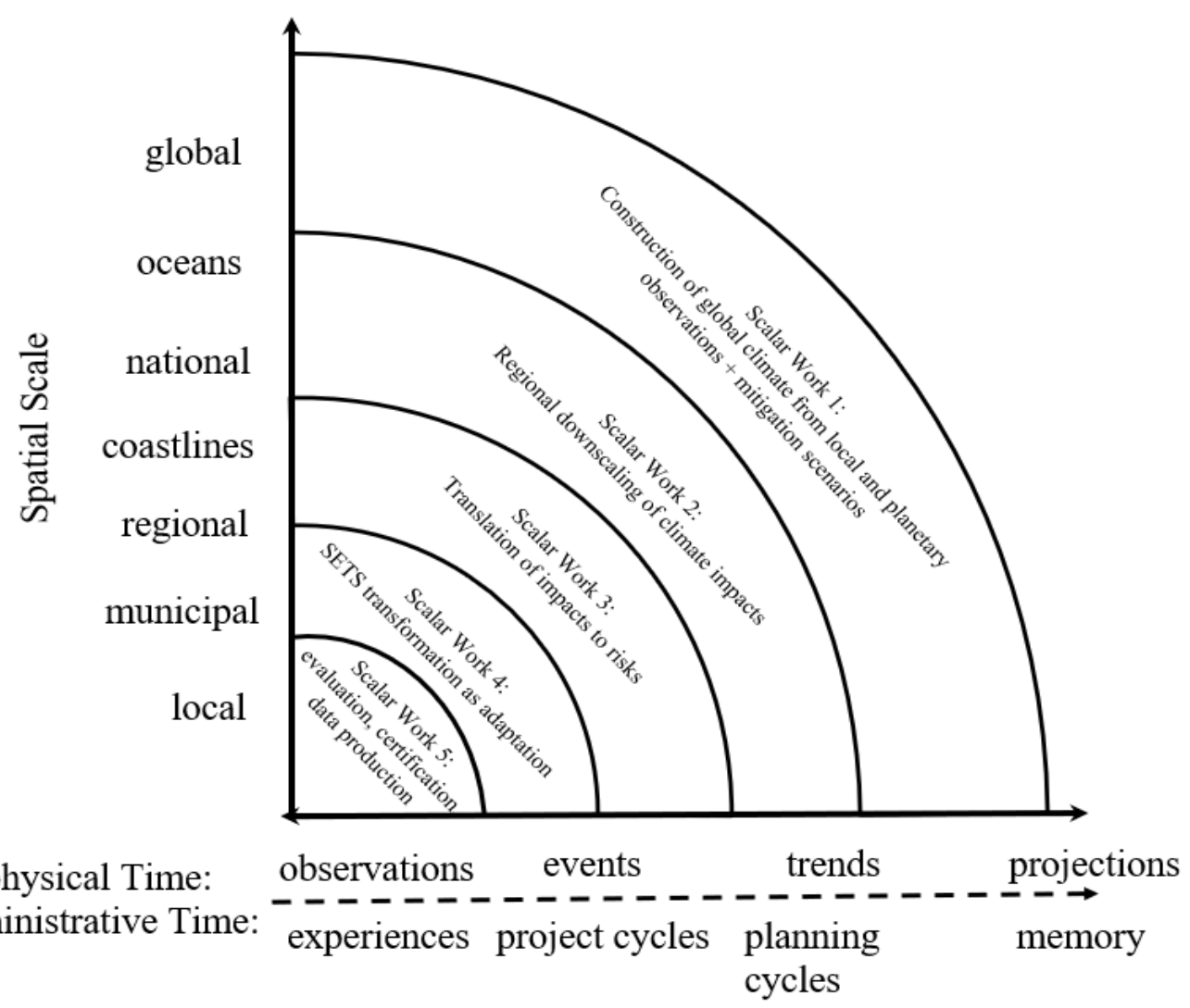

Figure 8.1: Distribution of the five scalar arenas across spatial, biophysical, and administrative time. 
Table 8.1 Summary of definitions, processes, and key tensions within the five arenas of scalar politics of risk.

\begin{tabular}{|c|c|c|}
\hline Definition: & Processes: & Key Tensions: \\
\hline \multicolumn{3}{|c|}{ Scalar Work 1: Construction of global climate from local and planetary observations } \\
\hline $\begin{array}{l}\text { Local data collection, data } \\
\text { aggregation, scenario } \\
\text { building, and local and } \\
\text { global discourses. }\end{array}$ & $\begin{array}{l}\text { Global bodies (IPCC, etc.) shape } \\
\text { climate knowledge requirements and } \\
\text { discourses. Local data collection } \\
\text { procedures are shaped by global } \\
\text { requirements and shape global data. As } \\
\text { local data is aggregated and taken up } \\
\text { into scenario building processes, } \\
\text { discourses and ways of knowing } \\
\text { compete for authority. }\end{array}$ & $\begin{array}{l}\text { Issues of temporal and spatial } \\
\text { scale, resolution, and } \\
\text { sensitivity; limitations of } \\
\text { translation from predictions to } \\
\text { reality; displacement of local } \\
\text { voices and needs. }\end{array}$ \\
\hline \multicolumn{3}{|c|}{ Scalar Work 2: Regional downscaling of climate impacts } \\
\hline $\begin{array}{l}\text { The creation of SLR } \\
\text { knowledge relevant to } \\
\text { localized governance } \\
\text { strategies from global } \\
\text { climate measurements and } \\
\text { regional biophysical } \\
\text { processes. }\end{array}$ & $\begin{array}{l}\text { Institutional and social players at the } \\
\text { global and regional level set SLR } \\
\text { adaptation priorities and lend authority } \\
\text { to particular ways of knowing. Based } \\
\text { on prioritization practices, historic and } \\
\text { scenario-based modeled outputs are } \\
\text { often used to project future } \\
\text { infrastructure and local policy needs. }\end{array}$ & $\begin{array}{l}\text { Top-down agenda-setting- } \\
\text { regional adaptation policies } \\
\text { structured by global knowledge } \\
\text { decisions. Downscaling data } \\
\text { challenges_-globally-produced } \\
\text { models lack specificity for local } \\
\text { decisions. Politics of temporal } \\
\text { choice_-political contestation } \\
\text { over planning horizons for } \\
\text { adaptations and infrastructures. }\end{array}$ \\
\hline \multicolumn{3}{|c|}{ Scalar Work 3: The creation of risks and vulnerabilities out of biophysical impacts } \\
\hline $\begin{array}{l}\text { Risks are produced by } \\
\text { SLR's interaction with } \\
\text { SETs, and the practices by } \\
\text { which those are analyzed } \\
\text { and prioritized. }\end{array}$ & $\begin{array}{l}\text { Institutional processes prioritize the } \\
\text { ecological, economic, technological, } \\
\text { and social dimensions of risk according } \\
\text { to existing expertise and structures. } \\
\text { Risk discourse shaped by what is } \\
\text { known and valued. }\end{array}$ & $\begin{array}{l}\text { Political economy of } \\
\text { expertise-authorization and } \\
\text { prioritization of particular ways } \\
\text { of knowing by groups with } \\
\text { power. Social constructions of } \\
\text { risk-the spatial and social re- } \\
\text { apportioning of SLR impacts } \\
\text { through discourse and } \\
\text { knowledge practices may not } \\
\text { address local issues. }\end{array}$ \\
\hline \multicolumn{3}{|c|}{ Scalar Work 4: SETs transformation via adaptation actions on-the-ground } \\
\hline $\begin{array}{l}\text { On-the-ground adaptation } \\
\text { actions transform the } \\
\text { social, ecological, and }\end{array}$ & $\begin{array}{l}\text { Political power exerted via technical } \\
\text { proposals for adaptation. Different } \\
\text { solutions are legitimized and/or } \\
\text { delegitimized through technical }\end{array}$ & $\begin{array}{l}\text { Expert vs. lived experience-- } \\
\text { the 'inevitability' of adaptation } \\
\text { can prioritize engineering } \\
\text { expertise above grassroots }\end{array}$ \\
\hline
\end{tabular}




\begin{tabular}{|l|l|l|}
\hline $\begin{array}{l}\text { technological systems } \\
\text { (SETs) of a local place. }\end{array}$ & $\begin{array}{l}\text { decision-making procedures around } \\
\text { infrastructure. Local prioritization, } \\
\text { authorization, and enactment of } \\
\text { adaptations transform material reality } \\
\text { on the ground, leaving legacy impacts. }\end{array}$ & $\begin{array}{l}\text { input. Adaptation vs. legacy- } \\
\text { climate changes demand shifts } \\
\text { in SETs and financial systems, } \\
\text { yet legacy impacts can be } \\
\text { resistant to change. }\end{array}$ \\
\hline
\end{tabular}

Scalar Work 5: Evaluation and certification of best practices for addressing risks

\begin{tabular}{|l|l|l|}
$\begin{array}{l}\text { Ways in which local } \\
\text { initiatives to manage risk } \\
\text { are monitored, as well as } \\
\text { how they interact with } \\
\text { local-global strategies for } \\
\text { managing risk. }\end{array}$ & $\begin{array}{l}\text { Evaluation procedures may or may not } \\
\text { exist, based on the institutional value } \\
\text { placed on assessment. Institutions that } \\
\text { do put evaluation procedures in place } \\
\text { set up procedures to determine the local } \\
\text { effectiveness of interventions based on } \\
\text { constructions of risk and prioritization } \\
\text { of expertise. Infrastructures are then } \\
\text { evaluated for how they fit with global } \\
\text { certification procedures as strategies for } \\
\text { effectively managing risk. }\end{array}$ & $\begin{array}{l}\text { Legitimization of risk } \\
\text { management-expertise } \\
\text { embedded in existing } \\
\text { institutional practices is } \\
\text { prioritized in determining } \\
\text { which risks to evaluate and } \\
\text { what knowledge to use to } \\
\text { evaluate them. Temporal issues: } \\
\text { outputs/outcomes of one-off or } \\
\text { pilot projects deemed } \\
\text { acceptable, while long-term } \\
\text { impacts are not assessed. Scalar } \\
\text { challenges: global and local } \\
\text { constructions of risk may be } \\
\text { considered separately, if at all. }\end{array}$ \\
& \multicolumn{2}{|l}{} \\
\hline
\end{tabular}


Scalar Work 1: Construction of global climate from local and planetary observations

Global sea level rise projections rely on complex coupled social, technological and environmental models to project climate and oceanographic conditions in the near and distant future. These modelled projections rely on ongoing practices of local (e.g. tidal gauges, buoys), remote (e.g. satellite measurements of mean sea level), and historical (e.g. stratigraphic records) data (Miller 2004). Practices of aggregating different forms of data (e.g. biophysical and socio-economic) are then used to construct possible future scenarios (Edwards 2001) and local and global discourses interdependent with these modelling processes are deployed (Jasanoff and Long-Martello 2004). Global projections are thus extremely sensitive to both scientific uncertainties (Hansen 2007) and the socio-economic and technological scenarios guiding emissions projections. They are also of limited relevance for local decision makers due to a mismatch in scales of data aggregation and analysis; this contributes to distrust against scientific, political, and humanitarian actors when models fail to match local experiences (Mahony 2014), or take into account uneven vulnerabilities (Nicholls and Mimura 1998) and longer standing practices of community resilience (Spencer et al. 2016), resulting in further victimization of local people rather than empowerment (Miller 2004; McNamara and Gibson 2009). In this arena, global institutions such as the IPCC represent a unified body of knowledge (Hulme 2013) yet rely on inherently contentious processes of legitimizing and constructing knowledge which can often mask the conditional elements of projections of future conditions (Hulme 2010). In response, a large body of work has sought to 'downscale' global climate projections to more relevant regional scales however, down-scaled 
results still contain the inherent uncertainties of global projections processes outlined above.

\section{Scalar Work 2: Regional downscaling of climate impacts}

Regional downscaling includes the creation of localized sea level rise rates and projections from global projections (e.g. mean sea level rise, tidal variance, extreme weather patterns) and regional biophysical processes (e.g. tectonic uplift, sediment accretion, tidal geometries). These biophysical processes are assessed using similar data collection and aggregation protocols, yet come with their own sets of assumptions, uncertainties, and social decisions about what constitutes the region (Fawn 2009) and what processes are considered relevant by different social actors involved in their creation. Adjudication of knowledge relevance cannot be separated from the constellation of social and political actors involved, all of whom have their own demands for regional sea level rise projections, while also being constrained by gatekeeping organizations (Lejano et al. 2013). The selection of metrics and scales (time, space, and administrative) to address sea level rise knowledge and governance, especially as regional downscaling is often performed by global actors (Miller 2004), produce tension between global institutions and the needs of regional decision makers. Additionally, such decisions can be shaped by political and financial pressures, rather than by best available science (Edwards et al. 2007). These dynamics can both disrupt or solidify institutional arrangements by identifying which problems are likely to emerge and implementing presumably — though not guaranteed —effective responses (Wildavsky 1988; Barnett 
2001), which ultimately depend on the ability to make regional impacts legible as matters of social concern or risk.

Scalar Work 3: The creation of risks and vulnerabilities out of biophysical impacts

Risks are produced by translating impacts into operational and functional damage to regional and local SETs (Adger et al. 2009), such as damages to the built environment, as well as potential loss of life. Risks are what make impacts meaningful for decision makers who possess their own institutional priorities and knowledge systems (Short and Clark 1992; Wisner et al. 2014) and are subject to the influence of powerful interests (Kelman 2014; McCubbin et al. 2015;). Risk translation as a scientific practice relies on higher precision models of localized impacts of anticipated events, yet in order to be robust, requires recognizing diverse risk and vulnerability knowledge for adequate system characterization (Dovers et al. 1996; Barnett 2001). Given that risks are both regional (e.g. regional infrastructure failure), and local (e.g. a neighborhood being washed away), we must avoid unproblematically valorizing the 'local trap' (Jasanoff and Long-Martello 2004), which equates locality with spatial smallness, social homogeneity, and norm similarity (Agrawal and Gibson 1999). By focusing on weaknesses and shortcomings, risk production can produce a loss of confidence in decision-making (Campbell 1997), as well as bounding the effectiveness of different management and adaptation strategies (McCubbin et al. 2015). 


\section{Scalar Work 4: SETs transformation via adaptation actions on-the-ground}

On-the-ground adaptation actions require specific transformations of given SETs.

In this arena, scalar politics move from socio-political processes of planning and into the seemingly apolitical technical practices of engineering and design. However, this process is indeed political as proposed and enacted material actions on the ground distribute risks, benefits, and costs differentially through the "hidden" work of project finance and design (Heynen et al. 2006), along with the internalization of assumptions from the previous 3 scalar arenas. sea level rise and climate change make SETs transformation inevitable; the key question then becomes how the lived experience of these transformations, including grassroots and unstructured responses, relate to formal processes of planning and designing adaptation measures, including adjudicating between competing technical proposals. Additionally, the path dependency of existing infrastructures and knowledge systems impede SETs transformations through pre-existing practices of prioritizing capital distribution and material inertia on the ground (Palm 2006). Flows of capital embedded in infrastructure systems shape local spaces, with the sunk costs of previous infrastructure choices impacting any future adaptation proposals (Palm 2006). Taken together, these considerations highlight both the complexity of translating risks into material adaptation proposals, making the evaluation of their effectiveness a key consideration for their contextual desirability, as well as global generalizability. 


\section{Scalar Work 5: Evaluation and certification of best practices for addressing risks}

Evaluation and certification of best practices for addressing risks involves the ways in which SETs transformations managing risk are monitored and evaluated, as well as how they scale up to act as best practices and generalizable strategies within the other four scalar arenas. As rapid sea level rise becomes a driving concern of regional and city level adaptation programs, there is a need to construct robust monitoring and evaluation programs that are shaped by contextual process and distributional concerns to assess the effectiveness of interventions and compare to global municipal peers (Holling and Meffe 1996). To do so, the original contexts of risk constructions and competing knowledge claims (e.g. marginalization of local voices, creation of pathological path dependencies) must not be ignored as institutions seek to attain measurable outcomes. Temporal and spatial challenges to representative assessment can impact the ability of locals to adequately assess their own interventions, not least because of global social and environmental concerns that make sea level rise rates uncertain. Mechanisms of evaluation encounter limited control comparisons for one-off or local projects, procedural justice assessments (e.g. how equitable is the process), as well as risk shifting (e.g. sea walls transferring risk to adjacent communities). At the same time, larger scale impacts are often ignored (e.g. the impacts of large scale construction projects on rates of climate change). 


\subsection{Applying Scalar Politics of Risk}

We apply the scalar work framework to case studies of sea level rise adaptation planning in the Pacific Islands (Table 8.2) and Miami-Dade County, Florida USA (Table 8.3), two regions that are undergoing adaptation planning and implementation. Case studies were developed based on empirical work done by two of the authors of this paper. Each case used interviews, document analysis, and literature reviews to examine conceptions of sea level rise risk. In each case, we identify key dynamics affecting the circulation of knowledge in framing vulnerabilities and solutions to climate change in each identified arena. The different scales that each case study represents allows us to explore how vulnerability is framed and by whom, to make explicit the scalar elements of risk construction and governance, and to understand how different communities are perceiving risk across scales. This illuminates the ways in which risk construction in urban environments is produced by, and productive of, global trends in climate change governance.

\section{Pacific Island Nations}

\section{PI-Scalar Work 1}

The Pacific Islands are often the focus of literature surrounding regions hit by sea level rise, and frequently portrayed as victims (Denton 2017). Lower levels of scientific and technical capacity require many Pacific Island countries to rely on IPCC projections of sea level rise--staffed by predominantly Northern, white, male scientists (Barnett and Campbell 2010) who value scientific expertise--or use global data collection networks' requirements as guiding forces. With the stringent requirements made by global data gathering networks, this means that PIs are mostly limited to gathering the data that is 
required globally without paying attention to local needs and conditions. As these capacity challenges play out in global discourses, there is rarely inclusion of beliefs or practices promoted by locals to combat these issues (Barnett and Campbell 2010). The Pacific Islands are the most commonly discussed and analyzed region within global climate change, which can be damaging when the same group of people are consistently framed as victims or as a vulnerable population. This focus on the Pacific Islands keyholes its people in the position of victims in the global sea level rise narrative, while other groups who are also facing very real dangers in terms of sea level rise are ignored.

\section{PI- Scalar Work 2}

As data is downscaled, the global framing of the Pacific Islands as victims creates politics over knowledge and expertise. For instance, in a recent study of Tuvalu's landmass, researchers found that, as adaptive ecosystems, the islands of Tuvalu had actually grown over the last four decades (Kench et al. 2018). These findings produced a wide range of reactions among recipients: hope among islanders, vindication among climate deniers, or anger and frustration among Pacific Island climate negotiators, depending on the recipient's position (Friedman 2018). Additionally, in 2016 the Guardian released a story entitled, "Five Pacific islands lost to rising seas as climate change hits" (Anon. 2016). Immediately after, the publication released a correction requested by the study's authors, "Headlines 'exaggerated' climate link to sinking of Pacific Islands” (Mathiesen 2016). Debates like this one are rarely simple, power and authority produced by and productive of climate change knowledge means that contestation is at the heart of the decision-making. 
Such contestation can put additional pressure on already constrained scientific and technical capacity of PIs. For instance, large-scale funders are prioritizing even more rigorous data collection processes to address these measurement issues rather than investing more heavily into adaptation strategies. This can be seen in recent efforts to use LiDAR to measure the landmass of islands in addition to the simple sea level rise buoy measurement used up to this point (UNCC 2018). The new procedures require costly technology and training to use properly, even as adaptation measures become more informed.

\section{PI- Scalar Work 3}

Risks are continuously shifting due to the adaptive nature of the islands, ecologically but also socially, and politically. Traditional ways of knowing trend toward an adaptive knowledge of nature that puts power to overcome climate risks in the hands of capable, adaptive communities (Denton 2018). Alternatively, global strategies tend to view nature as an object in need of control, therefore requiring scientific and technical capacity to overcome challenges. In response to the global strategies view of risk, one-off pilot projects are used to mitigate for rapid shifting social, ecological, and political changes. These strategies come about due to the global discourses of urgency and inevitability of biophysical climate risks that delegitimize alternative approaches. As Barnett and Campbell argue, "These regular statements have the effect of rendering climate change as an environmental fact against which actors can do little but suffer. They deny the agency of people at risk: to define the problem in their own terms; to apply their own systems of knowledge; to implement the solutions that are appropriate to their 
needs and values and which accommodate uncertainty; and to make knowledge claims of equal value to those of science" (2010, p. 2).

\section{PI-Scalar Work 4}

The construction of Pacific Islanders as victims in need of scientific and technical capacity to overcome climate challenges and control an unwieldy nature has fostered inconsistent and, at times, counterproductive infrastructure interventions. International investments in infrastructure in the region require extensive pre-grant assessments that can be prohibitively costly in terms of time and resources (Denton 2018). This fosters the emphasis on one-off and pilot projects that can have counterproductive outcomes. For example, seawalls are regularly used in the Pacific as a tangible adaptation to sea level rise that also appeals to global desires to control nature. Imbedded in these choices is also a colonial history and international aid that shapes the flows of finance in the region (Atteridge and Canales 2017). While alternative approaches like mangroves are used as well, considerations of beach development, the visibility of an intervention and the ability to "fly the flag" of the donating country, etc. are considered in determining this choice. In fact, local communities many times choose this option due to lower upkeep and the perceived lack of alternatives.

\section{PI- Scalar Work 5}

Although the region emphasizes scientific and technical capacity, it may seem ironic that evaluation and certification play such small roles in climate governance. The use of one-off and pilot projects means that projects can only be evaluated for achieving outputs or adhering to processes, but not for other desired impacts including alleviating risks and vulnerabilities. Projects that do run long-term have resource constraints that can 
make it challenging to evaluate broader impacts. Additionally, global constructions of risk can be privileged over local-level evaluation, hiding the nuances of attitudes between islands. One example of this is in the differing ways in which 'climate refugee' status is considered. Some countries such as Kiribati have purchased land on Fiji for climatebased migration, others like the Marshall Islands denounce migration seeing it as givingup on making polluters pay. 
Table 8.2: Pacific Island case study scalar work processes and key tensions.

\section{Pacific Islands}

SLR presents a pervasive risk to islands everywhere. In the Pacific Islands, detangling the specific risks presented by SLR from development pressure, ocean acidification, \& climatic changes resulting in extreme weather events can be challenging. This leads to multiple contestations over authoritative knowledge, power in decision-making, \& risk constructions, which move between \& across scales.

\begin{tabular}{|c|c|c|}
\hline & Processes: & Key Tensions: \\
\hline $\begin{array}{l}\text { Scalar Work 1: } \\
\text { Construction of } \\
\text { global climate } \\
\text { from local \& } \\
\text { planetary } \\
\text { observations }\end{array}$ & $\begin{array}{l}\text { Lower levels of scientific \& technical } \\
\text { capacity create reliance on IPCC SLR } \\
\text { projects. Efforts within the PIs are } \\
\text { mostly limited to gathering the data that } \\
\text { is required globally without paying } \\
\text { attention to local needs \& conditions. }\end{array}$ & $\begin{array}{l}\text { Global victimization of the region. } \\
\text { Contestation between local \& global } \\
\text { data/adaptation needs. }\end{array}$ \\
\hline $\begin{array}{l}\text { Scalar Work 2: } \\
\text { Regional } \\
\text { downscaling of } \\
\text { climate impacts }\end{array}$ & $\begin{array}{l}\text { Reliance on international community } \\
\text { pits scientific assessments against local } \\
\text { experiences of SLR resulting in debates } \\
\text { over knowledge within climate change } \\
\text { diplomacy \& governance. }\end{array}$ & $\begin{array}{l}\text { Regional contestation over } \\
\text { measurements. Scientific/technical } \\
\text { capacity constraints exacerbated by } \\
\text { global requirements. Adaptive capacity } \\
\text { possibilities \& realities largely ignored. }\end{array}$ \\
\hline $\begin{array}{l}\text { Scalar Work 3: } \\
\text { The creation of } \\
\text { risks \& } \\
\text { vulnerabilities } \\
\text { out of } \\
\text { biophysical } \\
\text { impacts }\end{array}$ & $\begin{array}{l}\text { The construction of risks is } \\
\text { commensurate with different views of } \\
\text { nature. Pacific Islanders often view } \\
\text { nature as an adaptive ecosystem which } \\
\text { puts power to overcome climate risks in } \\
\text { the hands of capable, adaptive } \\
\text { communities, while understanding } \\
\text { nature as an object in need of control } \\
\text { creates other problems \& solutions. }\end{array}$ & $\begin{array}{l}\text { Risks constructed without consideration } \\
\text { of multiple types of capacity or ways of } \\
\text { knowing. Views of nature delimit the } \\
\text { nature of risk \& opportunities for } \\
\text { addressing vulnerabilities. }\end{array}$ \\
\hline $\begin{array}{l}\text { Scalar Work 4: } \\
\text { SETs } \\
\text { transformation as } \\
\text { adaptation }\end{array}$ & $\begin{array}{l}\text { International investments in } \\
\text { infrastructure in the region require } \\
\text { extensive pre-grant assessments that can } \\
\text { be prohibitively costly in terms of time } \\
\& \text { resources. This fosters the emphasis } \\
\text { on one-off \& pilot projects that can have } \\
\text { counterproductive outcomes. }\end{array}$ & $\begin{array}{l}\text { Outside funding requires extensive up- } \\
\text { front investment in status evaluation, } \\
\text { limiting access to quality projects. Pilot } \\
\text { projects produce inconsistent \&, at } \\
\text { times, counterproductive infrastructure } \\
\text { interventions. Colonial flows of finance } \\
\text { can shift decision-making, leaving } \\
\text { long-term legacy impacts. }\end{array}$ \\
\hline $\begin{array}{l}\text { Scalar Work 5: } \\
\text { Evaluation \& } \\
\text { certification of } \\
\text { best practices for } \\
\text { addressing risks }\end{array}$ & $\begin{array}{l}\text { The use of one-off \& pilot projects } \\
\text { means that projects can only be } \\
\text { evaluated for achieving outputs or } \\
\text { adhering to processes, but not for if the } \\
\text { measures had the desired impacts-- } \\
\text { alleviating risks \& vulnerabilities }\end{array}$ & $\begin{array}{l}\text { One-off \& pilot projects are limited to } \\
\text { process evaluation instead of impact } \\
\text { evaluation, leaving little opportunity for } \\
\text { improvement. Evaluation of risk } \\
\text { abatement can be out of touch with } \\
\text { local valuations \& constructions of risk. }\end{array}$ \\
\hline
\end{tabular}


Miami-Dade County, Florida, USA

MDC-Scalar Work 1

Low-lying coastal regions of the United States such as South Florida are portrayed as ground zero for sea level rise by the media, scientists, and environmental activists. In the global narrative, sea level rise impacts in Miami-Dade County are primarily focused on tourism and affluent residents, which can overshadow discussions of vulnerable and marginalized communities within the region. The region has highlevels of technical and scientific capacity, with support from federal agencies to gather and integrate localized datasets into global sea level rise models.

MDC-Scalar Work 2

Southeast Florida Regional Climate Change Compact (Compact) formed in 2009 as a four-county partnership between Miami-Dade, Broward, Monroe, Palm Beach Counties, and cities align regional sea level rise projections and lobby for funding. Beginning in the mid-2000s, disagreements amongst scientists and policymakers centered around which sea level rise models and rates to adopt (e.g. IPCC, NOAA, and USACE), with some scientists arguing that because some sea level rise projections fail to account for ice melt acceleration and localized processes they underestimate sea level rise. While some local governments were reluctant to adopt sea level rise projections, external forces with locally relevant projections (including NOAA and the USACE), as well as the collaborative Compact effort, helped to drive the adoption of higher projections that extend further into the future. The Compact adopted projections from NOAA, the USACE, and the IPCC, which are now the primary projections referenced in Miami-Dade County. 


\section{MDC-Scalar Work 3}

Miami-Dade County development is supported by systems of canals and other stormwater infrastructure. Upon initial settlement, large-scale infrastructure projects were built to drain portions of the Everglades and allow for development. As such, risks from sea level rise are primarily understood in terms of physical, economic, and infrastructure domains. For example, a process called "bathtub modeling" is used to superimpose where water will rise with sea level rise stemming from the coast, adding water levels to hightides and using elevation gradients to determine what areas will be inundated. This form of modeling has several limitations as it assumes that land geomorphology, tidal surface variability and other conditions remain constant (e.g. groundwater surface water interactions), and it does not consider additional hydrodynamic effects during storm surges (SFRCCC 2012). Because of these limitations, the use of bathtub modeling emphasizes risks to coastal regions and de-emphasizes inland risks. And while the primary focus for assessments is on infrastructure, vulnerability assessments often highlight property values. Several interviewees shared that this is in part to get attention and garner action for adaptation strategies. At the same time, however, the emphasis placed on economic risks may lead to the ongoing focus of adaptation strategies that support the economy over others. Currently, it appears that sea level rise risk knowledge that supports an economically viable future is favored over knowledge that may threaten that future. For example, calls for fine resolution LiDAR to better understand elevation gradients support engineered solutions and building at higher elevations, and support dominant narratives that the region will not stop growing, that growth will happen in a different way. While community organizations emphasize concerns over high-elevation 
climate gentrification, emergency preparedness, displacement, insurance, and health impacts, few government assessments covering these issues have been completed, though recent planning efforts may begin to address these issues.

\section{MDC-Scalar Work 4}

Engineered solutions dominate SETs transformation and, as technical design tasks, are being viewed as an apolitical decision points with limited to no interaction with people prior to decisions around where to adapt and how to adapt have been made.

Planning decisions around infrastructure are made in an expert space and rooted in a path dependency around existing infrastructure. Infrastructure decisions around stormwater management, wastewater treatment, and water provision surround cost benefit analysis and risk management decision-making practices that focus on level of service and shaped by policies including the NFIP and Clean Water Act stormwater permitting. Issues of public versus private investments and responsibilities are emerging. In the City of Miami Beach, for example, roads are being raised with new stormwater drainage and landowners are expected to tie their driveways into the new system. Longer-term, people have begun to speculate and question whether it would be up to individual landowners to raise their homes, and historic designations and zoning disagreements have been emerging around the drive for new development and ground raising over older buildings that are susceptible to flooding. Planners also express concern over how to plan for lower income communities where the adaptation costs for private property may be prohibitively expensive. While additional efforts are taking place including community organizing efforts via education and organizing to access decision-making arenas; environmental organizations designing and implementing green infrastructure and living shoreline 
projects; and informal discussions of localized and regional planned retreat, these are primarily on the planning periphery.

\section{MDC-Scalar Work 5}

Several projects and programs have built in monitoring and evaluation. For example, the Compact, which develops regional goals and planning practices, holds an annual meeting with policy-makers, managers, scientists, and other practitioners to share information. In addition, the Compact has a process for reviewing sea level rise projections as new models and information are available. The recent Regional Climate Action Plan published by the Compact reflects broader inclusion than the first plan, expanding to groups and topics including social equity. And while at the regional level the tendency has moved towards evaluation and broader inclusion, individual projects have had varying levels of evaluation. Several projects initiated by the Compact and different foundations are evaluated as case studies communicated to cities around the world. The City of Miami Beach recently received high praise from an independent panel of experts brought in to evaluate their sea level rise adaptation strategies. Projects within the region have been used as case studies, design charrettes, and project feasibility assessments and this knowledge has circulated the region primarily via the Compact. This knowledge often focuses on the technocratic aspects and infrastructure designs and less about the process and public/community involvement. 
Table 8.3: Miami-Dade County, Florida case study scalar work processes and key tensions.

\begin{tabular}{|c|c|c|}
\hline \multicolumn{3}{|c|}{ Miami-Dade County, Florida, USA } \\
\hline \multicolumn{3}{|c|}{$\begin{array}{l}\text { Climate projections suggest that Miami-Dade County will experience increased flooding from SLR, } \\
\text { higher severity of extreme weather events. Municipalities have undertaken activities to mitigate } \\
\text { anticipated impacts from SLR. The City of Miami Beach, for example, is implementing an aggressive } \\
\& \text { expensive plan to combat SLR by moving water off city streets \& away from businesses \& houses. }\end{array}$} \\
\hline & Processes: & Key Tensions: \\
\hline $\begin{array}{l}\text { Scalar Work 1: } \\
\text { Construction of } \\
\text { global climate } \\
\text { from local \& } \\
\text { planetary } \\
\text { observations }\end{array}$ & $\begin{array}{l}\text { High technical \& scientific capacity \& } \\
\text { support from federal agencies allows for } \\
\text { local datasets \& technologies to be } \\
\text { integrated into SLR models. }\end{array}$ & $\begin{array}{l}\text { Ground zero for SLR but portrayed as } \\
\text { affluent \& able to handle the adaptation } \\
\text { challenges. The focus on economic \& } \\
\text { infrastructure risks overshadows } \\
\text { marginalized communities within the } \\
\text { city \& surrounding areas. }\end{array}$ \\
\hline $\begin{array}{l}\text { Scalar Work 2: } \\
\text { Regional } \\
\text { downscaling of } \\
\text { climate impacts }\end{array}$ & $\begin{array}{l}\text { The Southeast Florida Regional Climate } \\
\text { Change Compact (Compact) (a 4-county } \\
\& \text { multi-city partnership) was formed in } \\
2009 \text { to adopt a unified regional SLR } \\
\text { projection, lobby for funding, \& } \\
\text { coordinate planning activities. }\end{array}$ & $\begin{array}{l}\text { Process contested \& shaped by } \\
\text { reticence around ice melt, climate } \\
\text { change denialism, \& political } \\
\text { uncertainty. Pattern of gov. wanting to } \\
\text { adopt smaller projections, but support } \\
\text { for larger projections came from local } \\
\text { downscaling of models via NOAA, } \\
\text { USACE, and collaborative efforts. }\end{array}$ \\
\hline $\begin{array}{l}\text { Scalar Work 3: } \\
\text { The creation of } \\
\text { risks \& } \\
\text { vulnerabilities } \\
\text { out of } \\
\text { biophysical } \\
\text { impacts }\end{array}$ & $\begin{array}{l}\text { Development is supported by systems of } \\
\text { canals \& other stormwater infrastructure. } \\
\text { Upon initial settlement, large-scale } \\
\text { infrastructure projects were built to drain } \\
\text { portions of the Everglades \& allow for } \\
\text { development. As such, risks from SLR } \\
\text { are understood in terms of physical, } \\
\text { economic, \& infrastructure domains. }\end{array}$ & $\begin{array}{l}\text { Knowledge systems that support the } \\
\text { dominant political economy, linking } \\
\text { power with knowledge, is more } \\
\text { prevalent \& sometimes runs counter to } \\
\text { knowledge that addresses social risks. }\end{array}$ \\
\hline $\begin{array}{l}\text { Scalar Work 4: } \\
\text { SETs } \\
\text { transformation } \\
\text { via adaptation } \\
\text { actions on-the- } \\
\text { ground }\end{array}$ & $\begin{array}{l}\text { Planning decisions around infrastructure } \\
\text { are made in an expert space \& rooted in } \\
\text { a path dependency around existing } \\
\text { infrastructure, cost benefit analysis, \& } \\
\text { risk management decision-making. }\end{array}$ & $\begin{array}{l}\text { Public private tensions around } \\
\text { responsibility for funding adaptation. } \\
\text { Path dependency around engineered } \\
\text { solutions. Engineered solutions are } \\
\text { expensive \& may be unattainable for } \\
\text { many individuals \& communities. }\end{array}$ \\
\hline $\begin{array}{l}\text { Scalar Work 5: } \\
\text { Evaluation \& } \\
\text { certification of } \\
\text { best practices for } \\
\text { addressing risks }\end{array}$ & $\begin{array}{l}\text { Evaluation \& certification of best } \\
\text { practices occurs primarily via the } \\
\text { Compact \& foundations funding design } \\
\text { charrettes. Evaluation of stormwater } \\
\text { projects in Miami-Beach has recently } \\
\text { taken place with panel of experts. }\end{array}$ & $\begin{array}{l}\text { Knowledge gathered to evaluate } \\
\text { focuses on the technocratic aspects \& } \\
\text { infrastructure designs \& less about the } \\
\text { process \& public/community } \\
\text { involvement. }\end{array}$ \\
\hline
\end{tabular}




\subsection{Discussion}

As Foucault argues, "Power never ceases in its interrogation, its inquisition, its registration of truth; it institutionalizes, professionalizes, and rewards its pursuit" (1980, p. 93). In both PIs and Miami, technical and scientific approaches are largely privileged over local constructions of risk, as technological solutions are presented by global actors as working across scales without having to address many, if not all, cross-scale sociopolitical tensions. While PIs are largely making decisions in transnational space about sea level rise knowledge and adaptation, Miami's work at the urban scale mirrors many of the politics at play. Global constructions of a vulnerable and victimized Pacific Islands have prioritized scientific and technical approaches to risk abatement, while largely ignoring the knowledges, discourses, and capacities used by the Islanders, themselves. Alternatively, perceptions of affluence surrounding residents of the Miami area has left vulnerable and marginalized communities within the region largely ignored, instead measurable elevation and property value considerations are emphasized. The globalized, objective approaches to sea level rise in these areas obscure rights and knowledges from non-expert and local communities in attempts to scale up knowledges, practices, and discourses in sea level rise adaptation. As local populations are written off as victims in a global, technical space, they are left out of the sea level rise projections and models.

It is in these spaces that scalar politics of risk play out as knowledge systems interact and compete across scales, from global to local and back again. These tensions are cascading — global constructions of the climate victimize both Pacific Islanders and Miami-Dade County residents (Scalar Work 1), which then causes regional approaches to emphasize scientific measurement over local understanding (Scalar Work 2), which then 
constructs risks as technical concerns (Scalar Work 3) that transform SETs and leave legacy infrastructures (Scalar Work 4), which then pose challenges for quality evaluation (Scalar Work 5). These things also work in reverse, however, as legacy infrastructures (Scalar Work 4) impact global sea level rise measurements (Scalar Work 1) and opportunities for policy change (Scalar Work 2). Additionally, regional policy changes (Scalar Work 2) can transform the processes by which data is collected for global models (Scalar Work 1) and what risk abatements are evaluated (Scalar Work 5). Without addressing each scale within the system, hidden struggles over knowledge, discourses, and practices can remain just that-hidden.

\subsection{Conclusion}

We have used knowledge systems analysis to question the construction of science, and the framing of science as apolitical and objective, specifically in respect to multiscalar understandings of the risk of sea level rise. We look at five primary arenas in which a scalar politics of risk emerge: 1) the construction of the global climate; 2) the regional downscaling of climate impacts; 3) the local definition of risks; 4) the transformation of on-the-ground social-ecological-technical systems and infrastructures; and, 5) the evaluation of intervention efficacy.

The processes by which power flows through these knowledge systems can leave local populations, saddled with victim discourses, with little recourse. Adaptive capacities, non-expert/non-scientific knowledge systems, and everyday practices can be hidden by 'objective' investigations in to sea level rise. A thorough investigation of scalar politics thus works to take apart the "regimes of truth" that conceal the histories of how those ways of knowing came to be (Foucault, 1980). These principles and practices do 
not only apply to Miami and Pacific Islands but can work across knowledge systems at all scales. We encourage future work to continue to investigate these scalar politics of risk in this and other arenas. 


\section{References}

Adger, N., N. Arnell, and E. Tompkins. 2005. Successful adaptation to climate change across scales. Global Environmental Change, 15: 77-86.

Adger, N. and A. Jordan. 2009. Governing sustainability. Cambridge: Cambridge University Press.

Adger, W., S. Dessai, M. Goulden, M. Hulme, I. Lorenzoni, D. Nelson, L. Naessm J. Wolf, and A. Wreford. 2009. Are there social limits to adaptation to climate change? Climatic Change, 93(3-4): 335-354.

Agrawal, A. 1995. Dismantling the divide between indigenous and scientific knowledge. Development and Change, 26: 413-439.

Agrawal, A. 1999. On power and indigenous knowledge. In Cultural and spiritual values of biodiversity, ed. And comp. D. Posey. London: United Nations Environment Programme/Intermediate Technology Publications.

Agrawal, A. 2005. Environmentality: technologies of government and political subjects. Duke University Press.

Agrawal, A. and C. Gibson. 1999. Enchantment and disenchantment: The role of community in natural resource conservation. World Development, 27(4): 629649.

Ahern, J. 2011. From fail-safe to safe-to-fail: Sustainability and resilience in the new urban world. Landscape and urban Planning, 100(4): 341-343.

Alder, C. and G. Hirsch Hadorn. 2014. The IPCC and treatment of uncertainties: topics and sources of dissensus WIREs Clim Change 2014. Doi: 10.1002/wcc.297.

Anon. Five Pacific islands lost to rising seas as climate change hits. (2016, May 10). The Guardian. https://www.theguardian.com/environment/2016/may/10/five-pacificislands-lost-rising-seas-climate-change

Arnstein, S. 1969. A ladder of citizen participation. Journal of American Institute of Planners, 35(4): 216-224.

Atteridge, A. and N. Canales. 2017. Climate finance in the Pacific: An overview of flows to the region's Small Island Developing States. Stockholm Environment Institute.

Bäckstrand, K., and E. Lövbrand. 2006. Planting trees to mitigate climate change: Contested discourses of ecological modernization, green governmentality and civic environmentalism. Global Environmental Politics, 6(1): 50-75. 
Bakker, K. 2010. The limits of "neoliberal natures": Debating green neoliberalism. Progress in Human Geography, 34(6): 715-735.

Barnett, J. 2001. Adapting to climate change in Pacific Island countries: the problem of uncertainty. World Development, 29(6): 977-993.

Barnett, J. 2003. Redesigning cities: Principles, practice, and implementation. Chicago: American Planning Association.

Barnett, J. and J. Campbell. 2010. Climate change and small island states: Power, knowledge, and the South Pacific. Earthscan.

Beck, U. 1992. Risk society: Towards a new modernity. Sage.

Beier, P., L. Hansen, L. Helbrecht, and D. Behar. 2017. A how-to guide for coproduction of actionable science. Conservation Letters, 10(3): 288-296.

Berke, P. and E. Kaiser. 2006. Urban land use planning. University of Illinois Press.

Berke, P. and T. Campanella. 2006. Planning for postdisaster resiliency. The Annals of the American Academy of Political and Social Science, 604(1): 192-207.

Berkes, F. 2007. Community-based conservation in a globalized world. Proceedings of the National Academy of Sciences, 104(39): 15188-15193.

Bernard, S. "Gentrification and Climate Change are Totally Related, Says Report.” Seattle Weekly [Seattle] March 15, 2016.

Bocking, S. 2004. Nature's experts: Science, politics, and the environment. New Brunswick, NJ: Rutgers University Press.

Bogason, P. and J. Musso. 2006. The democratic prospects of network governance. American Review of Public Administration, 36(1): 3-18.

Borzel, T. 1998. Organizing Babylon — on the different conceptions of policy networks. Public Administration, 76: 233-273.

Boström, M., R. Lidskog, and Y. Uggla. 2017. A reflexive look at reflexivity in environmental sociology. Environmental Sociology, 3(1): 6-16.

Braun, V. and V. Clarke. 2006. Using thematic analysis in psychology. Qualitative Research in Psychology, 3(2): 77-101.

Brenner, N. 2001. The limits to scale? Methodological reflections on scalar structuration. Progress in Human Geography, 25: 591-614.

Brosius, J. 2006. What counts as local knowledge in global environmental assessments and conventions? In Reid, W., F. Berkes, T. Wilbanks, D. Capistrano, Eds. Bridging Scales and Knowledge Systems: Concepts and Applications in 
Ecosystem Assessment. Island Press.

Brugnach, M., A. Dewulf, C. Pahl-Wostl, and T. Taillieu. 2008. Toward a relational concept of uncertainty: about knowing too little, knowing too differently, and accepting not to know. Ecology and Society, 13(2): 30.

Brugnach, M. and H. Ingram. 2012. Ambiguity: the challenge of knowing and deciding together. Environmental Science and Policy, 15(1): 60-71.

Bulkeley, H. 2000. Discourse coalitions and the Australian climate change policy network. Environment and Planning C, 18: 727-748.

Bush, G. W. 2016. White Sand Black Beach: Civil Rights, Public Space, and Miami's Virginia Key. University Press of Florida.

Calvin, W. 2002. A brain for all seasons: Human evolution and abrupt climate change. University of Chicago Press.

Campbell, J. 1997. 'Examining Pacific Island Vulnerability to Natural Hazards', in Planitz, A. and Chung, J. (eds.), Proceedings of the VIII Pacific Science InterCongress, United Nations Department for Humanitarian Affairs, Suva, 53-62.

Chaffin, B. 2014. A decade of adaptive governance scholarship: synthesis and future directions. Ecology and Society, 19(3): 56.

Chasan, J. "Green group turns attention to affordable housing." Crosscut May 23, 2016.

Choo, C. W. 2007. The Knowing Organization: How Organizations Use Information to Construct Meaning, Create Knowledge, and Make Decisions. New York: Oxford University Press, Inc.

Church, J. and N. White. 2011. Sea level rise from the late 19th to the early 21 st century. Surveys in Geophysics, 32(4-5): 585-602.

Church, J., P. Clark, A. Cazenave, J. Gregory, S. Jevrejeva, A. Levermann, M. Merrifield, G. Milne, R. Nerem, P. Nunn, A. Payne, W. Pfeffer, D. Stammer and A. Unnikrishnan, 2013: Sea Level Change. In: Climate Change 2013: The Physical Science Basis. Contribution of Working Group I to the Fifth Assessment Report of the Intergovernmental Panel on Climate Change [Stocker, T., D. Qin, G. Plattner, M. Tignor, S. Allen, J. Boschung, A. Nauels, Y. Xia, V. Bex and P. Midgley (eds.)]. Cambridge University Press, Cambridge, United Kingdom and New York, NY, USA.

(Compact) Southeast Florida Regional Climate Change Compact. 2012. A region responds to a changing climate: Regional Climate Action Plan. 
(Compact) Southeast Florida Regional Climate Change Compact Sea Level Rise Work Group. October 2015. Unified Sea Level Rise Projection for Southeast Florida. A document prepared for the Southeast Florida Regional Climate Change Compact.

Clayton, S. 2003. Identity and the natural environment: The psychological significance of nature. Mit Press.

Collins, H. 1974. 'The TEA Set: Tacit Knowledge and Scientific Networks.' Science Studies, 4: 165-85.

Cornell, S., F. Berkhout, W. Tuinstra, J. Tàbara, J. Jäger, I. Chabay, and I. Otto. 2013. Opening up knowledge systems for better responses to global environmental change. Environmental Science and Policy, 28: 60-70.

Cornish, A. "Scorching Phoenix plans for an even hotter future." National Public Radio, August 12, 2012.

Cox, K. 1998. Spaces of dependence, spaces of engagement and the politics of scale, or: looking for local politics. Political Geography, 17: 1-23.

Crona, B. and O. Bodin. 2010. Power asymmetries in small-scale fisheries: a barrier to governance transformability? Ecology and Society, 15(4).

Cutter, S., L. Barnes, M. Berry, C. Burton, E. Evans, E. Tate, and J. Webb. 2008. A place-based model for understanding community resilience to natural disasters. Global Environmental Change, 18(4): 598-606.

DeConto, R. and D. Pollard. 2016. Contribution of Antarctica to past and future sea level rise. Nature, 531(7596): 591-597.

Demeritt, D. 2001. The construction of global warming and the politics of science. Annals of the Association of American Geographers, 91(2): 307-337.

Denton, A. 2017. Voices for environmental action? Analyzing narrative in environmental governance networks in the Pacific Islands. Global Environmental Change, 43: $62-71$.

Denton, A. 2018. Building Climate Empire: Power, Authority, and Knowledge Within Pacific Islands Climate Change Diplomacy and Governance Networks. Dissertations and Theses. Paper 4401. https://pdxscholar.library.pdx.edu/open_access_etds/4401

Dewey, J. 1927. The public and its problems. New York.

Dewulf, A., M. Craps, R. Bouwen, T. Taillieu, and P. Pahl-Wostl. 2005. Integrated management of natural resources: dealing with ambiguous issues, multiple actors and diverging frames. Water Science and Technology, 52: 115-124. 
Dillman, D., J. Smyth, and L. Melani. 2011. Internet, mail, and mixed-mode surveys: the tailored design method. Toronto: Wiley \& Sons.

Donahue, J. 2002. Market-based governance and the architecture of accountability. In Market-Based Governance, ed. J. Donahue and J. Nye. Brookings Institution.

Douglas, M. and A, Wildavsky. 1983. Risk and Culture: An essay on the selection of technological and environmental dangers. University of California Press: Berkeley, California.

Dovers, S., T. Norton, and J. Handmer. 1996. Uncertainty, ecology, sustainability and policy. Biodiversity and Conservation, 5(10): 1143-1167.

Dryzek, J. 2013. The Politics of the Earth: Environmental Discourses. Oxford University Press.

Dryzek, J. and J. Pickering. 2017. Deliberation as a catalyst for reflexive environmental governance. Ecological Economics, 131: 353-360.

Dunn, M. 1997. Black Miami in the twentieth century. University Press of Florida.

Edwards, P. 2001. Representing the global atmosphere: computer models, data, and knowledge about climate change. In Changing the atmosphere: Expert Knowledge and Environmental Governance. MIT Press.

Edwards, P., S. Jackson, G. Bowker, and C. Knobel. 2007. Understanding infrastructure: Dynamics, tensions, and design. Report of a Workshop on "History and Theory of Infrastructure: Lessons for New Scientific Cyberinfrastructures."

Elzen, B., F. Geels, and K. Green. (eds). 2005. System Innovation and the Transition to Sustainability: Theory, Evidence and Policy, Camberley: Edward Elgar.

Ernstson, H., S. Sörlin, and T. Elmqvist. 2008. Social movements and ecosystem services-the role of social network structure in protecting and managing urban green areas in Stockholm. Ecology and Society, 13(2): 39.

Fabricus, C., R. Scholes, and G. Cundill. 2006. Mobilizing knowledge for integrated ecosystem assessments. In Reid, W., F. Berkes, T. Wilbanks, D. Capistrano, Eds. Bridging Scales and Knowledge Systems: Concepts and Applications in Ecosystem Assessment. Island Press.

Fawn, R. 2009. 'Regions' and their study: where from, what for and where to? Review of International Studies, 35(S1), 5-34.

Feagin, J., A. Orum, and G. Sjoberg. 1991. A case for the case study. UNC Press Books. 
Feldman, D. and H. Ingram. 2009. Climate forecast, water management, and knowledge networks: making science useful to decision makers. Water, Climate and Society, 1: 19-21.

Fincher, R., and K. Iveson. 2008. Planning and Diversity in the City: Redistribution, Recognition and Encounter. Macmillan International Higher Education.

Fischer, F. 2000. Citizens, Experts and the Environment: The Politics of Local Knowledge. Duke University Press.

Fisher, R. and W. Ury. 1981. Getting to Yes. Simon \& Schuster Sound Ideas.

Flechas, J. "Miami Beach skips public bids to move fast on sea rise projects." Miami Herald [Miami] October, 23, 2015.

Flechas, J. and J. Staletovich. "Miami Beach's battle to stem rising tides." Miami Herald [Miami] October, 23, 2015.

Forester, J. 1999. The Deliberative Practitioner: Encouraging Participative Planning Processes. Cambridge, MA: MIT Press.

Foucault, M. 1980. Power/knowledge: Selected interviews and other writings, 19721977. Pantheon.

Foucault, M., G. Burchell, C. Gordon, and P. Miller, P. 1991. The Foucault effect: Studies in governmentality. University of Chicago Press.

Fox, N. 1999. Postmodern reflections on 'risk', 'hazards' and life choices. In Lupton, D. (ed.) Risk and sociocultural theory: New directions and perspectives, 12-33. Cambridge University Press, Cambridge.

Frickel, S. 2008. On missing New Orleans: Lost knowledge and knowledge gaps in an urban hazardscape. Environmental History, 13(4): 643-650.

Friedmann, J. 1987. Planning in the public domain: From knowledge to action. Princeton University Press.

Friedman, L. 2018. Tuvalu is growing (for now). New York Times.

Giddens, A. 2009. The politics of climate change. Polity Press.

Gieryn, T. 1999. Cultural Boundaries of Science: Credibility on the Line. Chicago: University of Chicago Press.

Gieryn, T. 2006. City as truth-spot: laboratory and field sites in urban studies. Social Studies of Science, 36(1): 5-38.

Gleeson, B. 2010. Lifeboat Cities. Sydney: University of New South Wales Press. 
Golledge, N., D. Kowalewski, T. Naish, R. Levy, C. Fogwill, and E. Gasson. 2015. The multi-millennial Antarctic commitment to future sea level rise. Nature, 526(7573): 421-425.

Google (n.d.). [Miami-Dade County, Florida]. Retrieved November 11, 2018 from https://www.google.com/maps/place/Miami-Dade+County,+FL/@25.8062051,87.0256184,6z/data $=! 4 \mathrm{~m} 5 ! 3 \mathrm{~m} 4$ !1s0x88d98b054de91839:0x49691e748195638b!8 $\mathrm{m} 2 ! 3 \mathrm{~d} 25.5516034 ! 4 \mathrm{~d}-80.6326916$

Gottlieb, R. 2005. Forcing the spring: The transformation of the American environmental movement. Island Press.

Grabowski, Z., A. Matsler, C. Thiel, L. McPhillips, R. Hum, A. Bradshaw, T. Miller, and C. Redman. 2017. Infrastructures as Socio-Eco-Technical Systems: Five Considerations for Interdisciplinary Dialogue. Journal of Infrastructure Systems, 23(4): 02517002.

Graham, S. and S. Marvin. 2001. Splintering Urbanism: Networked Infrastructures, Technological Mobilities and the Urban Condition. London: Routledge.

Gross, M. 2010. Ignorance and surprise: Science, society, and ecological design. MIT Press.

Grunwald, M. 2006. The swamp: the Everglades, Florida, and the politics of paradise. Simon and Schuster.

Gupta, A. 2004. When is global local: Negotiating safe use of biotechnology. In Earthly politics: local and global in environmental governance, Eds. S. Jasanoff and M. Long Martello. Cambridge: MIT Press.

Haas, P. 1992. "Epistemic Communities and International Policy Coordination." International Organization, 46(1): 1-35.

Habermas, J. 1984. "The Theory of Communicative Action: Reason and the Rationalization of Society (T. McCarthy, Trans. Vol. 1)." Boston: Beacon.

Hacking, I. 2002. Chapter 6, 'Making Up People.' Historical Ontology. Cambridge, MA: Harvard University Press.

Hajer, M. 1995. The politics of environmental discourse: Ecological modernization and the policy process. Oxford: Clarendon Press.

Hajer, M. and W. Versteeg. 2005. A decade of discourse analysis of environmental politics: achievements, challenges, perspectives. Journal of environmental policy and planning, 7(3): 175-184. 
Hansen, J. 2007. Scientific reticence and sea level rise. Environmental research letters, 2(2): 024002.

Harding, S. 1987. Feminism and methodology: Social science issues. Indiana University Press.

Harlem, Peter, "Sea Level Rise Map Projections" (2008). Sea Level Rise Collection. 2. https://digitalcommons.fiu.edu/sea_level_rise/2

Harris, A. Should Miami's sea level rise committee address climate change too? Miami Herald [https://www.miamiherald.com/news/local/environment/article208034699.html] April 5, 2018.

Hastings, A. 1999. Discourse and urban change: introduction to the special issue. Urban Studies, 36: 7-12.

Hay, C., E. Morrow, R. Kopp, and J. Mitrovica. 2015. Probabilistic reanalysis of twentieth century sea level rise. Nature, 517(7535): 481-484.

Healey, P. 1997. Collaborative Planning: Shaping Places in Fragmented Societies. UBC Press.

Hess, D. 2007. Alternative pathways in science and industry. MIT Press.

Heynen, N., H. Perkins, and P. Roy. 2006. "The Political Ecology of Uneven Urban Green Space: The Impact of Political Economy on Race and Ethnicity in Producing Environmental Inequality in Milwaukee." Urban Affairs Review, 42(1): $3-25$.

Hilgartner, S. 1992. "The Social Construction of Risk Objects: Or, How to Pry Open Networks of Risk," in Organizations, Uncertainties, and Risk, ed. James F. Short and Lee Clark (Boulder: Westview Press, 1992).

Hine, A., Chambers, D., Clayton, T., Hafen, M., and Mitchum, G. 2016. Sea Level Rise in Florida: Science, Impacts, and Options. University Press of Florida.

Hodson, M. and S. Marvin. 2010 World Cities and Climate Change. New York: Open University Press.

Holling, C. (Editor). 1978. Adaptive environmental assessment and management. London: John Wiley \& Sons.

Holling, C. and G. Meffe. 1996. Command and control and the pathology of natural resource management. Conservation Biology, 10(2): 328-337. 
Hommels, A. 2005. Unbuilding cities. Obduracy in urban sociotechnical change. MIT Press: Cambridge, Mass.

Howarth, D. 2000. Discourse. Open University Press: Buckingham.

Hughes, J. and J. White. 2016. Hydrologic conditions in urban Miami-Dade County, Florida, and the effect of groundwater pumpage and increased sea level on canal leakage and regional groundwater flow (ver. 1.2, July 2016): U.S. Geological Survey Scientific Investigations Report 2014-5162.

Hulme, M. 2009. Why we disagree about climate change: Understanding controversy, inaction and opportunity. Cambridge University Press.

Hulme, M. 2010. Problems with making and governing global kinds of knowledge. Global Environmental Change, 20(4): 558-564.

Hulme, M. 2013. Lessons from the IPCC: Do scientific assessments need to be consensual to be authoritative. Future directions for scientific advice in Whitehall, 142-147.

Florida Institute for Health Innovation. 2016. Health and sea level rise: Impacts on South Florida.

Innes, J. and D. Booher. 2004. Reframing Public Participation: Strategies for the 21st Century. Planning Theory and Practice 5: 419-436.

Innes, J. and D. Booher. 2010. Planning with Complexity: An Introduction to Collaborative Rationality for Public Policy. Routledge.

IPCC. Field, C. 2012. Managing the risks of extreme events and disasters to advance climate change adaptation: special report of the intergovernmental panel on climate change. Cambridge University Press.

(IPCC) Pachauri, R., M. Allen, V. Barros, J. Broome, W. Cramer, R. Christ, J. Church, L. Clarke, Q. Dahe, P. Dasgupta, and N. Dubash. 2014. Climate Change 2014: Synthesis Report. Contribution of Working Groups I, II and III to the Fifth Assessment Report of the Intergovernmental Panel on Climate Change / R. Pachauri and L. Meyer (editors), Geneva, Switzerland, IPCC, 151 p., ISBN: 97892-9169-143-2

Irwin, A. 1995. Citizen Science: A Study of People, Expertise, and Sustainable Development. Routledge, New York.

Irwin, A. and B. Wynne. 1996. Misunderstanding Science? The Public Reconstruction of Science and Technology. Cambridge University Press, Cambridge. 
Jacobs, K. 2006. Discourse analysis and its utility for urban policy research, Urban Policy and Research, 24, pp. 39-52.

Jaeger, C., O. Renn, E. Rosa, and T. Weber. 2001. Risk, uncertainty, and rational action. London: Earthscan.

Jarrett, B., A. Hine, R. Halley, D. Naar, S. Locker, A. Neumann, D. Twichell, C. Hu, B. Donahue, W. Jaap, and D. Palandro. 2005. Strange bedfellows - a deep-water hermatypic coral reef superimposed on a drowned barrier island; southern Pulley Ridge, SW Florida platform margin. Marine Geology, 214(4): 295-307.

Jasanoff, S. 1987. Contested boundaries in policy-relevant science. Social Studies of Science, 17: 195-230.

Jasanoff, S. 1998. Contingent knowledge: Implications for implementation and compliance. In Engaging Countries, ed. E. Weiss and H. Jacobson. MIT Press.

Jasanoff, S. and B. Wynne. 1998. Science and decisionmaking. In Human choice and climate change: The societal framework, ed. S. Rayner and E. Malone. Columbus, $\mathrm{OH}$ : Batelle Press.

Jasanoff, S. 2004. Science and Citizenship: a new synergy. Science and public policy, 31(2): 90-94.

Jasanoff, S. 2004. States of knowledge: The co-production of science and the social order. New Brunswick, NJ: Routledge.

Jasanoff, S. 2006. Technology as site and object of politics. Oxford Handbook of Contextual Political Analysis, R. Goodin and C. Tilly, eds. Oxford University Press: Oxford, UK.

Jasanoff, S. and M. Long-Martello. 2004. Earthly politics: local and global in environmental governance. Cambridge: MIT Press.

Johnson, R. and A. Onwuegbuzie. 2004. Mixed methods research: A research paradigm whose time has come. Educational Researcher, 33(7): 14-26.

Johnson, R., A. Onwuegbuzie, and L. Turner. 2007. Toward a definition of mixed methods research. Journal of Mixed methods Research, 1(2): 112-133.

Juhola, S. and L. Westerhoff. 2011. Challenges of adaptation to climate change across multiple scales: a case study of network governance in two European countries. Environmental Science and Policy, 14(3): 239-247.

Kaika, M. 2017. 'Don’t call me resilient again!': the New Urban Agenda as immunology... or... what happens when communities refuse to be vaccinated with 'smart cities' and indicators. Environment and Urbanization, 29(1): 89-102. 
Kelman, I. 2014. No change from climate change: vulnerability and small island developing states. The Geographical Journal, 180(2): 120-129.

Kench, P., M. Ford, and S. Owen. 2018. Patterns of island change and persistence offer alternate adaptation pathways for atoll nations. Nature communications, 9(1): 605.

King, J. “Rising Reality.” San Francisco Chronicle [San Francisco] May 2016.

Kjellström, E., L. Bärring, G. Nikulin, C. Nilsson, G. Persson, and G. Strandberg. 2016. Production and use of regional climate model projections-A Swedish perspective on building climate services. Climate Services, 2: 15-29.

Kleinberg, E. 2003. Black cloud: The great Florida hurricane of 1928. Basic Books.

Knox, C. 2013. Distorted communication in the Florida Everglades: A critical theory analysis of 'Everglades Restoration.' Journal of Environmental Policy and Planning, 15(2): 269-284.

Kopp, R., A. Kemp, K. Bittermann, B. Horton, J. Donnelly, W. Gehrels, and S. Rahmstorf. 2016. Temperature-driven global sea level variability in the Common Era. Proceedings of the National Academy of Sciences: 201517056.

Krimsky, S. and D. Golding (Eds.). 1992. Social Theories of Risk. Praeger Publishers, Westport, CT.

Kuhn, T. 1970. The structure of scientific revolutions. Chicago: Univ. of Chicago Pr.

Kunreuther, H., G. Heal, M. Allen, O. Edenhofer, C. Field, and G. Yohe. 2013. Risk management and climate change. Nature Climate Change, 3(5): 447-450.

Latour, B. 2004. "Why Has Critique Run out of Steam? From Matters of Fact to Matters of Concern." Critical Inquiry, 30: 225.

Latour, B. 2012. We have never been modern. Harvard university press.

Latour, B. and S. Woolgar. 1986. Laboratory Life: The Construction of Scientific Facts. Princeton University Press.

Leach, M., I. Scoones, B. Wynne. (Eds.). 2005. Science and Citizens: Globalization and the Challenge of Engagement. Zed Books, London.

Leach, M., G. Bloom, A. Ely, P. Nightingale, I. Scoones, E. Shah, and A. Smith. 2007. Understanding Governance: pathways to sustainability. Paper 2, Brighton: STEPS.

Lebel, L. 2006. The politics of scale in environmental assessments. In Reid, W., F. Berkes, T. Wilbanks, D. Capistrano, Eds. Bridging Scales and Knowledge Systems: Concepts and Applications in Ecosystem Assessment. Island Press. 
Lee, K. 1999. Appraising adaptive management. Conservation Ecology, 3(2): 3.

Lees, L. 2004. Urban geography: discourse analysis and urban research. Progress in human geography, 28(1): 101-107.

Lejano, R., M. Ingram, and H. Ingram. 2013. The power of narrative in environmental networks. MIT Press.

Lemos, M. and A. Agrawal. 2006. Environmental governance. Annual Review of Environmental Resources, 31: 297-325

Lengwiler, M. 2008. Participatory approaches in science and technology: historical origins and current practices in critical perspective. Science, Technology, and Human Values, 33(2): 186-200.

Lichtenberg, J. and D. MacLean. 1991. The role of the media in risk communication. In Communicating risks to the public (pp. 157-173). Springer Netherlands.

Lindblom, C. 1978. Why government must cater to business. Business and Society Review, 27: 5-6.

Lindseth, G. 2005. Local level adaptation to climate change: discursive strategies in the Norwegian context. Journal of Environmental Policy and Planning, 7(1): 61-84.

Litfin, K. 1994. Ozone discourses: Science and politics in global environmental cooperation. New York: Columbia University Press.

Lovell, H., H. Bukeley, and S. Owens. 2009. Converging agendas? Energy and climate change policies in the UK. Environment and Planning C, 27: 90-109.

Low, N. and B. Gleeson. 2001. Ecosocialisation or countermodernisation? Reviewing the shifting 'storylines' of transport planning. International Journal of Urban and Regional Research, 25(4): 784-803.

Lupton, D. (ed.) 1999. Risk and sociocultural theory: new directions and perspectives. Cambridge University Press, Cambridge.

Mahony, M. 2014. The predictive state: science, territory and the future of the Indian climate. Social Studies of Science, 44(1):109-133.

Mander, S. 2007. Regional renewable energy policy: a process of coalition building., Global Environmental Politics, 7: 45-63.

Mathiesen, K. (2016, May 10) Headlines 'exaggerated' climate link to sinking of Pacific islands. The Guardian.

https://www.theguardian.com/environment/2016/may/10/headlines-exaggeratedclimate-link-to-sinking-of-pacific-islands 
McCarthy J., O. Canziani, N. Leary, D. Dokken, K. White (eds). 2001. Climate change 2001: impacts, adaptation and vulnerability. IPCC working group II. Cambridge University Press, Cambridge.

McCubbin, S., B. Smit, T. and Pearce. 2015. Where does climate fit? Vulnerability to climate change in the context of multiple stressors in Funafuti, Tuvalu. Global Environmental Change, 30: 43-55.

McGuirk, P. 2012. Geographies of urban politics: pathways, intersections, interventions, Geographical Research, 50(3): 256-266.

McNamara, K. and C. Gibson. 2009. We do not want to leave our land': Pacific ambassadors at the United Nations resist the category of 'climate refugees. Geoforum, 40(3): 475-483.

McPhearson, T., T. Steward, A. Pickett, N. Grimm, J. Niemelä, M. Alberti, T. Elmqvist, C. Weber, D. Haase, J. Breuste, and S. Qureshi. 2016. Advancing Urban Ecology toward a Science of Cities. BioScience, 66(3): 198-212.

Meadows, D. 1999. Leverage points: Places to intervene in a system (pp. 1-19). Hartland, VT: Sustainability Institute.

Meadowcroft, J. 2002. Politics and Scale: Some implications for environmental governance. Landscape and Urban Planning, 61: 169-179.

Medema, W., B. McIntosh, and P. Jeffrey. 2008. From premise to practice: a critical assessment of integrated water resources management and adaptive management approaches in the water sector. Ecology and Society, 13(2): 29.

Molotch, H. 1976. The city as a growth machine: Toward a political economy of place. American journal of sociology, 82(2): 309-332.

(Recommendations). Miami-Dade County Climate Change Advisory Task Force. (2008). Second Report and Initial Recommendations Presented to The Miami-Dade Board of County Commissioners in April 2008.

(MA) Millennium Ecosystem Assessment. 2003. Ecosystems and human well-being: A framework for assessment. Washington D.C.: Island Press.

Miller, C. 2000. 'The Dynamics of Framing Environmental Values and Policy: Four Models of Societal Processes.' Environmental Values, 9: 211-30.

Miller, C. 2004. Climate science and the making of a global political order. States of knowledge: The coproduction of science and social order, 46-66.

Miller, C. 2008. Civic Epistemologies: Constituting Knowledge and Order in Political Communities. Sociology Compass, 2(6): 1896-1919. 
Miller, C. and P. Edwards. 2001. Changing the Atmosphere: Expert Knowledge and Environmental Governance. MIT Press.

Miller, C., T. Muñoz-Erickson, and C. Monfreda. 2010. Knowledge systems analysis. A report for the Advancing Conservation in a Social Context Project.

Miller, C. and T. Muñoz-Erickson. 2018. Designing Knowledge. Vol. 11. The Rightful Place of Science. Tempe, AZ: Consortium for Science, Policy and Outcomes.

Morgan, D. 1998. Practical Strategies for Combining Qualitative and Quantitative Methods: Applications to Health Research. Qualitative Health Research, 8(3): 362-76.

Morgan, D. 2014. Integrating Qualitative and Quantitative Methods: A Pragmatic Approach. Thousand Oaks, California: SAGE Publications, Inc.

Muñoz-Erickson, T., B. Cutts, L. Larson, K. Darby, M. Neff, A. Wutich, and B. Bolin. 2010. Spanning boundaries in an Arizona watershed partnership: information networks as tools for entrenchment or ties for cooperation? Ecology and Society, 15(3).

Muñoz-Erickson, T. 2014. Co-production of knowledge-action systems in urban sustainable governance: the KASA approach. Environmental Science and Policy 37, 182-191.

Nerem, R., D. Chambers, C. Choe, and G. Mitchum. 2010. Estimating Mean Sea Level Change from the TOPEX and Jason Altimeter Missions. Marine Geodesy, 33(S1): 435-446.

Nicholls, R. and N. Mimura. 1998. Regional issues raised by sea level rise and their policy implications. Climate Research, 11(1): 5-18.

NOAA Coastal Services Center. (2010b, August). Mapping Inundation Uncertainty. http://www.csc.noaa.gov/sea level rise/viewer/assets/pdfs/Elevation_Mapping_Confidence_Methods.pdf

NOAA NOS. (2010, September). Technical Considerations for Use of Geospatial Data in Sea Level Change Mapping and Assessment (NOAA Technical Report NOS 2010-01). http://www.csc.noaa.gov/digitalcoast/inundation/_pdf/SLC_Technical_Considerat ions_Document.pdf

O'Brien, K. and R. Leichenko. 2000. Double exposure: assessing the impacts of climate change within the context of economic globalization. Global environmental change, 10(3): 221-232.

Ostrom, E. 1990. Governing the commons: The evolution of institutions for collective action. Cambridge University Press: Cambridge. 
Ozawa, C. 1996. Science in environmental conflicts. Sociological Perspectives, 39(2): 219-230.

Pahl-Wostl, C. 2003. Polycentric integrated assessment. In Scaling issues in integrated assessment, ed. J. Rotmans and D. Rothman, 237-261. Lisse, The Netherlands: Swets and Zeitlinger.

Palm, J. 2006. Development of Sustainable Energy Systems in Swedish Municipalities: A Matter of Path Dependency and Power Relations. Local Environment, 11(4): 445457.

Perrow, C. 1984. Normal Accidents: Living with High Risk Technologies. New York: Basic Books.

Pietri, D., T. Stevenson, and P. Christie. 2015. The Coral Triangle Initiative and regional exchanges: Strengthening capacity through a regional learning network. Global Environmental Change, 33: 165-176.

Pilkey, O., L. Pilkey-Jarvis, and K. Pilkey. 2016. Retreat from a rising sea: Hard choices in an age of climate change. Columbia University Press.

Porter, T. 1996. Trust in Numbers: The Pursuit of Objectivity in Science and Public Life. Princeton, N.J.: Princeton University Press.

Pritchard, S. 2011. Confluence: The Nature of Technology and the Remaking of the Rhône. Harvard University Press.

Ragin, C. 1992. Introduction: Cases of "What is a case?". What is a case, 1-17.

Rancière, J. 2015. Dissensus: On politics and aesthetics. Bloomsbury Publishing.

Rayner, S. 1992. "Cultural theory and risk analysis.” In, S. Krimsky and D. Golding (eds.) Social Theories of Risk. Praeger Publishers, Westport, CT.

Reed, M., A. Graves, N. Dandy, H. Posthumus, K. Hubacek, J. Morris, C. Prell, C. Quinn, and L. Stringer. 2009. Who's in and why? A typology of stakeholder analysis methods for natural resource management. Journal of Environmental Management, 90: 1933-1949.

Reid, W., F. Berkes, T. Wilbanks, and D. Capistrano. 2006. Bridging Scales and Knowledge Systems: Concepts and Applications in Ecosystem Assessment. Island Press.

Renn, O., A. Klinke, and M. Van Asselt. 2011. Coping with complexity, uncertainty and ambiguity in risk governance: a synthesis. AMBIO, 40(2): 231-246.

Resilient Cities Assessment. 2017. Resilient Greater Miami and the Beaches. Website Retrieval resilient305.com/resources/\#tab2 
Rogers, P. and A. Hall. 2003. Effective water governance. Global water partnership.

Rosener, J. 1981. User-oriented evaluation: A new way to view citizen participation. Journal of Applied Behavioral Science, 17(4): 583-96.

Rowe, G., and L. Frewer. 2000. Public participation methods: A framework for evaluation. Science, Technology, and Human Values, 25(1): 3-29.

Rowe, G., and L. Frewer. 2004. Evaluating public participation exercises: A research agenda. Science, Technology, and Human Values, 29(4): 512-557.

Rydin, Y. 1998. The enabling local state and urban development: resources, rhetoric and planning in East London. Urban Studies, 35(2): 175-191.

Rydin, Y. 2005. Geographical knowledge and policy: the positive contribution of discourse studies. Area, 37(1): 73-78.

Sabatier, P. and H. Jenkins-Smith. 1993. The advocacy coalition framework: Assessment, revisions, and implications for scholars and practitioners. Policy change and learning: An advocacy coalition approach, 211-236.

Sarawitz, D., R. Pielke, and R. Byerly (eds.). 2000. Prediction: Science, Decision Making, and the Future of Nature. Island Press.

Sarewitz, D. 2004. How Science Makes Environmental Controversies Worse. Environmental Science and Policy, 7: 385-403.

Schmitter, P. 2001. What is there to legitimize in the European Union... and how might this be accomplished? No. 75, Political Science Series, Institute for Advanced Studies, Vienna.

Schwing, R. and W. Albers. 2013. Societal risk assessment: How safe is safe enough?. Springer.

Scott, J. 1998. Seeing like a state: How certain schemes to improve the human condition have failed. Yale University Press.

Shapin, S. and S. Schaffer 1985. Leviathan and the Air Pump: Hobbes, Boyle, and the Experimental Life. Princeton University Press.

Shi, L., E. Chu, I. Anguelovski, A. Aylett, J. Debats, K. Goh, T. Schenk, K. Seto, D. Dodman, D. Roberts, T. Roberts, and S. VanDeveer. 2016. Roadmap towards justice in urban climate adaptation research. Nature Climate Change, 6: 131-137.

Short, J. and L. Clarke, Eds. 1992. Organizations, Uncertainties, and Risk. Boulder: Westview Press.

Simons, H. 2009. Case study research in practice. London: SAGE. 
Singleton, R. and B. Straights. 2010. Approaches to Social Research. Oxford University Press: Oxford.

Smith, A., A. Stirling, and F. Berkhout. 2005. The Governance of Sustainable Sociotechnical Transitions. Research Policy, 34: 1491-1510.

Solecki, W., R. Leichenko, and K. O’Brien. 2011. Climate change adaptation strategies and disaster risk reduction in cities: connections, contentions, and synergies. Current Opinion in Environmental Sustainability, 3(3): 135-141.

Sommer, L. "Proposed Property Tax to Fight Climate Change Criticized as Unfair." National Public Radio May 11, 2016.

(Regional Projection /SFRCCC) Southeast Florida Regional Climate Change Compact Sea Level Rise Work Group. October 2015. Unified Sea Level Rise Projection for Southeast Florida. A document prepared for the Southeast Florida Regional Climate Change Compact.

(Vulnerability Assessment) Southeast Florida Regional Climate Change Compact Inundation Mapping and Vulnerability Assessment Work Group. August 2012. Analysis of the Vulnerability of Southeast Florida to Sea Level Rise. p. 103.

Spencer, T., M. Schuerch, R. Nicholls, J. Hinkel, D. Lincke, A. Vafeidis, R. Reef, L. McFadden, and S. Brown. 2016. Global coastal wetland change under sea level rise and related stresses: The DIVA Wetland Change Model. Global and Planetary Change, 139: 15-30.

Stake, R. 2005. Qualitative case studies. In N. K. Denzin and Y. S. Lincoln (Eds.), The SAGE handbook of qualitative research (3rd ed.) (pp. 443-466). Thousand Oaks, CA: SAGE.

Stirling, A. 2009. Participation, precaution, and reflexive governance for sustainable development in Governing Sustainability. Cambridge University Press.

Stowe, C. "Got Green, Puget Sound Sage Climate Change Report puts focus on South Seattle Community." International Examiner April 27, 2016.

Strauss, A. and J. Corbin. 1990. Basics of qualitative research: Grounded theory procedures and techniques. Sage: Newbury Park, CA.

Susskind, L. and J. Cruikshank. 1987. Breaking the Impasse. Basic Books.

Sweet, W., J. Park, J. Marra, C. Zervas, and Stephen Gill. 2014. Sea level rise and nuisance flood frequency changes across the United States. NOAA Technical Report NOS CO-OPS 073. 
Sweet, W., R. Kopp, C. Weaver, J. Obeysekera, R. Horton, R. Thieler, and C. Zervas. 2017. Global and regional sea level rise scenarios for the United States. NOAA Technical Report NOS CO-OPS 083.

Swyngedouw, E. 2000. Authoritarian governance, power and the politics of rescaling. Environment and Planning D: Society and Space, 18: 63-76.

Takacs, D. 1996. Ideas of Biodiversity: Philosophies of Paradise. Baltimore, MD: Johns Hopkins University Press.

Tanner, T., T. Mitchell, E. Polack, and B. Guenther. 2009. Urban governance for adaptation: assessing climate change resilience in ten Asian cities. IDS Working Papers, 2009(315): 01-47.

Tannert, C., H. Elvers, H., and B. Jandrig. 2007. The ethics of uncertainty: In the light of possible dangers, research becomes a moral duty. EMBO reports, 8(10): 892-896.

Taylor, B., T. Wallington, S. Heyenga, and B. Harman. 2014. Urban growth and climate adaptation in Australia: Divergent discourses and implications for policy-making. Urban Studies, 51(1): 3-21.

Tenenbaum, E. and A. Wildavsky. 1984. Why policies control data and data cannot determine policies. Scandinavian Journal of Management Studies, 1(2): 83-100.

Theuerkauf, E., A. Rodriguez, S. Fegley, and R. Luettich Jr. 2014. Sea level anomalies exacerbate beach erosion. Geophysical Research Letters, 41(14): 5139-5147.

Thomas, G. 2011. A typology for the case study in social science following a review of definition, discourse, and structure. Qualitative inquiry, 17(6): 511-521.

Thorns, D. 2002. The Transformation of Cities: Urban Theory and Urban Life. New York: Palgrave Macmillan Press.

Tompkins, E. and W. Adger. 2004. Does adaptive management of natural resources enhance resilience to climate change? Ecology and Society, 9(2): 10.

Tonkiss, F. 1998: Analysing discourse. In Seale, C., editor, Researching society and culture, London: Sage, 245-60.

Tuana, N. 2013. Embedding ethics in the practices of science: Bringing humanities to the sciences. Synthese: An International Journal for Epistemology, Methodology and Philosophy of Science, 190(11): 1955-1973.

Tuana, N. 2015. The essential role of coupled ethical-epistemic analyses. Communications of the Association for Computing Machinery, 58(12).

(UNCC) United Nations Climate Change. Mapping Exposure to Sea Level Rise. https://unfccc.int/climate-action/momentum-for-change/ict-solutions/mappingexposure-to-sea level-rise. Accessed on 7/16/2018. 
U.S. Census Bureau; American Community Survey, 2015, http://www.census.gov/quickfacts/table/PST045215/12086,06081; (14 October 2016).

van Asselt, M. and O. Renn. 2011. Risk governance. Journal of Risk Research, 14(4): 431-449.

van den Hoek, R., M. Brugnach, J. Mulder, and A. Hoekstra. 2014. Analysing the cascades of uncertainty in flood defense projects: How "not knowing enough" is related to "knowing differently." Global Environmental Change, 24: 373-388.

Vogel, J., E. McNie, and D. Behar. 2016. Co-producing actionable science for water utilities. Climate Services, 2: 30-40.

Wanless, H. Statement on Sea Level in the Coming Century. Presentation given April 22, 2008 to the Board of County Commissioners. Slides retrieved from https://www.miamidade.gov/environment/library/brochures/08-04-22-statementon-sea level.pdf on 7/18/2018

Warren, D, L. Slikkerveer, and D. Brokensha, eds. 1995. The cultural dimension of development: Indigenous knowledge systems. London: intermediate Technology Publications.

Wasserman, S. and F. Faust. 1994. Social Network Analysis: Methods and Applications. Cambridge University Press.

Weick, K., 1995. Sensemaking in Organizations. Sage Publications, Thousand Oaks, CA, USA.

Weiss, J. “Miami’s Low-Income Communities Might Finally Get a Voice in Sea level Rise Planning. Miami New Times May 20, 2016.

Wilbanks, T. 2006. How scale matters: Some concepts and findings. In Reid, W., F. Berkes, T. Wilbanks, D. Capistrano, Eds. Bridging Scales and Knowledge Systems: Concepts and Applications in Ecosystem Assessment. Island Press.

Wildavsky, A. 1988. Searching for safety (Vol. 10). Transaction publishers.

Winner, L. 1989. Do artifacts have politics? In The Whale and the Reactor: A Search for Limits in an Age of High Technology, pp. 19-39.

Wisner, B., P. Blaikie, T. Cannon, and I. Davis. 2014. At risk: natural hazards, people's vulnerability and disasters. Routledge.

Wynne, B. 1992. Uncertainty and environmental learning: reconceiving science and policy in the preventive paradigm. Global environmental change, 2(2): 111-127.

Wynne, B. 1996. A reflexive view of the expert-lay knowledge divide. Risk, environment and modernity: Towards a new ecology, 40: 44. 
Wynne, B. 2003. Misunderstood Misunderstandings: social identities and the public uptake of science, Chapter I in Irwin, A., and Wynne, B. 2003. Misunderstanding science: the public reconstruction of science and technology. Cambridge University Press.

Yin, R. 2014. Case study research: Design and methods. Sage publications.

Zalasiewicz, J., W. Steffen, R. Leinfelder, M. Williams, and C. Waters. 2017. Petrifying earth process: The stratigraphic imprint of key earth system parameters in the Anthropocene. Theory, Culture and Society, 34(2-3): 83-104. 


\section{Appendix A: Timeline of events related to sea level rise adaptation planning in}

\section{Miami-Dade County}

1992 Hurricane Andrew, Category 5.

1992 Responding to Andrew, Miami-Dade County improved stormwater management program.

1995 Florida updated building codes, primarily for wind.

1998 Miami-Dade County created first FEMA Local Mitigation Strategy.

2006: Miami-Dade County Water Conservation Program Established.

2006 The Board of County Commissioners established the Miami-Dade County Climate Change Advisory Task Force, through the adoption of Ordinance 06-113.

2007: The South Florida Water Management District passed a regulation that put a cap in the Biscayne Aquifer (Miami-Dade County's main source of drinking water). Led the county to implement aggressive water conservation program and plans to drill into the Floridan aquifer (which is deeper and less susceptible to saltwater intrusion).

2008 February: Miami-Dade County entered into Joint Funding Agreement 08E0FL20817 with the USGS to develop an integrated surface/groundwater numerical flow model, with one of the objectives of the project being to evaluate if sea level rise will cause salt water intrusion into coastal wellfields

2008 April: Miami-Dade County Climate Change Advisory Task Force delivered Second Report and Initial Recommendations to county commissioners.

2008: State Law governing water treatment outflows (forces Miami-Dade County to upgrade systems at cost of $\$ 3.3$ billion).

2009 Southeast Florida Regional Climate Change Compact formalized.

2009: The South Florida Water Management District's Interdepartmental Climate Change Group published a report entitled, "Climate Change and Water Management in South Florida." This report provides an overview of the impacts of sea level rise, temperature, evapotranspiration, rainfall, floods, drought, tropical storms, and hurricanes to South Florida. This report states that flood protection in Southeast Florida may be impacted by sea level rise. The report identifies several existing South Florida Water Management District coastal structures in Miami-Dade County that could be potentially impacted. The South Florida Water Management District initiates a new pilot project to determine the current level of flood protection in the C-4 basin, to consider future changes that may impact flood protection, and to develop adaptation strategies to address such impacts with funding from the Federal Emergency Management Agency. 
2010: Miami-Dade County Climate Change Advisory Task Force delivered Recommendations to county commissioners.

2010: Miami-Dade County GreenPrint Published, includes some of the recommendations from the Miami-Dade County Climate Change Advisory Task Force, but not the projections from the Science and Technology Committee.

2012: Miami-Dade County started negotiating second consent decree with EPA because of needed updates to water treatment facilities to come into compliance with regulations.

2012: City of Miami Beach approved stormwater master plan, the plan discussed sea level rise but no actions to address it.

2012 October: Southeast Florida Regional Climate Change Compact Publishes first set of projections.

2012: Southeast Florida Regional Climate Change Compact publishes first Southeast Florida Regional Climate Action Plan.

2013 July: Miami-Dade County Sea Level Rise Task Force Created through Miami-Dade County Resolution R-599-13, adopted on July 2, 2013. It was amended to add a seventh member through Resolution R-744-13, adopted on Sept. 17, 2013.

2013: Miami-Dade County and EPA finalized water treatment consent decree, total cost of prescribed projects/upgrades $\$ 1.6$ billion.

2013: Mayor Philip Levine elected to City of Miami Beach on a campaign to drain the streets.

2013 October: Board of County Commissioners approved amendments in Miami-Dade County's Comprehensive Development Master Plan to incorporate language addressing climate change and sea level rise in over thirty objectives and policies of the plan.

2014 April: Formal partnership between the South Florida Water Management District and the Ministry of Ministry of Infrastructure and the Environment of the Netherlands established.

2014 September: USGS integrated surface/groundwater numerical flow model published. This enhanced modelling is considered by scientists and planners to be extremely important to planning because of its improvement to "bathtub" sea level rise inundation maps.

2014: The streets in Miami Beach were dry during the King Tides. The city had plugged holes in the pipes and put in critical pumps during Mayor Levine's first year in office.

2014 January: City of Miami Beach Mayor's Blue-Ribbon Panel on Flood Mitigation meets for first time. 
2014: Resolution R-451-14 and Ordinance 14-79 were adopted in 2014, requiring that planning, design and construction of Miami-Dade County infrastructure consider potential sea level rise impacts.

2014 July: Miami-Dade County Sea level Rise Task Force submits recommendations to County Commissioners. The main recommendation is to implement the recommendations that the first Advisory Task Force produced in 2008 and 2010.

2015: South Florida Water Management District initiated a two-year grant project that is funded by NOAA's Sectoral Applications Research Program. It was awarded to the South Florida Water Management District and their partner, Deltares ${ }^{10}$, for their project entitled, "Flood and Drought Risk Management Under Climate Change: Methods for Strategy Evaluation and Cost Optimization."

2015: The Southeast Florida Regional Climate Change Compact Publishes second set of updated projections. These include NOAA and IPCC projections, not just USACE projections that the 2012 version had. Also, the 2015 projections extend to 2100 whereas the 2012 version only went to 2060 .

2015: City of Miami establishes Sea Level Rise Committee via Resolution: R-15-0072.

2015: January 21, 2015, the Board of County Commissioners (Board) passed seven (7) resolutions, each supporting the implementation of one of the seven recommendations included in the "Miami-Dade Sea Level Rise Task Force Report and Recommendations." Resolution R-48-15, which requires a quarterly status report and a final report within 364 days, directs the Mayor or Mayor's designee to work in conjunction with the Office of Intergovernmental Affairs (OIA), the South Florida Water Management District, the USGS, and other member Counties of the Southeast Florida Regional Climate Change Compact to conduct a comprehensive study and develop adaptation strategies to address potential flood damage reduction and salt water intrusion associated with sea level rise.

2016: Miami-Dade County, the City of Miami, and the City of Miami Beach selected as for the Rockefeller Foundation's 100 Resilient Cities Initiative.

2017: The 100 Resilient Cities Initiative for Greater Miami and the Beaches publishes their initial assessment of community, economic, and environmental "Stressors and Shocks."

2017: City of Miami joins the Southeast Florida Regional Climate Change Compact.

2017 April: Southeast Florida Regional Climate Change Compact begins updating Southeast Florida Regional Climate Action Plan 2.0

2017: Southeast Florida Regional Climate Change Compact publishes the second Southeast Florida Regional Climate Action Plan.

\footnotetext{
${ }^{10}$ Deltares is an independent research institute which focuses on applied research in the field of water, subsurface, and infrastructure. Deltares is based in Delft and Utrecht in the Netherlands, with a USA branch (Deltares USA) based in Silver Springs, Maryland.
} 


\section{Appendix B: Key Documents}

Document Name

MD County Stormwater Master

Plan C-7 Basin Phase II Executive

Summary and Final Report

Miami-Dade Climate Change

Advisory Task Force Second

Report and Initial

Recommendation

Presentation on SLR to first

climate change committee

Planning for Hazards and Climate

Change Impacts: One County's

Approach

An Update on USACE Sea Level

Change Guidance and Preliminary

Applications for Everglades

Restoration Projects

Miami-Dade County GreenPrint

Our Design for a Sustainable

Future

Climate Change Advisory Task

Force Status of Recommendations

Analysis of the Vulnerability of

Southeast Florida to Sea Level

Rise

A Region Responds to a Changing

Climate: Southeast Florida

Regional Climate Change

Compact Counties: Regional

Climate Action Plan

Implementation Guide: Southeast

Florida Regional Climate Action

Plan

Regional Impacts of Climate

Change and Issues for Stormwater

Management

US EPA Region 4 Adaptation

Implementation Plan

Nature Conservancy Coastal

Resilience Visualization Tool
Year

Author

2006

Miami-Dade County

2008

Miami-Dade County

2008

Dr. Hal Wanless, University of Miami

2009

NOAA

2010

US Army Corps of Engineers

2010

2010

Miami-Dade County

2012

2012

Miami-Dade County

Southeast Florida Regional Climate

Change Compact

Southeast Florida Regional Climate

Change Compact

2012

Southeast Florida Regional Climate

Change Compact

2012 Southeast Florida Regional Climate Change Compact; South Florida Water

Management District

2013 Environmental Protection Agency

2013 The Nature Conservancy 
Adaptation Action Area Pilot

Project Report

SFWMD Lower East Coast Water

Supply Plan Update

USACE Incorporating Sea Level

Change in Civil Works Programs

Miami-Dade Sea Level Rise Task

Force Report and

Recommendations

2014 Municipal Implementation

Survey Report

US DOT Climate Adaptation Plan

Ensuring Transportation

Infrastructure and System

Resilience

Workshop on Robust Decision

Making Under Deep Uncertainty

Nature-Based Coastal Defenses in

Southeast Florida

Regional Climate Action Plan

Health Impact Assessment

Policy and Advocacy

Implementation Report

Integrating Climate Change and

Water Supply Planning in

Southeast Florida

20-Year Water Supply Facilities

Work Plan

Miami 2040 Long Range

Transportation Plan

USACE Procedures to evaluate sea

level change: impacts, responses,

and adaptation

Sea Level Change and Long-

Range Water Resources Planning

for Florida

Unified Sea Level Rise Projection

Southeast Florida

Guidelines to Local Governments

for Temporary Coastal Armoring

Seaward of the Coastal

Construction Control Line
2014

2014

2014

2014

2014

2014

2014

2014

2014

2014

2014

2014

2015

2015
South Florida Regional Planning Council

South Florida Water Management District

USACE

Miami-Dade County Sea Level Rise Task

Force

Southeast Florida Regional Climate

Change Compact

US Department of Transportation

South Florida Water Management District

The Nature Conservancy

Florida Institute for Health Innovation;

Broward County; Southeast Florida

Regional Climate Change Compact

Southeast Florida Regional Climate

Change Compact

Southeast Florida Regional Climate

Change Compact

Miami-Dade County

Miami-Dade County

USACE

USACE

Southeast Florida Regional Climate Change Compact

Florida Department of Environmental Protection 
Miami-Dade County

Comprehensive Development

Master Plan

Village of Pine Crest

Comprehensive Development

Master Plan

Miami Comprehensive

Neighborhood Plan

Miami Beach Stormwater

Management Master Plan

Village of Pine Crest Stormwater

Master Plan Report

Pinecrest Survey for Landowners

about Flooding

Pinecrest Stormwater Plan

Effective Sea Level Rise

Communication Strategies for

Local Governments

Integrating the Unified Sea Level

Rise Projection into Local Plans

Local Mitigation Strategy Miami-

Dade County Whole Community

Hazard Mitigation

Memorandum Miami Dade

County: Final Status reports in

response to multiple resolutions

pertaining to recommendations by

the sea level task force

Assessment of Available Tools to

Create a More Resilient

Transportation System

Climate Adaptation: The State of

Practice in U.S. Communities

Report on Flooding and Salt water intrusion

Mobilizing Miami for Sea Level

Rise

Sea Level Rise and U.S. Coasts:

Science and Policy Considerations

(by Congressional Research

Service)

Reducing Climate Risk and

Creating Economic Opportunity

(Regional Climate Action Plan

Implementation Support Guidance

Series)
2015

Miami-Dade County

2015

Village of Pinecrest

2015

City of Miami

2015

City of Miami Beach

2015

Village of Pinecrest

2015

City of Pinecrest

2015

2016

2016

2016

2016

Miami-Dade County

2016

Miami-Dade County

2016

The Kresge Foundation

2016

2016

2016

Miami-Dade County

The Miami Foundation and the Knight Foundation, written by firm, Sightful

Congressional Research Service

2016

Southeast Florida Regional Climate

Change Compact 
Southeast Florida Climate

Indicators

Integrating the Southeast Sea

Level Rise Projections into

Community Planning

South Florida Climate Change

Vulnerability and Adaptation

Assessment Pilot Project

Adaptation Action Areas:

Feasibility Assessment

Miami Frontlines Coalition Letter

FreddieMac Life's a Beach:

Economic and Housing Insight

Health and Sea Level Rise:

Impacts on South Florida

Climate Change Advisory Task

Force

Strategic Implementation of the

Environmentally Endangered

Lands Program

Hydrologic Conditions in Urban

Miami-Dade County, Florida, and the Effect of Groundwater

Pumpage and Increased Sea Level

on Canal Leakage and Regional

Groundwater Flow

FEMA Letter to Mayor Cindy

Lerner about CRS rating in Village

of Pinecrest

USACE Guidance for

incorporating climate change

impacts to inland hydrology in

civil works studies, designs, and

projects

Arch Creek Briefing Book

Arch Creek Final Report

Pinecrest Climate Action Plan

What Climate Change Means for

Florida

Climate Change Leadership

Training

Rising to the Challenge, Together:

A review and critical assessment

of the state of the US climate

adaptation field

Miami-Dade County: selected

policies and legislation related to

sea level rise and climate change
2016

2016

2016

2016

2016

2016

2016

2016

2016

2016

USGS

2016

2016

USACE

2016

2016

2016

2016

2017

2017

2017

Miami-Dade County Change Compact Change Compact

Miami-Dade County

FreddieMac

Miami-Dade County

Miami-Dade County

FEMA

Miami-Dade County

Urban Land Institute

City of Pinecrest

Catalyst Miami
Southeast Florida Regional Climate

Southeast Florida Regional Climate

U.S. Department of Transportation

Community organizations and leaders

Florida Institute for Health Innovation

Environmental Protection Agency

The Kresge Foundation 
100 Resilient Cities Preliminary

Assessment

Miami-Dade Comprehensive

Planning Survey

Compact survey for feedback on

the Regional Climate Action Plan

2.0

USACE Guidance for detection of

nonstationarities in annual

maximum discharges

Joint Statement on Collaboration

for Regional Economic Resilience

in Southeast Florida

Regional Climate Action Plan 2.0
2017

2017

2018
Miami-Dade County, City of Miami, City of Miami Beach

Miami-Dade County

Southeast Florida Regional Climate Change Compact

USACE

Southeast Florida Regional Climate Change Compact

Southeast Florida Regional Climate Change Compact 


\section{Appendix C: Interview Guide}

\section{Interview guide for planning professional, manager, and government employees}

Tell me a bit about your background and how you got to your current position.

When did you first get involved in sea level rise planning?

[Alternatively: Can you tell me about your current role in sea level rise adaptation planning?]

What are some of the projects and policies you are aware of going on in the county?

What are your thoughts on how the region is doing regarding sea level rise adaptation planning?

[Alternatively: What are the biggest issues regarding sea level rise adaptation planning?]

What parts of the county do you see getting investment and resources for sea level rise adaptation?

Are there areas getting more resources and investments towards adaptation planning than other areas?

Follow-up questions:

- What is it about these areas that you think makes them receive more resources and investments?

- What do you see as driving adaptation planning?

- Where is the funding coming from?

What types of strategies do you see getting the most investment and resources for sea level rise adaptation?

Follow-up questions:

- What is it about these strategies that you think makes them receive more resources and investments? 
Can you tell me about some of the policy changes that have taken place since sea level rise adaptation planning became a priority for the region?

What was your main objective with [name of document/effort/adaptation/etc]

What do you think are the most important things that can be done to prepare the region for sea level rise?

Follow-up questions:

- What is it about these strategies that make them so important?

- How is the region addressing these strategies?

- What do you think it will take to implement these strategies?

- How would you prioritize these strategies?

Where in the county is most vulnerable to sea level rise?

Follow-up question:

- What about these places makes you think they are vulnerable?

Can you tell me about your relationship with other organizations in the area who are also working on sea level rise adaptation planning?

Follow-up questions:

- Who do you see are most involved in adaptation planning efforts?

- Who do you work with?

- How do you work with them?

- Who are your most vocal opponents/Critics?

What, in your opinion, would be a successful sea level rise adaptation project?

[Alternatively: How do you measure project success?]

What lessons have you learned from this process that you could share with other areas?

What is your hope for this region in 50 years from now? 


\section{Interview guide for community, environmental, or other organization}

Tell me a bit about your background and how you got to your current position.

What are your interests in sea level rise planning?

What are your thoughts on how the region is doing regarding sea level rise adaptation planning?

[Alternatively: What are the biggest issues regarding sea level rise adaptation planning?]

What are the biggest issues regarding some of the proposed adaptation strategies or policies affecting your organization?

What was your main objective with [name of document/effort/adaptation/etc]

What parts of the county do you see getting the most attention for sea level rise adaptation?

Follow-up questions:

- What is it about these areas that you think give them the most attention?

- What do you see as driving adaptation planning?

What parts of the county do you see getting the least attention for sea level rise adaptation?

Follow-up questions:

- What is it about these areas that you think give them the least attention?

What types of strategies do you see getting the most attention for sea level rise adaptation?

Follow-up questions:

- What is it about these strategies that you think give them the most attention?

What was your main objective with [name of document/effort/adaptation/etc] 
What do you think are the most important things that can be done to adapt to sea level rise?

Follow-up questions:

- What is it about these strategies that make them so important?

- How is the region addressing these strategies?

- What do you think it will take to implement these strategies?

- How would you prioritize these strategies?

Where in the county is most vulnerable to sea level rise?

Follow-up question:

- What about these places makes you think they are vulnerable?

Can you tell me about your relationship with other organizations in the area who are working on sea level rise adaptation planning?

Follow-up questions:

- Who do you see are most involved in adaptation planning efforts?

- Who do you work with?

- How do you work with them?

- Who are your most vocal opponents/Critics?

What, in your opinion, would be a successful sea level rise adaptation project?

[Alternatively: How do you measure project success?]

What lessons have you learned from this process that you could share with other areas?

What is your hope for this region in 50 years from now?

Ask questions directly related to their views on how risk is framed in adaptation planning. 


\section{Appendix D: Codebook used in Atlas.ti}

100 Focus of Risk

101 Economic/Tourism

102 Ecological

103 Infrastructure/Canals/Buildings

104 Wellness and health

105 Political

106 Identity, sense of place

107 Historical

108 Hazard

109 Water supply

110 Agriculture

111 Communities of Special Concern

112 Private Property

113 Affordable Housing

114 Future Generations

115 Legal/Liability

200 Interpret Information About Risk (Risk Measurement)

201 Models

202 Assessments/plans

203 Personal Experience

204 Historical Information

205 Community input

206 Cost benefit analysis/Valuation

207 Prioritize Projects

208 Best Available Science

209 Vulnerable Places in the County

210 Media

211 Maps

212 Materiality/Understanding of Physical Property of risk

213 Harmonization

214 Scientific Study

215 Scenarios

300 Risk Boundary

301 Baseline

302 Projection Range (temporal)

303 Uncertainty

304 Boundary (geographical) 
305 Constraints/Limitations

306 Monitoring/evaluation

400 Planning Process

401 Comprehensive Land Use Planning

402 Stormwater Planning

403 Water and Sewer Planning

404 Vulnerability Assessment

405 Adaptation Action Area

406 Hazard Mitigation Planning

407 Post Disaster Recovery

408 Adaptive Management/Planning

409 Sustainability/Resiliency Planning

410 Task Force/Committee

411 Adaptation Planning

412 Incremental Planning

413 Proactive

414 Reactive

415 Economic development

416 Regional Plan

417 Holistic

500 Governance

501 Laws/Policies/Regulations

502 Funding

503 Transparency

504 Accountability

505 Inclusiveness

506 Fairness

507 Collaboration/Integration

508 Capability

509 Adaptability

510 Legitimacy/Authority

600 Knowledge Networks

601 Partnerships

602 Trust

603 Miami-Dade County

604 City

605 Southeast Florida Regional Climate Compact

606 SFWMD 
607 Resilient Cities Network

608 Insurance/Reinsurance/FEMA/NFIP/CRS

700 Solutions

701 Public Perception/Educate

702 Communication

703 Business

704 Infrastructure

705 Policy changes

706 Design changes

707 Natural Systems

708 Flood Control

709 Retreat

710 Community Organizing

711 GHG Mitigation

712 Technology Innovation

800 Other

801 Barriers

802 Lack of Action

803 Politics

804 Vision

805 Adaptation project details

806 Climate Change Denial

807 Leadership

900 Other Documents

901 Potential Interviewees

902 Historical Information

903 Personal Background 


\section{Appendix E: Events Attended During Field Research}

\begin{tabular}{|c|c|c|}
\hline Name of Event & $\begin{array}{l}\text { Date } \\
\text { Attended }\end{array}$ & Brief Description \\
\hline $\begin{array}{l}\text { Stand Up Rise Up Film } \\
\text { Screening of Revolution }\end{array}$ & $3 / 22 / 2017$ & $\begin{array}{l}\text { Event put together by CLEO and other } \\
\text { environmental organizations to show film } \\
\text { about degraded coral reef habitat in South } \\
\text { Florida. Panel following screen filming } \\
\text { had several stakeholders involved in sea } \\
\text { level rise adaptation planning. }\end{array}$ \\
\hline $\begin{array}{l}\text { City of Miami Sea Level } \\
\text { Rise Committee Meeting }\end{array}$ & $3 / 27 / 2017$ & $\begin{array}{l}\text { Monthly committee meeting at City Hall } \\
\text { for sea level rise Committee. }\end{array}$ \\
\hline $\begin{array}{l}\text { Miami-Dade County FEMA } \\
\text { Risk MAP Technical } \\
\text { Update Meeting \#2 }\end{array}$ & $3 / 28 / 2017$ & $\begin{array}{l}\text { Meeting hosted by Taylor Engineering, no } \\
\text { FEMA Staff present. A technical meeting } \\
\text { to go over FEMA Risk Mapping updates. } \\
\text { Several county and city employees } \\
\text { (including floodplain administrators) } \\
\text { present for updates. }\end{array}$ \\
\hline $\begin{array}{l}\text { North Beach Neig } \\
\text { Association Meeti }\end{array}$ & 3/2017 & $\begin{array}{l}\text { Meeting about proposed zoning changes } \\
\text { to North Beach neighborhood in the City } \\
\text { of Miami Beach. Focus was on comparing } \\
\text { proposed changes with the recently } \\
\text { developed North Beach Plan. Sea level } \\
\text { rise was key component, up-zoning } \\
\text { discussion based on need for resilient } \\
\text { buildings, counter to community goals of } \\
\text { historic and maintaining quality of life. }\end{array}$ \\
\hline $\begin{array}{l}\text { City of Miam } \\
\text { Project Open }\end{array}$ & $4 / 4 / 2017$ & $\begin{array}{l}\text { Organized by City of Miami Beach to } \\
\text { share information with residents that will } \\
\text { be affected by stormwater upgrades } \\
\text { (including road raising) }\end{array}$ \\
\hline & $4 / 5 / 2017$ & $\begin{array}{l}\text { Climate justice panel organized by } \\
\text { community activists and lawyers. }\end{array}$ \\
\hline CLEO Institute $\mathrm{C}$ & $5 / 4 / 2017$ & Introductory training on climate change. \\
\hline $\begin{array}{l}\text { City of Miami General } \\
\text { Obligations Bond Public } \\
\text { Comment: City Hall }\end{array}$ & & $\begin{array}{l}\text { Information meeting about proposed } \\
\text { General Obligation Bond which featured } \\
\text { stormwater management and sea level rise } \\
\text { adaptation planning. }\end{array}$ \\
\hline
\end{tabular}




\begin{tabular}{|c|c|c|}
\hline $\begin{array}{l}\text { City of Miami General } \\
\text { Obligations Bond Public } \\
\text { Comment: Hadley Park }\end{array}$ & $5 / 15 / 2017$ & $\begin{array}{l}\text { Information meeting about proposed } \\
\text { General Obligation Bond which featured } \\
\text { stormwater management and sea level rise } \\
\text { adaptation planning. }\end{array}$ \\
\hline $\begin{array}{l}\text { City of Miami General } \\
\text { Obligations Bond Public } \\
\text { Comment: Little Havana }\end{array}$ & $5 / 16 / 2017$ & $\begin{array}{l}\text { Information meeting about proposed } \\
\text { General Obligation Bond which featured } \\
\text { stormwater management and sea level rise } \\
\text { adaptation planning. }\end{array}$ \\
\hline $\begin{array}{l}\text { City of Miami General } \\
\text { Obligations Bond Public } \\
\text { Comment: Juan Pablo } \\
\text { Duarte }\end{array}$ & $5 / 17 / 2017$ & $\begin{array}{l}\text { Information meeting about proposed } \\
\text { General Obligation Bond which featured } \\
\text { stormwater management and sea level rise } \\
\text { adaptation planning. }\end{array}$ \\
\hline $\begin{array}{l}\text { New Florida Majority } \\
\text { Presentation by Chris } \\
\text { Gongoria and Film } \\
\text { Screening from Dwight } \\
\text { Bullard: The Birth of a } \\
\text { Nation }\end{array}$ & $5 / 18 / 2017$ & $\begin{array}{l}\text { Community event organized by New } \\
\text { Florida Majority, an organization involved } \\
\text { in resiliency and community organizing } \\
\text { around climate justice and hurricane } \\
\text { preparation/response }\end{array}$ \\
\hline $\begin{array}{l}\text { City of Miami Sea Level } \\
\text { Rise Committee Meeting }\end{array}$ & $5 / 22 / 2017$ & $\begin{array}{l}\text { Monthly committee meeting at City Hall } \\
\text { for sea level rise Committee. }\end{array}$ \\
\hline Gen CLEO Meetup & $5 / 23 / 2017$ & $\begin{array}{l}\text { Event designed for youth engagement in } \\
\text { climate change work in Miami. }\end{array}$ \\
\hline
\end{tabular}

